
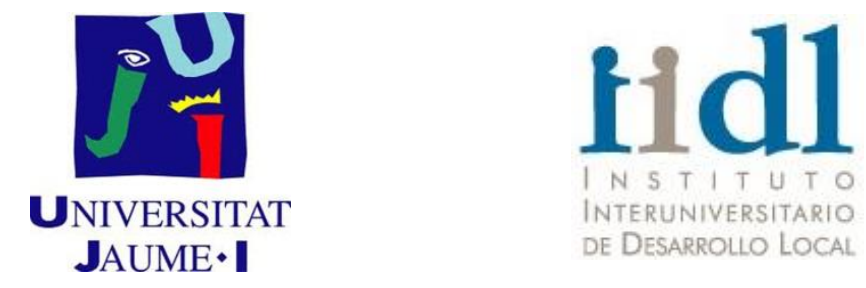

Doctorado en Cooperación al Desarrollo.

Instituto Interuniversitario de Desarrollo Local Universitat Jaume I

\title{
ASPECTOS PSICOSOCIALES DE LA JUVENTUD COLOMBIANA CON RIESGO DE EXCLUSIÓN SOCIAL. ANÁLISIS DEL DISCURSO MEDIÁTICO SOBRE LA VIOLENCIA
}

\section{TESIS DOCTORAL}

\author{
Presentada por: \\ Rosa Matilde Villamizar Rojas
}

\author{
Dirigida por: \\ Dra. Raquel Flores Buils \\ Dr. Antonio Caballer Miedes \\ Dra. Mónica García Renedo
}

Castellón de la Plana (España), mayo 2017 

A la memoria de mi tutora la Dra. Mónica García Renedo, por las huellas dejadas en este trabajo y en mi experiencia de vida.

A la memoria de las víctimas de la violencia de "falsos positivos" por recordarnos la presencia de una herida social y a sus familiares, por ser un ejemplo de paz y

reconciliación. 



\section{AGRADECIMIENTOS}

La culminación de esta tesis contó con el aporte de muchas personas, a cada de una de ustedes mis más sinceros agradecimientos. A quienes aportaron en el acompañamiento y análisis crítico del texto y contribuyeron a mi desarrollo intelectual. Asimismo, a quienes me apoyaron en todo el proceso vivido en estos cinco años de trabajo de investigación.

En especial a la Dra. Mónica García Renedo, quien me brindó no sólo su asesoría académica sino un ejemplo de humanidad y entrega al trabajo por las comunidades afectadas por la guerra. Su conocimiento y testimonio están impresos en cada una de estas páginas y en mi memoria.

A la Dra. Raquel Flores, al Dr. Antonio Caballer y al Dr. José Manuel Gil por su permanente dirección académica, su apoyo a cada una de las actividades investigativas y sobre todo por la confianza que me brindaron para culminar este estudio.

A los miembros del Tribunal, por la lectura y comentarios realizados a este estudio.

A la Dra. Mar Valero, quien me ofreció su apoyo durante mi estancia Castellón y a Miguel Martínez, quien contribuyó con sus conocimientos informáticos a la finalización de esta tesis.

A la Dra. Flor Alba Romero, profesora de la Universidad Nacional de Colombia, por su acompañamiento en la reflexión académica, la gestión de recursos y los trámites consulares.

Asimismo, quiero extender mis agradecimientos:

Al instituto Interuniversitario del Desarrollo Local (IIDL). Universidad de Jaume I, especialmente a las Dras. Raquel Agost y Rosa Ana Peris, Por la formación recibida en el máster de Cooperación al Desarrollo que fue fundamental en el diseño de esta tesis.

Al programa de ayudas para estudiantes de doctorado latinoamericanos del Banco Santander. Universidad Jaume I. Por el apoyo financiero para el desarrollo de este estudio.

A la oficina de Cooperación al Desarrollo y Solidaridad. UJI por su permanente colaboración en mi estancia en la ciudad de Castellón. 
A los Jóvenes de Ciudad de Ciudad Bolívar y Cazuca participantes de los procesos sociales adelantados por mí en este sector, porque ellas y ellos fueron la inspiración de esta investigación.

A mi familia, quienes me brindaron su ayuda económica y soporte emocional para cerrar mi proceso doctoral.

A mis amigas Ana Lucía Escobar, María Elena Ruíz y María Fernanda Pulido, quienes son mi segunda familia en Colombia por su motivación y acompañamiento constante en este dicho proceso doctoral

A mis amigos y amigas: Esther Afonso, Jairo López, Kadhija Harbaz, Irene Cremades, Andrea Rodríguez, Álvaro Gómez, Celia Demoor, Soledad Soto, Chloé Meulewater, Ahmadul Haque y Anna Haro, quienes estuvieron presentes en mi experiencia en España y me ofrecieron su apoyo incondicional.

A Hubert Ignatowicz por la motivación y ánimo ofrecidos en los momentos más difíciles de este proceso.

A todos ustedes mil gracias porque sin su permanente presencia este logro académico no hubiese sido posible. 


\section{ÍNDICE}

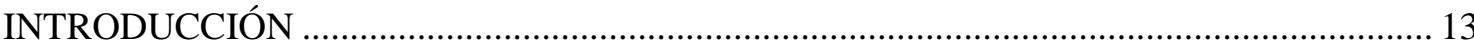

CAPÍTULO I. EL LENGUAJE Y LA PRODUCCIÓN DISCURSIVA EN CONTEXTOS DE GUERRA

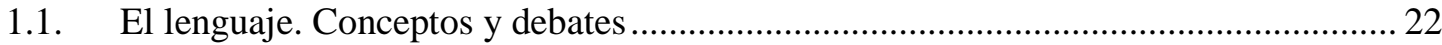

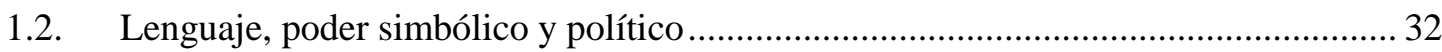

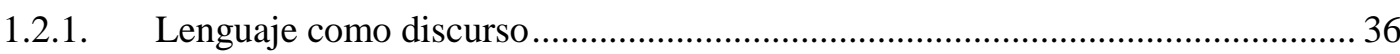

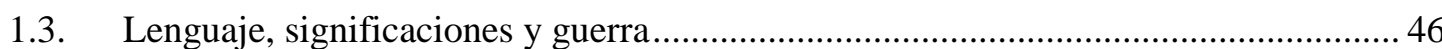

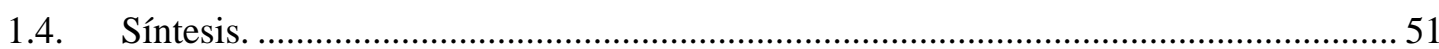

CAPÍTULO II. VIOLENCIA, CONFLICTO, JUVENTUD Y ESTIMA SOCIAL .................... 55

2.1. ¿La violencia en Colombia continuidad o discontinuidad?................................................59

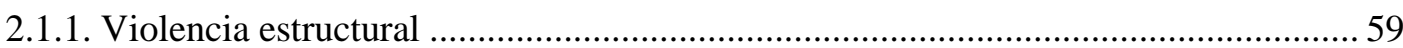

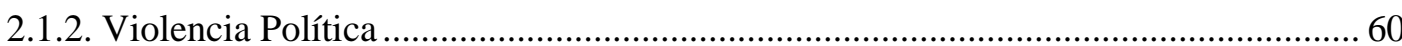

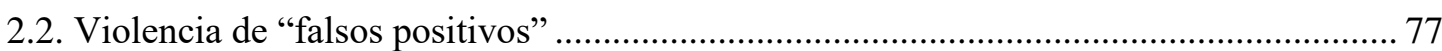

2.3 Violencia juvenil y fenómeno del sicariato juvenil en Colombia ....................................... 80

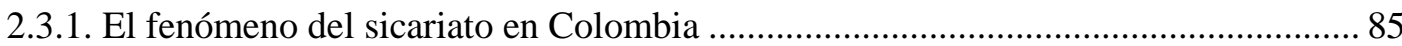

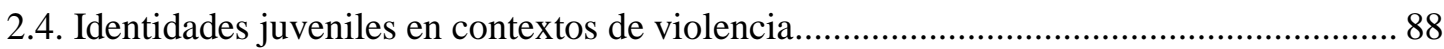

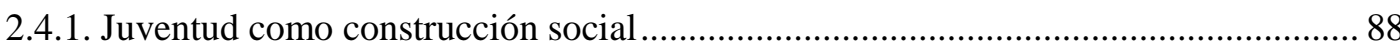

2.4.2. Conceptualización de la identidad juvenil................................................................... 95

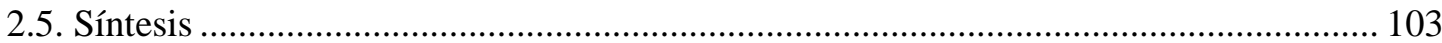

CAPITULO III. MEDIOS DE COMUNICACIÓN, CONFLICTO ARMADO Y ESTIGMATIZACIÓN JUVENIL EN EL CONTEXTO COLOMBIANO .................................... 107

3.1. Medios de Comunicación y Generación de Opinión Pública............................................ 110

3.2. El Papel de los Medios de Comunicación en el Caso del Conflicto Armado Interno Colombiano

3.3. Reseña histórica de los medios de comunicación: El Espectador, El Tiempo y la Revista

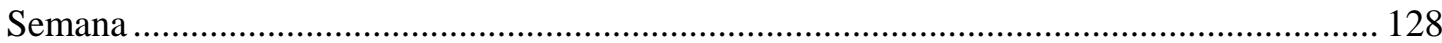

3.4. Medios de Comunicación y Estigmatización Juvenil....................................................... 136

3.5. La Construcción Social del Enemigo interno en el Discurso Mediático........................... 144

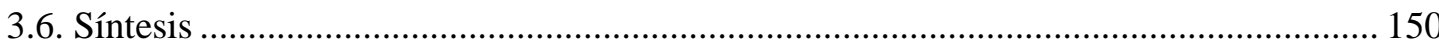

CAPITULO IV. DISEÑO METODOLOGICO. ANALISIS DEL DISCURSO DESDE LA

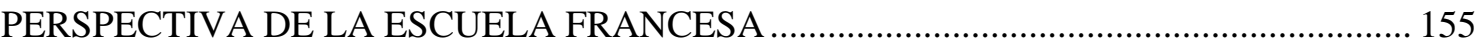

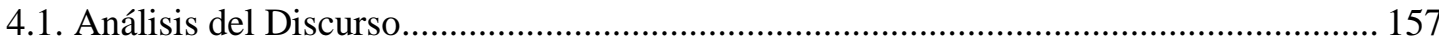

4.1.1. Análisis del Discurso desde la perspectiva de la Escuela Francesa ......................... 158

4.1.2. La pertinencia del Análisis del discurso desde la Escuela Francesa para el desarrollo de este estudio 


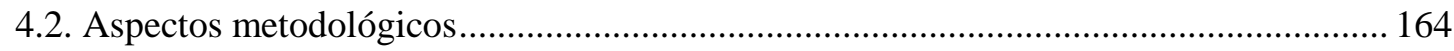

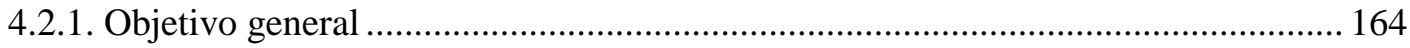

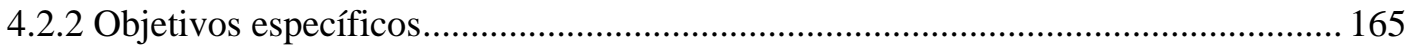

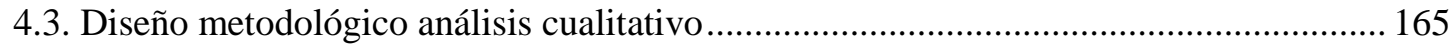

4.3.1 Sistematización y análisis de información ................................................................. 165

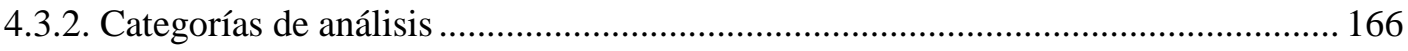

4.4. Diseño metodológico análisis cuantitativo..................................................................... 169

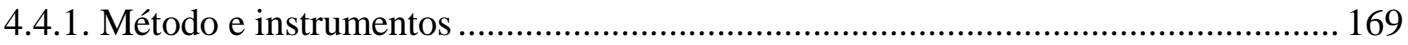

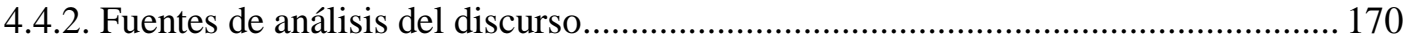

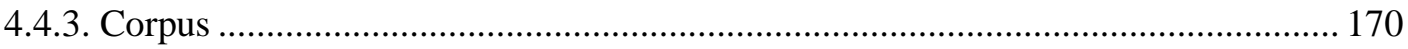

4.4.4. Clasificación temática de los artículos ................................................................... 171

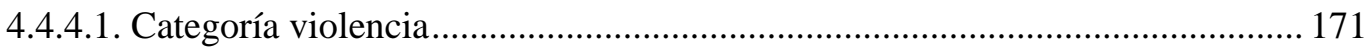

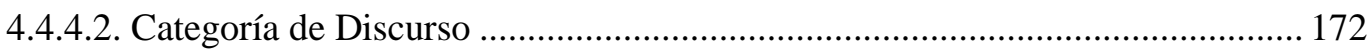

4.4.4.3. Categoría de contexto político......................................................................... 173

4.4.4.4. Categoría de Representación social del joven ................................................ 174

4.4.4.5. Categoría de Organización social juvenil y comunitaria................................... 175

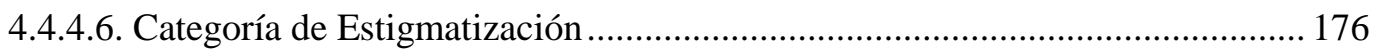

4.4.4.7. Categoría de Derechos Humanos ....................................................................... 176

4.4.5. Intencionalidad de los discursos mediáticos............................................................. 177

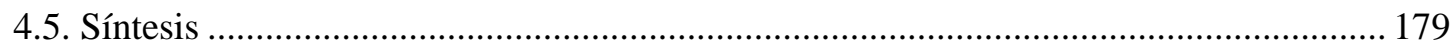

CAPITULO V. DESARROLLO METODOLÓGICO DE LA INVESTIGACIÓN.

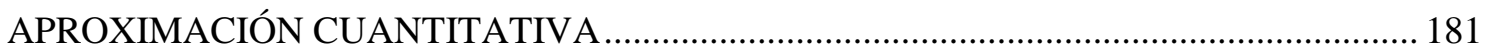

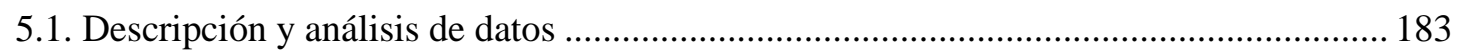

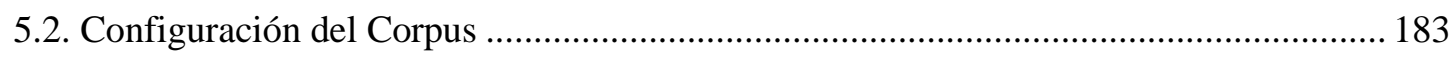

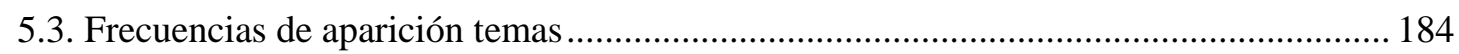

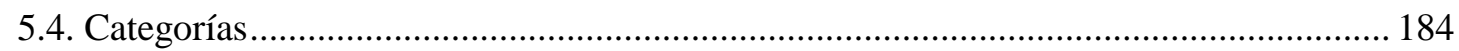

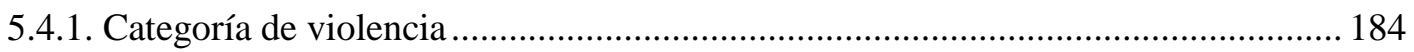

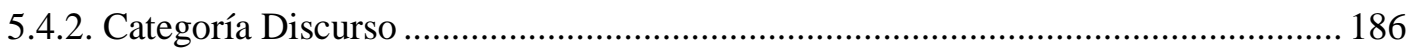

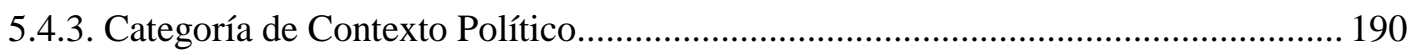

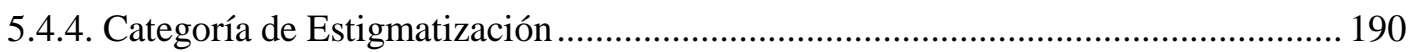

5.4.5. Categoría de Representación Social del joven .......................................................... 192

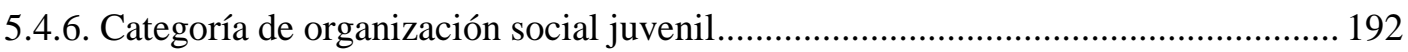

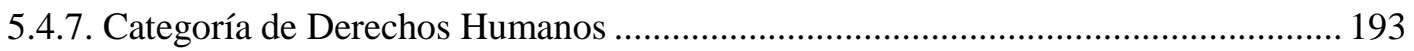

5.5. Frecuencias de aparición violencia por años (2007-2010) ………………………......... 195

5.6. Análisis de Frecuencia de Aparición Temática y Tendencias Ideológicas de los Medios

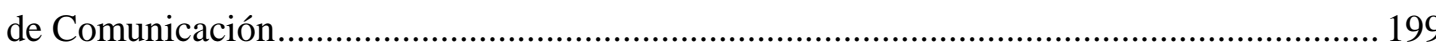


5.7.1. Análisis tendencias ideológicas de los medios de comunicación y variables de intencionalidad 203

5.8. Síntesis 204

CAPITULO VI. LA CONSTRUCCIÓN SIMBÓLICA Y DISCURSIVA DEL JOVEN EN EL CONTEXTO DE LOS “FALSOS POSITIVOS.” ANÁLISIS DEL DISCURSO 207

6.1. La construcción simbólica del joven víctima de la violencia de "falsos positivos" en el discurso mediático 209

6.1.1 Contextualización 211

6.1.2. El caso de "falsos positivos" Soacha 212

6.1.3 La desaparición de los jóvenes. 213

6.1.4. El Escandalo de los falsos positivos 214

6.2. El constructo social de los jóvenes en los Medios de comunicación 214

6.3. La construcción simbólica del joven desde el victimario 224

6.4 Análisis del Discurso sobre el joven en los medios de comunicación a luz de la teoría. 231

6.4.1. Constructo social del joven en los medios de comunicación 237

6.4.2. El discurso de los victimarios 240

6.5. Síntesis 242

CAPITULO VII. JUVENTUD Y VIOLENCIA. DISCURSOS HEGEMÓNICOS Y CONTRA HEGEMÓNICOS. LOS “FALSOS POSITIVOS” EN EL DISCURSO DE DIFERENTES ACTORES DE LA POLÍTICA Y LA SOCIEDAD CIVIL 245

7.1. Practicas discursivas sobre la violencia de "falsos positivos." Representantes del Gobierno, los familiares de las víctimas y la sociedad civil

7.1.1. El discurso del gobierno

7.1.1.1. Discurso militar: "Manzanas podridas" e impunidad 252

7.1.2. El discurso militar 255

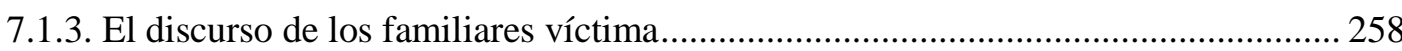

7.1.4. Discurso de los Organismos de Derechos Humanos ................................................. 263

7.2. Análisis del Discurso de los medios de comunicación a la luz de la teoría ................... 269

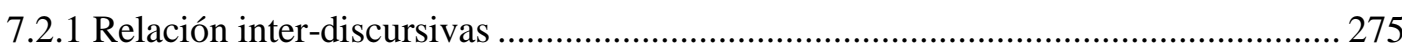

7.2.2 Principales discursos sobre el joven en el marco de la violencia de "falsos positivos"

7.2.3. Las formaciones discursivas en contextos de guerra................................................ 281

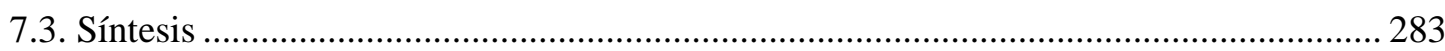

CAPÍTULO VIII. SÍNTESIS Y PROPUESTAS DE ACTUACIÓN ........................................ 285

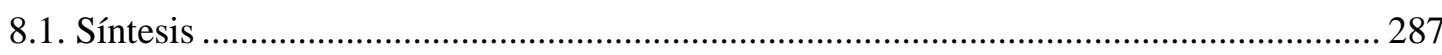

8.2. Aportaciones a la construcción de paz en contexto del post- conflicto............................ 293 
8.2.1. Puntos clave para trabajar en una propuesta en la construcción de paz

8.2.2. Posibles caminos hacia la construcción de la paz ..................................................... 296

8.3. Futuras líneas de investigación............................................................................................ 299

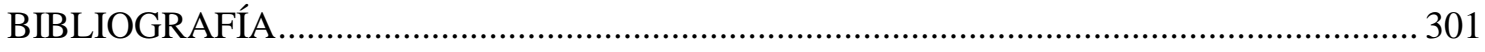

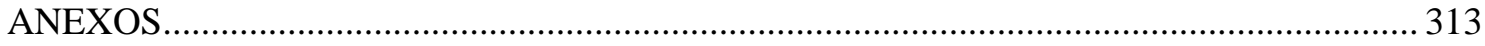

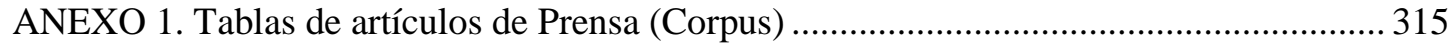

\section{ÍNDICE DE TABLAS}

Tabla 1. Síntesis sobre los puntos de acuerdo por la discreción ................................................. 122

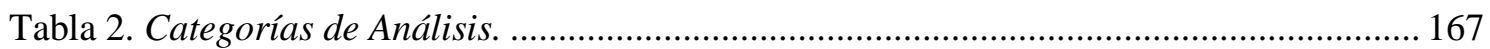

Tabla 3. Relación comparativa entre discursos actores políticos y sociales. ............................ 276

\section{ÍNDICE DE FIGURAS}

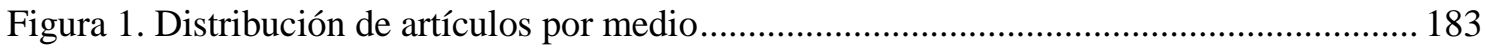

Figura 2. Frecuencia de aparición de violencia ......................................................................... 184

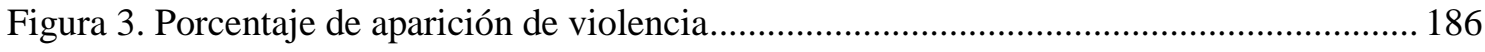

Figura 4. Frecuencia de aparición de discurso ......................................................................... 187

Figura 5. Porcentaje de aparición del tipo de discurso ................................................................ 189

Figura 6. Frecuencia de aparición del contexto político................................................................ 190

Figura 7. Frecuencia de aparición de estigmatización..................................................................... 191

Figura 8. Frecuencia de representación social del joven ............................................................ 192

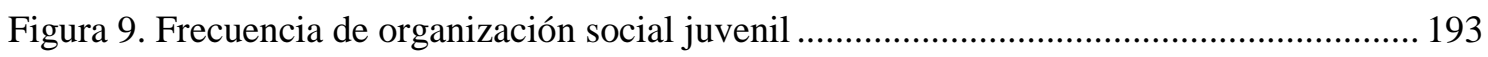

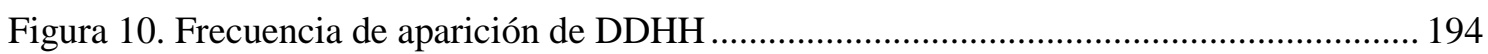

Figura 11. Porcentaje de distribución variables DDHH.............................................................. 195

Figura 12. Frecuencia de aparición categoría violencia por año ................................................ 196

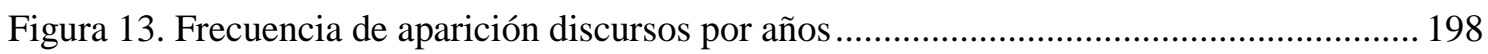

Figura 14. Frecuencia de aparición intencionalidad................................................................. 201 


\section{GLOSARIO DE ACRÓNIMOS}

ANAPO: Alianza Nacional Popular.

CINEP: Centro de Investigación y Educación Popular.

CLJ: Consejos Locales de Juventud.

DANE: Departamento Administrativo Nacional de Estadísticas.

DIH: Derecho Internacional Humanitario.

ELN: Ejército de Liberación Nacional.

EPL: Ejército de Liberación Popular.

FARC- EP: Fuerzas Armadas Revolucionarias de Colombia- Ejército del Pueblo.

FEDES; Fundación para la Educación y El Desarrollo y Social.

FN: Frente Nacional.

ICBF: Instituto de Bienestar Familiar.

NBI: Necesidades Básicas Insatisfechas.

MSF: Médicos sin Fronteras.

M19: Movimiento 19 de Abril.

OEA: Organización de Estados Americanos.

ONGs: Organizaciones no Gubernamentales.

ONU: Organización de las Naciones Unidas

PC: Partido Comunista.

PRT: Partido Revolucionario de los Trabajadores.

RCN: Radio Cadena Nacional.

RTDT: Red de Organismos Civiles de Derechos Humanos “Todos los derechos para todos y todas.

UNICEF: Fondo de Naciones Unidas para la Infancia

UP: Unión Patriótica. 



\section{INTRODUCCIÓN}

En esta investigación abordamos el discurso mediático sobre la violencia de los mal denominados: "falsos positivos." A partir del análisis del discurso desde la perspectiva de la Escuela Francesa exploramos y analizamos los constructos sociales designados a esta violencia y especialmente, al joven que fue víctima de la misma. El análisis se centra en desentrañar los sentidos de las configuraciones simbólicas sobre las víctimas de los "falsos positivos" expuestas en el discurso de los propios medios de comunicación y los sujetos discursivos: representantes del Gobierno, los militares, los familiares de las víctimas y los Organismos de Derechos Humanos.

La violencia de "falsos positivos" trata de una violación de los Derechos Humanos, tipificada en el Derecho Internacional como: Ejecuciones extrajudiciales, la cual consiste en asesinato de civiles por parte de fuerzas de seguridad del Estado. En Colombia se tiene conocimiento de la existencia de estos crímenes desde la década de 1980. Sin embargo, se presentó un incremento sustancial de estas prácticas de violación de Derechos Humanos en el periodo de 2006- 2010, en el marco de la política de Seguridad Democrática implementada en los dos periodos de Gobierno del Presidente Uribe.

En Septiembre de 2008 se destapó el denominado Escandalo de los "falsos positivos" a partir del emblemático “Caso de Soacha.” la desaparición de 19 jóvenes residentes del sur de Bogotá y Soacha. El hallazgo de sus cuerpos asesinados y con signos de tortura puso de manifiesto una de las aristas más crueles de la violencia generada en medio del conflicto armado. Este caso tuvo una repercusión mediática nunca antes observada sobre el tema de las ejecuciones extrajudiciales y obtuvo la atención de la comunidad nacional e internacional.

La intensidad y la crueldad de esta violencia sólo pudieron ser gestadas en un conflicto de larga duración y degradado a límites inimaginables al punto de violar los principios humanitarios que rigen las confrontaciones armadas. Es un desafío para los académicos, la sociedad civil, los gobernantes y la comunidad internacional; el desentrañar las fibras constitutivas de la violencia y el sufrimiento al que se puede llegar en un estado de guerra. El análisis de los entramados simbólicos y discursivos de esta violencia es sin 
duda una contribución para despojar a la violencia de "falsos positivos" de la posibilidad de repetición.

Este estudio es un aporte a la comprensión de la violencia ejercida contra la población joven en el contexto del conflicto armado y la construcción de lenguajes del horror. En esta investigación exploramos y analizamos los constructos sociales sobre el joven y la violencia en los terrenos discursivos del lenguaje mediático, partimos de que la guerra no sólo se trata de una confrontación armada sino que también es una disputa por el sentido simbólico. Asumimos que el lenguaje es un instrumento de poder que puede potenciar las más fuertes acciones de destrucción o de reconstrucción. De acuerdo con estos argumentos analizamos las materialidades sociales, simbólicas, culturales y políticas presentes en el discurso mediático sobre la violencia de "falsos positivos" y la construcción social de la juventud en el contexto del conflicto armado colombiano.

Este trabajo de investigación surge a partir de motivaciones personales y académicas. Entre las personales; en primer lugar, la experiencia de vida en el contexto del conflicto armado colombiano, conlleva a la necesidad de comprender las vicisitudes de la guerra y la búsqueda de aportar en la reconstrucción de los vínculos sociales fracturados por la violencia. En segundo lugar, un amplio trabajo académico sobre el tema de jóvenes y la violencia lleva a preguntarse por los sentidos y las construcciones sociales que de este sujeto circulan en los medios de comunicación y la influencia de dichos constructos en la significación de la juventud popular colombiana.

Las motivaciones académicas se establecieron de dos formas; en primer lugar, el recorrido académico sobre juventud y violencia en Colombia es amplio, sin embargo, estos estudios son insuficientes para abordar la magnitud del problema, por tanto un aspecto fundamental en este análisis es la construcción de sentido en el discurso mediático constructor de realidades en el contexto de guerra, bajo la comprensión de que las guerras no sólo se hacen con las armas sino sobre todo con palabras llenas de contenido y acción. En segundo lugar, es necesario recordar el compromiso de la academia en la construcción de escenarios de convivencia y paz. En este sentido, la comprensión de los elementos simbólicos, lingüísticos, políticos presentes en la violencia de los "falsos positivos", contribuye a establecer las transformaciones sociales, éticas y políticas que se producen en la guerra y actúan como reproductores de la violencia. 
Asistimos a uno de los momentos más importantes de la historia colombiana; la posibilidad de construir la paz y transitar los caminos del postconflicto, las bases de una paz duradera tienen innumerables desafíos, uno de ellos es comprender la construcción de sentido de la violencia en el tejido cultural y social del país. La violencia de "falsos positivos" fue infringida por el Estado colombiano con la colaboración de civiles. Estas prácticas de violación de los Derechos Humanos ponen de manifiesto las transformaciones éticas, morales y sociales presentes en la guerra y corroboran las transformaciones del lenguaje y las prácticas cotidianas de convivencia, donde se deterioran los principios humanitarios. Este deterioro de las relaciones sociales implica una desestructuración del tejido social. Por tanto, el postconflicto representa una de las etapas más importantes de la historia colombiana, la posibilidad de la reconstrucción del tejido social lacerado por las acciones de violencia, hace necesario reconocer las heridas causadas, asumir la existencia de lenguajes del horror, desaprender las prácticas de negación y construir los lenguajes de la reconciliación.

En este estudio realizamos un análisis del discurso de la violencia y juventud en tres medios de comunicación el periódico El Espectador, El Tiempo y la Revista Semana. La selección de la metodología, desde la perspectiva de la Escuela Francesa, tuvo una significativa importancia dado su componente interdisciplinario, esta circunstancia posibilitó el análisis del problema desde perspectivas: sociológicas, históricas, políticas, lingüísticas y semióticas, asimismo este método contribuyó a la exploración de los sentidos del discurso en relación a las relaciones de poder, las condiciones de producción, circulación y producción del discurso; así como las formaciones ideológicas e imaginarias.

La producción de esta investigación presentó muchos desafíos para sus investigadores; entre ellos la sistematización y análisis de artículos que escenificaban las experiencias límites de sufrimiento causado a las víctimas de esta violencia, a sus familiares y la sociedad en general. La existencia de un lenguaje mediático cargado de adjetivaciones para resaltar el horror y la barbarie contenida en estos hechos es un aspecto que requiere de una rigurosidad analítica. De esta forma, como investigadores, tuvimos el reto de analizar esta violencia a la luz de la teoría y la experiencia social sin caer en el dramatismo mediático. Todo ello sin dejar de lado, el compromiso por testimonio de lo sucedido y la generación de reflexiones académicas para abordar los impactos de este fenómeno de violencia y la búsqueda de no repetición. 
Este estudio se divide en ocho capítulos, en los cuales presentamos el marco teórico y metodológico de esta investigación, así como el desarrollo del análisis del discurso sobre el discurso mediático. Por último, presentaremos las conclusiones y líneas de acción para futuras investigaciones.

En el capítulo I, Lenguaje y producción discursiva en Contextos de Conflicto Armado, abordamos el lenguaje desde la perspectiva de la Escuela francesa, las aportaciones de Bourdieu $(1982 ;$ 2001) sobre el habitus (la comprensión de la existencia de constructos sociales inmersos en la cultura desde los cuales damos sentido al "otro" y producimos realidad desde un ordenamiento social dominante y socialmente compartido). Asimismo, las aportaciones de este mismo autor sobre la relación del lenguaje con el poder simbólico son fundamentales en la construcción discursiva sobre los jóvenes en Colombia. Las aportaciones de Foucault (1972) sobre la relación lenguaje y poder; las condiciones de producción, circulación y reproducción del discurso, formación social e ideológica son pertinentes para comprender que las prácticas discursivas están controladas y limitadas por las relaciones de dominación presentes en el contexto político y social.

El desarrollo de este capítulo se realiza a partir de cuatro apartados: el primero, relativo al concepto del lenguaje, de tal forma que podamos tener una visión de los aspectos fundamentales del mismo. En el segundo, realizamos una reflexión teórica acerca del lenguaje y el poder simbólico y político, aspecto fundamental para hallar el sentido preponderante del lenguaje en la construcción de los imaginarios de discriminación. En el tercero, desarrollamos la relación entre lenguaje y el discurso, lo cual nos posibilitará comprender la posibilidad de acción del discurso. Por último, profundizamos en el tema específico de esta investigación, es decir, en la relación con las transformaciones del lenguaje en contextos de guerra y de forma concreta en el escenario del conflicto armado interno colombiano.

En el capítulo II, Violencia, conflicto, juventud y Estigma Social, se presenta un recorrido teórico sobre la violencia en Colombia y la juventud colombiana, en este estudio asumimos la violencia como un fenómeno continuo, conexo y entretejido en el tiempo, por tanto tiene significativa importancia exponer el proceso histórico. También se recoge el concepto de juventud y la relación de éste con las identidades juveniles. Este capítulo se divide en cuatro apartados. El primero ¿La violencia en Colombia continuidad y discontinuidad?, realiza un recorrido histórico por el conflicto armado colombiano, 
estableciendo las líneas de continuidad de la violencia. El segundo, Violencia de "falsos positivos," define y conceptualiza la violencia objeto de este estudio. El tercero, Violencia juvenil y fenómeno del sicariato en Colombia, presenta el estado del análisis teórico sobre la juventud y la violencia. Por último, en el capítulo Identidades juveniles en contextos de guerra, se describe las implicaciones de la violencia en la identidad juvenil.

El Capítulo III, Medios de comunicación, conflicto Armado y Estigmatización juvenil en el contexto colombiano, expone las particularidades de la producción noticiosa sobre la violencia en Colombia y describe las principales tendencias ideológicas de los medios de comunicación encargados de la información sobre el conflicto armado. Las principales características del discurso mediático y su implicación en la producción de realidad. El desarrollo de este capítulo está divido en cuatro apartados. El primero, Medios de comunicación y generación de opinión pública, el segundo, El Papel de Los Medios de Comunicación en el Caso del Conflicto Armado Colombiano, el tercero, Reseña Histórica Medios de Comunicación: EL Espectador, El Tiempo y la Revista Semana, por último, Medios de Comunicación y Estigmatización Juvenil.

En el Capítulo IV, Diseño metodológico, se expone el análisis del discurso desde la perspectiva de la Escuela Francesa, se describe y analiza el método de investigación y se establecen las categorías de análisis que guiaran este estudio. Este capítulo se divide en tres apartados. El primero, Aspectos metodológicos, aborda el diseño metodológico de la investigación. El segundo, Análisis cualitativo, presenta el diseño metodológico del análisis del discurso. Por último, en el Análisis cuantitativo, se expone el diseño metodológico para el manejo de datos pertenecientes al corpus.

En el Capítulo V, Desarrollo metodológico de la investigación, se realiza una aproximación cuantitativa. Presentamos el análisis del corpus desde el análisis de datos cuantitativos de acuerdo a la frecuencia de aparición noticiosa por temas y la categoría de intencionalidad de los medios de comunicación. De esta manera, realizamos un contraste entre la publicación por temas y la tendencia ideológica de cada uno de los medios de comunicación. Este capítulo se divide en dos apartados: el primero; Análisis de datos por temas y el segundo, El análisis de datos por intencionalidad.

En el Capítulo VI, La construcción simbólica y discursiva del joven en el contexto de los “falsos positivos." Se expone el desarrollo de la investigación desde la perspectiva del 
análisis del discurso. Mostramos los resultados de la investigación a partir del análisis del discurso de los artículos de prensa del corpus de esta investigación. Abordamos los constructos sociales sobre la población joven víctima de esta violencia desde el discurso de la prensa y las prácticas discursivas del victimario. Este capítulo se divide en tres apartados. El primero, la construcción social de los jóvenes en los Medios de comunicación. El segundo, la construcción simbólica del joven desde el discurso del victimario. Por último, el tercero, se denomina Análisis del Discurso sobre el joven a la luz de la teoría.

En el capítulo VII, Juventud y violencia. Discursos hegemónicos y contra hegemónicos. Los "falsos positivos" en el discurso de diferentes actores de la política y la sociedad civil, presentamos el análisis del discurso de los diferentes actores del contexto político nacional: el gobierno, los militares, los familiares de las víctimas y los organismos de Derechos Humanos. Describimos y analizamos la relación de estos discursos con las tendencias ideológicas de los sujetos discursivos. El capítulo se distribuye en dos apartados, el primero denominado Discursos de actores políticos y Sociedad civil y el segundo, Análisis del discurso de los actores discursivos a la luz de la teoría.

Por último, en el capítulo VIII, denominado Síntesis y propuestas de actuación, se presentan las conclusiones de este estudio y las futuras líneas de actuación. 


\section{CAPÍTULO I. EL LENGUAJE Y LA PRODUCCIÓN DISCURSIVA}

EN CONTEXTOS DE GUERRA

1.1. Lenguajes, conceptos y debates.

1.2. Lenguaje poder simbólico y político.

1.3. Lenguaje y significaciones de la guerra.

1. 4. Síntesis. 



\section{CAPÍTULO I. EL LENGUAJE Y LA PRODUCCIÓN DISCURSIVA EN CONTEXTOS DE CONFLICTO ARMADO}

En este capítulo abordaremos uno de los temas más complejos de las ciencias sociales, el lenguaje. La importancia de éste en la manera como se produce la realidad social es debido a sus múltiples dimensiones culturales, sociales, lingüísticas y simbólicas que se encuentran presentes en el mismo. La existencia humana se produce a través del lenguaje, es a partir de Calidad informativa y cubrimiento del conflicto. Los actos de nominación que obtenemos nuestro lugar en el mundo. A través del lenguaje reconocemos la existencia de los otros y la propia, de esta manera, la palabra y el habla tienen el poder de construir los escenarios sociales, simbólicos y culturales.

El lenguaje es el vehículo a través del cual interpretamos el mundo, inter- relacionamos nuestras visiones internas y externas de los hechos que se nos presentan, de la misma manera que actúa como sistema de clasificación y categorización. La importancia de desarrollar la categoría teórica del lenguaje en estos estudios radica en conocer la capacidad del mismo para dar sentido a los constructos sociales de estigmatización sobre el joven popular en Colombia, ya que el lenguaje es el elemento por el cual se crea y recrea constantemente estos imaginarios sociales de discriminación.

La importancia del lenguaje para las ciencias sociales es innegable, y ha sido analizado desde muchas perspectivas. Ahora bien, para los fines de este estudio vamos a centrarnos en la Antropología lingüística, la cual nos permite entender sus dimensiones culturales; además, nos interesa su análisis desde la perspectiva sociológica (escuela francesa). Ello facilitará la comprensión de la relación lenguaje y poder, así como su significativo papel en la acción social.

El desarrollo de este capítulo se realizará a partir de cuatro apartados: el primero, relativo al concepto del lenguaje, de tal forma que podamos tener una visión de los aspectos fundamentales del mismo. El segundo, realizaremos una reflexión teórica acerca del lenguaje y el poder simbólico y político, fundamental para hallar el sentido preponderante del lenguaje en la construcción de los imaginarios de discriminación. En el tercero, desarrollaremos la relación lenguaje y discurso, lo cual no posibilitará comprender la posibilidad de acción del discurso. Por último, profundizaremos en el tema específico de esta investigación en relación con las transformaciones del lenguaje en contextos de guerra y de manera específica en el escenario del conflicto armado interno colombiano. 
La importancia de este acercamiento teórico para el estudio sobre los constructos sociales del joven como amenaza en Colombia, es prioritario, dado que, a partir de las dimensiones simbólicas, culturales y sociales, podremos dar luz a nuestras indagaciones sobre una realidad imaginada desde la exclusión social, que conlleva a la estigmatización, discriminación y rechazo de la juventud popular del país.

\subsection{EI lenguaje. Conceptos y debates}

En esta investigación asumiremos el lenguaje desde una perspectiva cultural, dado el interés por profundizar las materialidades simbólicas que componen los constructos sociales estigmatizados, enraizados y materializados en el marco de la cultura. En esta línea es fundamental la comprensión del concepto de antropología lingüística. Duranti (2000) afirma que ésta es la especificidad de la lingüística que asume las lenguas como constructos humanos que son síntomas y parte de la vida de los pueblos a su vez que son instrumentos de comunicación y representación del mundo.

Así, desde la perspectiva de la antropología lingüística es viable el análisis de los imaginarios sociales en relación a la capacidad del lenguaje de producir sentido, a partir de su uso de acuerdo a los contextos donde se utiliza el lenguaje, de esta manera nos podemos centrar en los sentidos que toman los actos de comunicación en los escenarios bélicos y de violencia. En este caso la antropología lingüística nos posibilita reconocer los significados de las palabras, expresiones y discursos connotados desde la existencia de la violencia.

En este análisis es importante establecer la relación entre lenguaje y cultura; en este sentido Duranti (2000), retomando a Levi Strauss, afirma que la cultura es un sistema que se comunica a través de actores sociales, de la misma manera que el citado autor retoma textualmente a Geertz (1973) cuando afirma que:

El concepto de cultura que propongo es esencialmente un concepto semiótico. Creyendo como Max Weber que el hombre es un animal inmerso en una trama de significación que él mismo ha tejido, considero que la cultura es esa urdimbre y que el análisis de la misma ha de ser, por tanto, no una ciencia experimental en búsqueda de leyes sino una ciencia interpretativa en búsqueda de significados. (p.5) 
Partiendo de este planteamiento, la cultura es vista desde el punto semiótico, como un entramado de significaciones creado por el hombre, así podemos determinar que los constructos sociales de discriminación son marcos de significación insertos dentro de la cultura. Por ello, la interpretación de los mismos nos lleva a los terrenos culturales y de ahí la importancia de la antropología lingüística en este trabajo.

El primer acercamiento al lenguaje nos hace ver que este es el modo en que nos comunicamos e interactuamos en el mundo, es a partir del mismo que expresamos las emociones y las necesidades; en este sentido, el lenguaje es netamente relacional, se recrea en el complejo entramado de las relaciones sociales. Así, el lenguaje tiene la capacidad de concebir la realidad social, mediante la asignación de sentido a las vivencias, a las situaciones y a las relaciones e interacciones sociales.

La relación lenguaje y pensamiento es clara, ya que el lenguaje produce y comunica lo que es el pensamiento, pues es la única forma de ser del pensamiento, y al mismo tiempo su realidad y realización. La existencia de una relación mutua entre pensamiento y lenguaje ha sido una preocupación desde los inicios.

Vigostky (1995) plantea que el lenguaje es ante todo un medio de comunicación, un medio de expresión y comprensión, pero además el lenguaje combina esta acción comunicativa con la del pensamiento, así afirma que para que haya comunicación se requiere de la existencia del concepto, que es el pensamiento. De esta manera expone: "La palabra está casi siempre disponible cuando lo está el concepto". Por consiguiente, hay fundamentos para considerar al significado de la palabra no sólo como la unidad del pensamiento y del lenguaje, sino también como la unidad de generalización y de comunicación, y a la par de la comunicación y el pensamiento.

Para Maturana (2001) la evolución del cerebro humano está relacionada con el lenguaje, lo peculiar en lo humano no está en su acción sino en el lenguaje y su entrelazamiento con el emocionar. En otras palabras, la construcción humana se establece en relación con el lenguaje y la emocionalidad y desde allí se genera la acción, por lo cual podemos asumir que estos elementos están presentes en el vivir.

Del pensamiento del citado autor es importante rescatar dos elementos en este análisis. Por un lado, el emocionar, de esta manera incluye el sentimiento como aspecto inherente al lenguaje responsable de la definición de lo humano y por otro es como lenguaje y 
acción se producen en la vida cotidiana. Así hablar en el sentido más profundo, es una experiencia vivida de manera intersubjetiva en relación y en interacción con el otro.

Desde otro punto de vista Bourdieu (1982) afirma que la importancia del lenguaje radica en que éste no es sólo un sistema lingüístico y de normas gramaticales, sino que es una herramienta para construir el mundo, en definitiva, transformar la realidad social. En este sentido el lenguaje es el vehículo de mediación de los seres humanos y todo aquello cuanto le rodea; es la forma a través de la cual objetivamos el mundo, es decir damos sentido a la realidad. Es el lenguaje lo que nos proporciona la condición de humano, diferenciándonos de las demás especies vivas que habitan en el planeta.

El proceso lingüístico no está desprovisto de intereses y poder, ya que el lenguaje actúa como modelo social, siendo a través del mismo cuando se generan los marcos culturales y sociales de la sociedad. Es éste quien determina la reproducción de los patrones de la cultura. Así, de manera histórica conforma el ser y devenir de las sociedades, residiendo en este aspecto su importancia en el análisis en tanto productor y organizador del orden social, donde se condensan los imaginarios sociales, las formas de sentido del "otro", las nociones del deber ser. Es a través del lenguaje que representamos hechos, personas y colectivos.

Así Bourdieu (1982) afirma que es a través del lenguaje cuando categorizamos la realidad, asimismo podemos construir formas de aprehensión del mundo y significación de los otros.

Lo anterior nos brinda herramientas para la comprensión de los procesos de selección que llevamos a cabo a través del habla, entre estos las definiciones de la alteridad, dado que es a partir de éste que damos sentido a lo otro, le comprendemos y construimos su ser en el mundo. Lo que precede tiene una aportación fundamental para la comprensión del modo como se configuran la identidad y las representaciones sociales.

El carácter configurativo del lenguaje será prioritario para comprender la construcción social de la imagen del joven popular como amenaza, dado la profunda influencia sobre ésta, la nominación, como acto de nombrar, asignar atributos es ante todo una acción lingüística. En este trabajo intentaremos demostrar la capacidad de un lenguaje específico, el mediático, de producir realidad social. 
Por ello, es importante observar que uno de los caminos académicos asumidos para la comprensión del lenguaje ha sido desde la inmersión en la cultura, como productor de unidad. Duranti (2000) afirma que es a través del lenguaje como el mundo se mantiene unido mediante los actos del habla y se conecta por medio de canales comunicativos. Hablar significa escoger un canal particular de entrar en ese mundo y un modo particular de mantener relaciones con aquellos con los que entramos en contacto. Desde un punto de vista amplio nos hacemos miembros de una comunidad de ideas y prácticas por medio del uso de la lengua.

A partir de esta conceptualización podemos señalar la importancia del lenguaje en la construcción de la identidad, ya que compartir códigos comunicativos permite la estructuración del sentido compartido. El actuar colectivo hace referencia al encuentro con otros y este contacto se da a través de la expresión comunicativa. Es de esta manera como construimos las nociones identificadoras y las alteridades, exponiendo de forma clara nuestra relación el otro.

De esta manera el habla es un acto de mediación del sujeto con el mundo que rodea, es a través de ésta como los seres humanos establecen la relación entre dos escenarios: lo público y lo privado, existiendo total interrelación entre estos dos ámbitos, ya que el mundo de lo privado se construye en articulación con lo público. En este sentido Duranti (2000) expresa que existe una relación profunda entre el pensamiento que es considerado del ámbito de lo privado y la conducta pública, ya que el pensamiento no puede ser definido por fuera de los recursos culturales y sociales que posee un sujeto para establecer las categorías, las teorías y las estrategias para la resolución de problemas.

Desde lo anterior podemos asumir la relación inherente entre lenguaje y mundo social, en este sentido, es relevante retomar a Duranti (2000) cuando observa que el lenguaje es una herramienta prototípica para la interacción con el mundo, y hablar es la acción de mediación del hombre con su realidad social. Por tanto, el acto comunicativo está constituido por la experiencia humana materializada en el lenguaje.

Echevarría (2003), observa que el lenguaje no se agota en las múltiples dimensiones constituyentes de lo humano; así nos habla de la existencia de tres dominios primarios, el dominio del cuerpo, el dominio de la emocionalidad y el dominio del lenguaje. De estos tres dominios el más importante es lenguaje y en sus propias palabras define: 
Por cuanto es precisamente a través del lenguaje que conferimos sentido a nuestra existencia y es también desde el lenguaje que nos es posible reconocer la importancia de los dominios existenciales no lingüísticos”. (p.32)

Estos tres dominios primarios planteados por el autor tienen relación directa con el lenguaje, debido a que es a través del mismo cuando tiene verdadero valor la expresión del lenguaje corporal y del lenguaje de las emociones, en otras palabras, el dominio del lenguaje permite la manifestación de los otros dos.

De otra parte, es necesario entrar en la discusión de la relación lenguaje, sujeto y acción. Los actos comunicativos más allá de ser sistemas descriptivos o enunciativos conllevan a la acción. Esta última es la capacidad que poseemos los sujetos de movilizarnos ante cualquier situación, es a partir de la acción que el lenguaje se convierte en hechos transformadores de la realidad social; lenguaje y acción son los dos elementos que nos proporcionan la calidad de humanos, de esta manera lo afirma Arentd \& Cruz (1993):

El discurso y la acción revelan está única cualidad de ser distinto, Mediante ellos, los hombres se diferencian en vez de ser meramente distintos, son los modos como los seres humanos se presentan unos a otros, no como objetos físicos sino qua hombres. Esta apariencia diferenciada de la mera existencia corporal, se basa en la iniciativa, pero en una iniciativa que ningún ser humano puede contener y seguir siendo humano. (p. 206)

Además, esta misma autora afirma que una vida sin acción y discurso está literalmente muerta, porque ha dejado de ser humana. Dicha observación es de gran utilidad en este estudio, ya que las narrativas mediáticas van más allá de ser una estructura discursiva y se convierten en actos, en formas de interacción social; tal como lo es la exclusión y la estigmatización de la juventud popular. En este sentido comprendemos que el discurso establece una realidad social que lamentablemente discrimina y niega a un sujeto social en un contexto de violencia. El lenguaje mediático y la apropiación del mismo por ciertos 
sectores de la sociedad colombiana conllevan a la construcción de la alteridad no marcada por la diferencia como es lógico, sino basada en el rechazo social.

Según el planteamiento de la citada autora, ninguna otra realización humana requiere del discurso en la misma medida que la acción, en todas las demás el lenguaje desempeña un papel subordinado, como medio de comunicación o simple acompañamiento, sin embargo, sí éste pudiese ser reemplazado por un lenguaje de signos, es la acción la que determina el discurso. De esta manera, la comprensión de que la humanidad está compuesta de sujetos, de discurso y de acción, nos lleva a concluir que el lenguaje puede ser considerado como un elemento generador de la acción y a su vez le entrega al hombre la posibilidad de realizar lo inesperado, debido a que el discurso y la acción lo hacen un ser único. Son estos dos elementos definen su pluralidad, en palabras de Arendt: vivir como ser distinto entre iguales.

En este mismo sentido, Echeverría (2003), nos proporciona el concepto de lenguaje generativo y con ello sostiene que el lenguaje es acción y afirma que es a través del lenguaje se describe y que se altera el curso espontáneo de los acontecimientos. El lenguaje no actúa de manera pasiva por el contrario el lenguaje crea realidades Si bien no se puede negar la existencia de una realidad externa, ésta es interpretada a través del lenguaje y transformada a través de actos lingüísticos.

Lo observado por el autor es trascendental para el análisis del discurso mediático sobre la juventud popular en Colombia, si tenemos en cuenta el papel generativo del lenguaje y su capacidad de influir en los acontecimientos, podemos comprender que el lenguaje al nombrarlo desde la violencia tiene el poder de la estructuración del otro. De esta manera, mediante la simbolización del joven como fuente de amenaza es posible transformar la categoría de juventud popular. Es por medio del lenguaje como se construyen las identidades, mediante la acción de definir al otro y definirse asimismo, de la manera que lo plantea Echevarría (2003), el lenguaje es el componente activo por medio del cual participamos de un proceso continuo de devenir; es a través de éste que construimos nuestras nociones colectivas de mundo y de sociedad, así como de un futuro deseado y un significativo presente.

En definitiva, queremos poner de manifiesto que la acción y el lenguaje, son elementos claves para moldear nuestra identidad y el mundo que vivimos. Es el lenguaje, el factor más importante para definir la forma como seremos vistos por los demás y por sí mismos. 
De esta manera podemos entender que toda experiencia humana se conforma desde un marco simbólico dado por el lenguaje, no es posible hacerlo por fuera del mismo y en palabras de Echeverría; El ser humano habita en el lenguaje.

Por tanto, este habitar es el que hace que las palabras sean acciones, dado que no son sólo un enunciado, tienen efectos transformadores de realidad; lo que es nombrado existe y en los constantes actos de nominación se recrea dicha realidad, por ello la importancia de conocer esta potestad del lenguaje es vital. Si bien los constructos sociales de estigmatización nacen a partir del lenguaje, es a través del mismo que se pueden transformar dando un nuevo sentido a partir de la generación de discursos incluyentes.

En este sentido, es importante retomar a Bourdieu (1982) cuando afirma que no hay que olvidar nunca al lenguaje por su infinita capacidad generativa. Así desde la perspectiva propuesta por Kant, donde el individuo es el que conoce y crea el mundo a partir de la lengua que le sirve de guía para la producción de la realidad social. De este modo, el lenguaje es determinante en el surgimiento de hábitos, costumbres, culturas y formas de interpretación de lo que nos rodea. La palabra al ser pronunciada da sentido a todo nuestro contexto.

Esta dimensión del lenguaje posibilitará estructurar el sentido del reconocimiento del sujeto joven, a partir de desentrañar las materialidades sociales, simbólicas, culturales propias del lenguaje de exclusión en los contextos en guerra, para dar sentido a las narrativas constituyentes del ser social, así como la comprensión de lo que nos distancia y lo que nos une como sociedades pluralistas, democráticas.

Para lograr esta comprensión es necesario entender el lenguaje desde su dimensión social. Desde esta perspectiva Maturana (2001) expresa que el lenguaje es un fenómeno social y no biológico, ya que a través de éste se constituye en dominio consensual y esta consensualidad hace referencia a compartir una serie de signos (gestos, sonidos, etc.), entonces el lenguaje se produce en la interacción social. Es a partir de ésta cuando se pueden compartir los distintos significados a los que puede dar lugar; de ahí que el habla tenga un papel fundamental en el sentido de organizador social.

La interacción social, la identificación con sistemas simbólicos y de códigos hace que el lenguaje nos proporcione algunas características comunes para la pertenencia a una comunidad lingüística, no obstante, el sistema del lenguaje no es un espacio uniforme; al 
contrario, es una interacción diversificada en la que cada miembro de la comunidad cumple un papel diferente.

En la difícil tarea de comprender el lenguaje es de gran importancia el aporte del sociólogo francés Bourdieu, para reconocer que el lenguaje se construye a partir de los comportamientos habituales de un grupo, en este sentido es pertinente comprender los conceptos de habitus y habitus lingüístico desarrollados en sus trabajos y que son de gran pertinencia para entender los actos comunicativos en relación con la cultura.

En este sentido, Bourdieu (1982) afirma que:

$$
\begin{aligned}
& \text { habitus, sistemas de disposiciones duraderas y transferibles, } \\
& \text { estructuras estructuradas dispuestas a funcionar como } \\
& \text { estructuras estructurantes, es decir como principios } \\
& \text { generadores y organizadores de prácticas y representaciones } \\
& \text { que pueden ser objetivamente adaptadas a su meta sin suponer } \\
& \text { el propósito consciente de ciertos dominios expreso en las } \\
& \text { operaciones necesarias para alcanzarlos, objetivamente } \\
& \text { reguladas y regulares sin ser para nada el producto de la } \\
& \text { obediencia de determinadas reglas, y, por ello, colectivamente } \\
& \text { orquestadas sin ser el producto de la acción organizadora de un } \\
& \text { director de orquesta. (p.136) }
\end{aligned}
$$

El concepto de habitus expuesto por este autor tiene gran importancia para entender los procesos y mecanismos sociales y colectivos determinantes del lenguaje. A través de la experiencia cultural hecha posible por el lenguaje se establecen formas de comprensión y acción que de manera no totalmente consciente determina los modelos de producción y reproducción social. Es el habitus el que nos lleva a que a partir de constructos sociales inmersos culturalmente signifiquemos al otro y le demos un sentido desde un ordenamiento social dominante y socialmente compartido.

Así podemos afirmar que es a través del habitus como se organizan las prácticas y representaciones sociales, la manera como se regulan éstas no tiene que ver con mecanismos conscientes; estas prácticas y representaciones se organizan de forma colectiva. El habitus es una capacidad infinita de engendrar, con total libertad (controlada) 
unos productos - pensamientos, percepciones, expresiones y acciones- limitados por las condiciones históricas y sociales en su producción.

De este modo, el concepto de habitus lingüístico, es un elemento fundamental para el uso del lenguaje y su adecuación al mundo social y es a partir de éste, que se nos permite saber que decir en determinadas situaciones. A través del mismo se regulan las normas sobre quien está autorizado para expresarse en determinado tema o área del saber. Frente a este tema e Bourdieu (2001) afirma que:

El habitus lingüístico implica cierta propensión a hablar y decir determinadas cosas (interés, expresivo) y una cierta capacidad de hablar definida a la vez como capacidad lingüística de infinita creación de discurso gramaticalmente semejantes y con capacidad social que permite utilizar adecuadamente esta competencia en una determinada situación por otro. (p.12)

Es a través del habitus lingüístico que se establece la producción discursiva semejante, lo anterior resulta relevante para el análisis de cómo se construyen las representaciones sociales a partir de un discurso específico, la apropiación de este y la producción de los mismos. De la mima manera, éste proporciona la competencia para la iniciación de actividades mediante lo que se construye una serie de expectativas sobre el mundo.

Asimismo, la configuración del habitus lingüístico recoge las prácticas individuales y colectivas de un determinado grupo, esta experiencia acumulada se refleja en las construcciones discursivas, las cuales cuentan con la experiencia activa de las experiencias pasadas y que se ponen de manifiesto a través del pensamiento y la acción. De igual manera es a través del habitus que se asegura la persistencia en el tiempo de estas prácticas individuales y colectivas al convertirlas en formas naturalizadas del pensamiento para estructurar lo que denominamos el sentido común.

En este tema es preciso reflexionar sobre la relación lenguaje comunicación, en referencia a su interacción dialógica, donde hacen presencia varios tipos de lenguaje; el verbal, el no verbal, la expresión corporal. En palabras de Rebellato (1998) un lenguaje cargado de deseo, capaz de despertar energías y potencialidades y de comprometerlas en los procesos 
de transformación. De igual manera afirma el autor que sin el lenguaje no hay comunicación y se requiere del deseo para transformar estructuras y subjetividades.

Así la relación lenguaje - comunicación es entendida en su acción transformadora de las subjetividades y las estructuras sociales; pero en el caso que analizamos, el discurso mediático, ha construido un discurso basado en presupuestos hegemónicos del deber ser del joven. De este modo, se ha llevado a cabo una profunda estigmatización, de manera que comprender el contenido transformador del lenguaje posibilita desde una visión contra- hegemónica ver la comunicación como vehículo creador de contra- discursos, donde la realidad social sea leída desde sus múltiples dimensiones sociales, culturales y políticas. Pero dichos procesos no son posibles sin la reinvención: del poder, del lenguaje de acción y de la comunicación crítica.

Ahora bien, en este análisis del lenguaje es imprescindible retomar el elemento emocional que hace parte del lenguaje. Como lo expresa Maturana (2001) el lenguaje se encuentra relacionado con la emoción, más allá de comprender el lenguaje como sistema de símbolos se constituye cuando se incorpora al vivir, al ser un fluir de coordinaciones consensuales que se dan como resultado de la convivencia; es decir el lenguaje se da en la interacción social.

Así en medio de las interacciones nos transformamos de forma constante de tal manera que todo lo que hacemos tiene consecuencias y de esta manera nos estructuramos, de modo que el lenguaje tiene la capacidad de ser productor y transformador de la realidad. La convivencia es todo un conjunto de conductas y de aceptación del otro, un modo de actuar, es a través del lenguaje que reconocemos al otro.

En este sentido Maturana (2001) observa que la convivencia humana se da en el conversar; lo cual a su vez está entrecruzado por el lenguaje y el emocionar; esto significa que el reconocimiento del otro es a su vez un acto hablado y emotivo, por tanto, el significado asignado a un sujeto o colectivo no se trata sólo de un acto de nominación, sino que lleva consigo un sentir que es el encargado de producir el rechazo o la aceptación del otro.

Lo expuesto por el citado autor tiene gran importancia para el análisis de los constructos sociales del joven popular en Colombia, dado que pone de manifiesto que la transformación de estos constructos sociales de estigmatización requiere abordar 
profundamente el componente emocional, es decir no se trata tan sólo de un asunto lingüístico, sino que recoge la subjetividad individual y social.

\subsection{Lenguaje, poder simbólico y político}

La humanidad vive constantes experiencias comunicativas formando parte de nuestro vivir y convivir. No existimos sin el habla que trasciende a la expresión oral, conduciéndonos a los escenarios de lo corporal, lo gestual, lo escrito, lo visual y todo el entramado complejo de maneras de comunicar. El lenguaje puede parecer un proceso natural, libre de presiones, en una situación dada; no obstante los actos comunicativos se inscriben en el escenario social y están sujetos a las relaciones de poder propias de todo grupo o sociedad. Asimismo, es a través del lenguaje cuando se originan las relaciones de dominación, teniendo como punto de partida el conocimiento de un determinado campo social, cultural o político.

Continuando con el aporte que nos provee la escuela francesa en torno al discurso, es pertinente recoger aquí el pensamiento de Bourdieu (2001), cuando afirma que:

No hay que olvidar que esas relaciones de comunicación por excelencia que son intercambios lingüísticos son también relaciones de poder simbólico donde se actualizan las relaciones de fuerza entre locutores y sus respectivos grupos. (p11).

De este modo, el lenguaje es asumido más allá de sus características lingüísticas para poder comprender el papel clave que tiene en la dimensión simbólica, ya que a través del acto comunicativo se genera el reconocimiento social de sujetos o colectivos, por la capacidad que se tenga de hablar de un tema en un campo específico. Es en este proceso de reconocimiento cuando se establece el reto de quién es portador de la verdad, y todo ello conlleva a una permanente discusión por ser el interlocutor válido. Además, la comunicación no es un proceso estático, en ella se reflejan las contradicciones propias de los contextos sociales y culturales.

En este orden de ideas podemos comprender la relevancia del lenguaje más allá de ser un vehículo de comunicación sin el cual el acto comunicativo no existe, es un elemento en disputa social y política, en sus dos aspectos fundamentales la producción y su acción. Estamos de acuerdo con Bourdieu (2001) cuando observa que el lenguaje no es sólo un 
conjunto de prácticas que integran un sistema particular de palabras y reglas gramaticales, sino también una lucha constante por fomentar el poder simbólico en la específica modalidad de la comunicación, con su propio sistema clasificatorio, formas de influencia y de tratamiento, así como de léxicos especializados.

En este trabajo tendremos en cuenta la perspectiva del lenguaje como forma de lucha por el poder simbólico, ya que al enfatizar en los medios de comunicación nos tendremos que detener en el poder que posee su lenguaje como ordenador de la realidad social. Por lo que resulta interesante comprender como se construye este poder en el ejercicio de la comunicación y como se instala en las audiencias del país.

Para comprender como se constituye este poder simbólico es necesario profundizar en los elementos sociales y políticos que contribuyen a generar ese poder. En esta línea, Bourdieu (2001), ofrece una reflexión sociológica sobre la forma como se construye este poder simbólico en los actos comunicativos; donde se tiene en cuenta el discurso, el portavoz y los grupos receptores de este discurso.

Este autor contradiciendo a autores como Habermas (1989) y Austin (1995) advierten que el poder de la palabra no está en el discurso sino en el acceso a los instrumentos legítimos de expresión y por tanto su participación en la autoridad de la institución. Así, el poder de las palabras depende de que quien lo anuncia no lo hace a título personal y sino que tiene la legitimidad del grupo al que representa, así como el conocimiento especializado adecuado.

En este orden de ideas es importante preguntarnos cómo se construye esta autoridad que hace que se constituya el poder simbólico. Según lo expuesto por el citado autor este principio de poder reside en las condiciones de producción y recepción del discurso. La autoridad del discurso no reside en que éste sea comprendido, ya que lo que ejerce efecto es el ser reconocido; para ello el discurso debe ser pronunciado en una condición legítima por la persona habilitada para hacerlo.

Sí observamos la relación del discurso mediático y el poder simbólico sobre éste en Colombia, podemos apreciar que:

- A los medios se les ha otorgado el status de portavoz autorizado en el campo del conflicto armado interno y la violencia juvenil, dado que son los únicos 
encargados de brindar esta información, incluso, la versión oficial (Estado y entes gubernamentales) es transmitida por las principales cadenas de comunicación.

- La información presentada en los medios de comunicación sobre el conflicto armado se obtiene de fuentes gubernamentales o militares, sin ser constatada con otros actores involucrados, de igual manera carece de un análisis riguroso acorde con el contexto en que se desarrolla. Asimismo, la información se traslada desde la opinión de los periodistas sin contar con el análisis de expertos académicos en el tema del conflicto. Sólo los medios alternativos de comunicación utilizan formatos de análisis y confrontación de fuentes noticiosas.

- La ciudadanía en general legitima la información de los medios de comunicación, puesto que no tiene acceso a otro tipo de información y desde este desconocimiento considera que el discurso de los principales medios es verídico y por tanto tiene la autoridad para abordar estos temas.

- Por último, es importante tener en cuenta que la labor mediática en Colombia es ejercida por Gremios económicos, Dueños de medios de comunicación y Políticos influyentes.

La concentración de la información mediática es una de las fuentes de ese poder, ya que los medios de comunicación son considerados como guardianes de la verdad, pues cuentan con la autoridad entregada por las instituciones y el Estado, así como la asignada en el imaginario nacional. De esta manera, el desconocimiento de la mayor parte de los colombianos sobre la realidad del conflicto armado, conlleva a que se les otorgue a los medios de comunicación la autoridad legítima para informar sobre lo que está sucediendo.

La construcción de la legitimidad de un determinado discurso requiere del uso de ciertos rituales de carácter público que buscan la obtención del reconocimiento legitimo por parte de los receptores del discurso, entre estos rituales encontramos (los lanzamientos de libros, revistas, las conferencias de prensa, las premiaciones). Con ello se logra que los miembros de un campo académico, religioso, mediático obtenga el reconocimiento como autoridad para hablar sobre un determinado tema.

En este sentido los medios de comunicación colombianos (las cadenas de radio y televisión: Caracol y RCN, El periódico el Tiempo y los periódicos locales; EL País, El Heraldo, entre otros) han contado con los recursos económicos para fomentar acciones 
que les lleven al reconocimiento como portadores de la información pública de lo que ocurre en el país y específicamente para ser aceptados por parte por la mayoría de los colombianos como medios legítimos de información sobre la guerra.

En definitiva, en la construcción del poder simbólico de los medios en Colombia se encuentran, dos elementos planteados por Bourdieu en sus trabajos; el portavoz autorizado y el desconocimiento sobre el campo por parte de las audiencias; en este caso específico el poco conocimiento de los colombianos sobre los aspectos más profundos que atañen al conflicto armado colombiano. Por ello los medios de comunicación son vistos como fuentes creíbles e irrefutables de información. En este sentido resulta válido recurrir a lo expuesto por Bourdieu \& Passeron (2001) en relación a la construcción de la autoridad del conocimiento que en sus propias palabras afirma:

El lenguaje de autoridad gobierna siempre con la colaboración de aquellos a los que gobierna, es decir mediante la existencia de los mecanismos sociales capaces de producir esta complejidad; fundada en el desconocimiento que es el origen de la autoridad." (p.73)

De esta manera se observa que, en el caso colombiano, la construcción del reconocimiento de los medios de comunicación, ha estado en gran medida asociado al acceso de las principales cadenas de noticias a la exposición pública y la implementación de diferentes acciones de reconocimiento público, así como el poder otorgado por los representantes de la política nacional.

Un aspecto fundamental para comprender la autoridad de un portavoz en un campo son las condiciones sociales de producción y reproducción del conocimiento en las clases sociales y el acceso al saber especializado. La violencia estructural presente en el país que conlleva a la desigualdad en el derecho a la educación y a que vastos sectores de la población colombiana no pueda ingresar a los estudios secundarios y universitarios con ello se genera un obstáculo para acceder a la comprensión de lenguajes especializados. Así en muchas ocasiones, los discursos que circulan en relación al conflicto armado interno, son de carácter tan especializado y no son fácilmente asimilables por el grueso de la población. Lo cual contribuye de manera significativa a que en el imaginario nacional se establezca la percepción de que el saber sobre la situación de guerra está en manos de los medios de comunicación. 
De esta manera se cumple lo expuesto por Bourdieu en sus trabajos acerca de que el desconocimiento de los ciudadanos sobre un determinado campo, es fuente de poder simbólico del portavoz autorizado. Así el desconocimiento de la sociedad colombiano sobre lo relacionado con el conflicto armado interno conlleva a que los medios de comunicación sean leídos como los depositarios de la autoridad en el tema de guerra y por tanto poseedores de la verdad de lo que está sucediendo.

Una de las fuentes de poder de los lenguajes ideológicos (políticos, religiosos) es la polisemia, es decir la variedad de sentidos que poseen las palabras, en muchos casos antagónicos, que no lleva a la comprensión de los mismos, por tanto se asigna el poder legítimo al portavoz de este discurso, mostrando que el acceso al conocimiento de un campo determina el poder que se otorga a quien representa este campo.

Para que se logre la eficacia de un discurso especializado se requiere que exista la correspondencia, por una parte, entre la estructura del campo social, campo político, campo religioso, campo artístico o campo filosófico; y por otra, con la estructura del campo social de las clases sociales en el que se sitúa a los receptores.

Bourdieu \& Passeron (2001) nos presenta elementos sociales que conllevan a la construcción del poder simbólico del discurso, en este sentido retomando los trabajos de Austin y de Habermas observa que para estos autores el poder sobre el discurso se encuentra en el mismo discurso, es decir reside en lo que expresa sobre un determinado campo, no obstante, para Bourdieu esto tan sólo se constituye en un testimonio, en el cual no se concentra en su totalidad el poder simbólico, ya que para el autor este poder viene de afuera, este es otorgado por las audiencias, dicha autoridad deviene de quien recibe el discurso y le da el sentido de portavoz autorizado.

El poder de la palabra radica en el poder simbólico acumulado que le otorga el campo del que hace parte el portavoz autorizado de este discurso, así como del poder asignado por quienes son receptores del discurso, a partir de considerar que el portavoz en este caso, las cadenas de noticias y prensa tiene la autoridad para informar sobre este tema.

\subsubsection{Lenguaje como discurso}

Hemos analizado anteriormente el lenguaje, sus implicaciones en el poder simbólico, hemos podido establecer la relación del lenguaje con la construcción de realidad social, así como determinado la no existencia de un mundo social sin el lenguaje. Ahora nos 
corresponde estructurar nuestra conceptualización del discurso. Con ello daremos sustento al análisis del discurso mediático a propósito de la juventud popular en Colombia; de ahí nuestro interés por reconocer sus puntos de distinciones con el lenguaje y sus especificidades en torno a la acción.

La importancia del discurso es su constitución como acción social, si bien el lenguaje se considera como elemento preexistente al sujeto, así como lo asume Negro (2010) retomando a Lacan, el sujeto no existe antes que el lenguaje, es éste quien lo determina y le transforma, el discurso recobra importancia como lazo social y constituyente de la comunicación. A su vez el discurso se genera en la articulación de palabra y lenguaje.

De otra parte, Arendt (1993) expresa la importancia de la palabra en relación con el discurso y la acción, específicamente ella afirma que con la palabra y el acto nos insertamos en el mundo humano, esto significa el verdadero nacimiento social. En este sentido podemos asumir que las dos particularidades del discurso son la palabra y la acción. A su vez el discurso es el medio por el cual los humanos muestran su ser social e incluso establecen sus sentidos de identidad, quien se es a diferencia de otros se estructura en los campos discursivos.

De otra parte, para Foucault el discurso no solo se trata de enunciados también son prácticas por proximidad a otros discursos, por sus reglas de organización, sus resultados surgen de las reglas que lo definen como objeto de ese discurso. El discurso no se encuentra en el interior, sino que lo constituye el entramado del mismo discurso. Así Foucault (1970) expresa que:

\section{(...) el discurso no es sólo es simplemente aquello que se} traduce en las luchas de los sistemas de dominación, sino aquello por lo y por medio de lo cual se lucha, aquel poder del que quiere uno adueñarse. (p. 12)

Foucault (1970) expresa la existencia de tres principios de exclusión presentes en el discurso: lo prohibido, el loco y la voluntad de la verdad. El primero, trata de las cosas que no pueden ser nombradas por cierto interlocutor porque no posee el status para hacerlo o porque esos temas están vedados, pertenecen a lo oculto. El segundo, se refiere a la sanción social sobre un portavoz al que no se le reconoce la autoridad para ejercer dicho discurso, por tanto, su mensaje es considerado nulo. El tercero se refiere a la 
exclusión en relación a quien tiene el poder de la verdad socialmente legitimado, de esta manera, quien no la tiene no se hace merecedor de explicitar ese discurso.

Lo anterior nos sirve para entender dónde radica el poder y el control del discurso. La relación de dominación en cuanto a lo expresado en el discurso, radica en sus procedimientos de exclusión; basados en la creación de jerarquías en relación a los mecanismos sociales de control. En esta misma línea, es importante reconocer la relevancia del control sobre el discurso expuesta por Bourdieu y Foucault, lo cual nos lleva a estructurar la idea de la imposibilidad de un discurso autónomo, ya que siempre éste estará modelado por relaciones de poder.

Entre estos procedimientos se encuentran los de control interno, lo cual hace referencia a la capacidad de un discurso de ejercer control sobre otro, entre estos procedimientos se encuentran:

- El principio de clasificación. Hace referencia a que en la sociedad existen discursos que surgen y desaparecen, discursos que reanudan otros discursos, que transforman y cuestionan. Es decir, el discurso por sí mismo tiene la capacidad de controlar la acción discursiva sobre un determinado tema.

- El principio de ordenación. Se refiere al autor que no se debe considerar como un individuo sino como el principio agrupador del discurso.

- El principio de distribución. Hace referencia a las disciplinas también es un principio se refiere a la existencia de normas para la constitución de cualquier disciplina con ello se establece un control del discurso para ser parte de una disciplina.

Así puede sospecharse que hay regularmente en las sociedades una especie de nivelación entre discursos: los discursos que se dicen en el curso de los días y de las conversaciones $\mathrm{y}$, que desaparecen con el acto mismo que los ha pronunciado; y los discursos que están en el origen de nuevas de palabras y que van más allá de su formulación.

Haidar (1998), retomando a Foucaut (1987), afirma que las condiciones de emergencia de discursos se analizan por tres grupos de procedimiento: a) procedimientos de exclusión, b) los procedimientos de control interno, c) los procedimientos de control de condiciones de utilización. A su vez, estos procedimientos contienen tres tipos de 
prohibición: 1) el tabú del objeto, 2) el ritual de la circunstancia, 3) el derecho exclusivo y privilegiado del sujeto que habla.

A partir de estos procedimientos se establecen las regulaciones del discurso, de tal manera que la producción discursiva cuenta con procedimientos de carácter interno y externo que definen el contenido que se hace público, de la misma manera, que se establece quien tiene el poder legítimo de representación de un determinado discurso. Por tanto, comprender las dimensiones del discurso en el ámbito social es una tarea que incluye el análisis de las condiciones de control de producción y reproducción de las narrativas discursivas. Al respecto Foucault (1970), afirma:

En toda sociedad la producción del discurso está a la vez controlada, seleccionada y redistribuida producida por cierto número de procedimientos que tienen la función de conjurar los poderes y peligros, dominar el acontecimiento aleatorio y esquivar la pesada y terrible materialidad. (p.11)

Lo anterior nos lleva a preguntarnos por el sentido que posee dicho control del elemento discursivo; una de las respuestas que podemos pensar sobre la relación de éste con las relaciones de dominación, así como que la disputa por lo narrado y el reconocimiento de la veracidad nos es ajena a las relaciones de poder. En el caso específico del discurso mediático, esto adquiere profunda relevancia, los mecanismos de selección y control se relacionan directamente con el poder político, social y económico presente en las esferas producidas por los medios.

No obstante, otros discursos como el académico, el político, el social, el cultural entre otros se rige por una serie de principios, claramente definidos en los trabajos de Foucault, los cuales actúan como formas de regulación y criterios de veracidad para dar reconocimiento y status dentro de la producción académica, social y política de una sociedad. Entre estos principios tenemos:

El comentario, de esta manera se conjura el azar, dado que permite decir otra cosa, la cual no está por fuera del texto mismo, bajo la condición de que sea ese mismo texto el que se diga y en cierta forma el que se realice. La forma como el comentario limita el azar del discurso es por medio del juego de una identidad que tendría forma de repetición, así se restringe al autor a su individualidad. 
La atribución se relaciona con lo que se considera verídico, en razón de ser pronunciado por un autor, de esta manera se pide al autor conservar una unidad de texto, es decir una unidad de donde proveen sus significaciones.

La disciplina, se basa en la existencia de una disciplina definida por un ámbito de objetos, por un corpus de proposiciones consideradas como verdad, un juego de reglas y definiciones de técnicas e instrumento: lo cual constituye un sistema anónimo a disposición de quien quiera o pueda servirle. La disciplina existe cuando tiene la posibilidad de formular indefinidamente nuevas proposiciones. A su vez para que una proposición pueda pertenecer a una disciplina debe inscribirse en un cierto tipo de horizonte teórico, en el interior de cada disciplina cada proposición reconoce proposiciones verdaderas y falsas.

La disciplina es una manera de controlar la producción del discurso, a través de los límites a la identidad, se reactualiza permanentemente y produce reglas y normas. A través de estas normas se limita el acceso al mismo, se requiere de poseer un reconocimiento de saber para pertenecer a una determinada disciplina. Ésta se encarga del ejercicio del discurso y a su vez de la exclusión a través del discurso.

La función de los procedimientos de control, radica en que no se puede decir todo, en cualquier momento circunstancia o fin, no se puede hablar de cualquier tema, se requiere del reconocimiento social para hacerlo. A su vez este reconocimiento es otorgado por el oyente, de esta manera, le da sentido a lo que escucha al interpretar la palabra enunciada de quien emite el discurso.

De otra parte, Haidar (1998), reconoce al discurso como una práctica discursiva y en este sentido asume el mismo como: un conjunto tras-racional que presenta reglas sintácticas y pragmáticas, un conjunto que presenta reglas de cohesión y coherencia; el discurso siempre tiene relación con las condiciones de producción y circulación y recepción, el discurso está constituido por varias materialidades entre estas materialidades es necesario resaltar; la ideológica, la lingüística, la pragmática, la del poder, la cultural, la estética, la histórica y la social. Las cuales actúan de manera distinta de acuerdo con los tipos y subtipos de discurso, así como las condiciones de recepción, además de los sujetos que participan en el discurso.

En este sentido el tipo de discurso dará mayor relevancia a una materialidad u otra, como por ejemplo un discurso político dará mayor importancia a la materialidad del poder, así 
como un discurso religioso a la ideología y un discurso artístico a la estética, en un mismo discurso se pueden presentar diversas materialidades, pero existirán unas con mayor preponderancia de acuerdo al tipo de discurso y las finalidades del mismo.

De otra parte, para la citada autora el discurso puede ser entendido como una práctica social y esto implica asumir que el análisis del discurso no puede ser considerado desde una perspectiva lingüística técnica, sino que está igualmente relacionado con las condiciones sociales de producción del discurso. Para la comprensión desde esta perspectiva del discurso, esta autora toma las categorías de formación social, formación ideológica y formación discursiva.

La formación social se define por la manera como se articulan los medios de producción por la estructura de clases sociales antagónicas, por la superestructura existente y la forma del Estado. La categoría de formación ideológica puede ser analizada por varias dimensiones, tales como; la capacidad hegemónica que tiene que ver con los tipos de hegemonía para desarrollar y los aparatos ideológicos que se estructuran definiendo sus relaciones con El Estado y por la forma que adquieren las redes ideológicas que constituyen una forma concreta de funcionamiento ideológico.

Así la formación discursiva la define por la relación que se establece entre el discurso y su exterior, que son los aparatos de hegemonía que se refieren a las posiciones ideológicas de clase y a la base lingüística constitutiva de la reproducción y la transformación social. De esta manera, la teoría de formación discursiva permite superar la comprensión de la comunicación centrada en una relación intersubjetiva entre hablante y oyente y orienta al análisis hacia la determinación de los efectos del sentido (los sistemas de representación) articulados a las formaciones ideológicas. Esto plantea el hecho de la interdiscursividad, haciendo referencia al análisis de las condiciones de producción y recepción del discurso, bajo el supuesto de que ningún discurso está aislado, sino que hace parte de una cadena infinita intersubjetiva. Es decir, existe una característica relacional en el discurso que supera la interacción social porque en éste se entrelazan las emociones.

De ahí que, aborde el tema del discurso como práctica social, debido a que de esta manera se pueden considerar como prácticas semiótico - discursivas, lo cual posibilita aplicar diferentes modelos desarrollados tanto por la semiótica, como por el análisis del discurso. La importancia de las prácticas discursivas en la producción de la realidad social es muy significativa, ya que las prácticas discursivas tienen la capacidad de transformar la vida 
social en todas sus dimensiones, poseen una capacidad performativa porque pueden dar origen a diversos tipos de prácticas sociales y culturales, así como producen y reproducen asuntos sociales como la hegemonía y el poder. En definitiva, las prácticas discursivas tienen la capacidad de potenciar mecanismos de persuasión y del convencimiento o de mecanismos para justificar la violencia y la desigualdad, así como pueden generar procesos de resistencia y lucha contra la dominación existente.

Igualmente, esta autora afirma que existen una infinidad de mecanismos de persuasión, de convencimiento y retomando a Reboul (1980) expone que, uno de estos mecanismos es el de la naturalización discursiva, éste radica en que las prácticas discursivas aparecen como lo que no son: objetivas, neutrales, verdaderas, ingenuas y sin ninguna perversión.

Lo cual es muy significativo para esta investigación puesto que la existencia de discursos públicos asumidos como objetivos, verdaderos en los medios de comunicación acerca de la violencia, ha sido un factor determinante para la aceptación y el reconocimiento de dichos discursos por parte de sociedad, contribuyendo a la construcción de imaginarios de discriminación en torno a la juventud.

Cuando estudiamos el Discurso adquiere una gran importancia la relación de las prácticas discursivas y la ideología, asumiendo el debate que se plantea entre los posicionamientos ideológicos (en el sentido del discurso expresado) y la interpretación del discurso recibido.

El concepto de ideología ha tenido diferentes definiciones, por ejemplo, para Van Dick (2008) las define de la siguiente manera:

Las ideologías son marcos básicos de cognición social, son compartidas por miembros de grupos sociales, están constituidas por selecciones de valores socioculturales relevantes y se organizan mediante esquemas ideológicos que representan la autodefinición de un grupo. Además de su función social de sostener intereses de los grupos, las ideologías tienen la función cognitiva de organizar las prácticas sociales (actitudes, conocimientos) sociales del grupo y así monitorizar indirectamente las prácticas sociales, 
grupales y por lo tanto también el texto y el habla de sus miembros. (p. 2008).

Asimismo, Haidar (1997) retomando a Robín (1973) plantea que los cuatro rasgos fundamentales que caracterizan la ideología son:

- Las ideologías no son arbitrarias, sino que son orgánicas e históricamente necesarias,

- Las ideologías tienen la función de desplazar las contradicciones reales de la sociedad y reconstruir sobre el plan imaginario de un discurso coherente que sirva de horizonte a lo vivido por los sujetos sociales,

- Una ideología no se expresa de manera consciente en los sujetos que la poseen, sino que se pone de manifiesto en los actos discursivos y

- Las ideologías tienen existencia material, entendida ésta como una serie de prácticas y una estructura institucional.

Las ideologías están compuestas por un sistema de creencias compartidas por los miembros de un grupo y desde allí se da interpretación a hechos, fenómenos, sujetos o colectivos. La conceptualización de las mismas se ha basado en los principios de la falsa conciencia y la conciencia verdadera; el primero definido como la distorsión de la realidad (sentido restringido), el segundo, los hombres se dan cuenta de los conflictos sociales (sentido amplio). Desde este planteamiento entendemos que, por un lado, la falsa conciencia es la que se encarga de producir constructos ideológicos como: el racismo, el sexismo, el clasismo, entre otros y de otra parte, la verdadera conciencia es la que posibilita interpretar los conflictos sociales donde se produce la discriminación.

Haidar (1997) después de analizar estos componentes de la ideología, concluye que: lo más oportuno, en el estado de la cuestión del tema de las ideologías, es asumir lo ideológico como un fenómeno complejo en el cual existen dos polos que van desde la falsa consciencia, hasta la verdadera abarcando por lo tanto dos sentidos opuestos. Desde esta perspectiva podemos observar que en el discurso se encuentran diversas posiciones con sentido ideológico basadas en la falsedad y la verdad, entonces es propio del análisis del discurso identificar estas influencias ideológicas.

En este sentido, Van Dijk (2008) afirma que la importancia de las ideologías es que permiten conocer como los miembros de un grupo interpretan y construyen la realidad 
social, y estas construcciones de sí mismo pueden incluir falsas creencia, igualmente las ideologías de resistencia pueden incluir como instrumentos de cambio las creencias verídicas para transformar los discursos de discriminación.

De otra parte, Haidar (1997) retomando a Reboul (1980) afirma que: la virtud de la ideología está en que no sólo confiere sentido a las palabras, sino, también poder; entre estos, el poder de la persuasión, de convocatoria, de consagración, de estigmatización de rechazo, de legitimación, de excomunión. Asimismo, advierte que el poder de la ideología recae en que se postula como racional y crítico para disimular el verdadero funcionamiento del discurso.

En términos del discurso, la ideología tiene el poder de ejercer control del significado, en tanto el discurso puede ser expresado desde un posicionamiento ideológico, ya sea a través de la exposición de ideas falsas o mediante la manipulación de información verdadera, por ejemplo, en el caso del discurso mediático colombiano sobre la guerra, el hecho de que las corrientes ideológicas de los medios sea de tendencia política de derecha, conlleva a que las noticias presentadas tengan mayor énfasis en los hechos violentos que en las potencialidades de paz de las comunidades, o a que se sobrevaloren las posiciones militares antes que dialogadas para la salida del conflicto.

Ahora bien, es importante tener en cuenta que el significado del discurso posee muchos elementos ideológicos, concebidos en las representaciones sociales, lo cual influye en la generación de modelos mentales, que hacen parte operativa de la manera como se configuran los discursos.

$\mathrm{Al}$ analizar el discurso tenemos que centrarnos en el sentido de las palabras, lo que se ofrece desde el mensaje y la significación con la que es recibida, en este orden de ideas tenemos que adentrarnos en lo que expresa Bourdieu \& Passeron (2001), la polisemia propia de las palabras, sobre lo que Ricouer (2001) le da un sentido asumiendo que: Casi todas nuestras palabras son polisémicas, pero la función contextual del discurso es tamizar, la polisemia encubierta en nuestras palabras; además, señala que es función del diálogo iniciar esta función tamizadora del contexto.

El diálogo es el mediador entre los diversos sentidos de las palabras, es de alguna manera, establecer esa relación consensuada en la comunicación expuesta por Maturana (2001), 
si bien la mulltiplicidad de sentidos no podrá reducirlo y no tendría fundamento hacerlo, la comunicación puede consensuar parte de estas diversas maneras de significar.

El diálogo para Ricoeur (2001) es un acontecimiento conectado con otro acontecimiento; a su vez, el acontecimiento es una experiencia expresada y comunicada, además de ser un intercambio intersubjetivo; de esta manera se puede entender que en el discurso se encuentran elementos emocionales, intersubjetivos que van más allá de lo observado. Si el diálogo permite tamizar los sentidos, el discurso es la expresión del mismo sólo que contiene los sentidos subjetivos, emocionales y colectivos.

En esta misma línea, este autor introduce otros dos conceptos: la referencia y el significado. El primero establece que el discurso siempre se refiere al mundo, porque el hablante se expresa desde la realidad en que se encuentra inscrito, por tanto a través de la referencia el interlocutor trae su propia experiencia al lenguaje. El segundo se refiere a lo que el hablante quiere expresar, es demarcado por la intención del hablante para obtener el reconocimiento por parte del oyente; en este sentido el significado es la interpretación que el hablante le da a su propia experiencia.

Al llegar a este punto es fundamental abordar el aporte de la semiótica en la construcción del sentido del discurso. En esta línea la semiótica es vista por Zeccheto (2002), en su función de verificar la estructura de los signos y la validez que pueden tener las percepciones culturales, procurando además enfrentarse con explicaciones teóricas que den razones coherentes de estos fenómenos que involucran la comunicación humana; de este modo la semiótica está vinculada al problema del conocimiento y con el modo por el cual podemos llegar a él a través del vehículo ineludible de los signos.

Desde este punto de vista, la semiótica se presenta como una forma de observar la realidad, en relación al modo en que las cosas se convierten en signos y son portadoras de significado, además de prestar atención a la semiosis, es decir, a la dinámica concreta de los signos en un contexto social y cultural. La semiosis es un sistema operativo contextualizado en el cual diversos sistemas de significaciones transmiten sentidos desde el lenguaje verbal al no verbal pasando por los lenguajes audiovisuales hasta las modernas comunicaciones.

La importancia de la semiótica radica en la posibilidad que nos ofrece de comprender el discurso con la cultura y las múltiples formas de interpretación de lo expresado en ella. 
En otras palabras, nos acercan a la complejidad simbólica del lenguaje, al entramado de significaciones de la palabra dicha, tanto en el sentido de la interpretación, como de la intención expresada.

La relación semiótica y semántica ha estado en un constante debate académico, desde algunas vertientes como la expresada anteriormente se considera la disciplina encargada de analizar el sentido, para otros como Ricouer (2001) como una mera abstracción de la semántica y la definición semiótica de signo como una referencia interna entre significante

y significado presupone la definición semántica como referencia a la cosa que representa. La definición más concreta de semántica, entonces, es que consiste en la teoría que relaciona la constitución interna o inmanente del significado con la intención interna o trascendental de la referencia.

\subsection{Lenguaje, significaciones y guerra}

En la última parte de este capítulo vemos necesario comprender como el lenguaje ha sido utilizado como medio de manipulación en la guerra. Dado nuestro interés de analizar la influencia del discurso mediático en la construcción del imaginario social del joven como amenaza en el contexto colombiano. Para ello acudiremos a lo expuesto sobre el tema desde la perspectiva del lenguaje colateral y algunos estudios realizados en Colombia sobre la relación lenguaje y conflicto interno armado.

Un conflicto empieza a ganar poder cuando está presente en los medios de comunicación. El lenguaje forma parte esencial del conflicto, así pues, son tan importantes las estrategias bélicas basada en las palabras como las estrategias militares, la guerra tiene sus mayores ganancias en los campos discursivos.

En el desarrollo de este capítulo hemos abordado el lenguaje en su capacidad generativa de realidad social, pero cuando se analiza la guerra este presupuesto se hace mucho más evidente, dado que se profundizan las palabras en torno a la construcción social del adversario, la justificación de la violencia y la búsqueda de legitimidad. Lo anterior es planteado Collins \& Glover (2003), de la siguiente manera: 
(...) Aunque el lenguaje da siempre forma a nuestras vidas, los efectos del lenguaje en la guerra son único, el lenguaje de la guerra que añade a nuestro léxico en curso, así como a los significados añadidos que ciertos términos requieren en tiempo de guerra. (p12)

El uso de lenguajes relacionados con lo bélico, es una de las características de los contextos de conflicto. La permanente escucha de discursos alusivos al conflicto, incide en la configuración de nuevas formas de expresarnos, no obstante, existe en esos escenarios un discurso cargado de intencionalidad, aquel que trata de lograr la justificación de la guerra, la consolidación de la imagen del enemigo.

Pero los efectos del lenguaje son amplios y profundos, ya que van más allá de la manera como significamos al otro, no quedándose en los dominios de lo simbólico, sino que se transfieren a otras esferas de la vida humana. Así lo afirma Collins \& Glover (2003) que para comprender la retórica política resulta necesario reconocer que lo que oímos afecta de manera significativa a nuestra manera de ver el mundo y a las personas concretas en este mundo.

Al estudiar los efectos del lenguaje en la guerra se ha construido el término de lenguaje colateral haciendo un paralelo con la existencia de daños colaterales producidos por las guerras, dicho concepto es creado para designar la presencia en discursos en medio de la violencia que atañen a sí misma. Collins \& Glover (2003) se refiere al lenguaje de la guerra como la práctica que añade a nuestro léxico nuevos significados de ciertos términos que se adquieren en tiempos de guerra.

Estamos de acuerdo con el citado autor en cuanto a la existencia de un lenguaje producido en el escenario de la guerra, no obstante, es importante, debatir el concepto de lenguaje colateral, al igual que el concepto que da origen de daños colaterales, puesto que, consideramos que ni el primero, ni el segundo son consecuencias no esperadas de otras acciones de la guerra, sino que los mismos están debidamente estipulados y planeados como estrategia bélica. Llamarlos así sería disminuir su impacto político y militar sobre las poblaciones situadas en medio de contextos de guerra.

En el caso de Colombia, en su larga historia de conflicto y la violencia que la precede, hemos observado la utilización del lenguaje como objetivo de guerra, desde las confrontaciones partidistas de la violencia de los cincuenta, llevada a cabo desde 1948 a 
1951, se expone un discurso de denominación de los contradictores, discurso que motivó de manera importante la violencia entre sectores de la sociedad civil.

En el largo Conflicto Armado actual hemos asistido a una disputa también en el campo discursivo a nivel de lenguaje; un lenguaje que transforma los sentidos a partir de lo que la autora De Hincapié (2004) denomina las nuevas palabras. En este sentido, se han generado nuevas formas de nominación utilizadas por los diversos actores que hacen parte de la guerra. Este proceso de inclusión de nuevos léxicos se realiza de diversas formas, entre otras, la construcción de nuevas palabras; el reciclaje de palabras que fueron utilizadas en otros ciclos de la violencia del país; la reconfiguración de nuevos sentidos semánticos de palabras existentes.

En esta línea, Gonzales (2009) nos describe tres tipos de procedimientos presentes en el lenguaje en el contexto bélico: eufemismos, disfemismo y neologismos. Estos tres aspectos son coadyuvantes en la aparición de nuevos léxicos en el proceso de guerra que estamos viviendo. Es de anotar que lo anterior, no es particular del caso colombiano, están presentes en la mayoría de los conflictos armados.

Los eufemismos consisten en imponer un lenguaje metafórico para despojar de sentido algunas palabras y darles otro sentido semántico, de esta manera se oculta lo que está sucediendo, a través de este lenguaje metafórico, se resta importancia a los actos de violencia, o de nombrar lo que se quiere que sea aceptado, tal como las estrategias bélicas desde perspectivas mayormente reconocidas por la población.

De otra parte, el disfemismo es un lenguaje utilizado para adjetivar ciertos grupos de manera negativa, mediante la calificación de estos grupos como bandoleros, pandilleros, terroristas, sediciosos, vándalos, delincuentes. Se busca que estos términos obtengan el reconocimiento popular y se constituyan en marcos de significación compartida para deslegitimar a quienes no se inscriben en sus estrategias de guerra.

Los neologismos, se trata de la construcción reciente de expresiones, ya sea a partir de retomar palabras de un lenguaje extranjero o de cambiar de denominación a algunas palabras. Con ellos se pretende dar énfasis en la lucha para la destrucción de los opositores (grupos subversivos, partidos de izquierda, movimientos sindicales y sociales...) al modelo estatal. En las últimas décadas han tenido gran influencia en la construcción de estos neologismos las políticas contra el terrorismo como amenaza mundial. 
La transformación semántica sobre el lenguaje en contexto de guerra, forma parte de una estrategia para la búsqueda de alianzas, pactos, legitimidad, condena, desprestigio. Así como reconocimiento de legitimidad en su lucha contra los ejércitos en confrontación. La utilización de un lenguaje ambiguo tiene como objetivos: desviar la atención de acciones realizadas, obtener la legitimidad por parte de la población civil y ganar adeptos a las causas bélicas.

Otro de los efectos de la utilización de este lenguaje bélico es el de naturalizar la violencia proveniente de la guerra, así como la existencia del conflicto. De este modo, sí tenemos en cuenta la capacidad generativa del lenguaje, en tanto productor de visiones del mundo y realidad social, observamos cómo esta terminología de uso cotidiano es apropiada por la sociedad, de esta manera estos nuevos léxicos se convierten en realidad social.

Así, Rodríguez (2011) nos presenta un nuevo concepto el nominalismo, este se entiende como el lenguaje usado a través del cual el Estado, justifica la defensa de un orden, la seguridad y la paz. Lo cual tiene en su centro un componente lingüístico con un poder indivisible. Este concepto tiene un papel fundamental en la definición de términos relacionados con la paz y a la guerra.

La disputa por el poder simbólico del lenguaje en las definiciones de la guerra es inherente a las de la paz. Sí hablamos de conflictos armados, no se puede nombrar la una sin la otra, en este sentido, también existe una disputa por el poder del lenguaje de la paz, tantas veces utilizada desde el poder. La población civil, la mayor receptora de los efectos de las confrontaciones bélicas, es la más necesitada del cese de las hostilidades, por ello se ha hecho uso de esta nominación para su manipulación de estos deseos bajo intereses políticos.

En este mismo sentido. Rodríguez (2011), retomando a Uribe \& López (2006), afirma que las guerras no se libran sólo en el terreno de las armas, pues las formas de nombrar, ocultar o desplazar realidades permiten presentar a la nación de una manera determinada; y por esta razón, las metáforas también matan. De esta manera, queda claro el papel fundamental del lenguaje como estrategia bélica, y así comprender su capacidad simbólica y material de actuar en la guerra.

En contextos de guerra, el lenguaje es una estrategia de dominio y control social y modificación del sistema de creencias, en este postulado radica la importancia del 
lenguaje en el análisis de los contextos bélicos. Es necesario desentrañar las ideologías presentes en el marco de la guerra, y el poder de sus actores para ejercer dicha manipulación. En el mismo sentido, se puede observar la presente relación entre lenguaje y poder; por una parte, la manipulación del lenguaje sólo es posible hacerla desde el soporte del poder político, social o cultural y a su vez, dicho poder se construye desde el lenguaje.

Un ejemplo claro del ejercicio de poder y manipulación del lenguaje lo encontramos en el caso colombiano, específicamente en los periodos de gobierno del presidente Álvaro Uribe (2002-2010), cuando se hizo evidente la transformación del lenguaje, la inclusión de nuevos léxicos para denominar a quienes se mostrarán en contra de su política de seguridad democrática. De esta manera académicos, periodistas críticos al régimen político, militantes de partidos de izquierda, representantes de organizaciones sociales, fueron encasillados en el discurso presidencial como: narco - guerrilla, narcoterrorista, terroristas académicos, entre otros. La ideología de extrema derecha de este gobierno conllevó a la generación de un discurso centrado en la existencia de un enemigo interno portador del mal y la inseguridad.

De otra parte, en este gobierno se cambió el sentido político a la situación de conflicto propia del país; como lo afirma Rodríguez (2011) en este periodo presidencial se tendió a la desaparición de los términos de guerra, conflicto armado, actores armados y la configuración de nuevos términos como: terrorismo, terroristas, amenaza terroristas con el fin de aplicar medidas militares más fuertes y con ellos deslegitimar la presencia de un conflicto social y político. Con esta transformación simbólica del lenguaje del conflicto se pretendió acabar con el reconocimiento internacional del conflicto, despojar a los actores opositores de su estatus de beligerantes, obstruir la búsqueda de salidas pacificas al conflicto; así como reafirmar una estrategia de guerra basada en las políticas antiterroristas generadas en los Estados Unidos a partir del 11 de septiembre de 2001.

A partir de la transformación semántica citados anteriormente, se transforman los procedimientos políticos y jurídicos, dado que esto tuvo la intención de eliminar las determinaciones del Derecho Internacional Humanitario. (DIH) que propende por la humanización de la guerra. Y lo que es peor, se trastoco la diferenciación entre combatiente y no combatiente. Extendiendo estas políticas contra la población civil. En este sentido, expresa Rodríguez (2011): 
En sí mismo, el apelativo terrorista parece sugerir la aplicación justificada de cualquier medio de guerra y exterminio. Sin embargo, la distinción entre el combatiente y el terrorista, conceptualizada por los portavoces gubernamentales no se atiene a la legislación internacional. Desde este marco, el concepto de terrorismo está contenido en el de conflicto armado interno. (p.5)

Ello conlleva definir nuevas formas de actuación frente a los grupos en conflicto, de esta manera se legitima la acción de represión en el campo nacional e internacional. Dicha legitimación se llevó a cabo en un momento donde la situación de derechos humanos era altamente cuestionada por los organismos internacionales de derechos humanos. De esta manera estas estrategias semánticas contribuyeron al ocultamiento de la violencia política ejercida contra la población civil.

En relación a la población civil este discurso se dirigió de forma contundente, "quienes no están contra ellos, están contra mí”; de esta manera el representante colombiano fomentó la polarización de la sociedad, y como ya sabemos, el lenguaje se constituye en acción, por tanto, esto conllevo a la división entre colombianos.

\subsection{Síntesis.}

En este capítulo hemos abordado la complejidad del lenguaje desde sus marcos de representación y significación a la relación con la guerra, hemos acudido a los planteamientos de la escuela Francesa, sobre los mecanismos de control y el poder simbólico del lenguaje, expresados por Foucault y Bourdieu, respectivamente, para comprender como el lenguaje es un campo en disputa y contiene en el poder, lo cual no sería posible si no fuera por lo que tan claramente define Foucault (1970) el poder del discurso lo obtiene porque nosotros se lo hemos dado.

A partir de este acercamiento encontramos la relación del lenguaje con la emoción y a la interacción social, desde este punto de vista, el lenguaje trasciende su componente social, para dar sentido, a lo inter- subjetivo. Así el lenguaje en las palabras de Matarán (2001) el lenguaje se da en el vivir, en medio de la convivencia con el otro y es un acto que tiene consecuencias. 
El lenguaje en su capacidad generativa, es originario de lo humano, es lo que nos define como tal, así entendido desde la antropología, sociología y el psicoanálisis, actúa como organizador de la cultura y desde ese lugar se constituye en configurador de las identidades y las relaciones de alteridad, ahí radica la importancia del mismo en relación a la producción de los imaginarios sociales de exclusión.

El análisis acá realizado nos lleva a pensar la relación entre el discurso y la ideología, posibilitando comprender como los posicionamientos ideológicos presentes en las narrativas discursivas, tienen la capacidad de generar sentido y realidad social, por esto, un papel fundamental del discurso es el de identificar los presupuestos ideológicos y desde allí, interpretar el contenido semántico del mensaje expuesto en la producción discursiva.

Asimismo, es importante resaltar el uso del lenguaje como disputa en la guerra y la manipulación del mismo como estrategia de guerra: En sentido, es necesaria la reflexión sobre el lenguaje expuesto desde el poder para dar nuevos sentidos y nuevas palabras a la guerra y su ejercicio en favor de sectores dominantes de poder. En el caso colombiano se hace evidente la utilización del lenguaje y la aprehensión de nuevos léxicos. A partir de los procesos de eufemismo. Disfemismo y neologismo.

A manera de conclusión, sobre este tema podemos advertir que existen unas transformaciones del lenguaje, en los contextos bélicos, que son utilizados por los actores del conflicto, su poder de acción residirá en el acceso a su expresión, de esta manera, la relación con los medios de comunicación puede ser una fuente de poder para generar opinión pública a su favor y en contra de sus adversarios; así como para fragmentar a la sociedad civil mediante la generación de imaginarios sociales de estigmatización.

Es importante, aquí, tener en cuenta lo planteado por Collins \& Glover (2003), sobre que este lenguaje se construye de manera histórica, a través del uso repetido, a menudo calculado y generalmente selectivo. Lo cual resulta muy interesante para analizar el caso colombiano por su longitud en el tiempo y la continuidad con otras violencias. Este elemento nos lleva a pensar en que en el país hemos recurrido a léxicos a partir de los ciclos históricos de violencia.

Por todo ello, destacamos que, si bien el lenguaje puede tener una instrumentalización de la guerra, también es él en sí mismo, una posibilidad para abordar el dolor producido por 
el conflicto, así como en la creación y producción de la organización social y las respuestas de resistencia no violenta al conflicto. Así, podemos afirmar que el lenguaje como práctica social está presente en los contextos de guerra como medio para profundizar las confrontaciones bélicas, de la misma forma que habita en las experiencias en búsqueda de superar el conflicto.

Desde nuestra perspectiva consideramos los aportes de la Antropología lingüística que relaciona el lenguaje con la cultura y el mundo social, es importante para comprender, una perspectiva del análisis del discurso relacionada con las significaciones, no obstante, esta perspectiva se centra en el papel del sujeto como productor del discurso, dejando de lado, las estructuras sociales en las que se instaura el lenguaje, aquellas relacionadas con el poder y la ideología.

De otra parte desde la postura de la Escuela Francesa se abordan los conceptos de ideología, poder y poder simbólico para entender el discurso, desde una perspectiva estructuralista se comprende que el lenguaje está inscrito en las relaciones de dominación, lo cual consideramos como cierto, sin embargo requiere de analizarse desde otras perspectivas culturales y simbólicas que nos permiten comprender como el lenguaje se constituye en productor de realidad social mediante procesos subjetivos y culturales.

Por último, estamos de acuerdo con los planteamientos de los autores sobre las transformaciones del lenguaje en los contextos de guerra y la utilización del mismo como estrategia de guerra. En el caso colombiano podemos constatar la transformación del lenguaje como estrategia de guerra, ya sea para deslegitimar las acciones de la sociedad civil en búsqueda de la paz o para mimetizar acciones de diferentes actores en confrontación. 



\section{CAPÍTULO II. VIOLENCIA, CONFLICTO, JUVENTUD Y ESTIMA}

SOCIAL

2.1. ¿La violencia en Colombia continuidad y discontinuidad?

2.2. Violencia de "falsos positivos"

2.3. Violencia juvenil y fenómeno del sicariato en Colombia.

2.4. Identidades juveniles en contextos de violencia.

2.5 Síntesis. 



\section{CAPÍTULO II. VIOLENCIA, CONFLICTO Y JUVENTUD Y ESTIGMA SOCIAL}

En Colombia la cotidianidad de nuestras vidas es asediada por la presencia de un conflicto armado interno que por más de cincuenta años ha estado presente en el país. Muchos colombianos hemos nacido y crecido con él, hemos asistido a la grave crisis humanitaria desprendida de la guerra más larga del continente americano. Aunque es de anotar que en éste no se deposita toda la violencia que vivimos, pero si puede actuar como espejo de la misma, dada su inmensa dimensión, los efectos y el sufrimiento humano que ha causado a las últimas generaciones colombianas.

Los impactos de esta violencia han sido múltiples tantos directos en número de víctimas (asesinatos, desplazamientos y desapariciones forzadas, entre otros), así como de carácter social, cultural y simbólico. Uno de los efectos que nos interesa abordar en este estudio es el impacto sobre el joven popular en Colombia, en un aspecto especifico; los imaginarios sociales de discriminación de la juventud. Para el desarrollo de este estudio nos interesa plantear de manera histórica los ciclos del conflicto acontecidos en el país y contextualizar la violencia procedente del narcotráfico, así como la violencia juvenil directamente relacionadas con la construcción de un imaginario de discriminación del joven popular en la nación.

La confrontación armada que vive el país se ha conceptualizado como conflicto armado interno, veamos cómo ha sido definido éste por parte de los estudiosos del tema.

Smith (2000), expresa que se definen los conflictos armados como confrontaciones abiertas entre dos o más partes organizadas, con continuidad de enfrentamientos, y disputas sobre el papel gubernamental y territorio.

Zuluaga (2004), retomando el concepto del Instituto de investigaciones para la paz de Estocolmo considera que el Conflicto Armado se presenta cuando hay enfrentamientos episódicos entre fuerzas militares, en los que a lo largo de su duración se produce más de un millar de muertos.

Y en el concepto expuesto por la Escola de Cultura de Paul en 2003:

Se considera conflicto armado todo enfrentamiento protagonizado por grupos de diversa índole, tales como fuerzas militares regulares o irregulares, 
guerrilla, grupos armados de oposición, grupo paramilitares y comunidades étnicas o religiosas, que usando armas u otros medios de destrucción provocan más de 100 víctimas en un año. La cifra de cien muertes debe relativizarse en función de otros elementos, como la población total del país y el alcance geográfico del conflicto armado, así como el nivel de destrucción generado y los desplazamientos forzados de la población que conlleva”. (p.7)

La conceptualización que se realiza sobre el conflicto armado tiene en cuenta los siguientes elementos: las partes organizadas, la continuidad de los enfrentamientos y las motivaciones y disputas claramente definidas.

Como colombiana no he conocido un solo día de paz en mi país, aun enmarcando la paz en la visión reduccionista de la paz como ausencia de guerra. Esto me ubica en una preocupación no sólo académica sino humana; en el porqué de esta violencia frente a un grupo de población, el juvenil, la cual tiene la mayor cuota de víctimas de este conflicto.

La palabra violencia en Colombia se ha convertido en una expresión para hablar de lo que ha sido una larga historia de confrontación interna que se complejiza con algunos visos internacionales. Enfrentados, a uno de los conflictos más duraderos del mundo, no sólo importante por la extensión en el tiempo si no por la intensidad de sus acciones.

En un país que como lo plantea Rojas (2006) resaltado en el continente como la democracia más estable en América Latina, por no haber sufrido interrupciones ni golpes militares que caracterizaron a la mayoría de los países en las décadas de los sesenta y setenta. De la misma manera que Pecaut (2004) afirma que en Colombia en un siglo no ha tenido un golpe militar, de ahí que se caracterice por su estabilidad institucional, su tradición civilista, su culto a las normas jurídicas, sus referencias democráticas y las elecciones se han llevado a cabo en intervalos regulares, dos partidos políticos han regido la vida política durante siglo y medio y han estructurado las identidades tanto personales como colectivas.

Desde lo planteado por estos dos autores podemos observar que el país ha contado con una democracia representativa estable, y a esto hay que sumarle la existencia de un mayor número de elecciones populares en la región, no obstante, ésta es una democracia que presenta muchos cuestionamientos y que requiere de ser revisada. Como observa Pecaut (2004) hay naturalmente, otra cara del régimen colombiano que no corresponde a los 
principios democráticos; las desigualdades sociales han sido de las más marcadas del continente, el clientelismo ha obstaculizado la construcción de un verdadero sentido de ciudadanía, los partidos con frecuencia han acudido a las armas para mantener su poder y han bloqueado, por todos los medios el surgimiento de fuerzas políticas y sociales, el recurso del estado de excepción se ha constituido en regla durante largos periodos por parte del Estado colombiano.

Así, teniendo en cuenta lo expuesto en este capítulo desarrollaremos la reflexión teórica que constituye la base del análisis de la información procedente del discurso mediático sobre la juventud y la violencia. En primer lugar, abordaremos la conceptualización de la violencia y en segundo lugar desarrollaremos la categoría de juventud con el fin de establecer la relación de estos conceptos teóricos con la producción discursiva sobre el joven popular.

\section{1. ¿La violencia en Colombia continuidad o discontinuidad?}

El tema de la violencia en el caso colombiano no hace referencia exclusivamente a la existencia de un conflicto armado, al contrario, éste es la manifestación de múltiples violencias que persisten en el país. Por ello la importancia de desarrollar en este trabajo el concepto de violencia. Fisas (1998), expone que:

Por la violencia podemos entender el uso de la amenaza del uso de la fuerza o de potencia abierta u oculta, con la finalidad de obtener de uno o varios individuos algo que no concierten libremente o de hacerles algún tipo de mal (físico, psíquico o moral) la violencia por tanto no es sólo un tipo de determinado acto, sino también una determinada potencialidad. No se refiere sólo a una forma de "hacer" sino también de "no dejar de hacer" de negar potencialidad. (p.24)

Es importante, además de enfatizar en el concepto de violencia, establecer algunos tipos de la misma que se constituyen en elementos necesarios para la comprensión de la violencia en Colombia.

\subsubsection{Violencia estructural}

La violencia estructural es una forma indirecta de violencia, que está anclada en las estructuras sociales. Está sostenida por un aparato policial y funciona tanto nivel nacional 
como internacional. Puede tener una naturaleza económica, política, militar, cultural o comunicativa. La violencia estructural obstaculiza la satisfacción de necesidades básicas de la población que la sufre, dicha violencia guarda relación directa con la pobreza y la desigualdad. La Red de Organismos Civiles de Derechos Humanos (2008) “Todos los derechos para todos y todas", define que:

La violencia estructural es aquella que se manifiesta tanto en la desigualdad como en la represión, es violencia legalizada que se corresponde con las injusticias estructurales, económicas y sociales, por discriminación sexual o racial, por la desigualdad de oportunidades, marginación, hambre y pobreza y por la violación a los derechos humanos. Es estructural porque al reproducir las estructuras sociales injustas y sus efectos reproduce también la desigualdad en el orden social, instrumental y legal existente. (p.1)

El contexto latinoamericano y por ende el colombiano ha vivido en una constante violencia estructural, la cual tiene incidencia en la conformación de otro tipo de violencias, especialmente en la derivada del conflicto interno armado que vive el país, con esto, la violencia estructural se convierte en una de las causas más importantes del estado continuo de guerra que ha afectado a Colombia en los dos últimos siglos.

\subsubsection{Violencia Política}

Cualquier Estado dispone de recursos para el ejercicio de la violencia política para imponer su autoridad, básicamente puede hablarse de tres:

- La represión, consiste en el empleo de mecanismos de control y la sanción de conductas que el poder califica como desviadas.

- El control social, comprende todos los instrumentos de actuación tanto positivos como negativos que utiliza la sociedad o grupo social para modelar a los miembros desde sus normas que caracterizan la vida comunitaria en impedir desanimar pensamientos que se desvíen de esas normas.

- La coerción legal se presenta cuando el Estado mantiene el orden a través del respaldo de la mayor parte de la ciudadanía.

En este trabajo se tomará la violencia política como la represión que hace el Estado contra la sociedad civil a través de sus fuerzas regulares o alianzas con fuerzas de extrema derecha con fin de coartar a sectores políticos que considera sus "enemigos"; 
con el uso de estrategias como la denominada "guerra sucia", que en periodos anteriores fue realizada por los organismos de seguridad del Estado. A partir de las tres últimas décadas se ha venido delegando a grupos ilegales que amenazan, torturan, producen desapariciones forzadas y asesinatos selectivos de sindicalistas, líderes sociales, defensores de Derechos Humanos, miembros de partidos de oposición, mujeres de organizaciones feministas; sin que por ello los gobiernos, ni las fuerzas regulares sufran detrimento de su imagen pública, además de muy pocas acciones desde lo jurídico que llevan a la impunidad presente en el país. A esto se suma la participación de miembros de la fuerza pública o la omisión ante acciones de los grupos paramilitares.

Así mismo, desde el Centro de Investigación y Educación Popular (CINEP) y la Comisión Intereclesial de Justicia y Paz (2009), se entiende por violencia política como aquella ejercida como medio de lucha político-social, ya sea con el fin de mantener, modificar o destruir un modelo de Estado o de sociedad; también para destruir o reprimir a un grupo humano con identidad dentro de la sociedad por su afinidad social, política, gremial, étnica, racial, religiosa, cultural e ideológica, esté o no organizado. Este tipo de violencia puede ser ejercida por el Estado o por particulares que actúan, con el apoyo, tolerancia y aprobación de las autoridades del Estado; en tal caso es tipificada como violación de Derechos Humanos, por los grupos insurgentes que combaten frente al Estado y orden social vigente. Cuando esta violencia se ajusta a las normas y costumbres de la guerra se les considera acciones bélicas, cuando no cumple dicha normatividad se le tipifica como una infracción al Derecho Internacional Humanitario.

Teniendo en cuenta lo anterior, una de las preguntas que nos hacemos es ¿Por qué la continuidad de la violencia en Colombia?

Esta continuidad ha sido motivo de análisis de diversos autores en el país. El historiador Pecaut (2004) esboza algunas de las posibles razones que producen esta continuidad:

- La construcción de unidad nacional ha sido incierta tanto en el plano simbólico como material. Lo que impide la constitución de referentes compartidos.

- La fragilidad de la autoridad del Estado, representada entre otras por: la fragmentación natural del territorio, las competencias entre diferentes polos urbanos, la transformación de los partidos políticos en culturas antagónicas. 
- La idea de que las libertades no se pueden conceder sino delimitando prerrogativas del Estado.

- El hecho que ningún movimiento nacionalista o popular de envergadura ha podido extenderse en todas las regiones.

- La incapacidad del estado colombiano para afrontar la inmigración interna y los procesos de colonización de las zonas fronteras.

Sumado a ello se pueden enumerar otras de vital importancia:

- Los conflictos por la tierra no resueltos.

- Una amplia desigualdad.

- La incapacidad de un ejercicio democrático que tenga en cuenta al otro diferente. Para la comprensión de la continuidad de la violencia en Colombia se requiere revisar la historia del país, por lo cual es necesario dar un breve recorrido por los hechos significativos de lo que se ha denominado la violencia en Colombia.

El historiador Sánchez (1986) afirma que en el país después de 14 años de independencia, vivió durante el siglo XIX, ocho guerras civiles, 14 guerras civiles locales y 2 guerras internacionales y en el siglo XX libró una guerra con el Perú y en la actualidad, el mayor conflicto de larga duración en la historia del continente.

Si existe continuidad entre las guerras del siglo XIX y el actual conflicto es un tema de debate por los estudiosos de la violencia en Colombia. Sánchez, Díaz y Formisano (2003), retoman lo expuesto por Alape (1985) donde argumentan que el periodo de la violencia no es un periodo atípico en la medida que sus antecedentes y orígenes se sitúan en elementos estructurales, como los odios heredados, las pasiones partidistas y la persecución religiosa de los años anteriores.

Este autor concede gran importancia a las guerras civiles del siglo XIX para explicar la relación de éstas con la violencia de los años de 1950. Sánchez et al. (2003), retoman a Deas (1991), cuando expresa que "la violencia como etapa no tiene antecedentes en la historia de Colombia", no considera que esto se repita, se basa en estructuras distintas. El autor además argumenta que las guerras del siglo XIX no duraron tanto, no fueron tan salvajes y dejaron un menor número de bandoleros que dejó la violencia de los cincuenta.

Para la mayor comprensión de la violencia es necesario revisar elementos fundamentales que tienen que ver con la constitución de la misma. Para ello partiremos de la violencia 
de los cincuenta que se constituye en hito fundamental para la conceptualización de la violencia contemporánea.

\section{a. La violencia de los cincuenta.}

La llamada Violencia de los cincuenta, es un periodo de confrontación bipartidista que se llevó a cabo entre 1948 y 1958. La confrontación política que vivía el país entre los partidos liberal y conservador se vio agravada por el asesinato del candidato a la presidencia Jorge Eliecer Gaitán el 9 de abril de 1948. El caudillo liberal había ganado el apoyo popular de un mayoritario número de electores lo que hacía prever su elección como primer mandatario del país.

El asesinato llevó a un levantamiento popular. Como lo afirman Paredes \& Díaz (2007) observan que:

El 9 de abril Gaitán es asesinado en plena calle y tras la muerte del caudillo popular se suceden manifestaciones multitudinarias en las principales ciudades del país con mayor intensidad en Bogotá, donde se produce un estallido colosal de cólera y anarquía de vastas proporciones conocida como el "Bogotazo", si bien fue un fenómeno urbano sus consecuencias se trasladaron rápidamente al campo donde se empiezan a generar los primeros movimientos guerrilleros, que progresivamente adquirirían en carácter de permanentes. (p.185)

La confrontación derivada de este conflicto se extendió por 10 años en lo que Pecaut (2004), la define como aquella guerra civil llevada a cabo bajo la égida de dos partidos políticos con visos de guerra de religión, en dicha confrontación terminaron enfrentados los sectores campesinos quienes manipulados por las clases élites se apropiaron de un conflicto entre ideologías: liberales y conservadoras que conllevaron a la violencia entre la propia población y terminaron con un saldo al menos de 20.000 muertos. Para el citado autor esto pasó de ser un conflicto intrapartidista y tomó connotaciones de guerra civil.

Este periodo de violencia caracterizado por una acción de barbarie, una confrontación donde desde los dirigentes de los partidos y la iglesia fomentaron el odio entre la población civil. La predominancia en el país hasta ese momento del pensamiento conservador de la mano del catolicismo radical propició la aniquilación de un sector de 
la población que se manifestaba en contra, así instauró una confrontación civil que sólo reproducía los intereses de las élites de los partidos.

A partir de la violencia de los cincuenta se instala en el imaginario colectivo una manera de nombrarnos como colombianos desde la violencia. Qué ha llevado a dicha connotación y por qué la violencia ha sido una constante en Colombia son preguntas irresueltas en el país.

La violencia de los cincuenta además de las pérdidas en vidas, los centenares de desplazados en las grandes ciudades, la creación de un sistema de gobierno antidemocrático que se turnaba entre dos partidos políticos, el conservador y el liberal negando la posibilidad de otras fuerzas políticas, también dejó heridas a ciertos sectores de la población que se verían reflejados en el surgimiento del conflicto armado que hoy vivimos en el país. Pecaut (2004), afirma:

Semejante experiencia no podía inspirar posteriormente un sentimiento de humillación e ira. Manuel MarulandaVélez, el jefe de las FARC, quien vivió su experiencia armada durante estos años, no deja de referirse a esta experiencia para justificar su combate. (p.77)

El 13 de junio de 1953 tuvo lugar el golpe militar contra el gobierno del presidente Laureano Gómez, que llevó a la Presidencia de la República al teniente general Gustavo Rojas Pinilla, quien contaba con el apoyo de los dirigentes de los partidos y las fuerzas militares y de policía nacional.

De acuerdo con los documentos de la presidencia de la República de Colombia la Asamblea Nacional Constituyente expidió un acto legislativo que otorgaba el título legítimo de Presidente de la República al General Rojas Pinilla, quien terminaría el periodo presidencial vigente.

Los dirigentes de los partidos políticos estuvieron de acuerdo con el gobierno militar, ya que tenían sus propios intereses. Paredes \& Díaz (2007) afirman que:

Lo que buscaban los partidos es que la salida militar logrará la pacificación del país, una vez alcanzado esto regresarán a los cuarteles y devolvieran el país en total calma, pero estas expectativas se fueron diluyendo progresivamente en la medida que la dictadura fue mostrando cada vez mayor 
claridad, sus aspiraciones de autonomía política frente a los partidos tradicionales. El 10 de mayo toma el poder el general Rojas Pinilla, al mando de la Junta Militar, nombre que se le dio al grupo de militares que se comprometieron a gobernar hasta el 2 de agosto de 1958, fecha en que finalizaba el periodo de Rojas Pinilla y se produce un acuerdo entre los miembros de los partidos para lograr que el país se conduzca a través de la democracia representativa. (p.186)

La Junta Militar y los miembros de los partidos se encaminaron por una alternativa a los gobiernos militares y se estableció en acuerdo que llevó a la constitución del Frente Nacional.

\section{b. Frente Nacional.}

El Frente Nacional es un acuerdo que pretendió poner fin a la violación y la inestabilidad política que existía en el país debido a la confrontación bipartidista de los años cincuenta. Una de las preocupaciones de los partidos políticos era la existencia de un gobierno militar, por lo cual fue de interés derrocar a dicho gobierno y el retorno a la democracia.

Acevedo \& Castaño (2001) afirman que:

El pacto nacionalista del Frente Nacional (FN) en Colombia fue un acuerdo realizado en España por Alberto Lleras Camargo y Laureano Gómez para hacerle frente al dictador Gustavo Rojas Pinilla; un año antes Alfonso López Pumarejo ya había hecho este llamado para cumplir con dicho propósito. Este acuerdo, que pactó la alternancia del poder durante dieciséis años (19581974), a la postre implicaría la puesta en ejecución de toda clase de experimentos "sociales" con el propósito de relegitimar el nuevo sistema político, al igual que sus propios "jefes naturales". Pero logró el efecto contrario. Las medidas religitimatorias eran tan evidentes y forzadas que no hizo sino desvirtuar aún más el dominio tradicional que los representantes de los dos partidos se habían forjado durante décadas. (p.1)

Este acuerdo se realizó mediante la decisión de los jefes de los dos partidos tradicionales, Conservador y Liberal. En estos acuerdos se estableció que: 
- La rotación del primer cargo ejecutivo del país (presidente) entre los partidos por periodos de cuatro años.

- La distribución paritaria de los ministerios y de los cargos del congreso, asambleas y consejos.

- La conformación del derecho al voto para la mujer.

- La legalización popular del gobierno en la Junta Militar para el 1 de diciembre de 1957.

Los acuerdos del Frente Nacional si bien contribuyeron a la salida del gobierno militar, no representaron avances democráticos, ya que se trató de una concentración de poder entre los dos partidos tradicionales, liberal y conservador, y la exclusión de otras fuerzas políticas. Como afirma Osorio (1993) “Con el Frente Nacional, se había consolidado el monopolio bipartidista, en donde el recurso del clientelismo en forma generalizada para mediar con la población civil, reducía la legitimidad del Estado”. (p.42)

En este periodo de la historia colombiana se llevaron a cabo los gobiernos de los presidentes:

- Alberto Lleras Camargo (1958-1962), liberal

- Guillermo León Valencia (1962- 1966), conservador

- Carlos Lleras Restrepo (1966 y 1970), liberal

- Misael Pastrana Borrero (1970 -1974), conservador

Aunque el Frente Nacional supuso una alternativa para dirimir las confrontaciones armadas que se presentaban entre los partidos políticos, se considera que éste tuvo una intencionalidad para lograr la exclusión de fuerzas políticas diferentes a los partidos tradicionales, en este sentido Pizarro (2002) afirma que:

El Frente Nacional más que buscar un alivio a los brotes insurreccionales y violentos surgidos permanentemente en el país, los dirigentes políticos intentaban asegurar su no exclusión del poder de los gobiernos militares. Esto probablemente ocasionó que ninguna reforma social importante echará raíces y sirviera para lograr la paz y la prosperidad en Colombia. (p.11)

Esta reforma no significó un cambio sustantivo para la democracia en Colombia, sino que se trató de una concentración de mayor poder de los partidos tradicionales tal como lo afirma Pizarro (2002): 
La dirección del cambio social fue canalizada casi por los mismos actores del liberalismo y del conservatismo que cuatro años atrás habían apoyado el golpe militar. Lo que en realidad ocurrió entre la caída de Rojas y el Frente Nacional fue el tránsito hacia un régimen democrático limitado y restringido, suscitado por el temor de las élites de los partidos al ser excluidos del poder del gobierno militar, la violencia en el campo y el estancamiento económico. (p.11)

Esta es la razón por la cual el Frente nacional fomentó una pedagogía entre dos partidos cada vez más parecidos, pero no consiguió cimentar la cultura política democrática. Desaprovechó la oportunidad de emprender reformas sociales básicas, desarrolló una actitud intolerante frente a la oposición en la historia de la persecución, represión y cooptación del Movimiento Revolucionario Liberal y la Alianza Nacional Popular entre 1960 y 1972 y relegó al segundo plano los elementos desencadenantes del conflicto político, con la cuestión agraria y en cuanto tuvo que responder abusó del Estado sitio.

De la misma manera que Paredes \& Díaz (2007) afirman que:

El Frente nacional tuvo una de las consecuencias no previstas el agravamiento al extremo del fraccionalismo partidista. En efecto la paridad y la alternación hicieron inútil la competencia interpartidista, dado que cada partido tenía asegurado de antemano el $50 \%$ en la composición de todas las corporaciones públicas, pero agudizaron dramáticamente la pugna intrapartidista. Esta pugna iría minando lentamente la organización interna de los partidos hasta culminar en la atomización actual. (p.188)

La experiencia del Frente Nacional no logró ser una propuesta conciliatoria entre la sociedad colombiana desgarrada por la violencia partidista. Este acontecimiento profundizó la división en los miembros de esta sociedad, tal como lo afirma Sánchez (2006):

En Colombia la memoria está más asociada a la fractura, a la división, a los desgarramientos de la sociedad. En Colombia realmente no se hace memoria del fin de la violencia (el advenimiento o caída de la dictadura del general Rojas Pinilla o la inauguración del Frente Nacional, sino ritualmente memoria de su iniciación del 9 de abril de 1948, referente simbólico de la división 
contemporánea de la sociedad colombiana, cuando con el asesinato de Jorge Eliecer Gaitán se pasó de manera generalizada de la guerra de las palabras, la violencia simbólica a la guerra de las armas. Más aún puesto que la violencia había comenzado antes del 9 de abril, la conmemoración de este es más una catástrofe que la apelación a un porvenir. (p.25)

\section{c. La aparición de los movimientos guerrilleros contemporáneos.}

Como una herencia clara de la violencia de los cincuenta y del Frente Nacional aparecen los grupos insurgentes, actores del conflicto interno que vive el país. Sánchez et al. (2003), afirman que, aunque el Frente Nacional redujo las acciones bélicas de las guerrillas liberales, algunas de estas guerrillas permanecieron dando origen a lo que es el ejército irregular más grande del país: Las Fuerzas Armadas de Colombia. Ejército del Pueblo. (FARC-EP). Dichas guerrillas se ubicaron al sur del país y fueron fuertemente atacadas por el Ejército Nacional de Colombia particularmente en Marquetalia.

Pecaut (2004), habla de la creación en 1964 de las Fuerzas Armadas Revolucionarias de Colombia - Ejército del Pueblo (FARC- EP) después del ataque del Ejército colombiano a una zona de resistencia comunista. Aunque no se puede definir el ataque como la única causa de surgimiento, si se considera como el hito fundador de este grupo guerrillero.

Sánchez et al. (2003) afirman que:

En un libro biográfico que reconstruye la vida de quien hoy en día es el comandante de las FARC-EP (Pedro Antonio Marín, alias Manuel Marulanda Vélez o Tirofijo), Alape (1985) afirma que el surgimiento de los primeros grupos de autodefensas campesinas obedece a la respuesta de los liberales (entre ellos Pedro Antonio Marín) tras la violencia conservadora. Para el autor, en un principio, estas agrupaciones de autodefensas liberales no se consideraban grupos guerrilleros, tenían un carácter netamente defensivo de matiz político y sólo ajusticiaban a conservadores en un afán de venganza. Sin embargo, en medio de este enfrentamiento partidista, surge una incipiente alianza entre los grupos armados liberales y comunistas, la cual permea las inclinaciones políticas de Pedro Antonio Marín. Los liberales rechazaron la propuesta de derrocar el régimen conservador. No obstante, Marín no compartió la actitud de su partido y por el contrario, comienza a simpatizar con el Partido Comunista. En este contexto, surge la guerrilla de corte 
comunista, con Pedro Antonio Marín como uno de sus comandantes y con objetivo principal de derrocar al régimen. (p.8)

Las FARC- EP que nacieron como guerrillas aisladas se propusieron la expansión a todo el país, que se calcula que hoy tiene alrededor de 17000 militantes; a partir de la permanencia se ha consolidado como la guerrilla más vieja del continente. El movimiento guerrillero logró su mayor expansión en los años de 1980; cuando según Sánchez et al. (2003), se autodenominaron el Ejército del Pueblo, FARC -EP. Es en este momento donde toman la decisión de urbanizar el conflicto y llegan al doble de Frentes (40) en todo el país.

De la misma manera, aunque este grupo surgió como un grupo de autodefensas campesinas, orientadas por el partido comunista que reivindicaban la tenencia de la tierra, su actuar se trasformó a partir de los años ochenta debido a la implementación de nuevas estrategias económicas y el fracaso de los procesos de negociación con este grupo.

En 1966 nace el Ejército de Liberación Nacional (ELN), en cuya base ideológica se encontraba la lucha por aminorar las diferencias económicas, políticas y sociales de la población. Igualmente, este grupo armado recibió la influencia de la revolución cubana, su accionar se planteó en principio en el área de rural, sin embargo, se extendió al área urbana.

El inicio de este ejército insurgente se atribuye a un grupo de 16 jóvenes que empezaron a operar en 1962 y que en 1966 se presentan como Ejército de Liberación Nacional (ELN).

Entre los objetivos que expresó este grupo se encuentran:

- La obtención de poder para las clases populares.

- La derrota de la burocracia y el sistema económico y político.

- Este grupo tiene mayor influencia en las clases estudiantiles y obreras.

Sánchez et al. (2003) afirman que:

Hoy en día, el ELN es el segundo grupo guerrillero más grande del país después de las FARC, tanto en número de hombres como en número de acciones perpetradas (...) pesen a tener tan sólo la mitad de los hombres de 
las FARC es al parecer responsable de la misma cantidad de secuestros y de actos de sabotaje. Así mismo, las acciones del ELN se han extendido tanto en las ciudades como en el campo. (p.12)

En 1970 surge el Movimiento 19 de abril, M19, a partir del fraude electoral, que le negó el triunfo a la Alianza Nacional Popular (ANAPO), donde algunos de sus militantes tomaron como vía la conformación de este movimiento, cuyo accionar estuvo enfatizado en el área urbana.

El M19 llegó a ser una guerrilla con poder militar en Colombia, un hecho importante es la toma que hace en movimiento armado del Palacio, acto llevado a cabo el 6 de noviembre de 1985. Sin embargo, el gobierno reaccionó desplegando un operativo de retoma del palacio en el que se emplearon tanques blindados con los que se disparó contra el edificio y posteriormente se ingresó a él. Durante el operativo se produjo un incendio que consumió el edificio. En total se calcula que la toma y retoma del palacio ocasionó la muerte a 94 personas que se encontraban en el interior y que hubo 244 sobrevivientes. Las Fuerzas armadas de Colombia se llevaron a 11 personas que fueron consideradas como desaparecidas.

En 1967 surgió el Ejército de Liberación Popular (EPL), su lucha se fundamentó en las contradicciones de clase y la búsqueda del poder para el proletariado y la clase obrera. Su surgimiento de ubica en las regiones de Antioquia, Urabá y Bajo Cauca.

Este movimiento insurgente tuvo un cambio profundo en su accionar en la década de 1980 como se evidencia en los trabajos de Zuluaga (2004):

El XI Congreso del PC (ML), realizado en 1980, rompe con la tradición maoísta que había inspirado la política de este partido y la acción del EPL. Como consecuencia de esta ruptura se abandonó la concepción de guerra prolongada y se aceptó la posibilidad de luchar por reformas que permitieran avanzar en la organización popular y acercarse a los objetivos de revolución socialista postulados por el Partido. (p.1)

Lo cual llevó al EPL a plantearse la posibilidad de una salida negociada por lo que firmó conjuntamente con el M19 una salida negociada el 24 de agosto de 1984, no obstante este proceso quedó roto ante el asesinato de uno de sus dirigentes en 1985. En 1990 se 
reanudan las posibilidades mediante acuerdos de este grupo con el gobierno nacional. Como lo afirma Zuluaga (2004) en sus investigaciones:

El proceso que se desarrolla es conocido. El 24 de mayo de 1990 el gobierno nacional y la comandancia del EPL firman una declaración que expresa "la voluntad de contribuir a un proceso de solución política negociada al conflicto armado". El 4 de junio, mediante un comunicado suscrito con el consejero presidencial para la paz, Rafael Pardo, el EPL, el Partido Revolucionario de Trabajadores. PRTy el Quintín Lame ratifican su voluntad de adelantar un proceso común, pero mediante reuniones individuales entre el gobierno nacional y cada uno de los grupos insurgentes. (p.4)

El 29 de enero de 1991 se firma el acuerdo de paz entre este grupo insurgente y el gobierno nacional. Junto con el M19 participaron en la Asamblea Nacional Constituyente, que mediante las transformaciones a la constitución. Es de anotar la búsqueda de estos movimientos de una sociedad basada en la justicia social y económica. Así como lo afirma Zuluaga (2004) en sus trabajos:

El acuerdo no es desde luego la consagración de ese tipo de sociedad. Apunta a objetivos, como ya he señalado, específicos, incluso regionales. La tarea de las reformas nacionales compete a la Asamblea Constituyente en cuyo seno los delegatarios del EPL pueden disputar sus propuestas. Pero este acuerdo tiene un valor fundamental: es un paso firme en la creación de condiciones de paz para el replanteamiento de las reglas del juego político y un voto de confianza en el futuro del país. Con él han ganado las fuerzas democráticas y se fortalece el pluralismo en el país minando, deslegitimando aún más las opciones de derecha e izquierda que miran el futuro de cambio por el oscuro cañón de los fusiles. (p.4)

\section{d. Los paramilitares.}

Los grupos de autodefensa tal como existen hoy tuvieron su primera conferencia regional en 1994 y tres años más tarde en 1997 tuvieron la conferencia nacional y establecieron una estrategia militar para derrotar a las fuerzas subversivas. Se les considera ejércitos privados porque sus acciones son financiadas ya sea por terratenientes, ganaderos, multinacionales y algunas élites económicas del país. 
Su estrategia contrasubversiva no sólo se dirigía a los miembros de la guerrilla, sino que también fue dirigida contra la población civil que vivía en las zonas ocupadas por la guerrilla o la que residía en zonas de interés económico quienes se convirtieron en víctimas de una intensa barbarie.

La modalidad de ejércitos privados que representan los paramilitares no es novedosa en Colombia, Sánchez (2004) afirma su existencia a través de la violencia colombiana: los ejércitos privados de las guerras del siglo XIX, la policía privada que pretendieron apagar los conflictos agrarios a inicios del siglo XX y mucho más a los denominados "pájaros" de la violencia de los cincuenta.

Las autodefensas surgieron bajo la doctrina de seguridad nacional que se extendió durante las décadas de los setenta y ochenta por toda Latinoamérica por parte de una estrategia mundial contra el comunismo. En su etapa inicial recibieron financiación de ganaderos y también de narcotraficantes, y en las últimas décadas han estado más asociados a batallas por el territorio, los recursos naturales y las economías ilegales.

Sánchez (2004) apunta a una paradoja del conflicto colombiano, la argumentación que hace tanto la insurgencia como los paramilitares, sobre su origen en la incapacidad del Estado para cumplir con sus obligaciones económicas, políticas, sociales y culturales. Asimismo, el origen de la guerrilla se basa en la incapacidad del Estado para cumplir con las responsabilidades de todo Estado moderno en relación con el derecho a la vida y las libertades individuales. La presencia de los actores armados en conflicto se relaciona con un vacío estatal, tanto como garante del orden como de los derechos humanos, Sánchez (2004) plantea que:

Aquí radica la esencia de la naturaleza de la crisis colombiana dos rivales contra un enemigo, ausente, el Estado no es ni regulador ni guardián del orden. La guerra ha entrado pues en un acelerado proceso de privatización con la consiguiente deslegitimación del Estado y de las instituciones públicas. (p.55)

En este marco de deslegitimación del Estado se han originado los actuales grupos paramilitares, que son una muestra de la incapacidad del Estado para regular el orden social por vías democráticas. En el fenómeno del paramilitarismo intervienen diversos factores de violencia. Como observa Romero (2000) la conformación de estos grupos está 
relacionada con la existencia del narcotráfico y la utilización de ejércitos privados en su guerra entre carteles y la violencia contra la población para llevar a cabo el despojo de sus tierras. Así también el paramilitarismo surge como una estrategia ilegal de las fuerzas armadas para combatir la insurgencia y la protesta social en el marco de la denominada "guerra sucia", caracterizada por la violación masiva de los Derechos Humanos por parte del Estado en complicidad con grupos de narcotráfico y otras economías ilegales.

Estos ejércitos privados actúan en Colombia desde los años de 1980, bajo la mirada del Estado Colombiano en algunos lugares del país sustituyen sus funciones como lo explica Duncan (2005):

En los municipios de Colombia donde ejercen el dominio los jefes de las autodefensas son los dueños absolutos del Estado. Regulan y extraen tributos a las transacciones económicas, amenazan y protegen a las comunidades, moldean la justicia y el orden político de acuerdo a su convivencia, y poseen control y por consiguiente las mayores ganancias económicas del tráfico de drogas. Durante más de una década la expansión geográfica de estos ejércitos de señores de la guerra ha ido en ascenso, hasta llegar a convertirse en parte importante de la estructura de poder político en zonas semi - urbanas y rurales del país. (p.3)

En síntesis, esta incapacidad estatal que ha llevado a la escalada actual del conflicto, es el resultado de la transformación de luchas insurgentes y contra-insurgentes tradicionales en estructura más compleja de la violencia, donde la aparición de los paramilitares, los cultivos ilícitos, la criminalidad organizada han conducido a una disminución progresiva del control del Estado sobre la mayor parte del territorio del país.

La violencia en Colombia es una continuidad. En la década de los 1970, el Estado, ante la crisis del régimen político, incrementa los mecanismos represivos, y declara el país en Estado de Sitio, lo que permitió entonces la tipificación de delitos para controlar el orden público, el establecimiento de medidas restrictivas de la libertad de reunión, de circulación, y de expresión, la limitación de libertades sindicales y sobre todo la detención y juicio mediante tribunales militares de dudosa imparcialidad, de los opositores políticos, de los líderes sindicales de quienes encabezaban diversas formas de protesta social, con la cual se inicia la denominada "guerra sucia", caracterizada por la pérdida del valor del 
otro como persona, prácticas inhumanas, asesinatos y desapariciones por parte de los diversos actores armados que involucran, de manera progresiva, a la población civil.

A partir de la década de los ochenta, con la aparición de paramilitares y el crecimiento de los grupos guerrilleros, se observa un aumento substancial del fenómeno del desplazamiento y el recrudecimiento de la violencia a lo largo del territorio nacional. El narcotráfico logra influir sobre los actores armados y ayuda a la financiación de la lucha contraguerrillera, y consolida el establecimiento de alianzas con paramilitares, con el fin de mantener el poder sobre algunos territorios; por otro lado, con la guerrilla se crean mecanismos que permiten compartir zonas de influencia. También, se introdujo en campos como la justicia, la política y fomentó la corrupción en estos niveles, deteriorando cada vez más los valores sociales, las garantías del debido proceso y redujo el acceso al ejercicio de la política. Blair (1999) afirma que:

Los narcotraficantes supieron, como ningún otro actor, manipular los intereses, 'pescar en río revuelto' y al hacerlo hallaron aliados fácilmente: guerrilleros anti-imperialistas, propietarios amenazados por la guerrilla, militares en lucha contrainsurgente, políticos fácilmente sobornables, jóvenes marginados y desempleados. Desestabilizaron hábilmente una sociedad frágilmente integrada y acabaron de descomponer los débiles hilos del tejido social. (p.109)

El narcotráfico tiene un papel importante en la internalización de la violencia, por la posibilidad de obtener recursos, dentro de un sistema económico y social inequitativo, que limita el acceso a los mismos, por lo que lo jóvenes encontraron en el sicariato una salida a su difícil situación. Además, logra extender cada vez más las economías ilegales, se instaura a la par con estas formas de relación que llevan a la pérdida del valor de la vida humana, puesto que "quién no esté conmigo", es mi enemigo y puede ser eliminado por un precio que el narcotráfico puede pagar, lo que se ve expresado en la pérdida del valor de la dignidad humana y hace más insensible al país frente a la violencia que lo azota.

La década de los 90 se caracteriza por la agudización del conflicto. Hacen presencia los mismos actores que habían surgido en los ochenta, pero ellos intensifican sus acciones, y tratan de ganar poder y dominio territorial. Para cumplir estos objetivos han involucrado cada vez más a la población civil en el conflicto. 
Para alcanzar sus propósitos, los actores armados requieren ampliar sus bases sociales, antes de la confrontación y durante la misma confrontación, ellos crean redes de poder, a las que deben articularse los pobladores, si no quieren morir o desplazarse. Redes de poder impuestas naturalmente a base de terror, estas redes de poder se estructuran en torno a campos bien diversos y complejos, desde la consecución y manejo de la información (inteligencia sobre todo lo que se mueve en el área de confrontación), la economía y la producción, los canales de abastecimiento; el conocimiento y reconocimiento del área (los guías) hasta el establecimiento de las nuevas bases (militares, paramilitares y guerrilleras) en los 'territorios controlados, y para ello han sometido a sus víctimas a las más degradantes agresiones de violencia.

Como estrategia para el mantenimiento del poder, los actores armados, implementan el uso de la masacre y con ella la producción de desplazamientos masivos, los cuales pueden estar relacionadas con el interés de mantener dominio territorial, por ser puntos neurálgicos a nivel económico o para la realización de acciones de guerra; por otra parte, su uso deliberado tiene que ver con la capacidad de desestructurar a individuos, familias y comunidades, mediante el terror que produce, por su connotación simbólica, y que no sólo logra afectar a quienes la sufren directamente, sino que se traslada a otros grupos, y aminora la capacidad de respuesta ante la incursión de los mismos.

En la historia de la violencia nos hemos encontrado con la poca respuesta de la sociedad frente a la devastadora acción de los grupos violentos y esto tiene diversas explicaciones. La situación actual indica que hemos llegado al momento en que el discurso y la normatividad protectora de la dignidad humana logró convivir con las más despiadadas formas de genocidio, de exterminio de las posiciones disidentes de guerra, contra 'enemigos internos' que constituyen las mayorías nacionales, de todo tipo de discriminaciones y crímenes de lesa humanidad.

Además, logra permear la cotidianidad de las comunidades, se instala como mecanismo para la solución de los conflictos, siendo imposible diferenciar la violencia política de otro tipo de violencias puesto que la guerra ha dejado de ser un medio exclusivo de actores políticos, es decir, desde o contra el Estado se extiende a sectores civiles en lo que podemos llamar guerra de micro-poderes.

La diversidad de actores armados que hacen presencia en las regiones azotadas por la violencia, confunde a sus habitantes en una serie de amenazas, pues cada uno les exige 
ser su aliado o sufrirá el retiro, por medio de la intimidación y la implantación del terror, permitiendo que sus acciones puedan camuflarse de tal manera que le den paso a la impunidad.

En el país la forma más utilizada para la solución de conflictos ha sido a través del uso de las armas, pues en el transcurso de la historia se han debilitado los intentos por construir tejido social, puesto que desde su conformación se ha fundamentado la violencia como un "mecanismo de negación absoluta del otro, al cual se le define como enemigo, esta ha sido la base de construcción de la nación, ante el cual se plantea la necesidad de transformarse construyendo otros referentes de relación entre los ciudadanos". La primera década del siglo XXI se vio marcada por el recrudecimiento de la violencia paramilitar, que se hizo visible en los ámbitos de la política pública, poniéndose de manifiesto un incremento de las violaciones de los derechos humanos. Todo ello marcado por una profunda impunidad. Asimismo, como la realización de un proceso de desmovilización de los grupos paramilitares pactado con el gobierno del presidente Uribe y llevado a cabo entre los años de 2003 y 2008. Dicha desmovilización se caracterizó por los siguientes aspectos: la creación de un marco legal que reducía las penas por delitos atroces a un máximo de ocho años, la desmovilización de grupos paramilitares no se dio de manera real ya que muchos de los desmovilizados se reorganizaron en otros grupos y siguieron las actividades ilegales que venían ejerciendo, y por último aunque se conoció parte de los crímenes cometidos y algunos familiares de las víctimas pudieron hallar los cuerpos de los desaparecidos; los grupos desmovilizados no contaron toda la verdad sobre lo acontecido y aún los familiares de víctimas desconocen el paradero de sus seres queridos.

Actualmente, Se lleva a cabo un proceso de paz después de las negociaciones entre el Gobierno colombiano y la FARC- EP, la guerrilla más importante del país. Este proceso de paz iniciado en noviembre de 2012 y con la mediación de dos países: Cuba y Noruega. El Proceso de negociación se realizó durante más de cuatro años. Los diálogos de paz fueron realizados por una comisión del Gobierno y Representantes del movimiento insurgente con el acompañamiento de países amigos: Cuba y Noruega.

Las partes llegaron a la firma de un acuerdo el 24 de noviembre de 2016, el cual fue refrendado en el Congreso de la República el 1 de diciembre de 2016. Con la firma de 
este acuerdo con la guerrilla más importante del país se da inicio a la implementación del post- conflicto.

De igual manera, en febrero de 2017 se instalaron las mesas de negociación del Ejército de Liberación Nacional ELN, la segunda guerrilla del país. Las negociaciones tendrán lugar en Quito Ecuador. Después de tres años de diálogos exploratorios se dio inicio a la mesa de negociación.

\subsection{Violencia de "falsos positivos"}

La violencia política que se vive en el contexto colombiano ha conllevado a múltiples violaciones de los Derechos Humanos, entre éstas los denominados "falsos positivos"; se trata de la muerte de civiles a manos de las Fuerzas armadas del Estado y la posterior presentación de sus cuerpos como muertos en combate. Esta violación a los Derechos Humanos se típica en el Derecho Internacional Humanitario como ejecuciones extrajudiciales y sobre éstas Henderson (2006) afirma que

Se podría decir que se está ante una ejecución extrajudicial, cuando un agente perteneciente a los cuerpos de seguridad del Estado, de manera individual y en ejercicio de su cargo, priva arbitrariamente de la vida de una o más personas. Aunque no hubiera una incidencia institucional previa, producido el hecho, ese agente podría intentar servirse del manto protector de relaciones estatales, a efectos de encubrir la verdad, o bien, para impedir u obstaculizar que se inicien investigaciones o acusaciones penales en su contra. Si bien este hecho puede carecer de una expresa intencionalidad política, luego de acaecido, el agente estatal se podría aprovechar de las facilidades que pudiera otorgarle el estar trabajando en un cuerpo de seguridad estatal, algo que, en principio se presenta como teóricamente inalcanzable para un particular que ha cometido un homicidio. (p. 287)

En esta línea las ejecuciones extrajudiciales son crímenes cometidos por agentes al servicio del Estado en contra de la población civil. En el caso colombiano, se conoce que este tipo de violación de Derechos Humanos se viene presentando desde la década de 1980. Dichos delitos demuestran la degradación del conflicto colombiano.

En Colombia, a partir del año 2006 se empezó a denominar esta violación de los Derechos Humanos como “falsos positivos", esta construcción semántica se produce a partir de que 
en el lenguaje militar se denomina "positivo" a la muerte de combatientes en enfrentamientos armados y al tratarse de la muerte de civiles los organismos del Estado lo nombraron como "falsos positivos."

Sin embargo, esta nominación no es una palabra ingenua, sino que representa una manera de nombrar de manera más sutil el homicidio agravado por parte de civiles.

La violencia de "falsos positivos" adquirió mayor resonancia en el contexto colombiano durante los dos periodos del Gobierno de Álvaro Uribe comprendidos entre 2006-2010. Este tema recibió la mayor atención mediática a partir de septiembre de 2008, cuando se produjo el escándalo de "falsos positivos" en octubre de 2008, ya que puso en evidencia que la desaparición de 19 jóvenes de Ciudad Bolívar y Soacha, respondía a que habían sido víctimas de tan grave violación de Derechos Humanos.

Dichos crímenes de Estado se llevaron a cabo en el marco de la política de seguridad democrática, impulsada por el entonces presidente Uribe, FEDES (2011) observo que:

Los objetivos de la política de "seguridad democrática" eran: combatir el terrorismo y el narcotráfico, recuperar y mantener el monopolio de la fuerza del Estado en el territorio nacional y la protección de la población civil, propósitos que obedecían a pilares básicos de eficacia, cooperación de la sociedad civil con las Fuerzas Amadas, fortalecimiento de toda la estructura militar, la retórica del respeto a los derechos humanos y, se decía, un apego estricto a la legalidad. $(\mathrm{p}, 6)$

En el contexto de la Seguridad Democrática se enfatizó en la estrategia militar. Entre las estrategias se establecieron incentivos para los militares, por ello se crearon las directivas ministeriales, especialmente: No 29 de 2005, por la cual se establecía un mecanismo de recompensa a los miembros de la Fuerza Pública por resultados en bajas de los movimientos subversivos. Rueda (2012) afirma que:

El artículo 8 de la Directiva preveía la creación de una comisión técnica para el seguimiento de los pagos y un procedimiento de pago, el cual se efectuaba previa presentación de documentos de respaldo a la comisión, por ejemplo, el documento oficial que ordenaba la operación de la unidad táctica, el informe de patrulla o de resultados, documentos que no existían en la mayoría de los casos de "falsos positivos". (p.66) 
La existencia de esta directiva pone de manifiesto una política que establece incentivos por la muerte de combatientes en un Estado de Derecho como constitucionalmente se define el colombiano, lo cual es propio de un Estado con más de cinco décadas de guerra.

Movimiento de Reconciliación \& La Coordinación Colombia Europa (2014) afirmó que el perfil de las víctimas de falsos positivos sucedidos entre los años de 2007 y 2010, respondió a las siguientes características:

_ Se trata en su gran mayoría de hombres jóvenes pues solo ellos correspondían al perfil de los guerrilleros o combatientes del que se los disfrazaría. Si bien no fue una generalidad, se conocieron varios casos de menores de edad, especialmente jóvenes de alrededor de 16 años.

-Una de las características principales es la de ser campesinos o habitantes de zonas rurales a donde iban dirigidas las operaciones militares.

- A menudo provenían de familias de escasos recursos económicos, y/o se encontraban desempleados, con lo cual eran fáciles de atraer bajo el señuelo de promesas laborales. Era frecuente que los jóvenes desaparecieran luego de acudir a una oferta de trabajo, de manera que al principio los familiares no tuvieron sospechas sobre lo que ocurría.

- En algunos casos, se trataba de jóvenes que habían tenido problemas menores de delincuencia o que habían participado de falsas desmovilizaciones.

_ En otros casos, se optó por personas indigentes o marginadas socialmente, de quienes no se esperaba que nadie fuera a reclamar por su destino, o cuyas familias desconocían cómo acceder a medios de denuncia.

_ Estas acciones revestían muchas veces el carácter de acciones de "limpieza social", siendo las víctimas personas consideradas indigentes, drogadictas o discapacitados.

En definitiva, el perfil de la víctima estuvo asociado a representaciones sociales de estigmatización, tanto por ser joven, como por los territorios vistos como peligrosos y/o relacionados con el conflicto armado.

Dichas construcciones sociales de estigmatización fueron utilizadas por parte de los victimarios como elementos de justificación de la violencia ejercida contra esta población, así como el ocultamiento de los hechos cometidos contra esta población. 


\subsection{Violencia juvenil y fenómeno del sicariato juvenil en Colombia}

Hasta aquí hemos analizado la violencia derivada del conflicto armado interno en Colombia, con ello, nos hemos adentrado en el complejo entramado de confrontaciones sin resolución presentes desde hace más de medio siglo. Así como en sus diferentes ciclos cronológicos, que nos permiten comprender la continuidad existente de la guerra de hoy con las confrontaciones bélicas vividas entre 1948 y 1958. Asimismo, reconocimos la presencia de una realidad compleja en tanto las dinámicas y la pluralidad de autores vinculados a ésta. Un elemento que profundiza la situación de guerra vivida por el país, es la existencia de otro tipo de violencias sociales que involucran aún más a la población civil.

En las ciudades se ha podido observar la presencia de múltiples conflictos sociales manifestados de forma violenta a través de organizaciones ilegales (bandas, asociaciones de micro - tráfico). Estas conflictividades tienen lugar en los escenarios más desfavorecidos de las grandes ciudades por ello se les ha denominado violencia urbana. Estas organizaciones son de carácter delincuencial mediante delitos como el robo y el atraco se convierte en el terror de los habitantes de las zonas más populares del país. Asimismo, estas asociaciones ilegales permanecen en una constante lucha por el dominio territorial, lo que conlleva a enfrentamientos armados en la cotidianidad de sus contextos que afectan de manera directa la población residente en estos sectores.

La participación juvenil en este tipo de violencia es una de las más preocupaciones sociales más importantes en el contexto colombiano. Las estrategias de reclutamiento de jóvenes son muy comunes en dicha violencia, no obstante, no es un tipo de conflicto propio de la juventud, como se ha querido mostrar por parte de algunos medios de comunicación que definen indiscriminadamente este asunto social como violencia juvenil generando un grave problema de estigmatización social del joven.

El concepto de violencia juvenil está más relacionado con aquella violencia que es protagonizada de manera directa por los jóvenes. Perea (2004) afirma que, en Latinoamérica, a partir de los años de 1980, ganaron presencia diversos escenarios de conflicto, donde los jóvenes son protagonistas, especialmente de las pandillas y el sicariato. 
Estos dos fenómenos (el pandillismo y el sicariato) pusieron de manifiesto un aspecto preocupante, el incremento de la participación del joven en acciones de violencia; por ello, el análisis de la violencia juvenil ha sido una preocupación académica. La búsqueda de las causas y explicaciones ha sido una tarea de la sociología latinoamericana. Comprender el fenómeno de la violencia juvenil significa profundizar en diversas perspectivas del problema para poder desmitificar la representación social del joven como actor violento.

En el análisis de la violencia juvenil es necesario tener presente el marco social, cultural y político donde se desarrolla esta violencia, Reguillo (2008) observa que la violencia juvenil se desarrolla en contextos de violencia estructural, un gran número de jóvenes no cuenta con lo necesario para cumplir sus objetivos de futuro, no tienen oportunidades de desarrollo, menos al estar inmersos en sistemas educativos desiguales en comparación con los jóvenes procedentes de las clases altas e incluso medias. De igual manera, el desempleo juvenil es uno de los problemas más severos del contexto de la región latinoamericana, con todo ello las expectativas sociales para los jóvenes son muy bajas.

Sin embargo, la violencia ejercida por los jóvenes no sólo se enmarca en las causas estructurales, por ello, es necesario examinar otros elementos de origen social y cultural que estarían en la base de forma de violencia. Los trabajos de Perea se han centrado en el tema de las pandillas en los contextos de Colombia y México, este autor a través de su larga trayectoria investigativa observa que en contex tos de exclusión juvenil y en ausencia de un Estado- Nación que de legitimidad a la juventud; la búsqueda de reconocimiento social y de respeto son la base de las luchas identitarias juveniles que al no tener escenarios pacíficos de tramitación desembocarían en la violencia.

En este mismo sentido Serrano (2005) afirma que en Colombia ha existido tal desconocimiento de lo juvenil, que tristemente los jóvenes empezaron hacer visibles para la sociedad colombiana en las décadas de 1980 y 1990, a partir de su incursión en la violencia del sicariato juvenil; con ello se constata que la ausencia de un reconocimiento por parte de la sociedad y el Estado colombiano conllevaron a que algunos jóvenes buscarán su lugar social a través de la violencia. No obstante, ésta no fue el camino más utilizado para encontrar este reconocimiento, también en estas décadas los sectores populares asistieron al florecimiento de la organización juvenil de tipo cultural y artístico. 
Para continuar con este análisis de los elementos culturales y sociales que soportan la violencia protagonizada por los jóvenes, es fundamental considerar el aporte de Reguillo (2008) cuando determina tres características básicas de las sociedades contemporáneas que contribuyen a la comprensión de la violencia, éstas son:

a) La erosión de los imaginarios de futuro. La realidad social contemporánea en la región latinoamericana está marcada por el desencanto y la pérdida de sentido de lo juvenil, los anclajes identitarios fundamentados en lo político que caracterizaron a las décadas de 1960 y 1970 han desaparecido y en las décadas posteriores no se visibiliza de forma clara que define lo colectivo juvenil. Además, la violencia política, así como la inmersión del joven en otro tipo de violencia ha hecho visible un descanto por la vida a partir de la posibilidad de la muerte temprana en los imaginarios sociales de la juventud.

b) El aumento exponencial de la precariedad tanto estructural como subjetiva. Las políticas neoliberales han llevado al mayor empobrecimiento de los sectores populares, al incremento de la desigualdad en el acceso a los derechos y servicios básicos (salud, educación, empleo, entre otros). La población joven es la que ha resultado mayormente afectada por dicha situación. De otra parte, las familias y comunidades se enfrentan a una mayor desestructuración social, lo que conlleva a una carencia de soportes afectivos para la población joven.

c) La crisis de legitimidad política. La incapacidad de los Estados latinoamericanos para configurarse como referente legítimo de orden social para la población y especialmente para la juventud ha conllevado a que otros actores (traficantes, guerrillas, paramilitares) asuman este rol en los contextos locales. Asimismo, estos actores se configuran en nuevos modelos a seguir por parte de los jóvenes ante la ausencia del Estado y sus instituciones.

La violencia juvenil en Colombia no es ajena al estado de guerra que ha vivido el país por más de cinco décadas en este estado permanente de violencia; dado que las diversas estrategias de los sectores en guerra han involucrado a la población juvenil como actor directo de violencia y por ello es muy frecuente el reclutamiento de jóvenes por parte de actores del conflicto o por organizaciones de económica ilegal (narcotraficantes, terreros, entre otros). De este modo la juventud es sometida a participar de manera directa en una violencia creada por adultos. 
Además la existencia de un conflicto armado por más de cinco décadas ha conllevado a que se instalen formas de resolución de los conflictos a través de la violencia, ya sea porque en muchas regiones del país los actores armados han asumido el papel de reguladores sociales y han tramitado conflictos sociales y cotidianos a través de la violencia o porque por un largo periodo de tiempo, la sociedad se ha visto expuesta a ver como los macro y micro conflictos se resuelven a través de mecanismos violentos y de esta manera se van incorporando elementos de la cultura de la guerra en los imaginarios sociales que van legitimando la agresión como forma de dirimir las tensiones propias de la vida social.

A todos los elementos propuestos en este análisis de la violencia juvenil, debemos incluir uno de suma importancia para una mejor comprensión de este fenómeno social. El carácter simbólico de la violencia; en este sentido Cerbino (2006) se refiere al concepto de déficit simbólico de la juventud. Éste se presenta cuando hay una fractura entre conformación de identidad y grupos de interés; generando obstáculos en la definición de la identidad y la alteridad. Los procesos de identificación y distinción de los "otros" propios de la construcción de la identidad son asumidos desde la perspectiva de que el "otro" es absolutamente contrario y a su vez como un enemigo para aniquilar. Así, muchos de los conflictos sociales inherentes a las identidades juveniles se convierten en conflictos violentos.

A nuestro modo de ver en contextos caracterizados por la guerra este déficit simbólico se profundiza, dado que uno de los más severos efectos de la guerra es la ruptura del tejido social y la generación de la desconfianza entre los miembros de las comunidades, la utilización de jóvenes como informantes por parte de los ejércitos armados conlleva a la generación de un sentimiento de inseguridad hacia los próximos y con ello la imagen del “otro" es significada desde el peligro. De esta manera, la construcción de la alteridad es realizada desde una deslegitimación del "otro" motivada por el miedo y la desconfianza.

De esta manera, se ve afectada la construcción de lo colectivo y el orden social pierde su legitimidad y con ello, los contextos de conflicto armado son más proclives al surgimiento de la violencia juvenil. Sí tenemos en cuenta lo planteado por Reguillo (2008) cuando afirma que:

Las violencias juveniles se instalan justo en el vacío de legitimidad y ausencia de un proyecto colectivo, portador de sentido, desde ahí desafían la legalidad, 
pero al hacerlo confrontan una ausencia, no una presencia y sin embargo a esta ausencia de legitimidad se responde con dosis redoblada de legalidad, en una espiritual punitiva que termina por alimentar las violencias. (p.222)

De este modo, se muestra la importancia del orden social en la construcción de los sentidos juveniles. Los contextos marcados por la violencia erosionan la cohesión social, enfatizan el autoritarismo, así se desmoronan los sentidos colectivos. Es fundamental tener en cuenta que la exposición permanente de la población colombiana a la violencia estructural, social y política conlleva al debilitamiento del orden social y con ello, aumenta los riesgos de la violencia juvenil.

El abordaje de la violencia y la juventud en Colombia por parte del Estado ha estado asociada a dos roles: ausente y represor. Por un lado, los sectores populares de las grandes ciudades viven el constante abandono estatal manifestado en la carencia de servicios básicos, el poco acceso a los derechos fundamentales y la falta de garantías para la seguridad. Por otro lado, El uso de la fuerza por parte de la policía y el ejército nacional contra la población civil y especialmente contra la juventud popular es una de las características más comunes del contexto colombiano. A partir de esta realidad la población joven asume sus identidades en confrontación con el Estado, desde diferentes vías como la organización social y cultural, y lamentablemente, algunos jóvenes responden incorporándose a escenarios violentos.

Por último, el análisis de los procesos violentos juveniles tiene que ser vistos no como expresiones de grupos de jóvenes que no se adaptan al sistema o como producto de la desestructuración familiar o social, sino en el marco de la configuración de modelos sociales y políticos en el escenario contemporáneo. De esta manera, lo propone Reguillo (2008).

Las violencias que protagonizan los jóvenes, ya no como víctimas o victimarios, deben ser calibradas en los contextos de los proyectos sociopolítico y los modelos socioeconómicos contemporáneos, ellas me parece, que proyectan sobre un imaginario social, al que puede faltar el imaginario colectivo, sobre una sociedad atemorizada por las señales constantes de la ruptura del orden conocido y el declive acelerado de las instituciones, perseguidas por la pobreza y la ausencia de un orden inteligible. (p.222) 
En este sentido, es relevante reconocer los vacíos de los modelos sociales, políticos y económicos de la región latinoamericana que perpetúan la desigualdad, el empobrecimiento de vastos sectores de la población y desconocen las demandas culturales y sociales de la juventud. Además de la tendencia al uso de la represión ante los conflictos sociales como los que están presentes en la violencia juvenil.

\subsubsection{El fenómeno del sicariato en Colombia}

Como ya venimos expresando a lo largo del trabajo, el ingreso de la violencia del narcotráfico al escenario de la violencia colombiana tuvo un elemento característico, mayor involucramiento juvenil en acciones de delincuencia; especialmente con la participación de jóvenes de los contextos urbanos como asesinos a sueldo. A mediados de la década de 1980 el país asistió a una violencia procedente de los carteles de la droga (cartel de Medellín y Cali, entre otras organizaciones del tráfico de drogas) que utilizaba a algunos jóvenes para llevar a cabo el aniquilamiento de líderes políticos, representantes de la justicia, líderes de izquierda, así como el ajuste de cuentas entre bandas del narcotráfico.

El asesinato del Ministro de Justicia en el año de 1984 y el candidato presidencial Carlos Pizarro; representante del desmovilizado partido de izquierda M19, son casos emblemáticos que manifestaban la presencia de un fenómeno social de gran envergadura en el país. De esta manera, lo advierte Salazar (1990):

Jóvenes dispuestos a morir, al estilo de los terroristas Shiitas o de los kamikazes japoneses con la diferencia substancial que estos suicidas no obran motivados por un ideal político, ideológico, religioso, evidente. (p.186)

Lo sorprendente de este fenómeno es como estos jóvenes estaban dispuestos de morir, dado que la vinculación al sicariato, predecía una vida corta, lo que para los análisis sociológicos de este momento presuponía, la existencia de una intención suicida en los jóvenes que se vinculaban a este tipo de organización criminal. El inminente peligro de morir en el acto de ejecutar el asesinato por la reacción de los sistemas de seguridad de sus víctimas, o la acción de las fuerzas del Estado o la posibilidad de ser asesinado después del crimen como una forma de ocultar las pruebas que pudieran incriminar a los autores intelectuales de dichas acciones. 
Son muchos los interrogantes que surgen alrededor del surgimiento de un fenómeno tan sorprendente como éste; entre los posibles factores que conllevaron a que los jóvenes se involucraran en este fenómeno violento se encuentran:

- Las condiciones estructurales y pocas posibilidades para el desarrollo del sector juvenil.

- La posibilidad de realizar los anhelos y deseos de reconocimiento negados por la sociedad.

- La frustración de la juventud de los sectores popular obligados a vivir en la carencia.

- La existencia de un contexto marcado por el consumo y la presión mediática impulsada por el mercado para hacer del joven un objeto de consumo.

No obstante, los anteriores elementos no resultan suficientes para explicar el fenómeno, ya que miles de jóvenes de las grandes ciudades latinoamericanas viven en medio de situaciones similares y no optan por salidas violentas. Por ello, es necesario acercarse a dicho fenómeno desde las perspectivas sociológicas y culturales presentes en el mismo. Schlenker (2008), retomando a Pecaut (1996), afirma que también el sicariato es una manera que utiliza el joven para subvertir el orden social; en el sentido que ya no requiere sujetarse a unas jerarquías del modelo de producción, sino que alguien de escasos recursos, de manera rápida puede llegar a tener mucho dinero y asimismo infundir temor y respeto. De esta manera, esta forma de violencia puede ser asumida en la búsqueda del reconocimiento social.

Asimismo, autores como Medina, Vargas, Medina \& Jaramillo (2011) afirman que el involucramiento de la población joven en el fenómeno del sicariato puede estar asociado a sentimientos de odio, generados a partir de la represión violenta realizada por parte del Estado en contra de la juventud de los barrios populares. En este sentido se vislumbra una causa que tiene que ver con los sentimientos de injusticia y venganza en medio del conflicto armado vivido.

De otra parte, este autor relaciona el problema del sicariato con la construcción de identidad juvenil, ya que el joven no sólo actúa en esta violencia recibiendo ordenes de arriba, sino que también es una manera de construir una imagen de sí mismo y apropiarse de formas de como otros lo ven: muchos jóvenes no se definen como víctimas de la 
violencia. Al contrario, las múltiples formas de violencia le permiten desarrollar una identidad concebida para generar en el entorno temor y respeto.

Retomando a Pecaut (1996) cuando afirma la existencia de una cultura del narcotráfico, donde el sicario aparece como una mezcla entre lo moderno y lo tradicional, ya que se convierte en el nuevo modelo de adquirir dinero rápidamente y ganar respeto sobrepasando las jerarquías existentes, pero por otra parte el joven sicario está impregnado de una cultura tradicional, basada en la religiosidad. En este sentido, el narcotráfico no sólo funciona como una economía ilegal, sino que generó una cultura fundada en el consumo y la supremacía sobre los otros a través del dinero y las armas, que además, adiciono los valores tradicionales como la religiosidad.

Así en términos simbólicos el sicario se convirtió en una imagen que condensaba una nueva cultura de ascenso social fugaz, tan bien descrita por Von der Walde (2001) cuando se refiere a la imagen del sicario en la película. "La virgen de los sicarios", de la siguiente manera:

(...) se trata como todos saben de un joven sicario portando todos los emblemas que le han convertido prácticamente en una figura del culto, el revólver obviamente y las imágenes religiosas que le protegen, le garantiza buena puntería cuando ejecutan sus víctimas y les asegura el pago que le han prometido los que lo contratan. La imagen es la estetización y estilización de uno de los síntomas más notables no sólo de la violencia en Colombia, sino de la confusión imperante sobre el significado de lo que es una catástrofe sin antecedentes en esta sociedad.

El surgimiento del sicariato juvenil es uno de los episodios de la violencia colombiana; es un doloroso capítulo de nuestra historia, que demostró los más profundos efectos de la violencia en la población joven. El análisis del mismo es aún insuficiente en el país, ya que a pesar de los esfuerzos de algunos académicos aún no contamos con respuestas que nos permitan comprender lo sucedido; sin embargo, hoy vislumbramos que su estudio debe realizarse desde el sufrimiento humano y la crisis humanitaria que ha dejado el estado permanente de violencia en el país. 


\subsection{Identidades juveniles en contextos de violencia}

La relación entre el sector juvenil, la violencia y los procesos de construcción de identidad se presenta como una necesidad académica ante una realidad empírica en el contexto colombiano: la presencia de múltiples violencias. En dicho contexto los jóvenes no han sido sujetos pasivos, donde no se puede desconocer su participación en acciones de violencia, de la misma manera que no se puede desconocer su aportación en las iniciativas sociales que demuestran su compromiso con la sociedad y los Derechos Humanos.

\subsubsection{Juventud como construcción social}

"El riesgo de no establecer las distinciones analíticas pertinentes es el de permanecer atrapados en la esencialización de lo joven como si fuera un dato "natural" y no como de hecho es un construcción social e histórica." Reguillo (2000a)

Para la cultura llamada occidental la emergencia de la juventud puede ser situada hacia finales del siglo XVIII y principios del XIX con la consolidación de la sociedad moderna. La estructura familiar, la configuración de la infancia, los procesos de socialización secundaria, han construido el período de la juventud como parte del ciclo vital en el que los individuos se acondicionan para asumir determinados roles sociales, los de la vida adulta.

La construcción de esta categoría se ha considerado desde varios enfoques. En un primer lugar desde el ciclo vital, como un periodo de vida inscrito en una determinada edad. Margulis \& Urresti (1998) observan que inicialmente esta categoría es etaria, sin embargo, al caracterizar este sector poblacional de acuerdo a la edad se limita la conceptualización del joven porque no existe tal homogeneidad. La población juvenil tiene una diversidad de características comportamientos, horizontes de posibilidades y códigos culturales que diferencian el ser joven en las sociedades contemporáneas. Por ello, estos autores hablan de la existencia de juventudes reafirmando su pluralismo y heterogeneidad.

Desde este enfoque, la Juventud no pueden ser interpretada desde una única perspectiva, ya que las diferencias de clase social, género, procedencia regional, cultural, los referentes identitarios, lenguajes y formas de sociabilidad les signan formas de ser en el mundo y les conceden atributos para la construcción de múltiples formas del ser juvenil, y 
determinan que la categoría genérica de juventud albergue en su interior muchas formas de ser joven.

Un segundo elemento observado en la conceptualización del joven, es el concepto de "moratoria social", como periodo de tiempo en el que la juventud puede prepararse para la adultez. Margulis \& Urresti (1998) plantean que la moratoria social es un privilegio para determinadas clases sociales que pueden prolongar el tiempo de estudio y con ello postergar aquellas responsabilidades asignadas a la madurez social como son trabajar o tener hijos. Para estos autores el concepto de moratoria social, creado por la Sociología contribuye a caracterizar un tipo de juventud, el de las clases acomodadas pero dicho concepto no aplica para otro tipo de jóvenes insertos en las clases sociales desfavorecidas.

Otro concepto abordado para entender en tema de juventud es el de generación, relacionado con la edad pero procesada por la cultura, es decir, tiene en cuenta las particularidades de esta población en un determinado periodo de tiempo con relación a los otros miembros de la sociedad (niños- adultos), además de lo anterior articulan a las particularidades culturales de esta población, como por ejemplo las estéticas, gustos, participación social todo aquello que los diferencia del vivir juvenil en otros momentos históricos, un caso particular lo podemos observar en la asociación del joven con el hipismo en los años de 1960 o revolucionario en la década de 1970 con la participación en el movimiento estudiantil.

También la juventud ha sido vista como una etapa de transición entre dos periodos del ser humano la niñez y la adultez. Reguillo (2000a) expone que con pocas excepciones el Estado, la familia, la escuela, siguen pensando en la juventud como futuro valor por lo que será y dejará de ser. Mientras que para los jóvenes el mundo ha estado anclado al presente, situación que ha sido finalmente captada por el mercado.

La transitoriedad como forma de comprender a la población juvenil es un elemento integrante de las políticas públicas de América Latina; dichas políticas se han centrado en preparar al joven para el ingreso al mercado del consumo, al mercado laboral, y la preservación de los sistemas tradicionales de familia y sociedad. Aunque en la primera década de este siglo se han dado cambios en la forma de cómo son concebidos los jóvenes en la esfera pública, aún no se ha dado mayor sentido a la participación en equidad de este sector y no se han superado las fracturas entre sociedad y población juvenil. 
Para efectos de este estudio comprendemos la noción de juventud como categoría social, cultural e histórica que no se reduce a la distinción etaria, es decir a verla como una etapa del ciclo vital, sino a la pluralidad de sujetos que cobija, de igual manera, se tendrá en cuenta en esta definición la forma como ha sido representado este grupo socialmente, señalando que la manera como se define la juventud está íntimamente ligada con la forma como es representada colectivamente.

De igual manera, el concepto de jóvenes es resultado de la construcción histórica de una noción de sujetos que varía social y culturalmente. La definición de ellos está atravesada por los procesos de identificación que los crean y recrean, por ellos mismos y por los otros. Así, jóvenes pueden ser entendidos de muy diversas formas, hasta contradictorias, en diferentes tipos de sociedades y culturas.

Es esta relación dinámica entre la categoría social asignada por la sociedad y la subjetividad de este grupo poblacional donde el joven se establece como sujeto. Como lo afirma Reguillo (2000b) ser joven no es fundamentalmente una categoría social homogénea, tampoco es un dato que se concluye en la acumulación biológica de años. Ser joven es primordialmente una clasificación social y como toda clasificación sugiere el establecimiento de múltiples diferencias. La integración de estas diferencias es lo que otorga particularidades precisas, contenidos, límites y sentido al continente ser joven.

Lo anterior, cuestiona la tendencia a ver al joven desde una perspectiva etaria y biológica que ubica a este grupo poblacional en un determinado rango de edad, sino que le da sentido en la realidad subjetiva de la interacción con otros y las formas de asumirse como un determinado grupo social en un contexto especifico que le asignará los atributos que le distinguen de la categoría generalizadora de juventud.

Como lo plantea Reguillo (2000a) es importante enfatizar que los jóvenes como sujetos sociales, componen un universo social cambiante y discontinuo, cuyos atributos son resultado de una negociación-tensión entre la categoría social asignada por una sociedad específica y las subjetivaciones que los mismos llevan a cabo a partir de la interiorización distinta de los patrones de la cultura en la que se inscriben.

Perea (1998) observa que los jóvenes han sido considerados de diversas maneras como una subcultura con poca integración al sistema de mercado, como marginal, sin normas sociales. Una contracultura disfuncional y contestaría, pero con una capacidad para el 
consumo, de igual manera el joven ha sido significado desde un "no lugar" en el que todavía no es sino hasta que llegue a ser adulto. Las sociedades han construido imaginarios sociales donde el joven popular es considerado una población en riesgo de convertirse en delincuente o de propiciar una crisis social.

Para comprender el ser joven se necesita tener en cuenta las variadas esferas en que ellos y ellas viven, así como los contextos que los circundan. Por significarlos en planos unidimensionales se ha llegado a caracterizaciones y estigmatizaciones de los jóvenes como personas indefensas en riesgo, carentes de culturas propias y desligadas de la vida social, política y económica.

De la misma manera desde las esferas legislativas y administrativas colombianas se limita quien es joven por el rango de edad, en búsqueda de efectividad en las políticas públicas que pretenden atenderlos. Es necesario en el contexto de la exigencia de derechos y obligaciones tener un marco referencial que concrete los sujetos sobre quienes se ejercen políticas públicas o leyes específicas. Pero en otros ámbitos del actuar social, los jóvenes se pueden encasillar como todas aquellas personas entre los 14 y 26 años (Ley 375 de 1997), puesto que el ser joven sobrepasa las barreras de edad impuestas por las corrientes discursivas oficiales.

En resumen, en el curso de los desarrollos disciplinares y de los discursos políticos los jóvenes han sido significados como: (1) idealizados, (2) como actores de riesgo, (3) como víctimas y victimarios, (4) como receptores de programas y políticas públicas, y (5) como consumidores.

En este trabajo entenderemos el concepto de jóvenes como un sujeto social construido en referencia a una etapa vital no homogénea dada su interrelación con la cultura, el contexto social donde este se inscribe y que le aporta particularidades que le diferencia con otros con los que comparte un rango de edad. Dos elementos para definir a los jóvenes son cómo se asumen ellos en su identidad juvenil y cómo son representados por los otros.

Para ello es necesario acercarnos al desarrollo académico de la relación juventud y violencia; en Latinoamérica, el tema de la juventud en relación con la violencia es en el campo de lo académico una preocupación reciente. Reguillo (2000b) afirma que en general la investigación sobre la juventud no nace desde la Academia; sino surge más de 
la acción de las organizaciones no gubernamentales enfrentadas a una violencia social temprana protagonizada en buena medida por los sectores más jóvenes.

Esta visión estuvo en gran medida permeada de los imaginarios sociales del joven como sujeto en riesgo, que parecía evidenciarse con una dolorosa realidad en el contexto de América Latina, la inmersión juvenil en las dinámicas violentas. Lo cual no está muy desligado de la manera como se construyen los imaginarios del ser joven; es la percepción de incapacidad de este sector por parte de la sociedad que lo ha puesto en una exclusión social frente a otros grupos etarios. De la misma manera que esta forma de concebir al joven ha permitido que adultos miembros de organizaciones violentas los coopten para participar en sus organizaciones delincuenciales, es así como la falta de reconocimiento de este sector lo ha llevado a búsquedas del mismo en acciones que confronten a quienes les niegan.

Es necesario afirmar que si bien la población joven en ocasiones ha "optado" por formas de violencia no se trata de la mayoría, también ellos se pronuncian desde otras alternativas que han sido menos analizadas por la Academia y vistas por las organizaciones de la sociedad civil. De otra parte, es necesario tener en cuenta que el contexto latinoamericano ha sido marcado por la presencia de la violencia política y social donde los jóvenes han sido las mayores víctimas.

La región latinoamericana ha presentado una incapacidad histórica para resolver los conflictos y las inequidades sociales, lo que conllevaría a que los jóvenes en la década 1970, la inmersión de muchos jóvenes en la guerrilla y a los movimientos de resistencia en diferentes países; fueron pensados en ese momento como; guerrilleros y subversivos.

Las interpretaciones de la sociedad y algunos sectores de la Academia se inclinaron por ver este hecho como una manipulación de lo juvenil por los gobiernos internacionales (Cuba y la Unión Soviética) sin retomar el problema de raíz, las profundas desigualdades y la exclusión de la población juvenil.

Las diversas representaciones y conceptualizaciones de lo juvenil tienen que ver con coyunturas políticas, es así como la nominación de "enemigo interno" surgida en Latinoamérica en la década de 1970 a partir de los golpes militares y las dictaduras que afectaron a la mayor parte de la región. La categoría de "enemigo interno" se fue 
extendiendo como una forma de señalar a los opositores la mayoría estudiantes y miembros de organizaciones juveniles.

Dicha categoría fue usada por países que estaban en democracia como en el caso colombiano, donde se implantó el estatuto de seguridad a través del cual, y se justificó la persecución de organización estudiantiles, llevando a numerosas muertes y desapariciones forzadas de estudiantes de universidades públicas.

La categoría de "enemigo interno" es importante en este análisis en la medida que a pesar de que su surgimiento radica en la década de 1970, se ha extendido en las siguientes cuatro décadas e influenció de manera significativa la construcción del joven como violento.

Y continuando que con el proceso histórico que conceptualiza al joven en Latinoamérica, Reguillo (2000a) observa que para la década de 1980 la derrota política y especialmente simbólica de las alternativas políticas de las dos décadas anteriores, aunando al desencanto de los jóvenes, definió lo que sería la década de los 80, la llamada década perdida. De la cual se ocuparon los académicos: en esta etapa la producción de investigación de lo juvenil estuvo más ligada a la relación: víctimas - victimarios; con el ingreso de sicarios financiados por el narcotráfico de muchos jóvenes en las ciudades de Medellín y Cali especialmente, así como la participación en agregaciones como pandillas, bandas y milicias.

Al finalizar esta década e inicios de 1990 los jóvenes aparecen en los imaginarios sociales como delincuentes y violentos, drogadictos. En cada uno de los países empiezan a tener lugar central en los medios de comunicación y los organismos del Estado como sujeto peligroso. En este momento inicia la tendencia de los estudios culturales para la comprensión tanto de los imaginarios sociales y las formas de la construcción de lo juvenil.

Para la década del 2000 el análisis se centró en los temas de las culturas juveniles, las identidades y los imaginarios sociales del ser juvenil, el tema de las adscripciones, las agrupaciones se convierten en un elemento fundamental de la nueva forma de nombrar al sujeto juvenil. En este escenario el sujeto joven también es nombrado desde las diferencias que proporcionan las apuestas de identidad juvenil con la tradición adulta. 
No obstante, aunque abunda la producción académica sobre el tema de la juventud son pocos los estudios que abarcan el problema cultural, sobre esto Reguillo (2004) observa que hay en estos estudios una tendencia fuerte a confundir el escenario situacional en las representaciones profundas de estos jóvenes o, lo que es peor, a establecer una relación mecánica y transparente entre prácticas sociales y universos simbólicos.

En Colombia, Martín-Barbero (1998) ubica un hito donde se inicia la mayor preocupación por la diada: jóvenes y violencia. El asesinato del Ministro de Justicia Lara Bonilla a mediados de los años de 1980 por dos jóvenes pondría en evidencia una compleja realidad, la inmersión de la población juvenil a la violencia del sicariato. A partir de este momento, tuvo lugar en las imágenes de la prensa que le dieron la vuelta al mundo y se da inicio una preocupación por ver al joven desde una forma bipolar: Víctima y victimario, que ocupó el desarrollo investigativo en la década de 1980 e inicios de la década de 1990.

El lugar de reconocimiento del joven y la juventud partió de un estigma del joven como peligroso, como amenaza para la sociedad. Dicho imaginario social se extendió a la sociedad colombiana y estableció una imagen negadora del joven que lo asociaba con violencia, encasillaba a los jóvenes colombianos y se limitaba el análisis del joven en relación con la cultura, el contexto socio económico y político. Se creó un constructo social que determinaba al joven en relación a la violencia.

Martín-Barbero (1998) afirma que el estigma (víctima-victimario) desde el inicio ha estado presente fuertemente por la preocupación y la mirada a la dificultad para definir las proximidades de ese nuevo objeto de conocimiento que serían los jóvenes, un objeto nómada de límites difusos. A esto se le sumó el constructo social que veía a este sector poblacional como una amenaza social, desviación y violencia.

La preocupación de la sociedad por la juventud desde la representación como "violenta", por el joven pandillero, miembro de bandas asociado al lumpen y al sicario, guerrillero miembro de las milicias, revela según Martín-Barbero (1998) que la preocupación no es tanto por las transformaciones y trastornos que la juventud esté viviendo sino que se trata más del cuestionamiento que hacen los jóvenes de forma explosiva de las mentiras que la sociedad se hace así misma para seguir creyendo en la normalidad social que el desconcierto político, la desmoralización y la agresividad explosiva de los jóvenes está desenmascarando. 


\subsubsection{Conceptualización de la identidad juvenil}

La identidad es un proceso social, pero ante todo cultural, donde los seres se asumen y se nombran como parte de un colectivo, a partir de la identificación y diferenciación con “otros", frente a ello, Valenzuela (1998), afirma que las identidades sociales son complejos procesos relacionados que se conforman en la interacción social, dichos procesos son constructos en relación con "otro". Y de allí se derivan formas de adscripción que se establecen principalmente por la posición de los otros y por una definición grupal compartida que trate de ganar sus propios espacios de reconocimiento.

Reguillo (2000a), observa que la identidad es centralmente una categoría de carácter relacional, la identificación y diferenciación y todos los grupos sociales tienden a instaurar su propia alteridad. La construcción simbólica del "nosotros" los jóvenes instaura diferentes alteridades fundamentalmente, aunque no exclusiva con respecto a la autoridad; la policía, el gobierno, los viejos, etc.

No obstante, los procesos identitarios se establecen en una relación dialéctica entre el "nosotros" y los “otros", mediada por la identificación y la diferenciación, el sujeto es en tanto se identifica y se diferencia; se construye en el efecto espejo, la imagen que se refleja y la imagen que se devuelve. La identidad se construye en una mediación intersubjetiva lograda a través del lenguaje y la experiencia vivida.

En este mismo sentido, Costa, Pérez \& Tropea (1996) consideran la identidad como un proceso relacional, donde el término "nosotros" permite el reconocimiento de la identidad colectiva. El aporte más importante de los citados autores se centra en observar que se ve fortalecida en conflictos sociales de los jóvenes a partir de la búsqueda de la reafirmación del "nosotros" a diferencia de ellos. En su investigación sobre grupos de jóvenes urbanos asociados a pandillas muestran que la identificación grupal se hace más fuerte al enfrentarse con otros grupos por el reconocimiento. De ahí podemos asumir que cuando la identidad grupal juvenil se ve amenazada, el grupo afectado genera dispositivos simbólicos y culturales para su mantenimiento.

No obstante, la identidad no sólo se basa en la construcción de alteridad sino también en las identificaciones como lo expresa Ricoeur (1996):

En efecto, gran parte de la identidad de una persona, de una comunidad está hecha, de estas identificaciones con valores, normas, ideales, modelos, 
héroes en los que la persona, en la comunidad se reconocen, el reconocerse dentro de contribuye a reconocerse en... la identificación con figuras heroicas manifiesta claramente esta alteridad asumida, pero esta ya es latente en la identificación con valores que nos hace situar la causa por encima de la propia vida, un elemento de lealtad, de fidelidad, se incorpora así carácter y hace inclinarse hacia fidelidad, por tanto a la conservación de sí. (p. 116)

Además de los procesos relacionales se requiere la interiorización que el sujeto joven hace de sí mismo. En palabras de Ricouer (1996) "la enunciación entendida como la capacidad del sujeto de signarse a sí mismo al significar el mundo”.

Reguillo (2000b), plantea tres elementos propios de la identidad: (1) el grupo juvenil, (2) la alteridad, es decir los "otros", (3) el proyecto de futuro. Estos aspectos además de tener en cuenta el elemento relacional nombrado en este estudio y hacer énfasis en el escenario donde se materializa, es el proyecto colectivo que puede darse de forma formal o informal. Este proyecto puede entenderse como el anclaje donde los jóvenes cimientan su posición en el mundo.

El escenario de lo cultural tiene gran sentido en la forma como el sujeto joven ha construido sus identidades, es en el ámbito de los significados y las significaciones donde el joven adquiere distintas particularidades y es ahí donde construye sus sistemas de representación que configuran los campos de acción diferenciada.

En términos prácticos, hoy como nunca la identidad está atravesada por fuerzas que rebasan la dimensión local y conectan las comunidades imaginarias, por ello resulta fundamental indagar sobre las fuentes que nutren los imaginarios de los jóvenes y ubicar los referentes a los que atribuyen mayor o menor credibilidad y cómo a partir de estas fuentes se derivan en programas de acción.

Asumir el enfoque cultural para definir la identidad juvenil, que afortunadamente empieza a ser perspectiva compartida por muchos estudiosos de las culturas juveniles, implica entender que los jóvenes no están por fuera de lo social que sus formas de adscripción identitaria, sus representaciones y sus anhelos, sus sueños, sus cuerpos, se construyen y se configuran en el "contacto" con una sociedad de la que también hacen parte.

Quizás uno de los elementos más pertinentes de estos procesos en relación de las culturas juveniles es lo que podemos denominar "la invención del territorio" noción que permite 
trabajar entre la reorganización y geopolítica del mundo y la construcción y apropiación que hacen los jóvenes de nuevos espacios a los que dotan de sentidos diversos al trastocar e invertir los usos definidos desde los poderes.

Los actores juveniles, al inventar los territorios para la acción en una forma de respuesta a las exclusiones, valores, símbolos y formas de comunicación derivadas de la globalización y portadoras de sus propios mecanismos de dominación señalan que todos los procesos de escala planetaria no desaparecen en el territorio, ni lo convierten en un "no lugar" a la manera de Auge (1993). El análisis de las culturas juveniles desde estas lógicas posibilita entender la reconfiguración de lo local en sus relaciones complejas (de resistencia, negociación y conflicto).

Así mismo, resulta necesario asumir a los jóvenes desde su identidad social más allá de la mera transición entre los dos grupos de edad cuya existencia es reconocida socialmente: niños/ adultos. Sino más bien desde un lugar que cuestiona esquemas preconcebidos y construidos desde la visión adulta. Martín-Barbero (1998), utiliza la metáfora de palimpsesto para aproximarse a un tipo de identidad que desafía nuestra percepción adulta como nuestros cuadros de racionalidad, y que asemeja a ese texto en que el pasado borrado emerge, aunque borroso, en las entrelineas que escriben el presente. Es la identidad que se gesta en el doble movimiento des-historizador y des- territorializador que atraviesa las demarcaciones culturales.

Para analizar el tema de la identidad juvenil en relación a la violencia es necesario observar su desarrollo teórico en el caso colombiano donde con el inicio de los estudios culturales ofrecieron una aproximación a uno de los puntos claves para el análisis de lo juvenil y la participación en la violencia, es en la década de 1990 donde empieza a darse las primeras puntadas del tejido que significa la identidad.

El trabajo de Salazar (1990) a partir de un acercamiento a los jóvenes de los sectores populares de Medellín vinculados al sicariato, establece uno de los puntos neurálgicos para el desarrollo de la investigación sobre los- jóvenes en Colombia. Este autor encontró como resultado de su investigación que los jóvenes están anclados en el presente; afirma que los jóvenes no ven el futuro, esto marcó una tendencia analítica que en Colombia se denomina "Presentismo". 
Esta categoría analítica "el presentismo" se constituyó en una de las primeras formas de interpretación de la construcción de la identidad del joven en medio de la violencia en Colombia. Esta interpretación del sin sentido de los jóvenes que les lleva a involucrarse en la violencia bajo la premisa de la muerte. Vivir la vida como si fuera el último día, asegurar un "dinero" para la familia y entregar la vida en un instante sin pensar en el futuro. Ubicó lo que por más de una década tuvo vigencia para interpretar la identidad del joven.

Es necesario contextualizar el momento donde se interpretó "el presentismo". La participación de los jóvenes de la comuna nororiental de Medellín en la violencia del narcotráfico les dio lugar como "asesinos a sueldo". Los narcotraficantes aprovecharon las carencias de la población joven; la pobreza y la exclusión social, la presión del mercado por convertir al joven en consumidor y la falta de reconocimiento social para esta población. Bajo la "ilusión” de obtener una mejor situación económica para sus familias mediante las ganancias que ofrecía el narcotráfico y a pesar de su propia vida.

La violencia contra los jóvenes de Medellín, Cali no sólo provenía del narcotráfico también fueron víctimas de los organismos de Seguridad del Estado, de las milicias populares derivadas de actores de izquierda y los paramilitares. Lo cual produjo la más contundente muestra de violencia contra los jóvenes, la mayor tasa de mortalidad en el año de 1985 donde los jóvenes fueron la mayor cuota.

Perea en sus investigaciones analiza los procesos de identidad y la participación de jóvenes agrupados en parches y pandillas, de igual manera, incluye una visión de no futuro, "el pandillo" frente al exterminio de jóvenes que realizan diversos actores (las fuerzas de seguridad del Estado, micro- traficantes, paramilitares) está dispuesto a morir, la muerte no ocupa el lugar de la vida, el joven la observa como un destino seguro, además, están dispuestos a morir por el respeto del parche donde tiene anclada su identidad colectiva.

Este mismo autor plantea el imaginario de la muerte como un acto simbólico del joven en un país que ha vaciado a la población juvenil del reconocimiento, mediante un constructo social de amenaza social, ante esta no existencia el joven se impone desde la muerte para establecer la lealtad que tiene con el grupo del reconocimiento. 
Perea (2001) al analizar el fenómeno de las pandillas en el suroriente de Bogotá afirma que:

No todos los jóvenes populares son pandilleros, como lo quiere mostrar el nefasto estigma que convierte la edad y la pobreza en insuperable motivo de degradación y violencia. Muchos se meten al ruedo, sin duda, arrastrados por el embeleso de una mirada paralizante capaz de hacer que un man se erice (p.39)

Así este autor introduce otro elemento propio de la identidad juvenil en medio de la violencia; el respeto como una búsqueda de la población joven en un país en que desde las lógicas de la guerra, la represión del Estado y la violación de Derechos humanos dio la mala lección de que los conflictos se resuelven con la violencia. Además de una continuidad del estigma sobre la población como incapaz, en tránsito, en un no lugar llevó a un grupo de jóvenes a encontrar el respeto en la agregación violenta.

La juventud es una etapa donde se precisa de afirmación de quién se es frente a un "otro", (el adulto, la autoridad, el mercado, las instituciones sociales) lo que Perea (2001) denomina la urgencia notoriedad, que en los jóvenes en pandillas no se agota únicamente en la necesidad de ser vistos, sino de ser observados desde un lugar que machaque la fragilidad de la vida humana.

De igual manera este autor retoma la noción de "presentismo" para analizar la relación con la vida y la muerte, este actor se encuentra en un sin sentido, el enfrentamiento con la sociedad y el Estado ya que le persiguen a través de la mal llamada "limpieza social." Además, los anclajes identitarios son difusos ni la escuela, ni la iglesia, ni la política le representa sentido de pertenencia.

Ante la violencia del Estado, de los grupos paramilitares y otros grupos que se toman por vía propia, la justicia que debería ser del el Estado y la falta de lazos que lo unan con la vida, con la comunidad, Nos dice Perea (2001) "El pandillero se sale, ya nada le agarra, consciente de que su única alternativa está en apostarle a la muerte. . . y ganar”. (p.53)

Riaño (2000) debate y refuta la noción de "presentimo juvenil" de Salazar (1990) desde el abordaje de la memoria de los jóvenes de Medellín, con amplio trabajo etnográfico demuestra que los jóvenes no están atados al presente, sino que el pasado es un asunto activo en la construcción de su identidad. A partir del recuerdo interpreta la huella dejada 
por la violencia en sus vidas simbolizadas en elementos conmemorativos como las placas, los nombres de las casas juveniles. La memoria de los hechos violentos que cegaron la vida de cientos de jóvenes de Medellín entre 1982 y 1992 es un punto de referencia para nombrarse una década después. Esta investigadora lo expone así:

La placa y la narrativa representan una forma de conmemoración que adquiere el significado de recuerdo intenso de aquellos que son parte de un grupo o comunidad. Las placas conmemoran un aspecto de sus vidas en particular, su participación comunitaria y defensa de los derechos de los jóvenes o los barrios. Esta interacción entre memorias privadas y narrativas públicas ilustra las cambiantes posiciones bajo las cuales nosotros como miembros de las comunidades, como miembros de las comunidades y grupos con el fin de solidificar lazos existentes o crear una comunidad temporal de sentimientos. (p.28)

Una de las categorías que presenta en su análisis en el sentido de lugar, la manera como estos jóvenes que vivieron la violencia resignifican el territorio de acuerdo a la violencia vivida (las masacres, los asesinatos colectivos) han quedado fijados en la memoria de cada uno de los jóvenes dando otro sentido a las calles y al barrio, otra forma de nombrar a partir de la violencia. La construcción desde el recuerdo de una "cartografía de la muerte evidencia que el territorio y la territorialidad han cambiado de sentido tanto en la connotación simbólica que hace la población joven del lugar, como en sus prácticas cotidianas en el ahora en los espacios físicos que habitan.

La manera como estos jóvenes de comuna nororiental de Medellín se nombran, se establece en relación con los otros, "los que se han ido", los muertos ocupan un lugar en el presente, ellos actúan como referentes, están presentes en la noción del territorio, en la forma como se construye en colectivo. Cómo lo explica Riaño (2000)

Ellos y ellas los que se han ido tienen un lugar central como organizadores de la memoria colectivas de los jóvenes. Referencias al status de la vida y en la muerte se entrelazan en las narrativas colombianas y constituyen en un modo de contextualizar y periodizar las historias compartidas. (p. 26)

Los jóvenes asesinados en Medellín habitan en el presente de los jóvenes de la comuna nororiental, lo que denomina la "la memoria viva de la muerte," esto significa una ruptura 
con la manera que se había venido analizando la relación entre jóvenes y violencia. La contundencia de su conclusión acerca de los procesos simbólicos que construyen la relación entre vida y muerte, donde el "otro" no se limita al que habita físicamente el presente, sino que puede ser él que ha quedado el recuerdo y tiene capacidad de organización de las identidades del presente.

Darle sentido de vida a los que se han ido es una manera de atarlos al presente, hace parte de esa forma como se socializa la profunda herida social que deja la violencia en la vida y los cuerpos de los jóvenes del sector popular colombiano es una evidencia de que la guerra y la violencia toca su más profunda identidad como sujeto; la experiencia cotidiana violenta hace las fronteras difusas entre vida y muerte. Un ejemplo es el uso de la canción de Rubén Blades por los jóvenes para hablar de los muertos. Como lo expresa Riaño (2000):

El énfasis está puesto en el hecho de que, aunque sus cuerpos físicos 'no están aquí', su presencia pesa más que un cuerpo común y corriente al habitar obsesivamente el presente y en el aquí de los lugares del recuerdo. Es una presencia que no es una simple narrativa, sino que corporaliza y emplaza en lugares específicos. La evocación es nostálgica y con frecuencia el cuerpo ausente es descrito como 'desaparecido'. Dicha referencia nombra tanto la práctica de las desapariciones forzadas de habitantes de la zona por fuerzas militares y paramilitares que tuvo un periodo crítico entre los años 1989 y 1991 o como una construcción que enfatiza en el vacío del aquí y el ahora debido a la ausencia corporal del ser amado, el amigo. En este caso, el desaparecido no es alguien que necesariamente ha sido 'desaparecido' por otros sino aquel (la) que está ausente del mundo de los vivos. (p.29)

Riaño (2000) concluye "al nombrar a los muertos como desaparecidos la brecha tajante entre la vida y la muerte se hace más ambigua para otorgándole un lugar simbólico vivencial en el mundo de los vivos". (p.30)

Riaño (2006) además de ampliar y argumentar lo expuesto anteriormente sobre la construcción de la identidad juvenil, nos proporciona otros elementos para fortalecer dicho análisis. Retoma el hito de Martín-Barbero (1998) para analizar el inicio de estigma que sobre la población juvenil popular existe en el país. Este constructo social que se constituye en una manera endógena de nombrar lo juvenil también tiene efectos en la 
manera como los jóvenes se significan así mismos y la relación con la sociedad que les circunda, denominando esta representación social como "una imagen perturbadora de la juventud," tal forma de categorizar socialmente al joven popular como portador de violencia y amenaza social posibilitó que la sociedad colombiana permaneciera con actitud indiferente y permisiva frente a la violencia y el exterminio de la población joven de Medellín y Cali en la década de 1980 a inicios de la década de 1990.

El análisis de la violencia en términos de la identidad juvenil nos ubica en el campo de lo simbólico, lo emocional, la relación de este sujeto con el entramado de interacciones culturales, nos posiciona frente a la mirada simple, dicotómica de "buenos y "malos" del conflicto armado interno colombiano y la violencia, de igual manera nos compromete desde la investigación académica con los territorios de lo humano y como la constitución cultural y emocional del sujeto joven que se ve afectada por la violencia.

Por ello, es válida la problematización que hace Riaño (2000) a dos conceptos el de la banalización de la violencia y la rutinización del terror como para explicar la forma como se tramitan las violencias por parte de la población que las afronta, como ella lo expresa:

Mi crítica a una preocupación con el modo en que estos análisis desdibujan las dimensiones humanas y vivenciales de la experiencia cotidiana de las violencias, mientras que colocan a los sujetos en la búsqueda de motivaciones restringidas negándoles la posibilidad de un posicionamiento diferente, contradictorio y/o cambiante. (p.23)

La aproximación a la relación entre jóvenes, violencia e identidad en el caso colombiano ha presentado un sesgo de partida, ya que se ha centrado mucho más en los efectos de la violencia y un poco menos en las alternativas que ellos han construido ante una realidad que les constriñe. Riaño (2006) al revisar el papel de los jóvenes en la década de 1980 y 1990 expresa que, en estos años los jóvenes se convirtieron en actores sociales claves en tanto diseminadores y /o víctimas de la violencia, pero también líderes de una cantidad de iniciativas sociales y comunitarias para afrontarla.

Las identidades juveniles en el contexto colombiano se han visto asediadas por la guerra y otras formas de violencia, ante lo cual, los jóvenes han respondido mediante la reafirmación de su identidad en dos posibles vías: la acción violenta y las alternativas artísticas y sociales en la búsqueda de la construcción de paz en los micro- contextos y el 
ámbito nacional. De una forma u otra el joven no ha permanecido inmóvil, ha desplegado la fuerza que lo caracteriza.

\subsection{Síntesis}

La presencia continua en Colombia de violencia ha sido una preocupación de los académicos en el país, dada su permanencia en el tiempo desde la misma constitución como República. En este capítulo fue de gran importancia establecer que el conflicto armado que vive el país se conecta con la violencia de los años cincuenta, así como tiene que ver con la permanencia en el país de una violencia estructural caracterizada por amplia desigualdad, acumulación de la tierra y los recursos económicos por un reducido sector de la población, además de una marcada tendencia a la represión de las iniciativas populares por parte del Estado.

Lo anterior conllevó a la aparición de los movimientos insurgentes a partir de la injustica social y económica que vive el país y la falta de alternativas políticas para construir una real democracia en dicho contexto. Como estrategia represiva no sólo se implementaron múltiples violaciones de los Derechos Humanos por parte de los organismos del Estado, sino que se propició el establecimiento de los paramilitares como un grupo de ultraderecha para atacar a las guerrillas. Lo cual degradó y escaló el conflicto hasta el punto de convertir a la población civil en la mayor víctima del mismo.

Uno de los grupos más afectados de la guerra que se sostiene en el país es el de los jóvenes que no sólo se representan en el sector poblacional más afectado por número de muertes, sino que se constituyen en un grupo altamente vulnerable a ser cooptado por los actores armados en conflicto. En este sentido, en el capítulo se presentan las bases teóricas para comprender la juventud como categoría social, los procesos de construcción juvenil en el país en relación a la violencia.

Asimismo, en el capítulo examinamos el fenómeno de sicariato y la violencia juvenil como dos tipos de conflictos sociales violentos protagonizados por algunos jóvenes de sectores populares relacionados con la larga historia de conflicto armado y la violencia estructural y cultural característica del contexto colombiano.

La diada juventud y violencia ha tenido un amplio desarrollo académico en el país, los primeros estudios sobre el tema tiene su inicio en la última década del siglo XX; Salazar 
(1990) con su trabajo sobre jóvenes sicarios en las comunas nororientales de Medellín de su libro "No nacimos pa' semilla", un análisis de las pandillas juveniles desde la cultura enfrentados a la reducción de la violencia juvenil a efecto de la injusticia social, al desempleo, la violencia política y la facilidad de dinero que ofrecía el narcotráfico. La investigación de Salazar no ignora esto, sino que se inscribe en un contexto más complejo y de larga duración el tejido socio- cultural en que se insertan las violencias.

También han de nombrarse los trabajos de Carlos Mario Perea, que abrieron camino al análisis de la violencia juvenil señalando que no está únicamente relacionada con la pobreza, la falta de oportunidades, la manipulación adulta, sino que hay en ésta una afirmación de cómo un sujeto que cuestiona el lugar homogéneo que la sociedad ha dado y la exclusión en los lenguajes oficiales. Así como son de gran importancia en este análisis los desarrollos teóricos de Martín-Barbero (1998) y Serrano (2005) los cuales ponen de manifiesto la relación entre prácticas discursivas e identidad juvenil. De este mismo modo, es fundamental el aporte realizado por Riaño (2006) y Alape (2006) en relación a la presencia de la memoria y la violencia en la configuración de la identidad juvenil.

Para la comprensión de la violencia juvenil fue importante adentrarnos en el tema de la juventud, en este análisis este concepto ha sido definido desde diversas perspectivas, desde aquella que consideran que la juventud se define a partir de pertenencia a grupo de edad hasta aquellas que consideran que ser joven se define a partir de una categoría social e histórica. En este estudio nos acogimos a la comprensión de la juventud como una categoría social, dado que reconocemos que en su consolidación se encuentran inmersos diversos elementos relacionados con el contexto social donde se produce, de igual manera, que esta categoría incluye a múltiples maneras de ser joven que se define a partir de los procesos de pertenencia cultural.

El desarrollo teórico nos permitió establecer que la relación violencia y juventud está mediatizada por los imaginarios sociales que han construido la imagen del joven en Colombia desde la amenaza y el "no lugar". La construcción de la identidad se constituye en un proceso complejo de identificación y diferenciación cargado de materiales simbólicos y sociales. Las dinámicas del conflicto armado colombiano han incidido en la construcción identitaria, no como se expresa de manera simple cargando al joven de violencia sino en la complejidad de respuestas en búsqueda de un lugar como sujeto social. 
La violencia acontecida en el país se vio profundizada con el crecimiento del narcotráfico en la década de 1980, con ello, surge el fenómeno del sicariato juvenil, lo cual configura uno de los capítulos más dolorosos del país, la inmersión directa de la población joven evidenció un grave problema social, así como un desafío para la comprensión analítica.

La manera como este fenómeno fue abordado por el discurso mediático, tuvo un efecto innegable en la construcción de un imaginario de discriminación del joven popular, lo cual lo asoció como una amenaza social. Desde esta comprensión este capítulo se ocupó de tratar tanto el fenómeno del sicariato y la violencia juvenil.

Desde nuestro de punto de vista compartimos con los citados autores que la violencia en Colombia se caracteriza por una continuidad de ciclos que a partir de la década de 1950 han puesto de manifiesto la existencia de conflictos no resueltos en las dimensiones estructurales, sociales y políticas del país; que han llevado a la vivencia de más de cinco décadas en medio de la violencia. Dicha situación ha tenido un efecto en las formas como la sociedad construye sus formas de relación social, la significación de los otros y las maneras de resolución de los conflictos. No obstante; la constante referencia a la violencia deja de lado las innumerables prácticas pacificas de la sociedad colombiana que denotan que la historia del país no se reduce al acontecimiento de la violencia.

En relación a la violencia juvenil nos acogemos a las explicaciones expuestas sobre este tipo de violencia por parte de los autores referenciados. Consideramos que Reguillo (2008) aporta a la comprensión del fenómeno a partir de los elementos: crisis de legitimidad política, la erosión de los imaginarios de futuro, el aumento exponencial de la precariedad y la ausencia del proyecto colectivo que caracteriza a las sociedades modernas, así como los aportes de los autores Perea (2004) y Serrano (2005) sobre la falta de reconocimiento como causa de esta violencia, además del concepto expuesto por Cerbino (2006) sobre el déficit simbólico; partimos de que estos conceptos son un avance en la comprensión del fenómeno de la violencia juvenil.

Por último, nos identificamos con las tendencias académicas expuestas en este trabajo que comprenden la juventud como una categoría social y cultural, distanciándose de las conceptualizaciones biológicas y esencialistas, dado que desde la perspectiva cultural se puede entender el sujeto joven desde sus propias concepciones identitarias y las comprensiones del mundo. Nos parece importante sumar a este análisis el elemento 
discursivo como formas desde las que se estructura el sujeto joven desde el lenguaje que se le nombra y él resignifica y da sentido a su ser juvenil. 


\section{CAPITULO III. MEDIOS DE COMUNICACIÓN, CONFLICTO}

\section{ARMADO Y ESTIGMATIZACIÓN JUVENIL EN EL CONTEXTO COLOMBIANO}

3.1. Medios de comunicación y generación de opinión pública.

3.2. El papel de los medios de comunicación en el caso del conflicto armado colombiano.

3.3. Reseña histórica medios de comunicación: EL Espectador, El Tiempo y la Revista Semana.

3.4. Medios de comunicación y estigmatización juvenil.

3.5. La Construcción Social del Enemigo interno en el Discurso Mediático.

3.6. Síntesis. 



\section{CAPÍTULO III. MEDIOS DE COMUNICACIÓN, CONFLICTO ARMADO Y ESTIGMATIZACIÓN JUVENIL EN EL CONTEXTO COLOMBIANO}

En Colombia los medios de comunicación se convierten en las principales fuentes de información sobre el conflicto armado; un tema difícil de tratar por su complejidad, dada la clandestinidad de algunos de sus actores, las estrategias de ocultamiento o visibilidad propias de quienes se encuentran en la confrontación bélica. En este sentido la información producida por la televisión, la radio y la prensa es la fuente de conocimiento sobre uno de los aspectos más preocupantes de la realidad nacional. Estamos haciendo referencia al estado permanente de guerra y la crisis humanitaria que se desprende de esta.

Así, uno de los temas que se hace fundamental abordar es analizar la relación medios de comunicación y conflicto armado interno. Existen en el país investigaciones que han abordado la significación del discurso mediático en relación al conflicto armado. El análisis en este tema se ha centrado en el manejo que los medios han hecho de los procesos de paz vividos en el país, así como del discurso construido sobre actores armados. De esta revisión documental podemos deducir que los medios de comunicación han tenido un papel relevante en esta temática dentro del conflicto colombiano.

A partir de lo anterior surgen una serie de preguntas, tales como: ¿cuál es el papel de los medios de comunicación en el marco de este conflicto? ¿Pueden estos actuar con la objetividad y neutralidad necesaria para producir información real de lo que está sucediendo? En sentido De la Roche (2005) afirma que los medios terminan tomando partido en calidad de actores del conflicto, en virtud de las afinidades políticas con dueños o directores o de las hegemonías político o militares de las regiones donde operan, las cuales les demandan incondicionalidad, neutralidad tolerante o silencio cómplice con el orden allí construido.

Lo anterior nos ubica en uno de los ejes problemáticos en lo que concierne a la producción mediática del país. La necesidad que tiene la población de tener una información clara y precisa frente a uno de los asuntos de mayor interés como es el estado permanente de guerra. El derecho que tenemos como colombianos a conocer lo que sucede es de alguna manera dejado en manos de los medios de comunicación sin mayores reflexiones políticas de las implicaciones que conlleva esta situación. 
Por todo ello, para dar inició a la reflexión teórica, abordaremos la constitución de la opinión pública desde el pensamiento de Habermas (1981) y algunas críticas hechas a su desarrollo teórico, bajo la comprensión de que, a pesar de éstas, se sigue considerando relevante la teorización hecha por este sociólogo alemán sobre opinión pública y esfera pública. Asimismo, se analizará la relación entre Medios de Comunicación y Guerra en el caso específico colombiano, a partir del recorrido académico elaborado sobre el manejo realizado en los medios de comunicación de los procesos de paz llevados en el país y la generación noticiosa de la violencia.

\subsection{Medios de Comunicación y Generación de Opinión Pública}

Los medios de comunicación tienen el poder de informar a la ciudadanía sobre hechos de interés nacional, no obstante, su papel no se reduce sólo a producir información, sino que son generadores de opinión pública. De ahí la importancia de trabajar el concepto de opinión pública, para lo cual es necesario retomar a Habermas (1981). Así, en sus trabajos afirma que la opinión pública se construye dentro de la esfera pública, donde se puede dar la concurrencia de ciudadanos que se relacionan para unirse, expresar y publicar libremente opiniones que tengan que ver con asuntos relativos al interés general; para ello se requiere de la concurrencia de medios de comunicación como: Periódicos y revistas, radio y televisión.

Este autor relaciona el concepto de Opinión Pública con el de esfera pública por lo cual hace un recorrido histórico para determinar el surgimiento de los dos conceptos. En primer lugar, afirma la no existencia de la esfera pública en épocas anteriores al surgimiento del Estado moderno y del capitalismo, puesto que, dentro de los periodos de la monarquía, el poder se concentraba en las cortes y la nobleza, y no existía una interacción de la nobleza con otros sectores de la población. De este modo, la construcción de la esfera pública es un proceso social en el cual la vida pública se va construyendo a través de la interacción de los ciudadanos en lugares como plazas de mercado y asambleas donde se reunían a discutir cuestiones del día. Así, esta interacción generada en el marco de la constitución del Estado moderno configuró una nueva forma de interacción con el Estado que es la esfera pública. Para sus críticos como Thompson (1996) este concepto de esfera pública se reduce a un ámbito abierto de debate en el que aquellos individuos que tenían reconocido por derecho el status de ciudadanos podía interactuar entre sí como iguales. 
El origen de la esfera pública tuvo su parición en el siglo XVI a partir de cambio institucional en Europa, donde la monarquía perdía poder y se inclinaban más por el surgimiento de un Estado moderno, al mismo tiempo que surgía la sociedad civil como una entidad privada por el Estado. Así se constituye una nueva esfera pública denominada por Habermas (1981) como la esfera burguesa; en ella confluían las élites intelectuales y debatían la administración del Estado. Los principios de esta nueva esfera pública estuvieron marcados por la persuasión de la razón.

El surgimiento de la esfera burguesa tiene dos elementos fundamentales a partir de la lectura de este autor; por una parte, el surgimiento del periodismo y de los centros de sociabilidad en los que se debatían temas de interés general, donde las elites intelectuales y la nobleza podían interactuar más o menos en condiciones de igualdad. Este aspecto tiene relevancia en el sentido que el periodismo estuvo vinculado a la posibilidad de tratar cuestiones de interés de los ciudadanos con relación al naciente Estado Moderno.

De otra parte, la congregación de individuos en lugares públicos como cafés u otros centros de sociabilidad donde podían participar en las "críticas" sobre las actividades del parlamento y la corona. En este sentido, el autor enfatiza sobre la importancia de la separación entre lo público y lo privado, observando que las transformaciones se generan en el espacio de lo público.

Un aspecto fundamental desarrollado por Habermas (1981), sobre la temática que estamos abordando tiene que ver con la conformación de la publicidad, como un elemento que transformó las propias intenciones de hacer política, en tanto tiene un papel mediador entre el Estado y la sociedad. El autor lo expresa de la siguiente manera:

Conforme a la opinión pública existe al mismo modo disposiciones en torno a la publicidad (...) la esfera de lo público como mediadora entre la sociedad y el Estado, en la que se forma como concurrencia pública de la cual corresponde el siguiente principio, cada publicidad que debió realizarse en contra de la política enigmática de los monarcas permite el control democrático de la acción estatal”. (p. 124)

Para este autor la importancia de la publicidad y los medios de comunicación radica en el poder de generar opinión pública, así como la instrumentalización por parte de los poderes políticos, argumentando que la prensa no tenía como única función la presentación de 
noticias, sino que se tornaron en portadores y líderes de opinión pública, así como se convirtieron en medios de lucha de los partidos políticos.

Lo anterior pone de manifiesto el poder de la esfera burguesa como una posibilidad de democratizar el Estado, a partir de la teoría de la persuasión a través del ejercicio realizado en ese momento por los periódicos existentes en la época, la base de la teoría comunicativa se concentra en la persuasión que pueden hacer los "públicos" a la gestión de sus gobernantes, para este autor la esfera pública se iría transformando de tal manera que se consolida como actor crítico de esta gestión.

Esta postura ha llevado a numerosas críticas, entre ellas destacamos la de Thompson (1996): en la que pone de manifiesto el desconocimiento de la existencia de otros públicos además del burgués, ya que a la par existió una esfera plebeya que se constituyó de manera antagónica y conflictiva. De ahí que, el declive de la esfera burguesa tiene que ver con la conflictividad de estos públicos.

El carácter universal y masculino de la esfera pública, donde únicamente los hombres estaban capacitados para del debate desconocía la capacidad de la mujer para participar en los temas de interés político. Thompson (1996) afirma que, aunque este debate es reconocido por Habermas en sus trabajos no lo realiza en el sentido que debía plasmarse, puesto que éste es considerado como un asunto secundario. Ahora bien, la Escuela de Frankfurt lo crítica, ya que la ausencia de lo femenino en la esfera pública no era un asunto de segunda clase sino era un principio fundamental de cómo la esfera burguesa concebía lo público.

En definitiva, la crítica más profunda desarrollada por la Escuela de Frankfurt pone de manifiesto que la opinión pública no puede ser generada únicamente por la prensa, y de este modo no se dará una transformación en el Estado moderno a partir de la publicidad y la influencia de la esfera pública. No obstante, en el tema que nos ocupa resulta valido preguntarnos ¿cuál es el papel de los medios en la construcción de la opinión pública del joven popular?

Al respecto, creemos que los medios de comunicación han contribuido de manera clara en la instauración de un constructo social del joven como amenaza social en Colombia. La argumentación a esta afirmación la hemos construido a partir de la constatación teórica de la existencia de una imagen perturbadora del joven popular en la nación. Así Riaño 
(2006) retomando a Martin-Barbero (1998) quien afirma que el hito de surgimiento de dicha imagen se da en 1984 con la publicación en los medios de comunicación de la foto de un joven de 16 años herido y capturado tras haber asesinado al ministro de justicia Rodrigo Lara Bonilla. Ello pone de manifiesto la necesidad de una reflexión acerca de cómo la economía del narcotráfico involucraba a la población joven de sectores populares en el ejercicio de la violencia.

La presentación por parte de los medios de comunicación de todo el mundo del asesinato del Ministro de Justicia, hizo énfasis en la violencia juvenil, extendiéndola a todos los jóvenes de los sectores populares, y ofreciendo una imagen de peligro sin reconocer las causas sociales y culturales de esta violencia. Además, se generó un discurso donde el joven aparecía sin capacidad de pensar por sí mismo y por ello presa fácil para convertirlos en asesinos a sueldo. Esta manera de ver lo sucedido deja de lado, no sólo el análisis de la influencia de las estructuras socioeconómicas, sino también los marcos emocionales y culturales, así como la falta de reconocimiento de este sector social en la generación de esta violencia.

La constante violencia que ha vivido Colombia ha conllevado diversos problemas para construir la alteridad. La violencia del joven sicario pone de manifiesto la dificultad de la juventud para sentirse reconocida por la sociedad, de esta manera se pone en evidencia un asunto problemático, las fracturas sociales producidas por la exclusión social del joven popular y la dificultad para la resolución de conflictos de manera pacífica en el contexto colombiano.

¿Cuál es la intencionalidad mediática cuando se desconoce que en ese momento cientos de jóvenes en las comunas de Medellín y el resto del país daban una intensa lucha por su reconocimiento a través del arte y la acción social?¿por qué se omite su trabajo intenso por evitar ser incluidos en la violencia, o $\dot{i}$ la cotidianidad en la cual la población joven realiza sus estudios? o $\Varangle$ el ingreso temprano al mundo laboral? ¿ por qué no tiene lugar en este discurso las vicisitudes que enfrenta la juventud en su día a día?. La respuesta a estas cuestiones requiere realizar en Colombia un debate. Y esto constituye una de las deudas que la Academia tiene con la juventud popular.

En este recorrido esperamos encontrar las raíces de estas tendencias inmediatistas, no contextualizadas para nombrar a la juventud popular. Suponemos que estas respuestas están más allá de la idea que el sensacionalismo y dramatismo resultan más rentables para 
los medios de comunicación, esperamos encontrar las razones profundas en relación a la producción mediática discriminatoria del joven popular y el interés del público receptor por el contenido de este tipo de información estigmatizadora sobre esta población.

También tenemos que reconocer que no todos los medios de comunicación tienen estas formas de presentar la noticia, Así, contamos con medios y periodistas que se han ocupado de mostrar la realidad, aunque sometidos a estar en los horarios menos favorables o incluso al cierre de noticieros o a la persecución política de periodistas que los ha llevado al exilio.

Si bien, lo propuesto por Habermas $(1981,1990)$ sobre el papel de la prensa en el control al Estado por parte de la esfera pública, ha tenido numerosas críticas, por considerarse que no es suficiente la influencia de la prensa para la construcción de la opinión pública y la transformación del Estado. En el caso de la construcción del joven popular como amenaza social asumimos como relevante dicha idea para entender como desde el discurso mediático se configura la nominación de un sector social desde la amenaza; sin embargo, esto no es suficiente para comprender la magnitud del problema. Es prioritario reflexionar sobre las condiciones para que el discurso mediático tenga el poder de generar los imaginarios sociales concebidos como realidad, ya que se encuentran anclados en la sociedad como formas de interacción social.

El concepto de la publicidad crítica expuesto por este Habermas (1981), es decir una opinión pública reflexiva ante la información producida por los medios y las instituciones, es un elemento importante para comprender la producción mediática del país y la forma como estamos interpretando y asimilando los colombianos la información proporcionada a través de los medios de comunicación. Un paso necesario es conocer los avances académicos realizados sobre el manejo de los medios de comunicación de la situación de conflicto armado interno y la crisis humanitaria vivida por el país.

\subsection{El Papel de los Medios de Comunicación en el Caso del Conflicto Armado Interno Colombiano}

En Colombia asistimos a un Conflicto Armado Interno por cinco décadas, este largo periodo de confrontación bélica ha experimentado innumerables hechos de violencia, el acceso a dicha información ha estado en manos de los medios de comunicación. En mayor medida la información ha sido suministrada por la televisión caracterizada por tener la 
mayor audiencia, así como por ser el medio más visto por las clases populares, antes que la radio y la prensa.

El tema de Medios de Comunicación y conflicto armado ha recibido atención por varios autores, es de resaltar los trabajos de De la Roche (2005) sobre el manejo de los medios de comunicación en los procesos de paz llevados a cabo en el país con guerrillas de izquierda, así como los desarrollos académicos de Jorge Bonilla sobre los medios de comunicación, conflicto y esfera pública; además de sus investigaciones sobre medios de comunicación y procesos de paz. José Martin Barbero, quien en sus trabajos ha analizado la apropiación de imaginarios a partir de los discursos mediáticos. Por último, son relevantes los recientes trabajos desarrollados por Sierra (2001) sobre las normas de conducta de los periodistas en la información acerca del conflicto armado recogidas en el acuerdo de discreción firmado por dueños y directores de medios de comunicación en Colombia.

La importancia de estos trabajos para esta investigación radica que a partir de ellos podemos revisar las tendencias de información en el contexto nacional, las características que poseen los medios de comunicación a la hora de informar situaciones particulares de la situación de violencia del país, así como las tendencias informativas para ofrecer la información a los ciudadanos. En este sentido De la Roche (2005) afirma que:

"El periodismo y los medios de comunicación, en su cubrimiento noticioso y de opinión del conflicto armado interno, de los procesos de paz pasados y futuros y de las posibilidades de reconciliación nacional, constituyen un campo de tensiones sociales e institucionales, como también de presiones de parte de distintos actores político- militares. Así mismo ellos funcionan como un importante lugar de encuentro de experiencias, ideas, perspectivas y propuestas de distintos grupos sociales, nacionales e internacionales que participan hoy en la discusión del presente y futuro de sociedad”. (p.1)

El autor expresa la existencia de tensiones en la tarea que realiza el periodista en Colombia. Por un lado, las presiones de distintos actores del conflicto, los cuales intentan incidir en la información presentada por los medios de comunicación, ya sea a través del ocultamiento o la exposición de hechos de acuerdo a la manera más conveniente para su estrategia de guerra. De otra parte, existe una segunda tensión derivada de las relaciones de directores y dueños de medios de comunicación como empresarios o políticos de gran 
representatividad en el país con intereses relacionados con el conflicto. Así lo expresa el propio autor:

(....) los medios terminan tomando partido en calidad de actores del conflicto, en virtud de sus afinidades políticas de sus dueños o directores o de las hegemonías político- militares de las regiones donde operan las cuales la mandan incondicionalidad, neutralidad, tolerante al servicio cómplice con el orden allí construido(p.19)

En el mismo sentido Serrano (2006) observan que los medios de comunicación en el contexto colombiano se convierten en objetos de interés de los diferentes actores armados dada su capacidad de generar opinión pública entorno a la guerra y con ello lograr la legitimación de las acciones bélicas, así como las ideologías que legitiman su participación en la guerra. De este modo el poder de la información es uno de los elementos más codiciados por los actores en confrontación.

De otra parte, existe una utilización de los medios de comunicación por parte de sectores oficialistas como forma de promover estrategias político- militares abanderadas no sólo por actores en conflicto, sino también por sectores políticos, gremios y dueños de medios de comunicación.

Dentro de esto es muy importante reconocer que en contextos de guerra existe una lucha por lograr el reconocimiento y legitimidad por parte de la población civil. Para los ejércitos en confrontación resulta una ganancia tener un lugar en la producción mediática, como posibilidad de legitimar sus acciones, ideologías y estrategias bélicas o sencillamente, por la posibilidad de desprestigiar a su enemigo. En este sentido es fundamental asumir que la contienda entre ejércitos no sólo se da en espacios de confrontación armada, sino que también es una lucha en los terrenos del discurso.

Así, hemos asistido en el caso colombiano a numerosos hechos mediáticos donde las disputas se hacen evidentes. Por citar un caso. las liberaciones de secuestrados sucedidas a partir del año 2006, se efectuaron tras intensos y largos procesos de negociación por parte de miembros de la sociedad civil y los organismos internacionales de acción humanitaria, gobiernos de países amigos, además de sectores políticos comprometidos con el dolor de las víctimas y la esperanza a una salida negociada al conflicto. 
La búsqueda de la humanización del conflicto de organizaciones de la sociedad civil no en pocos casos fue desprestigiada por los medios de comunicación que actuaban a favor de la visión del gobierno. Asimismo, observamos el papel de la Insurgencia en cuanto a conseguir el reconocimiento de su intención de paz por parte de la sociedad civil. Todo ello para demostrar que, a pesar de la propaganda del gobierno, ellos no eran un grupo derrotado y sometido a vivir en los recónditos lugares de las montañas del país, sino que tenían, incluso, capacidad de negociación con el mismo gobierno.

Todo lo anterior está contrastado con las imágenes y narrativas de dolor sobre los secuestrados, la utilización de historias conmovedoras tanto de la vida de sus familias como de las propias víctimas del secuestro. La competencia por mostrar las escenas más dramáticas se convirtió en una de los mayores retos, especialmente para las cadenas televisivas encargadas de hacer la transmisión en directo del retorno de los secuestrados a la libertad.

Además de las presiones por intereses políticos, económicos y sociales la información sobre el conflicto se encuentra en disputa desde sus aspectos semióticos. Así, tal como lo afirma Bonilla (2003) la guerra es una forma extrema de lucha donde se enfrentan antagonismos con diversos intereses no sólo en la búsqueda de movilizar armamentos, ganar golpes militares sino la gestión de significados en tanto no sólo son máquinas de producción de muerte sino también de producción de sentido.

Lo anterior nos lleva a pensar en que la guerra tiene como objetivos lograr legitimidad a través de estrategias semióticas. En la experiencia colombiana hemos asistido a innumerables hechos bélicos realizados con el fin de lograr reconocimiento, es así como acciones de guerra son efectuadas contra personas o lugares representativos para demostrar el poder de algunos de los ejércitos beligerantes. Además, los actores en confrontación al tener acceso a los medios de comunicación hacen uso de estrategias simbólicas a través del lenguaje, tales como tocar las fibras más emocionales de la ciudadanía en la búsqueda de reconocimiento o de sembrar el terror.

Lo expresado por este autor nos lleva a pensar sobre la importancia de asumir las dimensiones culturales en los análisis de medios de comunicación; de modo que cuando distintos órdenes están enfrentados y las representaciones simbólicas están en disputa las definiciones sobre la guerra y la paz son variadas, ambiguas y ambivalentes. Desde ahí se pueden plantear diferentes posturas a los medios de comunicación. 
En el contexto del conflicto colombiano se presentan versiones confrontadas acerca de los temas de paz y violencia. Para algunos la paz se gana a través de la violencia propuesta por los dos gobiernos. Para otros la paz se logra a través del dialogo. A su vez entre estas dos posiciones se encuentran una serie de matices en orden a definir los significados de paz y violencia. No se trata sólo de una pluralidad de sentidos sino de una conflictiva lucha por la definición de estos términos, desde los cuáles se asumen acciones políticas. De esta manera el discurso mediático sobre paz y guerra es fragmentado y contradictorio y por ende las comprensiones de los colombianos sobre el discurso mediático en estos temas guardan un sentido fragmentado, contradictorio y ambivalente.

Siguiendo a Bonilla (2003) la guerra requiere de un régimen comunicativo para su subsistencia, por tanto, se ve en la necesidad de producir y reproducir un modelo de comunicación. Siempre esto estará mediado por la intencionalidad de los guerreros por hacer más o menos visibles sus acciones de acuerdo a la conveniencia de las mismas.

Es necesario agregar a la observación de este autor la participación en el conflicto de actores no armados como son: los sectores políticos y los gremios, quienes junto con las presiones internacionales influyen en la producción noticiosa sobre el conflicto.

Otro aspecto fundamental en este análisis es el acceso de las fuerzas políticas existentes en el país a los medios de comunicación, ante la existencia de medios privados en Colombia con dueños y directores inclinados hacia las corrientes políticas tradicionales, liberales o conservadores. De esta manera quedan excluidas las fuerzas políticas alternativas dentro de los medios de mayor difusión.

El acceso a las fuentes de información es otro de los temas relevantes a la hora de pensar el papel que cumplen estas organizaciones de la comunicación y las normas y reglamentaciones que en caso de conflicto están enmarcadas en el periodismo. Es así, como, por ejemplo, puede ser penalizado el profesional que tenga como fuente de información a un comandante guerrillero; esto implica que una parte de la realidad no está siendo conocida por el país. Tal como lo expresa Serrano (2006) retomando a De la Roche (2002):

En el caso colombiano, los actores armados que representan al Estado consideran que los medios de comunicación deben ser incondicionales con ellos porque son legítimos y representan el orden social establecido. Como el 
gobierno y los actores armados que lo representan gozan de cierta legitimidad, pueden reglamentar la aparición de la guerrilla y de los paramilitares en los medios de comunicación. Si los periodistas sólo pueden acceder y publicar lo que las fuentes oficiales comunican, los medios de comunicación terminan reproduciendo el orden social dominante negando así la posibilidad de expresión mediática a cualquier alternativa política y/o social. (p.4)

En este sentido nos hacemos una pregunta clave ¿cómo podemos construir la visión de un país incluyente, si sólo podemos tener acceso a una visión parcializada de la realidad con la que se identifican las clases gobernantes, elites y los gremios? La necesidad de encontrar una salida negociada del conflicto, así como las maneras para lograrlo requieren del conocimiento de la realidad de lo sucedido, sólo así podremos lograr reconocer las pluralidades políticas para construir el futuro deseado.

¿Cómo podemos los colombianos comprender un conflicto de tan grandes dimensiones si no poseemos el acceso a fuentes plurales que nos permitan conocer las aristas de tan compleja confrontación bélica? ¿Cómo soportamos sus efectos que nos fragmentan como nación? Serrano (2006), retomando (Sabucedo \& Alzate, 2005), afirma que no dar acceso en los medios a otras alternativas políticas en una sociedad es un elemento desencadenante de conductas violentas, así como de la aparición de guerras y conflictos.

Esto pone de manifiesto la importancia del debate que se está dando en el país sobre la "neutralidad" y la "objetividad" para los periodistas en el caso de un país en conflicto armado interno, bajo las diversas presiones que este contiene. No obstante, es necesario reconocer como lo dice De la Roche (2005), la libertad de prensa en ningún país, ni en los más pluralistas está asegurada, son innumerables las presiones que se reciben desde los diversos actores (económicos y políticos), y por tanto no podemos partir de la premisa de que la guerra es el único factor que impide la libertad de prensa.

En contextos de conflicto armado se presentan elementos inhibidores de la libertad de prensa, esto no quiere decir que los medios y los periodistas sometan obligatoriamente su labor a las presiones de actores en conflicto o a los intereses de sectores de poder. Un buen número de periodistas decide informar desde códigos éticos enmarcados en la veracidad, la búsqueda de "objetividad", si bien es cierto que existe una dificultad mayor para informar en estados de guerra. Ahora bien, no podemos dejar de lado que los 
periodistas, de acuerdo a sus concepciones éticas, tienen cierto margen de decisión respecto a la información que emiten.

De igual manera, tal como lo advierte De la Roche (2005) a los medios de comunicación no se les puede asignar la responsabilidad total de la información que producen sobre el Conflicto Armado Interno; ellos sólo actúan como coproductores de información con otras instituciones que ofrecen la información y reaccionan frente a ella. Este elemento es crucial para comprender el compromiso de otros sectores en la producción de la información originaria emitida por los medios de comunicación, entre otros, las fuerzas militares, los entes gubernamentales, los ejércitos en confrontación.

En definitiva, los medios de comunicación se encuentran inscritos en un campo en disputa por la definición semántica de la realidad:

- por dar prioridad a unos elementos sobre otros.

- por determinar el sentido del discurso de actores en confrontación en medio de una diversidad de intereses,

- por lograr dar prioridad a sus discursos,

- por posicionar sus propias concepciones

Teniendo en cuenta lo expuesto anteriormente, los periodistas y los medios de comunicación no pueden desviarse de las normas reguladoras de su labor, bajos los argumentos de las presiones a las que están sometidos.

Tras décadas de experiencia en la producción de la información derivada de la guerra el periodismo en Colombia ha adquirido algunos aprendizajes en la labor de cubrimiento de los temas de paz y del conflicto. Tal como lo explica De la Roche (2005) son producto de la reflexión académica y la apertura de algunos medios de comunicación colombianos. A partir de ahí se han construido algunos principios básicos del periodismo tales como: los equilibrios informativos, la objetividad, el distanciamiento crítico de las fuentes oficiales, la superación del unifuentismo, la defensa de la verdad en la construcción de la fuente noticiosa, el compromiso con el ejercicio de la profesión.

Esto significa un logro importante en la búsqueda de una labor periodística ética y consecuente con las necesidades del país. No obstante el cumplimiento de estas normas se da de manera desigual, ya que intervienen algunos factores que condicionan dichas normas, entre otros destacamos: la voluntad de los directores y dueños de los medios de 
comunicación donde se lleva a cabo el ejercicio periodístico; las características de la región del país donde se desarrolla la labor periodística, ya que en las ciudades grandes los periodistas cuentan con un mayor margen de acción que en los pueblos alejados, donde son más afectados por las presiones de actores armados o grupos de poder.

Por todo ello queremos poner de manifiesto que, realizar el cubrimiento en medio de un conflicto tan extenso como el colombiano no es una tarea fácil, ya que tiene grandes desafíos y la producción mediática se puede ver influenciada por diversas presiones; pues la posibilidad de hablar de un conflicto dentro del mismo trae consigo sus propios obstáculos.

Entre los esfuerzos por lograr una información más consecuente con las necesidades del país, en noviembre de 1999.se llevó a cabo el Acuerdo por la Discreción firmado por 32 directores de medios de comunicación. Dicho acuerdo establece normas para la presentación de la información acerca del conflicto armado presente en el país, con el fin de elevar la calidad noticiosa relacionada con hechos de violencia.

Serrano (2006), sintetiza los puntos de acuerdo a los que llegaron los directores, además de presentar los problemas que existían para que esos puntos fueran de vital importancia en el establecimiento de dicho acuerdo. En ellos se consideran aspectos como la veracidad de la información, la transmisión en directo de hechos relacionados con el conflicto armado, las razones éticas y de responsabilidad social, los criterios de regulación de imágenes y fotografías y el respeto por el pluralismo ideológico. Todos estos puntos están resumidos en la tabla 1 . 
Tabla 1. Síntesis sobre los puntos de acuerdo por la discreción

\section{Acuerdo por la discreción}

Práctica Periodística criticada

1. El cubrimiento informativo de los actos violentos, ataques contra poblaciones, masacres, secuestros $\mathrm{y}$ combates entre los bandos será veraz responsable y equilibrado para cumplir con este propósito cada medio definirá medios de actuación profesional que fomenten la calidad del periodismo $\mathrm{y}$ beneficien al público.

2. No presentaremos rumores como si fueran hechos. La exactitud que implica ponerlos en contexto debe primar sobre la rapidez.

3. Fijaremos criterios claros sobre la transmisión en directo, con el fin de mejorar la calidad de la información y evitar que el medio sea manipulado por los violentos.

4. Por razones éticas y de responsabilidad social no presionaremos periodísticamente a los familiares de las víctimas de hechos violentos.

5. Estableceremos criterios de publicación de imágenes y fotografías que puedan generar repulsión del público, contagio con la violencia o indiferencia ante esta.

6. Respetaremos el pluralismo ideológico, doctrinario y político. Utilizaremos expresiones que contribuyan a la convergencia entre los colombianos. Preferimos perder una notician antes que una vida.
Los medios de comunicación reconocen que siempre verifican la información que proveen $\mathrm{y}$ tienden a favorecer a ciertas posiciones.

Por favorecer ciertas fuentes informativas y por el síndrome de la chiva, los medios no verifican, ni contextualizan la información.

La transmisión en directo va en detrimento de la calidad informativa. Los medios son manipulados por los actores armados.

La competencia comercial es resultante del síndrome de la chiva conlleva a los periodistas a irrespetar a las víctimas de los hechos violentos.

El sensacionalismo y amarillismo pueden llevar a los medios a difundir imágenes que aporta valor informativo.

El uso del lenguaje no es equilibrado, se favorecen ciertas posiciones, desconociendo otras posibles. 
Lo anterior pone en evidencia que los problemas que existen en Colombia referentes al Conflicto Armado Interno. Como ya lo habíamos tratado uno de los aspectos más importantes es la incapacidad que ha tenido el periodismo para recoger la pluralidad de visiones propias de este conflicto. Este aspecto es necesario para poder tener en cuenta las dimensiones de la confrontación bélica y hablar desde su realidad.

Los cuestionamientos de Serrano (2006), al acuerdo para la discreción se basan en la falta de claridad en la definición de conceptos como: veraz, responsable, equilibrado, porque en el acuerdo no se especifican cuáles son los comportamientos profesionales y las condiciones adecuadas para lograr el equilibrio informativo. En este sentido cabe una amplia reflexión acerca de cómo construir unos criterios sobre el manejo de la información procedente del conflicto armado interno; esto significaría crear los mecanismos propios para lograr el cumplimiento de estas normas.

Uno de los puntos éticos trabajados en el acuerdo y que hace parte de los aspectos éticos en los que se enmarca el periodismo es la "objetividad" como un deber ser. Serrano (2006), afirma que La "objetividad" es una norma discursiva creada para despolitizar la información, es decir, los periodistas se limitan a exponer los hechos sin expresar comentarios alrededor de los mismos. El ejercicio de la objetividad requiere de la independencia respecto a los medios de comunicación, de los partidos políticos, de los gremios económicos o grupos de interés. Actualmente en Colombia, la comunicación no tiene esta independencia, los medios en su mayoría son privados con dueños de claras tendencias políticas de derecha.

De otra parte, la objetividad debe ser entendida más allá de la omisión de comentarios en la presentación de la información; el debate requiere asumir asuntos como la selección de la noticia, el lenguaje usado para su presentación, la recurrencia a varias fuentes de información, el dar acceso en equidad a diferentes grupos implicados en la situación; todos estos aspectos en el caso colombiano aún son incipientes.

Una de las debilidades del contexto de los medios de comunicación colombianos es la alta privatización, ante lo cual los medios tienen la exigencia del cumplimiento de los índices de audiencia, lo cual conlleva a la búsqueda de estrategias de fidelización del público. Tal como lo afirma Serrano (2006), el hecho de que las principales empresas periodísticas del país sean privadas somete la labor periodística a la rentabilidad económica en detrimento de la veracidad de la información presentada. Así, concluimos 
que, el Acuerdo de Discreción presenta muchos obstáculos para su cumplimiento, ya que no es acorde con la realidad del contexto de guerra y no reconoce la presión de los actores armados, de modo que los medios recibirán en menor y mayor medida la influencia de estos actores. El desconocimiento de este hecho es una falta de honestidad con los ciudadanos y con ellos mismos.

De otra parte, la información presentada en Colombia en relación al conflicto armado interno y la paz ha presentado muchos problemas tales como: la concentración de los medios de comunicación en ciertas noticias sobre el conflicto armado, mientras se soslayan otras noticias de interés nacional sobre todo cuando la información tiene efectos de carácter político en detrimento del derecho de los ciudadanos a estar informados sobre las decisiones y asuntos de interés nacional.

A pesar de los esfuerzos hechos en el país para mejorar la calidad de la información sobre el conflicto armado y la paz en el país, el periodismo sigue teniendo grandes dificultades para su realización, aún tiene muchos desafíos para la optimización de su labor con relación al cubrimiento del Conflicto, De la Roche (2005) afirma que en el país se siguen priorizando las escenas dramáticas y exposiciones al dolor de las víctimas que abundan en la nación. Este estilo de información busca la atención de la ciudadanía mediante la manipulación de las emociones, desconoce elementos fundamentales de respeto a la dignidad de las víctimas, particulariza la violencia, descontextualiza la situación de las víctimas, sus capacidades sociales de manejar el dolor. Así este tipo de información lleva consigo la tendencia de mostrar las víctimas como un dato estadístico sin conexión con los hechos y factores sociales, políticos y culturales que definen a las mismas.

Otros problemas que se le asignan al periodismo en contexto de guerra se expresa en el inmediatismo que conlleva a la búsqueda de la "chiva", es decir en ser el primer medio en contar lo sucedido, lo que conlleva a la competencia entre los periodistas y medios de comunicación. Como lo expone Serrano (2006) retomando a De la Roche (2003), la competencia entre los medios y las presiones de fuentes oficiales conducen a la homogeneización de la información, y las agendas informativas, bastante reducidas, enfatizan las malas noticias porque desde el imaginario social las buenas noticias no son atractivas. Bonilla (2003) retomando a Bourdieu (1967) afirma que:

La competencia lejos de ser automáticamente generadora de originalidad y diversidad tiende a menudo a favorecer la originalidad de la oferta. De ahí 
que los mayores esfuerzos para desembarcarse de la homogenización informativa consistan precisamente en exacerbar el afán por la primicia que es el afán por la diferenciación de otros que son iguales. Lo que por cierto va más allá del error. (p.62)

Para De la Roche (2005), el periodismo en Colombia presenta características de dramatismo, sensacionalista y coyunturalista con respecto a la presentación de la noticia relacionada con el Conflicto y las diferentes apuestas de paz. Así como éste carece de seguimiento a la información presentada; lo anterior pone en evidencia la ausencia de trabajo editorial de la noticia. Otro aspecto ausente en el discurso mediático sobre la guerra y la paz es la falta de análisis académico, no se recurre a la opinión de expertos en el tema y cuando se acude a ellos se realiza en espacios muy cortos.

En este mismo sentido Bonilla (2003), observa que, a modo de hipótesis, las agendas mediáticas - especialmente - de televisión se están confeccionando desde la prensa sensacionalista. El autor pone sobre la mesa un debate importante: la necesidad de analizar el nuevo sentido del régimen comunicativo, en el cual se da visibilidad a las tragedias y horrores en relatos mediáticos cargados de banalidad, fragmentación, destemporalidad, incertidumbre y espectáculo, al igual que los nuevos modos de miedos y sus viejas maneras de agenciarlo presentes en los géneros y formatos aparentemente más débiles políticamente hablando del docudrama y la televisión real que llaman al consentimiento social desde la resignación, el fatalismo y la retirada. En ese sentido se pregunta por el tipo de códigos culturales que configuran el discurso mediático.

La información producida por los medios en Colombia está enmarcada en la inmediatez, así como los temas acerca del conflicto son tratados de forma coyuntural, es decir basándose en la información en el momento sin conectar los hechos con situaciones anteriores que permitan comprender sus características históricas, así como aquellos aspectos que impiden que la violencia sea vista en su integridad. De este modo, todo lo dicho anteriormente nos remite a otro de los elementos que habla de la comunicación sobre el conflicto, es decir, la presentación de actos de violencia o de paz sin conexión con la historia y dinámicas del conflicto.

Para analizar lo dicho anteriormente, un aspecto fundamental es la participación del periodista en la forma como define la noticia, Así, Serrano (2006), pone de manifiesto que es el periodista quien toma las decisiones sobre como presentar los hechos y darles 
el lenguaje oportuno con el que es relatado; sí además se tienen en cuenta las condiciones laborales en las que los periodistas desarrollan su trabajo (bajos salarios), hace que estos presenten noticias de "tinte amarillista" para conseguir la audiencia necesaria.

También es necesario recoger aquí una situación propia del papel mediático en el conflicto armado colombiano, dada su larga duración y las huellas dejadas, así como las pocas posibilidades que como colombianos hemos tenido para la reconciliación. En este sentido, la existencia de heridas no resueltas ha llevado a que algunas tareas periodísticas se realicen desde estos sentimientos. Tales heridas quedan reflejadas en la en la labor periodística; en tal circunstancia se pierde la capacidad de análisis de lo que significa la guerra. También esta información estuvo caracterizada por la evidente toma de partido de los periodistas como lo expresa De la Roche (2005):

Lo que observamos a menudo durante los tres años del proceso de paz, bajo la administración Pastrana, fue la toma de partido a favor del Estado de las visiones de empresarios dueños de los medios y la presencia desmedida de fuentes de opiniones oficiales consultadas, reproducidas muchas veces como si fueran palabra de Dios" (p.10)

A partir de lo anterior se requiere situar el análisis de la responsabilidad social sobre la comunicación social frente a un tema tan delicado como el del conflicto y el estado de guerra presente en el país. El entramado de relaciones e intereses presentes en este contexto merece un debate profundo en el propio país. La experiencia vivida en medio de esta confrontación es paradójica por un lado los medios han cumplido una función necesaria en el fin de informar y de otro lado, han tenido dificultad para consolidar una información independiente y veraz.

El uso del lenguaje centrado en el dramatismo es una muestra de la incapacidad de los medios para cumplir con del deber de informar; el sufrimiento dejado por la guerra en Colombia no puede ser mostrado de manera fragmentada, parcializada, sin contexto; esta manera de mostrar la realidad sólo conlleva a profundizar en el sufrimiento de los colombianos.

No podemos afirmar de manera tajante que el periodismo en Colombia ha sido absolutamente víctima de estas presiones de intereses producto de la guerra, es de anotar que muy a pesar de las presiones, existen líneas del periodismo que se deciden por mostrar 
una realidad desde diversas fuentes, reconociendo la pluralidad de visiones y experiencias, encargándose de dar una visión más integral de lo sucedido. Aún con todos los problemas que tiene el periodismo en Colombia, no podemos hacer una lectura unívoca de su trayectoria, ya que en el transcurso de estos años ha mostrado, al menos, una parte de la realidad de uno de los conflictos más complejos del mundo.

La responsabilidad de informar sobre la violencia ha quedado en manos de los medios de comunicación, es importante hacer el debate sobre el compromiso de regulación de la acción periodística. Así, dos preguntas son necesarias, ¿en qué manos se encuentra esta función? y en el contexto de guerra colombiano donde interactúan tantos actores ¿cómo se logra la imparcialidad requerida en favor de una información más democrática?

En el tema que nos compete, es fundamental ver las implicaciones que tiene el discurso mediático en la configuración de imaginarios sociales. En este sentido, hay que retomar lo expuesto por De la Roche (2005), en relación a que los medios tienen que tener cuidado con las pasiones y los estados de ánimo que propician y alimentan con sus mensajes, ya que los propios abusos de los actores del conflicto han dejado dolores y sentimientos de sufrimiento. Esta reflexión es muy necesaria si tenemos en cuenta la fragmentación dejada en la sociedad a causa de la guerra, pues una información cargada de significados emocionales conlleva a exaltar más sentimientos de dolor y una mayor fragmentación de la sociedad.

Los medios de comunicación tienen grandes retos en el reconocimiento de las acciones de las organizaciones en la búsqueda de paz. Las cuales han sido estigmatizadas en los discursos mediáticos, menospreciando el valor de ello para la sociedad colombiana; de modo que la construcción de una comunicación adecuada a un país en situación de conflicto debe acoger las iniciativas existentes en temas de paz.

De igual manera, es pertinente que tanto la guerra como la paz sean analizadas por los medios de comunicación desde las dimensiones presentes: reduciendo las estigmatizaciones a ciertos sectores, reconociendo la participación de cada uno de los ejércitos en la violación de los derechos humanos de la sociedad, asumiendo el dolor en su dimensión social y política, y finalmente en la búsqueda de la transformación en acciones solidarias y de justicia. 


\subsection{Reseña histórica de los medios de comunicación: El Espectador, El Tiempo y la Revista Semana}

En este análisis tenemos en cuenta la información proveniente de tres medios de comunicación: los periódicos: El Tiempo; El Espectador y la Revista Semana, a continuación, desarrollaremos una breve reseña histórica de cada uno de éstos, con el fin de establecer algunos rasgos del componente ideológico y su influencia en el discurso producido sobre la violencia contra los jóvenes.

\section{- El Espectador.}

El periódico El Espectador fue fundado por Fidel Cano Gutiérrez en el año de 1887, en la ciudad de Medellín, En sus inicios realizó publicaciones dos veces por semana. Posteriormente se convirtió en diario hasta el año 2000 se produciría como semanario debido a una crisis económica hasta en mayo del 2008 cuando volvió aparecer como Diario.

En sus inicios este medio de comunicación promovió las ideas liberales por lo cual fue sancionado varias veces por los gobiernos de corte conservador de Rafael Núñez (18841886), Carlos Holguín, no obstante, el periódico reapareció el 12 de febrero de 1891, luego de nuevas confrontaciones fue clausurado otro par de veces. Por divergencias con el gobierno de Rafael Reyes (1904-1909) fue clausurado en diciembre de 1904 y dejo de circular hasta el año 1913.

En 1915 se inicia una publicación simultánea en Bogotá, edición que se sigue publicando hasta este momento, la publicación de Medellín se suspendió en el año de 1923. Tuvo varias sanciones en la época de la Violencia en Colombia. Es así como en 1948, dado los hechos de violencia derivados del asesinato de Gaitán, el periódico tuvo que suspender su circulación por tres días. Desde este momento, el periódico debió someterse a la censura del gobierno conservador, entre estas es de anotar el decomiso de la edición en 1949, que conllevó a la renuncia de su director como protesta por estos hechos.

En 1952 sus oficinas fueron saqueadas y parcialmente destruidas junto a las casas de algunos dirigentes políticos del país. En 1955 el diario tuvo una posición crítica frente al gobierno del general Rojas Pinilla, en represaría el gobierno culpó al periódico por supuestas irregularidades contables, además de la prohibición de publicar algunas editoriales. Dicha persecución llevo a que las directivas del periódico suspendieran la 
publicación del Espectador y en su reemplazo se creará: El Independiente, que apareció en 1956 y en este mismo año se cerró por la censura política a su director Carlos Lleras Restrepo que era acusado de conspirar contra el régimen militar.

En 1957 reaparece El Independiente bajo la dirección de Guillermo Cano, en mayo de 1957, de común acuerdo con los principales periódicos; El independiente clausuró sus publicaciones; el 10 de mayo de 1957 Rojas Pinilla renuncio y fue reemplazado por la Junta Militar, El Independiente reapareció ese mismo y circulo hasta el 1 de junio de 1958, fecha en la cual regreso El Espectador.

En la década de 1980, El periódico se mantuvo como fuente de información y mostró noticias relacionadas con el narcotráfico y sus delitos, lo que conllevó a la retaliación por parte de los narcotraficantes y es así como el 17 de diciembre de 1986, fue asesinado Guillermo Cano a manos de sicarios contratos por el capo del narcotráfico Pablo Escobar. Como homenaje al periodista la UNESCO creo el premio mundial a libertad de la prensa, dado el compromiso que mostró por la defensa de la libertad de expresión y la justicia en Colombia. En los años posteriores este medio continuó siendo perseguidos por los carteles del narcotráfico. El 2 de septiembre de 1889 un carro bomba explotó en frente a las oficinas del periódico, así como en el mes de octubre fueron asesinados la gerente y el jefe de circulación del periódico en la ciudad de Medellín.

En el año de 1997 dada la crisis económica la familia Cano tuvo que vender la mayoría de sus acciones al grupo Comunican S.A, de propiedad del señor Julio Santo Mario Santo Domingo, dueño de otros medios de comunicación como Caracol Radio y otras empresas como Avianca y Bavaria. Desde septiembre 2001, el diario pasó hacer Semanario dominical. A partir de esa fecha; El Espectador se dedicó a la publicación de artículos mayormente por el análisis, de investigación y de opinión. Este periódico volvió hacer Diario en mayo de 2008.

El Periódico EL Espectador mantuvo posiciones críticas frente a hechos políticos y de violencia, entre las cuales se pueden destacar: En la década de 1980 este medio de comunicación presentó denuncias contra el Grupo Gran Colombiano por préstamos y actividades económicas irregulares y en represaría algunos grupos económicos dejaron de pautar en este periódico. 
En el periodo de Gobierno Julio Cesar Turbay (1978- 1982), El periódico mantuvo sus críticas ante los abusos y violaciones de Derechos Humanos que caracterizaron a este periodo presidencial. Por lo cual, el gobierno consideró a este periódico como "prensa subversiva".

Asimismo, este medio de comunicación fue crítico al gobierno de Álvaro Uribe, especialmente, en lo referente a la Política de Seguridad Democrática, la parapolítica, así como el propio director dijo no estar de acuerdo con el gobierno del Presidente Uribe. La posición del diario conllevó a las presiones de grupos sociales y económicos e incluso algunas amenazas que llevaron a varios de sus periodistas al exilio.

Un caso emblemático de violación de Derechos Humanos, fue el sucedido a la periodista Jineth Bedoya, quien fue secuestrada y torturada por miembros paramilitares. Así como se dieron amenazas por parte de grupos paramilitares a periodistas como Alfredo Molano o Arturo Alape, en los primeros años de la década del 2000 se presentó el exilio de varios periodistas de este medio de comunicación.

\section{- Periódico: El Tiempo}

El periódico El Tiempo fue fundado el 30 de enero de 1911 por Alfonso Villegas Restrepo, a partir del año 1913, la familia Santos entra hacer propietaria de este medio de comunicación, Eduardo Santos llega hacer el dueño del periódico y su hermano Enrique Santos ejerce como director del periódico. En sus inicios este medio de comunicación se presentó como oposición al gobierno, desde una perspectiva liberal se ejercían críticas frente a la tendencia conservadora que había mantenido el poder en el país desde 1886.

Es de anotar que la familia Santos que ha sido la propietaria del periódico el mayor tiempo, es de la familia del hoy presidente Santos, que además de haber tenido un papel importante en el desarrollo de la prensa, han sido participes en el sistema político Colombia

El deterioro político del partido conservador, un clima político turbulento en el país debido a la Masacre de las Bananeras y la crisis económica de 1929 conllevó a que el candidato liberal Enrique Olaya Herrera llegará a la presidencia en el año1930. Lo cual significó que la línea del periódico reconocida de carácter liberal pasará de la oposición a ser gobiernista. Este medio tuvo que ver de manera clara en el triunfo liberal en las 
elecciones, máxime si se tiene en cuenta que el jefe de debate de la campaña electoral fue Eduardo Santos.

Durante los cuatro mandatos de hegemonía liberal el periódico se consolidó como el medio de mayor influencia sobre la opinión pública, en los gobiernos de Olaya Herrera y Alfonso López Pumarejo, Eduardo Santos ejerció varios cargos en el gobierno tales como: Ministro de Relaciones Exteriores, Embajador de Colombia ante la sociedad de naciones, Ministro plenipotenciario en Europa, Representante a la cámara y representante al Senado. Posteriormente, ejerció el cargo de Presidente de la Republica, una vez terminado el periodo presidencial, él continuo con la dirección del periódico hasta su muerte.

En 1946, el partido conservador vuelve al gobierno; Mariano Ospina Pérez, obtiene la presidencia, y el diario pasa de ser un aliado del gobierno a la oposición. En este período se exacerba la violencia partidista en Colombia a partir del asesinato del candidato liberal Jorge Eliecer Gaitán.

Los gobiernos Ospina Pérez (1946-1950) y Laureano Gómez (agosto 1950Noviembre1951), se caracterizaron por la censura a los medios de comunicación, la cual se intensificó en la dictadura de Rojas Pinilla (junio 1953-mayo 1957) donde el periódico fue clausurado. Ante el cierre del periódico Eduardo Santos creo la Casa Editorial el Tiempo y se publicó el Intermedio, diario creado para reemplazar El Tiempo, mientras cambiaba la situación política.

La renuncia de Rojas Pinilla a la presidencia de la república y su posterior salida del país en mayo de 1957, propició que la población celebrará el fin de la dictadura y solicitará, el regreso del periódico El Tiempo. Así como el regreso de Eduardo Santos de su exilio en Francia.

En el conflictivo contexto que se vivía en el país, dada la violencia partidista que vivía el territorio colombiano, se dio inicio a una forma de gobierno que alternaba las dos fuerzas políticas presentes en el país. Lo cual es conocido en la historia de Colombia como el Frente Nacional. Este periódico mostró su apoyo a este acuerdo logrado entre los partidos políticos más importantes del país. De esta manera fue tomando parte por los dos sectores políticos hegemónicos, descalificando cualquier vertiente política que no estuviera dentro de los ideales liberales y conservadores. 
En la portada del Tiempo del 8 de junio de 1958 se puede observar como la posición del periódico El Tiempo (1954) se acogía a la ideología representada por El Frente Nacional.

El Tiempo está al servicio de los ideales de fe democrática y solidaridad patriótica que el Frente Nacional preconiza, y a cuyo amparo, los principios consagrados en la carta de los Derechos Humanos, como fuero de los pueblos libres, han de ser la realidad constante para todos los colombianos". (P.1)

Por tanto, la información que se producía no incluía las perspectivas políticas diferentes a las del partido conservador y al partido liberal.

En la década de 1980 dado el contexto de violencia procedente del narcotráfico y con ello las amenazas a los periodistas por parte de las organizaciones narcotraficantes, los diferentes medios de comunicación crearon el Frente Unido, y a través de esta unión los más importantes medios del país produjeron informes y artículos relacionados con los vínculos de la política y el narcotráfico que fueron publicados en forma simultanea por los diversos medios de comunicación.

En las últimas décadas El Tiempo pasó a ser propiedad de unos de los más importantes empresarios del país; el señor Luis Carlos Sarmiento considerado una de las personas más ricas del mundo, reconocido por sus empresas de construcción y ser propietarios de importantes corporaciones en el país. El cambio de dueño del periódico conllevó a una transformación en los principios ideológicos de este medio de comunicación.

Es importante resaltar que en las tres décadas este periódico tuvo una mayor perspectiva oficialista y conservadora, especialmente en los dos gobiernos del presidente Uribe, donde se mantuvo como defensor de la política de Seguridad Democrática.

\section{- La Revista Semana}

La Revista fue fundada en 1946 por Alberto Lleras Camargo, representaba al ideario del Partido liberal y circuló hasta finales de 1961. En 1982, la Revista reapareció bajo una nueva administración, al ser refundada por Felipe López al comprar los derechos del primer director.

En la reseña presentada por La Biblioteca Luis Arango (2016) se afirma que en la primera editorial de semana se expresó que la Revista no se declara ni liberal ni conservadora, sino que tiene una filosofía contemporánea que aspira que a colocar la información por 
encima de grupos de presión y de intereses que puedan limitar la expresión y la información hacia los lectores.

El periodista Flórez (2012) expresa sobre la fundación de la Revista Semana que ésta surgió indirectamente de la Revista Alternativa, revista de izquierda que a pesar de tener un excelente equipo de redacción se vio en la obligación de cerrar por problemas financieros.

La perspectiva de este medio de comunicación estuvo dirigido al análisis de temas de interés políticos, en 1982 cuando reapareció la Revista Semana se enfocó en el abordaje del tema del terrorismo, en una coyuntura de alta violencia dada la presencia de violencias como el sicariato, la guerra sucia propiciada por los grupos de ultraderecha y los continuos golpes del Movimiento de izquierda M19 al Estado colombiano.

El grupo Semana dueño de la Revista cuenta con varias iniciativas entre ellas las siguientes: Fundación Semana, Publicaciones Semana, Sostenibilidad Semana y Foros Semana. En la actualidad la Revista cuenta con un espacio televisivo denominado Debates Semana en un canal privado denominado Cable Noticias.

Según documentos de la Luis Ángel Arango retomando a la editorial del Tiempo, la Revista Semana fue creada para el lector, que ante tanta información dada por los otros medios de comunicación se ve atiborrado de tanta información, por lo que requiere de alguien que le haga el seguimiento.

La Revista Semana declara no ser una Revista Política ni doctrinaria, es el lector quien tiene que expresar su necesidad y reconocer la información, ésta se encarga de la difusión amplia de los hechos, con un criterio amplio que le organice sin emitir comentarios porque este deberá ser emitido por los lectores.

Al igual que los otros dos medios Reseñados, la Revista Semana ha sido objeto de persecución política, por ejemplo, debió cerrar entre 1946 y 1982 una portada en la que apareció Fidel Castro que definitivamente llevó a un debate y al cierre de la Revista, El 11 de mayo de 1982 circuló nuevamente con un titular "El terrorismo que hay detrás."

Así como en la última década ha sido objeto de constantes cuestionamientos por parte de miembros de los partidos de derecha que la acusan de ser aliada grupos armados de izquierda. 


\section{Análisis sobre los tres medios de comunicación.}

Una vez tratados los principales elementos de los tres medios de comunicación nos atrevemos afirmar algunos puntos que se pueden decantar de lo expuesto anteriormente con el fin de analizar los aspectos que se aproximan o diferencian en sus apuestas ideológicas.

El análisis nos lleva a ver que el surgimiento de los tres medios de comunicación está ligado a un vínculo político y económico, y sus labores las desarrollaron o bien a favor o en oposición al gobierno.

De otra parte, podemos ver como los diferentes ciclos de violencia han influido en el trabajo de los medios de comunicación, es así como uno de los periodos más álgidos de la historia, el llamado La Violencia (1948- 1951), Los periódicos: El Espectador y El Tiempo tuvieron persecución que los llevaron incluso a la suspensión y cancelación de sus publicaciones.

En relación al componente ideológico, revisar la historia de los medios de comunicación podemos advertir que desde el mismo surgimiento de los medios de comunicación están inherentes los rasgos ideológicos, es así como los diarios surgen desde una perspectiva liberal, sin embargo, dicha perspectiva ideológica tiene algunas diferencias.

Si bien el diario Espectador fue crítico de los primeros gobiernos conservadores, dicha crítica estaba más orientada a defender los programas e ideales del partido liberal, pero no era muy crítico ante los hechos que iban en contra de la democracia, no obstante, para El Espectador su producción de información se realizaba de forma crítica ante las diversas situaciones que se daban en contra de la democracia.

El momento histórico donde hay mayor distancia ideológica entre estos dos medios de comunicación se presenta en el acuerdo político denominado "Frente Nacional", donde el periódico El Tiempo sólo incluía información favorable a los dos partidos políticos liberal y conservador. Mientras que El Espectador mantuvo una postura crítica a esta forma de gobierno que se consolidó como una fuerza excluyente de las opciones políticas que no pertenecieran a las dos fuerzas hegemónicas.

La Revista Semana, ideológicamente estuvo más ligada a una tendencia independiente de los partidos políticos. Por lo cual enfatizó en un discurso con mayor contenido intelectual 
para unos lectores interesados en temas especializados sobre el Conflicto Armado y la coyuntura política nacional e internacional. Debido a esta tendencia ideológica sus artículos se establecieron desde la perspectiva del análisis político desde la perspectiva de académicos y analistas expertos en los temas de violencia, política, economía y otros temas de interés nacional.

Otro elemento que podemos deducir de este recorrido histórico por los medios de comunicación abordados en este estudio, es que la violencia que ha vivido el país, incluso la precedente al actual Conflicto, tienen una influencia en las acciones que realizan los medios de comunicación, y dicha influencia se realiza en varios campos, la producción discursiva, la publicación y el mismo desempeño de la labor como periodistas. Es de anotar que la prensa en el caso colombiano se ha visto también amenazada y perseguida por actores de la violencia y los diferentes sectores de poder. Por ejemplo, en la década de 1980 los actores del narcotráfico dieron golpes muy fuertes al periodismo y con ello se puede constar que en contextos de guerra la primera sacrificada es la verdad.

No obstante, la presión de sectores de la violencia sobre los medios de comunicación no se hace con la misma intensidad, la cual depende del tipo de información que estén publicando, por ello en la década de 1980, el periódico que se vio mayormente afectado por la violencia del narcotráfico fue El Espectador, puesto que este medio fue enfático en la denuncia del vínculo entre política y narcotráfico.

En el análisis de los medios de comunicación es muy importante tener en cuenta que una forma de hacer presión sobre la información de los medios de comunicación, es de carácter financiero. La consecución de las pautas publicitarias está muy influenciada por el tipo de noticias y los discursos mediáticos que sean afines a los intereses económicos. Además, es muy importante tener en cuenta como en los últimos años, los dos periódicos: El Tiempo y El Espectador fueron comprados por los gremios de económicos.

El interés de los gremios económicos por obtener la propiedad de los medios de comunicación, puede explicarse desde el marcado interés por el control de la información que se puede ubicar como una fuerza de poder importante, de igual manera, la conexión existente entre el poder económico y la política en el país, históricamente, la política ha estado en manos de sectores económicos de poder, por tanto, el mantenimiento de este poder requiere de poner a su servicio, el discurso masivo ya que esta es una manera de construir realidad. 


\subsection{Medios de Comunicación y Estigmatización Juvenil}

Una vez analizado el papel de los medios frente a la guerra y las características del periodismo en la situación de conflicto colombiano, hablaremos acerca de cómo se construyen los discursos de discriminación en dichos medios, especialmente en el caso del joven popular en contextos de guerra. Partiendo de que: "los medios son los principales transmisores de ideologías y cosmovisiones. Su impacto en la construcción de imágenes colectivas determina la opinión que las personas tienen sobre las regiones que conocemos y las percepciones del sistema en que vivimos"

En este sentido, es importante acceder al análisis del papel de los medios en la producción de las representaciones sociales para definir lo juvenil. La capacidad de los medios de comunicación para generar opinión pública frente a hechos, lugares, personas y colectivos, tal como lo expresa De la Roche (2005): uno de los problemas de las grandes ciudades colombianas es la estigmatización de nuestros barrios, zonas o localidades que efectúan los medios a través de las narrativas asociadas a la inseguridad, la violencia, la criminalidad, la drogadicción, el pandillismo y el sicariato juvenil.

La vida urbana de las grandes ciudades colombianas se vio marcada por las violencias derivadas del narcotráfico, del conflicto armado interno, de la expansión de la violencia de ultraderecha paramilitar; todo ello contribuyó en gran medida a la generación de los estereotipos de estigmatización de la población joven en Colombia. Los ciclos de violencia vividos en el país nos ubican en una cruda realidad, el abandono estatal a numerosos sectores populares, que por largos periodos han quedado en manos de actores que luchaban por el poder territorial.

Para realizar esta reflexión se hace necesario abordar el concepto de estigma social, lo primero a anotar es que éste hace parte de las representaciones sociales, como constructos configurados simbólicamente desde el lenguaje y la interacción con los otros. Las representaciones sociales son formas de comprensión del mundo creadas cotidianamente desde las cuales damos sentido a los aspectos sociales que nos rodean.

Para comprender el concepto de representaciones sociales acudiremos a lo expuesto por Jodelet (1984) sobre los elementos que configuran las representaciones sociales tales como:

1. El contexto concreto donde se encuentran los individuos y los grupos. 
2. La comunicación que se establece entre ellos.

3. Los marcos de aprensión que proporciona la cultura.

4. Los códigos, valores e ideologías que se relacionan con las posiciones y pertenencias sociales específicas, en donde el sujeto produce una representación que se refleja normas institucionales, derivadas de la posición que ocupa.

Hay que resaltar que las representaciones sociales presentan constructos cognitivos como el estereotipo y el estigma con los cuales comprendemos el mundo que nos rodea. Los estereotipos son imágenes con las que se pretende fijar comportamientos y prejuicios para definir las colectividades, éstas se van constituyendo en modos de ser de los pueblos, etnias, clases sociales y géneros. Así mismo se constituyen en formas de comportamiento esperadas por los otros. Cuando los grupos o los individuos se comportan de una manera distinta a lo que los otros esperan se configura el estigma, este constructo social lleva a la generación de rechazo para la persona o grupo que lo porta. Así se configuran formas de exclusión social basadas en el estigma social.

Para Goffman (1970) el estigma es un atributo profundamente desacreditador, el cual lleva a condiciones de desventaja a quien lo porta; en razón del mismo se presenta la segregación y la exclusión social. Este constructo social es una manera de aprehensión del otro desde el rechazo, partiendo de un concepto de normalidad predeterminado y, por tanto, lo que está fuera del mismo se puede concebir como rechazo.

La persona o grupo que no porta ese determinado atributo genera una reacción emocional de incomodidad frente a quien es poseedor de dicho estigma. Definiendo su componente emocional, Mirié (2003) retomando a Stangor y Crandall (2000), asumen que los estigmas se consolidan desde un componente emocional y otro racional; el primero es una como una activación fisiológica, visceral, directa y experimentada por el individuo desde una relación de repugnancia hacia el portador de dicho atributo. En el segundo se establecen “ideologías de justificación”, éstas dan sentido al sentimiento de rechazo producido hacia quien es estigmatizado, estas formas de justificación se basan en el miedo al "contagio".

En el caso del estigma sobre el joven popular se argumentan razones como la perdición en el mundo de la drogadicción, la criminalidad y el desborde de la sexualidad. Estas justificaciones no tienen argumentación desde la razón, sino que se encuentran ancladas en lo emocional. 
De ahí que, uno de los retos en el tratamiento social del estigma es trabajar desde su componente emocional, puesto que en éste se concentra la relación de estigmatización; por ello, los argumentos basados en la emoción tendrán pocas posibilidades de ser refutados desde la razón. La naturaleza emocional configuradora del estigma le proporciona su arraigo social, haciendo difícil su eliminación.

La producción de estigmas conlleva a la discriminación social, pero de una manera más radical que si se tratase de una discriminación; por ejemplo, la juventud en razón de su estereotipo ligado con la inexperiencia puede producir discriminación respecto a un lugar de trabajo, mientras que el estigma que recae sobre el joven popular actúa como fundamento del ejercicio de la violencia, incluso de la justificación de la muerte.

El estudio de Botero, Pinilla, Lugo \& Calle (2011) constata que en las narrativas sobre el conflicto y la juventud en Colombia se establece la tendencia a ver al joven como problema, alusión profundizada a partir del incremento de la violencia en el país vinculadas al narcotráfico y la insurgencia que señala a los jóvenes populares como responsables de la violencia, de la inseguridad ciudadana y el desorden social. Además, afirman que a los jóvenes se les estigmatiza como desviados y delincuentes, se les acusa de poner en riesgo a sus comunidades por estar en acciones delictivas. Igualmente se argumenta que los sujetos jóvenes están en crisis por las pocas oportunidades, las carencias materiales, el desempleo, la deserción escolar y la falta de seguridad social.

En este estudio se reafirma la existencia de un estigma sobre el joven popular, expuesto por otros autores como Martín-Barbero (1998), Perea (2001), Perea (2007), Riaño (2006), Serrano (2005), lo cual significa la perduración y la existencia de un constructo social estigmatizante sobre este sector poblacional por más de tres décadas. Por su puesto no se trata de una representación estática, ésta va reapropiando elementos del contexto político -social para reconfigurar el sentido. Si bien en éste permanecen los orígenes de la discriminación, se complejiza asignándole mayor rechazo a partir de la asociación con transformaciones del contexto violento y los nuevos actores que hacen parte de mismo.

A partir del discurso mediático se han generado representaciones colectivas basadas en el miedo, especialmente en las zonas más desfavorecidas de las principales ciudades del país, como por ejemplo, en Bogotá la localidad de Ciudad Bolívar y la zona limítrofe de Cazuca en Soacha, en Medellín la comuna nororiental, en Cali los sectores de Agua Blanca. Estos sectores entre otros de la capital han sido signados como centros de riesgo 
y peligro, denominación utilizada también para nombrar a sus habitantes. Dichos constructos sociales son asumidos por la sociedad, las instituciones y no en pocos casos han tenido relación con la negación de derechos como por ejemplo, el ingreso al trabajo de jóvenes pertenecientes a estos sectores.

Por tanto, la vivencia de la juventud popular en el contexto colombiano es una experiencia dolorosa en tanto, es una lucha constante por demostrar que se está fuera de la violencia, en medio de las más fuertes presiones para vincularse a la misma. Ante la exclusión social anclada en los imaginarios de los colombianos, el joven se define y redefine en contraposición con el imaginario asignado.

En nuestro trabajo Villamizar (2013) sobre la construcción de identidad en contextos de violencia, pudimos concluir que las identidades juveniles se construyen en contraposición con el estigma impuesto no obstante en las complejas interacciones sociales y culturales, se apropian elementos propios de la estigmatización, sin embargo, ellos, los jóvenes de los contextos de Ciudad Bolívar y Cazuca, viven una intensa búsqueda de reconocimiento social.

De la misma manera, lo anterior ha sido advertido por varios autores, como por ejemplo en los trabajos de Perea (2004), Reguillo (2000), así como en una reciente investigación de Botero, Pinilla, Lugo \& Calle (2011) se afirma que:

La lucha por la supervivencia social se hace explícita en la búsqueda de reconocimiento de los sujetos jóvenes en ámbitos diversos; hay un reclamo de sus derechos y de ser tratados como iguales dentro de la estructura social. El irrespeto jurídico de sus derechos y valoración social negativa de la que se sienten objeto, les cierra posibilidades, les resta seguridad sobre su capacidad para poder hacer aquellas cosas que la sociedad estima como valiosas. (p.106)

Un factor de interés para este análisis es el tratamiento por parte de los medios de comunicación de la participación en la violencia juvenil. La participación de la población joven en la violencia se incrementó en la década de 1980 con el recrudecimiento del narcotráfico y la consolidación de estrategias de organizaciones narcotraficantes por incluir en sus actos violentos a la juventud. La existencia de una profunda injusticia social que condenaba a cientos de jóvenes a vivir en la pobreza excluidos de los derechos a la educación, el trabajo y la falta de reconocimiento social a lo juvenil, aunado a las 
presiones del consumo impuestas por el mercado conllevó a que algunos jóvenes fueran seducidos por estas formas de economía ilegal. Todo ello acompañado de una total desidia Estatal ante la realidad social y política que se encuentra en trasfondo de la violencia juvenil.

En el caso colombiano, los medios de comunicación tuvieron todo el poder sobre la información producida de la violencia juvenil, a partir del discurso y las imágenes de hechos de violencia sicarial. Esta información se efectuó desde una visión inconexa con las causas sociales, políticas, históricas en que se llevaban a cabo estas manifestaciones violentas. A su vez el discurso mediático se produjo desde un lenguaje de discriminación que asoció pobreza con violencia.

En esta misma línea lo apunta claramente Cerbino (2007) que:

Se asiste a una mirada mediática que estigmatiza a los jóvenes en general y a las pandillas en particular. Los jóvenes cuando están presentes en los medios es para llenar las secciones de crónica roja, o en los mejores casos los deportes. En ambos casos lo que muestra es todo lo otro, sus representaciones, prácticas culturales, los complejos procesos de construcción identitaria a los que precisamente contribuyen los medios de comunicación y las nuevas gramáticas audiovisuales, generadas a escala planetaria por las industrias culturales. (p. 408)

Este argumento expuesto por Cerbino (2007) en su investigación sobre el tratamiento de la prensa española de la violencia juvenil protagonizada por jóvenes inmigrantes nos muestra la tendencia mediática no sólo nacional sino internacional a ubicar al joven popular como un peligro social. El uso de la pandilla juvenil como forma de activar los imaginarios sociales de discriminación es recurrente en las noticias.

En la configuración del estigma inciden otros factores presentados en el discurso mediático conectados entre sí, pobreza, violencia y joven popular: De la Roche (2005) expone que:

Una de las ligerezas o asociaciones indebidas a evitar desde la recreación periodística de la realidad, que puede dar origen a múltiples representaciones estereotipadas y prejuiciadas de lo popular, es aquella que tiende a poner en 
relación de proclividad o de causalidad a la pobreza y los comportamientos violentos. (p.95)

En esta reflexión es relevante asimilar el debate en torno a la existencia de otros elementos asociados al constructo social del joven como amenaza, la asociación con otros factores de discriminación como son la pobreza, aspecto igualmente planteado por Bañón (2010) al analizar la forma como la prensa española registra el tema de la inmigración, la tendencia a relacionar pobreza con violencia.

En el caso colombiano evidenciamos la existencia de esta relación estereotipada de los territorios periféricos de las grandes ciudades, receptores de población desplazada por el conflicto o de migrantes económicos empobrecidos por la falta de oportunidades y la desigualdad de acceso a los recursos; las características precarias de dichos lugares son percibidas desde el estigma. Son los habitantes de estos sectores sobre quienes recaen los estigmas tanto por residir en lugares nombrados desde el discurso mediático como "zonas rojas", imaginarios exacerbados en el caso colombiano por las dinámicas del conflicto armado.

En este escenario tanto los sectores de residencia como sus habitantes son depositarios de la exclusión social, en tanto en las connotaciones simbólicas son divididas en bipolares que definen el bien y el mal. La búsqueda incesante de la determinación de la normalidad conlleva a dar sentido a la diferencia a partir de la discriminación y la exclusión social. Reafirmada por el discurso más conocido el producido por las instituciones mediáticas.

En relación al constructo discriminante del joven popular en Colombia algunos autores como Martín-Barbero (1998), Riaño (2006), Serrano (2005), asumen la generación de estos imaginarios en la mitad de la década de 1980, con la profundización del fenómeno del sicariato en el país. Este tipo de violencia producida por vinculación de jóvenes al mercado de la muerte, generado por el narcotráfico. Tal fenómeno social propicia el cuestionamiento a las maneras como se construyen los sentidos de vida los jóvenes populares, agobiados por la escasez económica, la exclusión social y las presiones de mercado por ser sujeto de consumo.

Comprender cuál ha sido el tratamiento dado por los medios de comunicación a la violencia juvenil, es uno de los aspectos a dilucidar el surgimiento de este imaginario social como una prioridad sociológica, el acercamiento a éste nos muestra la tendencia 
por asumir esta realidad social desde la configuración de imagen negadora del otro. Cerbino (2007) propone que el tratamiento dado por los medios de comunicación a la violencia protagonizada por algunas pandillas juveniles se enmarca en la generación de estereotipos y retomando a Hall (1997) el nombrar las pandillas como violentas es una forma de establecer una división entre lo normal y lo anormal, lo aceptable y lo inaceptable. Así, esto conlleva a una clasificación entre el joven bueno y el joven malo, ésta es socialmente utilizada para excluir a quien se considere diferente.

En el contexto colombiano la violencia juvenil se convirtió en un aspecto de alto interés mediático, así como dio lugar a una nueva manera de significar al joven. Al respecto, Serrano (2005) pone de manifiesto que, el sicario se convirtió en una de las representaciones mediáticas y sociales más comunes de la condición juvenil. De este modo, el fenómeno del sicariato se convirtió en una forma de dar visibilidad al joven popular. Él llegó a tener una posición en la sociedad reconocida públicamente a partir de la transgresión de la norma que le permitió afirmar su identidad.

Para continuar con el análisis en necesario revisar las características de la información producida sobre la participación de la juventud en la violencia. Si tenemos en cuenta la influencia de la información mediática sobre la ciudadanía, en cuanto a organizador de emociones e imaginarios en este sentido es relevante retomar a Cerbino (2007) cuando expresa que:

La práctica del periodismo como un potente organizador de las emociones ciudadanas. Y este es un negocio atractivo en la medida que responde (cuando los medios quedan atrapados en la simple lógica de la medición de los índices de audiencias o de venta) a una demanda de noticias fascinantes noticias cuya intención es producir un efecto de realidad que deje al público, adherido a la información. La construcción de reportajes y las notas sobre el tema de pandillas juveniles se realiza yuxtaponiendo algunos matices discursivos: al sensacionalismo se agrega la criminalización, el racismo y la naturalización de los jóvenes. (p.96)

La producción noticiosa en el tema de la violencia queda expuesta a la demanda por parte de la audiencia a través de noticias con contenidos que exacerben la emocionalidad, confirmando el dramatismo como un elemento atractivo. Un desafío para las ciencias sociales es desentrañar cómo se configuran estas expectativas de los públicos receptores, 
que a su vez contribuyen a la perpetuación de una carga emocional manipuladora de los contenidos mediáticos.

En esta directriz el discurso mediático construye sujetos depositarios de una emocionalidad del rechazo, de acuerdo al contexto social en el que se genera el discurso, de modo que en cada escenario se determinan los aspectos diferenciadores. Así, en el espacio de la inmigración, el inmigrante será depositario de dicha estigmatización, y si es en el contexto de lo urbano, el joven popular cargará con el estigma en razón a un discurso que divide a unos y otros; ya que la existencia del estigma requiere de la existencia del "bien” y el "mal”, constituyéndose así una línea social divisoria entre la juventud. Esto implica la configuración de constructos sociales estigmatizadores en diferencia al modelo de juventud esperado.

En el caso colombiano hemos asistido las tres últimas décadas a la configuración del joven popular como peligro social, De la Roche (2005), afirma que:

La representación de los jóvenes en muchos formatos de la ficción televisiva en Colombia, abusa también de la asociación del joven de sectores populares al delincuente juvenil, drogadicto y pandillero. Toda una gama de posibilidades de vida de los jóvenes, alternativa a ese estereotipo, que funciona en la vida real de los sectores populares, encuentra sólo excepcionalmente representación en el dramatizado, la telenovela o el programa radial o televisivo dirigido a audiencias juveniles." (p.96)

De otra parte, Cerbino (2007) afirma que los medios de comunicación han dado un tratamiento al tema de la violencia juvenil similar a otros hechos de violencia como el terrorismo que son considerados amenaza mundial; en este sentido el papel de las agencias noticiosas se asimila más a organismos de control social y judicial que al propio deber de informar. La participación de ciertos sectores de la juventud en la violencia no ha sido tratada por la mayor parte de los medios como un problema social y cultural.

Esta exclusión queda patente en otros estudios llevados a cabo con población inmigrante no colombiana, poniendo de manifiesto los elementos que influyen en el cubrimiento mediático expuestos claramente por Cerbino (2007) y (2006), al analizar el discurso mediático sobre la violencia juvenil en España, resaltando en éste la existencia de cuatro elementos que influyen en la generación de un lenguaje de exclusión juvenil: 
sensacionalismo, la criminalización, racismo, naturalización de la juventud. La definición conceptual de los términos nos posibilita establecer la relación discurso y discriminación.

Sensacionalismo: a través del dramatizado (formato que se utiliza en televisión en Colombia para afirmar que lo que se está proyectando es un hecho real) narra los hechos, de este modo establecen un efecto de realidad, presentándola como verdad irrefutable. Por medio de la proliferación de imágenes que aumentan el miedo en la ciudadanía con respecto a la participación de la juventud en la violencia.

Criminalización: se produce al utilizar un vocabulario que asocia de manera insistente la acción pandillera con otro tipo de delitos graves, propios de bandas criminales, delincuenciales e incluso terroristas.

Racismo: este elemento determina al protagonista de los hechos en relación a su pertenencia racial o proveniente de los sectores populares, lo cual contribuye a la negación, material y simbólica de un determinado sujeto social, eliminando sus relaciones sociales y negándole el valor como ciudadano. Todo ello a partir de la construcción de un estigma transformador de su identidad social.

Naturalización de la juventud, a partir de la asociación entre joven con los discursos de violencia. El sujeto juvenil por su condición etaria y biológica estaría más dispuesto a cometer actos ilícitos, se establece así una característica a priori del sujeto joven. En este elemento se refleja una forma de concebir al joven incluso desde las instituciones sociales, la cual se basa en asignar a este sujeto social una tendencia a actuar de forman violenta.

En esta reflexión teórica se puede anotar la relación estigmatización juvenil en el discurso mediático con aspectos como la pobreza, segregación juvenil urbana, incluso con elementos culturales propios de dicha población, como por ejemplo sus gustos estéticos, tal como lo describe Cerbino (2007) la cadena de: ser joven, ser pobre y vestir de cierto modo es motivo suficiente no sólo para sospechar, sino para emitir un juicio explícito.

\subsection{La Construcción Social del Enemigo interno en el Discurso Mediático.}

El concepto de enemigo interno nace dentro del marco de la seguridad nacional, su surgimiento se asocia a la etapa de la guerra fría, a partir de la creación del concepto de seguridad interna como una estrategia para atacar el comunismo y las revoluciones 
externas. Para Buitrago (2003) el concepto de seguridad en América tuvo algunas variaciones con respecto a Europa como por ejemplo la seguridad del Estado mantiene la seguridad de la sociedad y que para lograr el mismo se requería el control de las fuerzas militares estatales. La segunda diferencia fue la configuración del enemigo interno. En esta conceptualización del enemigo interno se consideraba además de los grupos insurgentes a cualquier colectivo o persona que tuviera ideas opuestas a los gobiernos militares.

La instrumentalización de la doctrina de seguridad a favor de intereses militares y políticos se hizo evidente en la región latinoamericana, mediante ésta se justificó la represión a diferentes grupos sociales y civiles, convirtiéndose en la justificación de los Estados autoritarios de la región, con lo cual se intentaba el aniquilamiento de la movilización social, de acuerdo con esto Buitrago

(2003), afirma que:

con el tiempo la doctrina de convirtió en una especie de razón social o rotulo usado por varios sectores sociales para identificar, generalmente connotaciones ideológicas y fines políticos a una amplia gama de acciones llevadas a cabo por militares en la región. (p.75).

En contexto de conflicto armado existe una necesidad imperativa configurar la noción de enemigo, así como la legitimación del mismo por parte de la ciudadanía. Las dinámicas de los conflictos se orientan desde relaciones de poder donde el manejo de la información es uno de los ámbitos más codiciados, Ahmed-Ali, Galán, Ignacio \& Nos-Aldás (2011) retomando a Ignatieff (2003) afirman que: en la guerra la primera eliminada es la verdad, sin embargo, los medios de comunicación crean la ilusión de lo que estamos viviendo es verdad.

La ausencia de esta verdad se expresa en un sinnúmero de elementos, entre ellos: en contra de quien se ejerce esa guerra; el interés de quienes poseen el poder hegemónico de instaurar en las representaciones sociales colectivas una noción de "enemigo", lo cual se constituye en elementos justificantes de las acciones bélicas.

La configuración del constructo social de enemigo tiene sus orígenes en el discurso hegemónico desde la influencia de los países más poderosos externos a la región. Ahumada (2007), afirma que: 
En efecto la concepción de enemigo interno se instaura a través de un proceso de difusión desde las grandes potencias a los países desarrollados en situación de dependencia estructural, brindando argumentos para la negación de una apertura y flexibilidad en la participación del poder y reafirmando la exclusión del otro. (p.19)

De esta manera, como forma de perpetuación de las estructuras de poder autoritario, este constructo social se convierte en globalizante para contrarrestar los movimientos alternativos u otros grupos sociales. Por ello se entiende como enemigo no sólo al opositor armado sino también a quien se declara ideológicamente contrario.

El concepto de enemigo interno se puede comprender desde diversas facetas, al igual que ha sido un concepto dinámico en el tiempo, como ya vimos en sus inicios se constituyó en relación a la oposición, específicamente al comunismo posteriormente se utilizó para nombrar a quien no estaba de acuerdo con los gobiernos. Para algunos autores esta connotación empieza a cambiar y se utiliza para denominar a colectivos o grupos sociales sin la necesidad de que estos tengan contradicción expresa con los Estados.

Ante estas particularidades de la guerra se hace necesario preguntarse por la consolidación social del enemigo, en el contexto colombiano y específicamente en el caso juvenil. En este tema De la Roche (2005) observa que actualmente la construcción social del enemigo pasa irremediablemente por los grandes medios de comunicación; ahora y antes, los poderes hegemónicos intentan homogeneizar y aglutinar las sociedades en el rechazo y condena unánime y sin fisuras de ese enemigo al cual atribuyen con frecuencia todos los males del país.

En muchos casos esta construcción se dirige directamente a la población joven, la percepción del joven como amenaza, se constituye en uno de los pilares de información propuestas por los medios de comunicación social. Para el análisis de este tema Reguillo (1998) afirma que:

- Los contextos de violencia donde las fuentes de violencia no son claramente identificables se configura un discurso autoritario y se incrementan los dispositivos de control y seguridad.

- Las prácticas discursivas alrededor de la inseguridad producen el "miedo al otro", el joven del sector popular. 
- El uso amarillista que hacen los medios de comunicación masivo de las situaciones de violencia en las que se involucran los jóvenes es descontextualizada, despojada del contexto social, donde se produce y reproduce la violencia juvenil.

La información producida por los medios se convierte para los ciudadanos en una verdad absoluta sin dar lugar a cuestionamientos, por tanto, es un asunto problemático en la manera como se construye la noción de alteridad en sociedades afectadas por el conflicto. En este sentido De la Roche (2005) expresa que las sociedades democráticas en sus opiniones públicas, deben evitar las construcciones abusivas del enemigo. Realizadas a menudo desde el poder de los medios de comunicación que poseen la capacidad de producir homogenizaciones y dinamismos indebidos de opinión. Con mucha frecuencia los medios de comunicación hacen énfasis en estos constructos sociales de adversario y con ello, invisibilizan otros agentes de riesgo social.

En el análisis que hace Reguillo (1998) se concluye que el joven es representado en los medios de comunicación como "peligroso", "drogadicto o marihuano", "violento". Se recurre también a la descripción de ciertos rasgos raciales o de apariencia: "dos peligrosos sujetos jóvenes de aspecto cholo", "el asaltante con el cabello largo y aspecto indígena...". Entonces, ser un joven de los barrios periféricos o de los sectores marginales es ser "violento," "vago", "ladrón", "drogadicto", "malviviente" y "asesino" en potencia o real. Se refuerza con esto un imaginario que atribuye a la juventud el rol del "enemigo interno" al que hay que reprimir por todos los medios.

La configuración del enemigo en la dimensión simbólica tiene estrecha relación con las prácticas de represión e incluso con la violación sistemática de los derechos humanos llevada a cabo contra la población joven, Esta nominación de enemigo actúa como marco justificante de acciones de represión contra la población joven, a su vez, como distractor de la opinión pública, lo cual conlleva al ocultamiento de otros actores de violencia. Así como esta construcción imaginada del joven contribuye a fragmentar más la ya débil relación entre el mundo adulto y el juvenil.

La creación del joven como enemigo interno es explicada por Reguillo (1998) como la aparición de nuevos mitos desde una perspectiva negativa, donde estereotipos y estigmas, se objetivan en una especie de "manual para la sobrevivencia urbana", que opera 
pragmáticamente. Es decir, de un modo no reflexivo "El mal" las violencias, el riesgo y las amenazas, encuentran en estas formulaciones explicaciones causales automáticas.

Estas producciones mediáticas están en concordancia con aspectos políticos y sociales de la realidad de la región latinoamericana, es a partir de los regímenes dictatoriales de las décadas de 1970 y 1880, donde como lo explica Reguillo (2000) se enuncia una nueva categoría para nombrar a los opositores, la de "enemigo interno". En esta clasificación se incluyeron diversas organizaciones de izquierda, entre éstas, los numerosos movimientos estudiantiles y juveniles establecidos en ese momento en la región latinoamericana. Dicho constructo social se constituyó en el soporte de la violencia estatal contra la población joven, siendo ésta la mayor víctima de la desenfrenada violación de los derechos humanos llevada a cabo por los gobiernos autoritarios.

La importancia de la construcción de la categoría del "enemigo interno" en el análisis de la relación jóvenes y violencia es su continuidad y vigencia. En el caso colombiano el Estatuto de Seguridad implementado en 1979 por el gobierno de Julio Cesar Turbay con su controvertible Estado de Sitio que permitía a las fuerzas militares funciones de policía judicial hasta su derogación en el año 1982. Esta situación llevó a una intensa violación de los derechos humanos, a la confrontación armada y a denuncias ante la comunidad internacional (Turbay, 2009).

Entre las personas que fueron detenidas arbitrariamente, torturadas, asesinadas, desaparecidas y obligadas al exilio se encontraban un número representativo de estudiantes de las universidades públicas. Mientras en el Cono Sur se vivían las dictaduras establecidas, en Colombia, se vivía una "democracia” con muchos cuestionamientos por los organismos internacionales de Derechos Humanos.

Estas maneras de significar al otro desde el no reconocimiento de la diferencia, al punto de llevarlo a la eliminación se han anclado en el discurso mediático, y ha contribuido a la segregación de grupos y colectivos sociales, profundizando en las relaciones de exclusión social, la pobreza y mostrando al mismo tiempo las dificultades de las sociedades para construir las verdaderas democracias.

A través de la propaganda como estrategia de guerra se señalan a grupos y organizaciones sociales como adversarios de la seguridad estatal, en concordancia con el mismo, se idea un lenguaje simbólico que condensa el sentido de negación de estos sectores e incluso la 
desaparición del otro. Además de la propaganda como estrategia de guerra para proponer falsas verdades, se generan otras para evitar que la información salga a la opinión pública.

Samayoa (1990) identifica el papel de los medios de comunicación en la representación mental del "enemigo", En contextos de guerra, el uso de la propaganda se constituye en parte fundamental del quehacer social, ya que en toda guerra la propaganda es crucial, al tiempo que toda propaganda parcializa y distorsiona la realidad, donde el "enemigo" queda fuera de lugar hasta tal punto de deshumanizarle.

En este sentido, Martín-Baro (1990) expone como la "mentira institucionalizada", hace referencia al ocultamiento sistemático de la realidad por parte de medios masivos de comunicación. Esta se realiza a través de ignorar: hechos cruciales de la realidad, la supremacía de la historia oficial, la generación de estrategias mediáticas que relega hechos contundentes de violación de derechos humanos al olvido y la criminalización de los medios y periodistas que contradicen la visión oficial.

El tema del autoritarismo es vital para analizar la generación de estos constructos sociales de discriminación, Lechner (1990) expresa como es propio de los contextos autoritarios la producción de miedos, especialmente el miedo al otro, para ello, los Estados totalitarios utilizan discursos que hacen énfasis en el aumento de la inseguridad y la delincuencia; a partir de esto, la ciudadanía demanda mayor represión para el mantenimiento del orden y con ello le otorga mayor poder al Estado dictatorial.

De otra parte, el miedo, genera la desconfianza entre los ciudadanos y con ello se fracturan lo lazos sociales, incluso con los más cercanos. Ante lo cual, bajo el autoritarismo la sociedad presenta una sensación de caos e incertidumbre en relación a la búsqueda de seguridad, así como la ciudadanía manifiesta su deseo por una mayor utilización de la represión por parte de la fuerza pública que le permita salir del caos y la incertidumbre.

En contextos de guerra El miedo al "otro" se constituye en el mediador de las relaciones sociales, desde los medios de comunicación se imparte un discurso de la inseguridad, en el cual sectores geográficos y pobladores son generadores de peligro. A partir de esto se instala en la percepción ciudadana la concepción del caos y de inseguridad que fractura la confianza en el otro. 


\subsection{Síntesis}

En este capítulo nos hemos centrado en la relación medios de comunicación y violencia, para ello hemos analizado el tratamiento mediático del conflicto armado interno colombiano. En este sentido podemos observar que la información sobre el conflicto colombiano se produce en el marco de las relaciones de poder, ya que está en manos de los dueños de las cadenas noticiosas, afines a representantes de los medios económicos y miembros del gobierno. El discurso mediático sobre la guerra tiene un claro enfoque oficialista que desconoce las voces de otros actores armados, así como de las víctimas de esta confrontación.

El discurso mediático a partir de la exposición constante de hechos de violencia a través del lenguaje y las imágenes conllevan a la estructuración del conflicto como algo "normal”, como hecho "natural" en los imaginarios sociales de los colombianos. Además, a partir del uso de formatos como el dramatizado y las series (El Capo, Caín, El cartel de los sapos, entre otros) se realzan valores propios del guerrero o el traficante y con ello se establecen idealizaciones de los protagonistas asociándole como la valentía y el poder económico conseguido por medio de la violencia.

El discurso mediático entorno a la juventud y la violencia en Colombia ha caído en la estigmatización del joven popular, en tanto se ha tratado el tema desde el sensacionalismo, el amarillismo y el dramatismo, desconociendo los factores estructurales, sociales e históricos propiciadores de la violencia juvenil, asimismo se han activado narrativas comunicativas que generalizan y asocian al joven popular con la violencia.

Es relevante asumir el papel de los medios de comunicación en la producción de la noticia en torno a lo juvenil, la influencia de estos en la construcción del imaginario social coma amenaza. Si bien lo descrito hasta ahora, no nos ofrece argumentos suficientes para determinar dicha relación, si podemos deducir que nos ofrece herramientas para seguir la indagación por esta vía.

En cuanto a lo analizado sobre el papel de los medios de comunicación frente a la violencia es de anotar la existencia de una intencionalidad marcada en el discurso para definir la juventud desde la violencia, Cerbino (2007), expresa como los medios representan al joven de una manera esquizoide, por un lado, la constitución de la identidad juvenil no se produce por fuera de la influencia audiovisual creada y puesta en circulación 
desde las industrias culturales globalizadas. Desde allí, la industria mediática se generan nuevas sensibilidades, modos y estilos de vida para los jóvenes. Pero de otra parte, los medios de comunicación ubican a los jóvenes en los espacios de crónica roja como protagonistas de violencia y con ello se contribuye a la generación de constructos sociales estigmatizadores.

Estas dos dimensiones del periodismo requieren ser analizadas profundamente, ya que hacen parte de dos maneras de significar lo juvenil como sujeto potencial o real de la violencia y como objeto de consumo material y cultural, las intencionalidades presentes allí, tienen relevancia en las apuestas por la identidad juvenil, dado que el sujeto joven reafirma su identidad a través de la identificación o el rechazo a un discurso que lo nombra como violento, de igual manera, que estructura sentidos de ser a partir de un modelo juvenil ligado al consumo propuesto por los medios de comunicación.

El trabajo periodístico en relación al sujeto joven abre muchas inquietudes en torno al manejo de la noticia en relación con la seguridad y la inseguridad, allí el joven popular está presente como potencial generador de violencia. En este sentido los autores consultados sobre este tema expresan la necesidad una reflexión sobre el papel del periodismo, que entre otras cosas apunte a la formulación de nuevos criterios de lo noticiable, especialmente aquellos referidos al cubrimiento de la inseguridad, que permitan una visión profunda de la realidad social que los medios de comunicación tienen ante sus audiencias.

El anterior es un aspecto fundamental para la construcción de sociedades más democráticas, por ello, se requiere repensar la manera como se está dando tratamiento a las noticias relacionadas con el conflicto. Esto es importante en razón de evitar la profundización del conflicto. Si recordamos que este no sólo se define en términos de la violencia directa sino también en los marcos de las representaciones sociales, además en la significación social del otro, donde construimos nuestra alteridad.

El análisis de la información procedente del conflicto armado interno colombiano en los medios de comunicación requiere de una reflexión sobre el contenido y la utilización de un lenguaje estigmatizador de la juventud y otros sectores sociales, para ello es importante el análisis desde las dimensiones sociales, políticas y culturales en las que se enmarca este conflicto. De tal manera que las violencias en la que se involucran los jóvenes sean 
leídas en las dimensiones que contextualizan esta confrontación armada, desde sus particularidades, históricas, sociales y culturales.

La sociedad colombiana requiere reflexionar sobre la influencia de los medios de comunicación en la construcción de las relaciones sociales entre los ciudadanos, dado que a partir del discurso mediático producido en el contexto de guerra se han derivado imaginarios sociales que llevan a la estigmatización de vastos sectores urbanos y con ello a la fragmentación de los lazos sociales comunitarios. En este contexto la configuración de la imagen del otro se ve altamente atravesada por las nociones de peligro y rechazo lo cual contribuye a generar en una buena parte de la sociedad indiferencia o cierta aceptación de la sistemática violación de los Derechos Humanos

En nuestra opinión los medios de comunicación en Colombia influyen en la generación de constructos sociales sobre la población joven, puesto que no guardan independencia de otros sectores económicos y políticos de mayor poder en el país, a su vez, al no contar con la independencia económica representan ideologías de oficialistas y de derecha que está interesadas en la perpetuación del conflicto armado para continuar en el ejercicio del poder y las ganancias económicas que provienen de las economías asociadas a la guerra.

No obstante lo anterior, la generación de un imaginario sobre el joven popular como amenaza en Colombia no puede recaer bajo la responsabilidad de los medios de comunicación, dado que ya en la sociedad se presentan dichas configuraciones sociales, producto de los procesos de violencia que ha vivido el país. Consideramos que a partir de la persistencia de esta violencia se han generado modelos autoritarios de relaciones sociales que han instaurado la desconfianza en la sociedad y conllevan a la búsqueda del enemigo al interior de sus propias comunidades.

De acuerdo, con las afirmaciones que consideran que, en tiempos de guerra, el discurso es un elemento más en disputa y que los actores protagonistas están interesados en el poder sobre la información puedo considerar que el conflicto armado colombiano, se han generado transformaciones discursivas asociadas a la guerra, mucho más si consideramos el extenso periodo de tiempo de este conflicto y la multiplicidad de actores que participan.

En definitiva, podemos concluir que la influencia de la información producida por los medios de comunicación en la construcción de la noción del enemigo se ha transformado a lo largo de la historia bélica del país, y ha sido utilizada para nombrar y destruir a 
diversos sectores sociales, entre ellos al joven popular. A partir de esto, se implementa su destrucción, de modo que tal como lo expresa Bonilla (2003), las confrontaciones armadas no movilizan únicamente armamento de destrucción para derrotar e imponer su voluntad al enemigo, sino que les interesa gestionar la esfera pública y los marcos de interpretación en búsqueda del control hegemónico de las representaciones simbólicas de la sociedad. 



\section{CAPITULO IV. DISEÑO METODOLOGICO. ANALISIS DEL}

DISCURSO DESDE LA PERSPECTIVA DE LA ESCUELA FRANCESA

4.1. Análisis del Discurso.

4.2. Aspectos metodológicos.

4.3. Diseño metodológico análisis cualitativo.

4.4. Diseño metodológico análisis cuantitativo. 



\section{CAPITULO IV. DISEÑO METODOLOGICO. ANALISIS DEL DISCURSO DESDE LA PERSPECTIVA DE LA ESCUELA FRANCESA}

En este capítulo desarrollaremos el diseño de la metodología de esta investigación basada en el análisis del discurso. Para ello expondremos la conceptualización del análisis de este método y explicaremos la perspectiva implementada por la Escuela Francesa, método escogido para el análisis del discurso mediático sobre el tema de la violencia contra los jóvenes denominada "Falsos Positivos". Este trabajo tendrá un énfasis de carácter cualitativo, no obstante cuenta con un análisis cuantitativo del corpus de este estudio.

La presentación de este capítulo se hará de la siguiente manera, en primer lugar, se expondrá la conceptualización del análisis del discurso, en segundo lugar, describiremos los aspectos metodológicos, en tercer lugar, diseño metodológico del análisis cualitativo y en cuarto lugar, el diseño metodológico del análisis cuantitativo. Por último, presentaremos una breve síntesis del capítulo.

\subsection{Análisis del Discurso}

El Análisis del Discurso es una metodología reciente, más o menos iniciada en las décadas de 1960 y 1970, y que cuenta con diversas corrientes como son la Escuela Francesa, la Escuela Anglosajona, el Análisis crítico del Discurso, entre otros, si bien estas corrientes metodológicas presentan algunas diferencias en el enfoque, todas ellas se remiten a un mismo objeto de estudio que es el lenguaje y sus significados.

El análisis del discurso es un método de investigación cualitativa, que se basa en el estudio del lenguaje presente en un texto; dicho análisis recoge las interacciones comunicativas propias de un grupo o de la sociedad en un contexto específico. Por tanto, se trata de una observación rigurosa del discurso como práctica social. Uno de los elementos fundamentales para el desarrollo de un análisis del discurso riguroso es la conceptualización del discurso como objeto de estudio que en este caso hemos expuesto en el Capítulo I de esta investigación.

En este estudio hemos seleccionamos la perspectiva de la Escuela Francesa, ya que desde esta perspectiva metodológica nos interesa observar el discurso desde tres elementos que se constituyen en los ejes de la interpretación de este análisis: Texto, formación discursiva 
y sujeto. Desde esta mirada podemos examinar el discurso mediático sobre la violencia contra los jóvenes como un texto social e históricamente construido desde las interacciones del lenguaje, el sujeto enunciador y las condiciones de producción de este discurso. Para que el lector tenga una mejor comprensión de este método expondremos en adelante sus principales características.

\subsubsection{Análisis del Discurso desde la perspectiva de la Escuela Francesa}

En este estudio nos interesa centrarnos en el enfoque propuesto por la Escuela Francesa, dado que esta corriente profundiza en la relación entre poder e ideología. Asimismo, es de gran importancia para este estudio el análisis de las condiciones de producción, circulación y recepción del discurso que propone esta vertiente de análisis.

Para comprender porque hemos elegido esta corriente es necesario centrarnos en los principales aspectos que hacen parte de la misma. Este análisis se enmarca en el campo de la interdisciplinaridad, en esta perspectiva confluyen elementos de la lingüística, la etnolingüística, la sociología, el psicoanálisis y la semiótica entre otros. Es desde las interacciones de estas disciplinas con el discurso que se puede comprender las particularidades integrales del discurso.

El análisis del discurso se inscribe en el segundo grado interdisciplinaridad, puesto que se establece en interrelación de más de dos disciplinas. El auge del Análisis del Discurso como método de investigación se presenta a partir de que los objetos de análisis de investigación trascienden los límites de sus propias disciplinas para convertirse en macroobjetos articulados a la interdisciplinariedad. En este sentido el discurso al ubicarse en el cruce de varias disciplinas se constituye en elemento potencial de innovación para las corrientes metodológicas. De otra parte, la dialéctica del discurso que le permite estar presente antes, durante y después de cada práctica social lo constituye en un elemento necesario para en análisis y comprensión de cualquier práctica social, cultural e histórica.

En sentido el análisis del discurso se puede considerar como un método de producción de conocimiento que como expresa Haidar (1998) el análisis del discurso contribuye a la potenciación de los tres aspectos que conllevan la producción de conocimiento: la acumulación, la ruptura y la convergencia. Por ello es de vital importancia en el análisis del discurso sobre la violencia contra los jóvenes interpretar de manera rigurosa, los procesos de construcción de conocimiento en torno a las significaciones de la violencia 
contra los jóvenes, los imaginarios de lo juvenil y el lenguaje mediático, identificando de manera clara las continuidades y rupturas en estos discursos y la convergencia de los mismos.

Uno de los aspectos más relevantes en esta perspectiva de análisis son las relaciones de poder, donde son valiosos los aportes de los trabajos de Foucault, en este sentido, el análisis del discurso se relaciona con la comprensión de las condiciones de producción y enunciación del discurso. Por ello, como lo afirma Pardo (2013) en esta perspectiva el sujeto ocupa un lugar socio- histórico, donde se tienen en cuenta las condiciones de producción y circulación de los discursos en un contexto económico y político. En este sentido, el análisis del discurso se ocupa de las relaciones que potencialmente ocurren entre el uso de la lengua y las manifestaciones ideológicas que allí se inscriben.

En esta perspectiva texto, sujeto y marcos de producción del discurso interactúan dinámicamente, el sujeto adquiere significado como ser psicológico y ser social, por ello el lenguaje se encuentra relacionado con quien lo produce y las condiciones de su producción y se condiciona por las prácticas sociales que determinan lo implícito y lo explícito.

El otro elemento que lleva a que el análisis del discurso tenga auge en las últimas cuatro décadas es que la dimensión pragmática que hace que adquiera mayor relevancia que la dimensión sistémica porque se da prioridad al análisis del lenguaje en acción. Desde esta perspectiva es de anotar el interés por analizar las siguientes particularidades del lenguaje: El lenguaje en acción, el lenguaje como acción y los actos de habla.

El estudio del discurso se ha inscrito en diversas disciplinas, en este sentido, Pardo (2013) observa que el análisis del discurso en esta perspectiva articula los aportes del estructuralismo lingüístico, del materialismo histórico y del psicoanálisis, así el discurso es entendido como el lugar en que se observan las relaciones que potencialmente ocurren entre el uso de la lengua y las manifestaciones ideológicas que allí se inscriben.

Para la Escuela Francesa las principales características que están contenidas en los discursos se basan en la existencia de reglas semánticas, pragmáticas y sintácticas que se interrelacionan dentro de un mismo discurso, de igual manera, el discurso está compuesto por un conjunto de frases que presentan cohesión y coherencia. Así como los trabajos de Foucault el discurso se relaciona de manera profunda por las condiciones de producción 
circulación y recepción, para el citado autor es de gran importancia observar las condiciones históricas y sociales que pre-existen al discurso; así como las relaciones de poder y dominación que posibilitan la aparición y circulación de las prácticas discursivas.

Otro concepto importante a la hora de definir el discurso es el concepto de materialidades fue acuñado en primer lugar por la Escuela Francesa de análisis del discurso, en principio estuvo relacionada a las categorías de ideología y poder. Haidar (1998) establece otras materialidades discursivas a partir de los avances en la aplicación del análisis del discurso en diversas investigaciones, estas materialidades son: 1. La lingüística, 2. la comunicativo- pragmática, 3. La ideológica, 4. La del poder, 5. La cultural, 6. La histórica, 7. la social, 8. la cognitiva, 9.la del simulacro, 10. La psicológica, 11. La psicoanalítica, 12. El estético retórico, 13.la lógica física.

La propuesta de análisis del discurso de la Escuela Francesa propone varios elementos a tener en cuenta para llevar a cabo la articulación de la metodología y los objetos de estudio, los tipos de discursos y las preguntas de investigación. A continuación, presentaremos y describiremos dichos elementos:

\section{a) Las condiciones de posibilidad de emergencia de los discursos.}

El análisis del discurso se inscribe en el segundo grado interdisciplinaridad, puesto que se establece en interrelación de más de dos disciplinas. El auge del Análisis del Discurso como método de investigación se presenta a partir de que los objetos de análisis de investigación trascienden los límites de sus propias disciplinas para convertirse en macroobjetos articulados a la interdisciplinariedad. En este sentido el discurso al ubicarse en el cruce de varias disciplinas se constituye en elemento potencial de innovación para las corrientes metodológicas. De otra parte, la dialéctica del discurso que le permite estar presente antes, durante y después de cada práctica social lo constituye en un elemento necesario analizar la comprensión de cualquier práctica social, cultural e histórica.

Es importante tener en cuenta los aportes propuestos en los trabajos de Foucault (1972) y Pechêux (1969). El primer autor brinda sus aportes sobre los procedimientos de selección, control interno y control de las condiciones de utilización. El segundo autor al observar que toda formación social contiene posicionamientos ideológicos y políticos que nos son construidas por los individuos en sí mismos, sino son producto de las condiciones de producción en el ámbito colectivo 
b) La relación entre formación social, formación ideológica y la formación discursiva.

La formación social también denominada formación del lenguaje, es definida como un conjunto reglado de prácticas del lenguaje que las organiza según relaciones de fuerza en prácticas dominantes y prácticas dominadas. Con ello se pretende demostrar que el lenguaje no sólo contiene un elemento lingüístico, sino que tiene un alto componente social.

Las formaciones ideológicas se encuentran presentes las contradicciones de clase, la existencia de culturas dominadas y de dominación y el uso del discurso para para perpetuar la dominación. En este sentido es necesario apuntar a lo que los medios de comunicación han cumplido un papel alto en la transmisión de elementos ideológicos. A través una práctica discursiva, en la cual se puede observar diversos matices discursivos ya que, aunque todo discurso tiene una materialización concreta que lo hace único e irrepetible, no podemos decir que un discurso se parece a otro en alguna forma. Sin embargo, puede tener un punto de anclaje con otros discursos al inscribirse en una misma ideología, que a su vez es una matriz común a un conjunto de discursos que hacen parte dela misma formación ideológica y discursiva.

Por último la formación discursiva hace referencia a lo planteado por Foucault (1972) al conjunto de enunciados referibles al mismo sistema de reglas históricamente determinadas. Los desarrollos de Pechêux (1969) concluyen que las formaciones discursivas actúan de manera abierta, ya que pueden se influenciadas por elementos de otros discursos, por lo cual este autor asocia las formaciones discursivas con el interdiscurso, en este sentido afirma que las formaciones discursivas influyen en las trasformaciones semánticas de un discurso, ya que enunciados preconcebidos pueden ser afectados por discursos trasversos.

\section{c) Las formaciones imaginarias.}

Las formaciones imaginarias son constructos sociales por medio de los cuales, los sujetos definen y clasifican a los "otros," Estas representaciones sociales son construidas a partir de marcos colectivos y modelos ideológicos imperantes en la sociedad. Dichas representaciones sociales pueden ser dispositivos de aceptación o de rechazo social. 
Pechêux (1969) afirma que es a partir de estas formaciones imaginarias que las personas reconocen su lugar y a la vez reconocen el lugar del otro. Estas formaciones están relacionadas con los procesos de subjetivación e identificación. Las formaciones imaginarias tienen en el fondo muchas contradicciones que están asociadas a los campos afectivos, sociales e ideológicos.

\section{d) La relación discurso - coyuntura}

La coyuntura es un principio desarrollado por Robín (1973), este autor precisa la influencia de los hechos sociales, políticos relevantes en un determinado momento sobre la producción discursiva en dicho momento. De la misma manera, los hechos políticos y sociales influyen en las condiciones de recepción de determinado discurso. La propuesta de la citada autora refiere a la necesidad de entender la coyuntura no sólo como elemento exterior, sino como parte constitutiva del discurso. Abarcando las condiciones que lo provocaron y las consecuencias que lo producen. La coyuntura comprende tanto las prácticas discursivas que le preceden como las que le siguen, pero al mismo tiempo prácticas no discursivas de un orden distinto tales como lo económico, lo político y lo social.

\section{e) Los procesos de interdiscursividad.}

Este punto hace referencia a que toda formación discursiva está interrelacionada Courtine (1981) y de esta manera, cada producción discursiva está constituida por otras que le han precedido. Es decir, las dimensiones del discurso no se agotan en el presente, sino que tienen implícita o explícitamente la influencia de otros discursos del pasado. Para Haidar (1996) la interdiscursividad puede expresarse de forma diacrónica, cuando en el discurso predominan elementos de los discursos precedentes y de forma sincrónica cuando en el discurso predominan los elementos del discurso actual.

\section{f) El sujeto del discurso para la Escuela Francesa.}

De otra parte, es necesario ubicar esta discusión del enfoque del Análisis del Discurso desde la Escuela Francesa, en relación con el sujeto y el discurso. En este sentido, Pardo (2013) afirma que para esta Escuela, el sujeto es simultáneamente un ser psicológico y social, así el lenguaje no puede ser considerado como un ente independiente de quien lo 
produce y está condicionado por las prácticas sociales que demarcan lo que queda expresado como implícito y lo que en efecto es explícito. En este sentido el discurso es hacer- decir con una significación que combina las prácticas sociales, los sujetos y los lugares de interacción.

En esta misma reflexión Pechêux (1969) plantea que la constitución del sujeto tiene que ver de manera intrínseca con la producción de sentido, que se genera por los mecanismos de interpelación ideológicos, a través de los cuales nos significamos unos a otros, y en esta línea, las representaciones sociales sobre el otro tienen un profundo componente ideológico.

Haidar (1998) retomando a Pereira (1984) observa que los sujetos entran, necesariamente, en relaciones sociales y culturales que no son reductibles a simples relaciones intersubjetivas. Reducir las complejas relaciones sociales a relaciones intersubjetivas es entrar en un falso análisis. Desde esta perspectiva materialista, los sujetos entran en relaciones sociales, en cuanto les personifican lugares socioeconómicos y son por tanto portadores de determinadas relaciones e intereses de clase. En esta Escuela de análisis del discurso el sujeto es asumido desde la perspectiva del materialismo histórico y el psicoanálisis, por lo cual es determinado como (colectivo, pasivo, socio-cultural e histórico, sujetado no libre, soporte de sentido, matriz de sentido, contradictorio).

En definitiva, En la perspectiva del análisis del discurso de la Escuela Francesa el sujeto es interpretados desde las condiciones estructurales que lo configuran, en este sentido retoma gran importancia las contradicciones sociales y económicas de la sociedad, así como las relaciones de dominación en los diversos ámbitos de la sociedad.

\subsubsection{La pertinencia del Análisis del discurso desde la Escuela Francesa para el desarrollo de este estudio}

La definición de la perspectiva de Análisis del Discurso de la Escuela Francesa está basada en el tipo de análisis a desarrollar, dado que este método nos permitirá analizar los discursos entorno a la violencia de los "Falsos Positivos" y el lugar que estos discursos tienen en el constructo del joven popular del sector sur de la capital del país. Así desde el uso de esta perspectiva analítica nos adentraremos en las condiciones de producción discursiva desde dos aristas: El ejercicio del poder mediático y las condiciones de 
exclusión del sujeto joven víctima directa de esta violencia. Es por la existencia de estas contradicciones sociales que el análisis del discurso desde la perspectiva francesa resulta pertinente para esta investigación.

También esta perspectiva estructuralista nos permite dimensionar las posibilidades de acceso a la producción discursiva, mediante el ejercicio del poder y el soporte de la ideología. A partir de lo cual podremos establecer la relación del poder económico, político con las posibilidades de producción del discurso de los medios de comunicación. Así como este contexto determina las posibilidades de acceso de la población al conocimiento y al análisis crítico de los discursos expuestos por los medios de comunicación.

De igual manera desde esta perspectiva podremos examinar la relación de las prácticas discursivas con el contexto histórico, social, político colombiano entrelazado a la existencia de un conflicto armado interno y manifestaciones de violencia contra la población joven.

El aporte de la Escuela Francesa se encuentra en asumir el discurso más allá de sus elementos significantes y establecer la preexistencia de un contexto al discurso. Dicho contexto enmarcado en las relaciones del poder y dominación. En este sentido, aunque el lenguaje y las prácticas simbólicas tienen un papel importante en la construcción prácticas sociales, pero ello debe tener en cuenta la existencia de prácticas extra discursivas que no se reducen a la dimensión textual.

Una vez expuesta la metodología desde la perspectiva del análisis del discurso de la Escuela Francesa, nos adentraremos en el diseño metodológico, el cual contiene los pasos a seguir en el desarrollo de la investigación.

\subsection{Aspectos metodológicos}

\subsubsection{Objetivo general}

Examinar las prácticas discursivas sobre la violencia de "falsos positivos" y su posible influencia en la configuración de un constructo social de discriminación del joven popular. 


\subsubsection{Objetivos específicos}

- Analizar los elementos ideológicos y de poder presentes en el discurso mediático sobre "falsos positivos" en el caso emblemático de Soacha.

- Identificar los constructos sociales sobre el joven popular expuestos en el discurso mediático sobre la violencia de "falsos positivos" presentes en el corpus de esta investigación.

- Establecer la relación de las prácticas discursivas de actores políticos y sociales y la configuración del imaginario social de discriminación de la juventud popular.

\subsection{Diseño metodológico análisis cualitativo}

El análisis cualitativo se centrará el análisis del discurso mediático sobre "Falsos Positivos" hechos de violencia ocurridos en el periodo (2007-2010). De esta manera, abordaremos la construcción de sentido, en el discurso mediático, donde reflexionaremos sobre las condiciones políticas, sociales en las cuales se construyen y posibilitan los discursos. En este sentido nos interesa adentrarnos en la relación de estos discursos con las tendencias ideológicas de los medios de comunicación y el contexto político de la violencia denominada: "Falsos Positivos."

Los objetivos que nos proponemos desarrollar en el análisis cualitativo son los siguientes:

. Identificar las materialidades sociales, culturales, ideológicas y políticas en relación a la construcción del sujeto joven en los marcos discursivos de este corpus.

. Analizar las tendencias discursivas en torno al tema a la violencia de "Falsos Positivos" desde la postura política de los diferentes actores del gobierno y la sociedad civil.

- Examinar la influencia de los discursos de los tres medios de comunicación en la construcción de realidad en el Conflicto Armado en Colombia.

\subsubsection{Sistematización y análisis de información}

La sistematización de la información procedente de los discursos mediáticos se sistematizará y ordenará a partir de categorías de análisis, además la agrupación de ejes temáticos que nos lleven a encontrar conceptos comunes y propicios para dar respuestas 
a la investigación. El análisis de la de la información se desarrollará a partir de la interpretación de los datos bajo la luz de la teoría pertinente y descrita en el marco teórico de investigación.

\subsubsection{Categorías de análisis}

Las categorías de análisis se desprenden de tres ejes temáticos: 1) Discurso mediático, 2) Constructo social del joven popular y 3) Violencia política. Estos conceptos están en permanente interrelación y cruzan todas las categorías de análisis. Para el análisis de las categorías de investigación de este estudio se tendrán en cuenta los siguientes puntos:

1) Discurso mediático.

- Condiciones de producción, circulación y de recepción de los discursos.

- Materialidades discursivas relacionadas con el constructo social del joven popular como amenaza.

- Tendencias ideológicas de los discursos sobre el joven popular.

- Intencionalidades implícitas o manifiestas.

2) Constructo social del joven popular

- Hitos de conformación del constructo social.

- Mecanismos ideológicos de la conformación de dicho constructo.

- Representaciones sociales sobre el joven popular.

3) Violencia política.

- Hechos relevantes de violencia política periodo del surgimiento del constructo social del joven como amenaza. Persecución a la corriente política de la Unión patriótica, el fortalecimiento de la violencia del narcotráfico en el país y sus vínculos con sectores políticos del país y la participación de la juventud en la violencia del narcotráfico.

- La política de seguridad democrática en el periodo (2006-2010): la violación sistemática de los derechos humanos denominada "Falsos Positivos."

Además de estas categorías hemos encontrado categorías emergentes las cuales son el resultado del desarrollo de la investigación, entre estas se encuentra la categoría de 
intencionalidad, la cual se retomará del análisis cuantitativo. Asimismo, se incluirá la categoría de Violencia contra los jóvenes.

Los elementos que se tendrán en cuenta en estas categorías son los siguientes:

1. Intencionalidad

- Estrategias de los medios de comunicación para atraer la audiencia.

- Tratamiento hecho por los medios de comunicación de los discursos de líderes políticos, sociales, familiares de las víctimas, miembros de organismos internacionales y sociedad civil.

- Tratamiento dado a la información noticiosa sobre la violencia de "Falsos Positivos".

2. Violencia contra los jóvenes

- Abordaje de la prensa de la violencia de "Falsos Positivos".

- Violencia contra los jóvenes en el marco del Conflicto armado interno.

Estas categorías se analizarán desde las relaciones que se establecen en la matriz de análisis expuesta en la Tabla 2.

Tabla 2. Categorías de Análisis.

\section{Categoría Subcategoría Conceptos teóricos de referencia de análisis}

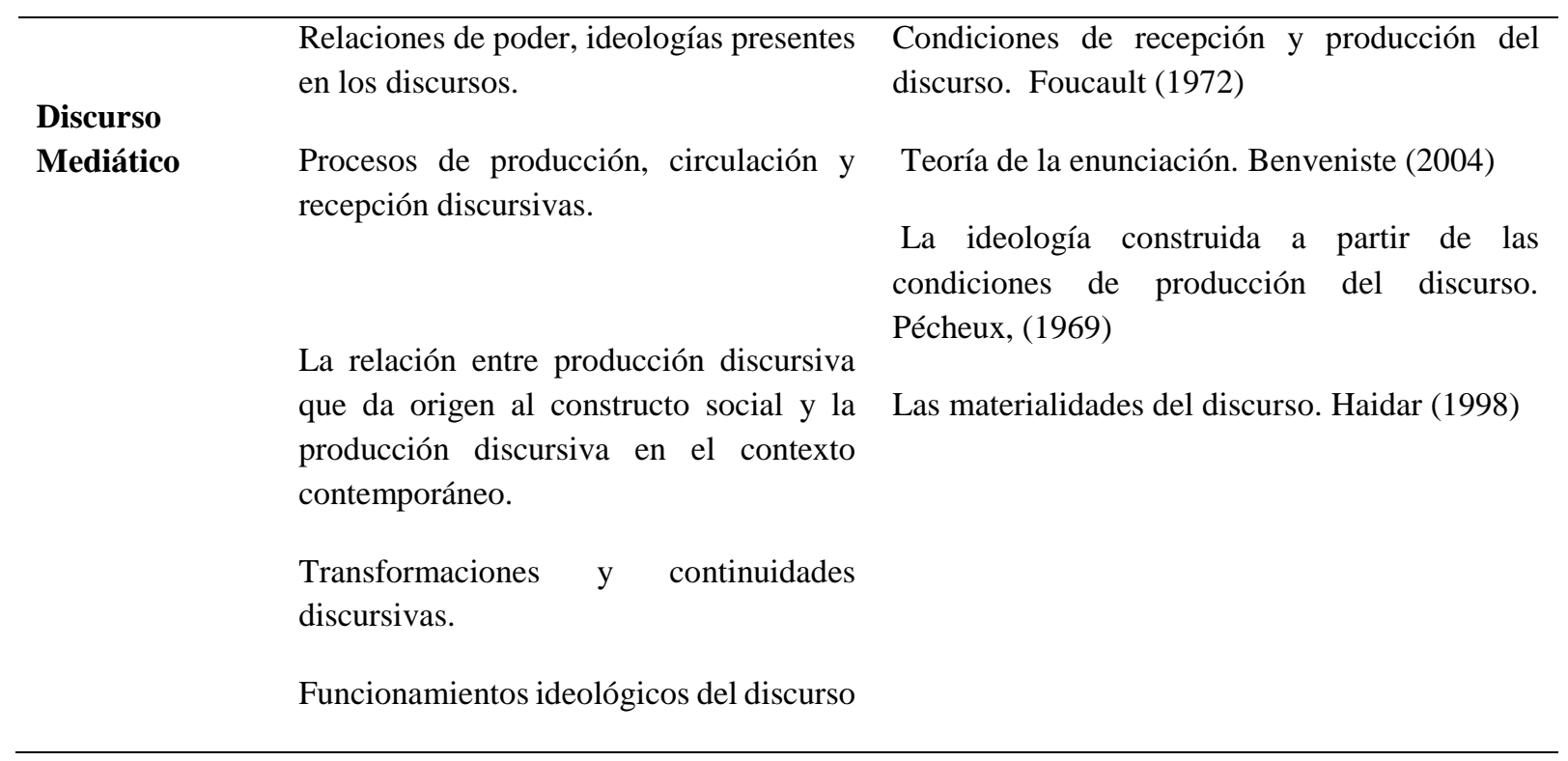


Tabla 2. Categorías de Análisis. (Continuación)

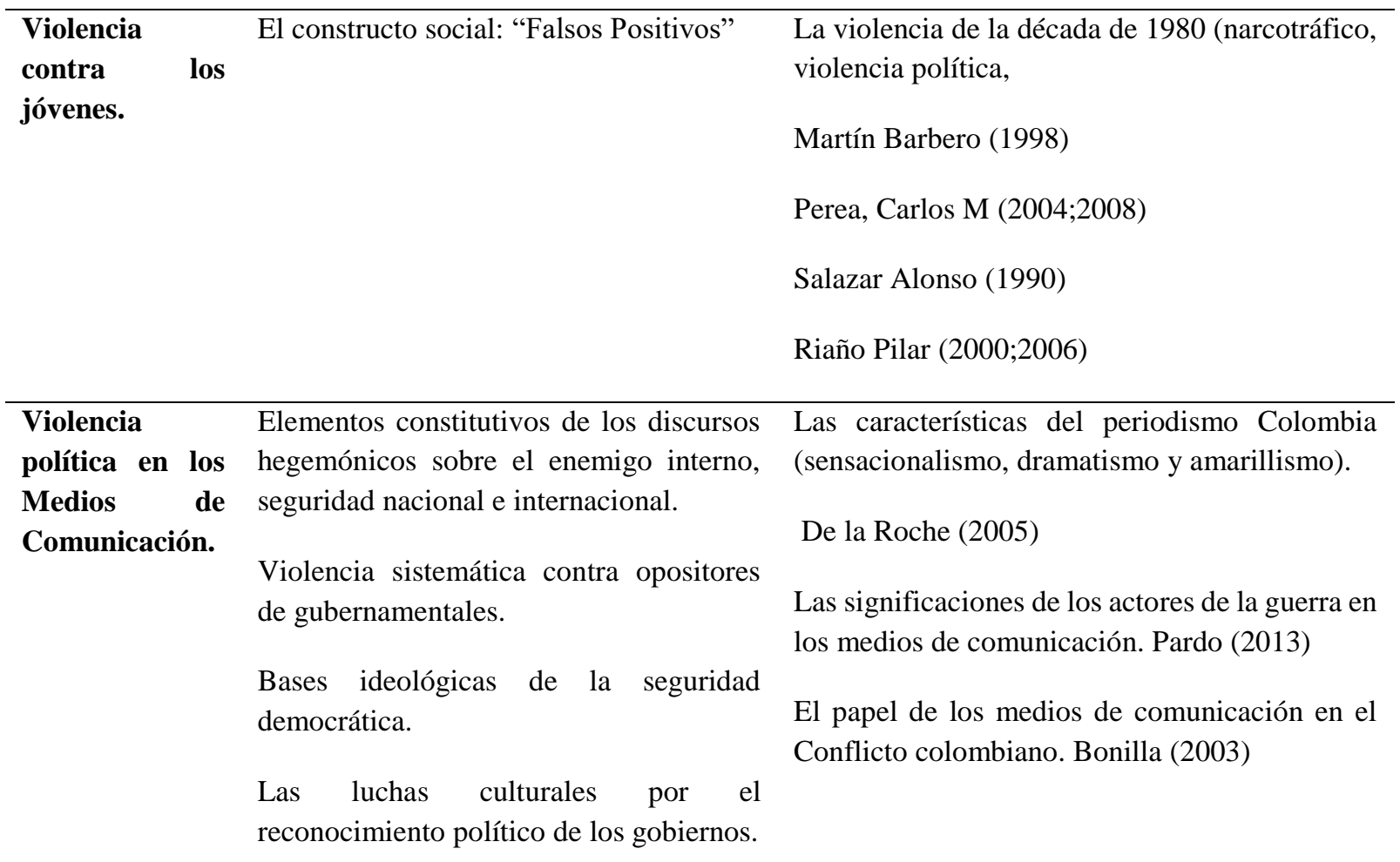

\begin{tabular}{ll}
\hline $\begin{array}{l}\text { Configuración } \\
\text { de un }\end{array}$ & $\begin{array}{l}\text { Formaciones ideológicas en las que se } \\
\text { sustenta este discurso. }\end{array}$ \\
$\begin{array}{l}\text { Constructo } \\
\text { pocial del joven }\end{array}$ & $\begin{array}{l}\text { Relación conceptualización teórica sobre } \\
\text { el joven y la producción del constructo }\end{array}$ \\
& social del joven como amenaza.
\end{tabular}

El constructo social del joven como amenaza. Martín Barbero (1998)

El papel de la violencia en la construcción de identidad del joven popular. Riaño, Pilar (2006)

Estrategias bélicas y estrategias discursivas.

Disputas simbólicas y disputas bélicas.

Procesos de circulación, recepción e internalización del discurso discriminante.

Intencionalidad Sentidos del lenguaje mediático. del Discurso
Información contextualización descontextualización.

El lugar del Sujeto en el discurso de la violencia de "Falsos Positivos"

\section{La generación pública.}

y El papel de los medios de comunicación en la generación de opinión pública sobre el Conflicto Armado en Colombia. López, Fabio. Bonilla, Jorge. 
A partir de estas categorías de análisis elaboraremos la discusión de esta investigación que aborda la construcción social y simbólica del joven, donde desentrañaremos los sentidos del joven víctima de la violencia de "Falsos positivos". En este análisis podremos contrastar los discursos de diferentes enunciadores de campos de la política, lo social y los Derechos Humanos.

De igual manera, en el análisis nos posibilitará debatir sobre el papel que cumplen los discursos mediáticos en la construcción de realidad en el medio del conflicto armado.

\subsection{Diseño metodológico análisis cuantitativo}

En este estudio abordaremos desde una perspectiva cuantitativa la información del corpus. A partir de categorías de análisis temáticas construidas desde el acercamiento académico al análisis del discurso y la lectura de las 297 noticias que hacen parte del corpus analítico de esta investigación. El análisis de la información se ha realizado desde una clasificación temática en la que nos interesa adentrarnos en las frecuencias de aparición de dichas temáticas y de otra parte el análisis

Los objetivos del análisis cuantitativo que nos proponemos alcanzar en este capítulo son los siguientes:

1. Observar las frecuencias de aparición noticiosa sobre el fenómeno de violencia de "Falsos Positivos" en cada uno de los medios de comunicación y los hechos políticos y de violencia en el periodo de 2007 a 2010.

2. Establecer si existe relación entre tendencias ideológicas de los medios de comunicación y la intencionalidad presente en las noticias que forman parte del corpus de este estudio.

\subsubsection{Método e instrumentos}

Como parte del Desarrollo metodológico realizamos un análisis de los datos que hacen parte del corpus de investigación, partiendo de los principios de la investigación cuantitativa, es decir la producción de conocimiento a partir del manejo de datos numéricos. Mediante este tipo de investigación podremos observar la relación que se establece entre medios de comunicación y publicación de noticia inscritas en una tipología temática. Asimismo, este acercamiento nos aportará información sobre la 
relación entre la intencionalidad presente en el discurso y las publicaciones por parte de dichos medios de comunicación.

Para llevar a cabo el análisis de la información se utilizó el programa: Statistical Package for the social- Sciences. SPSS. Para el manejo de datos se clasificó la información en variables de acuerdo a dos tópicos temas y la intencionalidad presente en cada uno de los discursos. El establecimiento de dichas variables se realizó a partir de la lectura previa del total de artículos que hacen parte de este corpus y el análisis de los mismos a luz del marco teórico de esta investigación.

\subsubsection{Fuentes de análisis del discurso}

Las noticias se seleccionaron a partir de tres fuentes: El periódico El Tiempo; El Espectador y Revista Semana, considerados tres medios de comunicación más relevantes del país. Es de tener en cuenta la periodicidad con que se realizan las publicaciones; El Tiempo y El Espectador son medios de circulación diaria y la Revista Semana es magazín semanal.

\subsubsection{Corpus}

Para la selección del corpus de este estudio se efectúo la revisión de la producción de noticias sobre Jóvenes y violencia, en el periodo comprendido entre el año 2007 y 2010 en el contexto nacional, se encontraron 3600 registros distribuidos de la siguiente manera según el medio de comunicación: El Tiempo (1997), El Espectador (1270) y la Revista Semana: (353) noticias en el contexto nacional. Para acotar la investigación se identificó el caso de los "Falsos Positivos" de Soacha como un caso emblemático y propicio para realizar el análisis de la información. En este tema específico encontramos 852 registros noticiosos; los cuales se encuentran distribuidos de acuerdo al medio de comunicación de la siguiente manera: El Tiempo (370); El Espectador (326) y la Revista Semana (156).

Para la selección del corpus aplicamos los siguientes criterios:

- Que la noticia mostrará la presencia de un discurso que abordará el tema.

- Se buscaba observar la presencia de diversos actores del discurso; se evitó que la selección del mismo tema repetidas durante la misma semana (en el caso del Tiempo que se hizo énfasis en las capturas a los militares involucrados y de 
manera repetitiva se expuso la misma noticia, en ese sentido se trató de seleccionar la noticia más completa).

- Se trataba de que el corpus contará con actores discursivos relevantes como es el caso de: los familiares de las víctimas, El gobierno, los militares, la oposición política y los Organismos Internacionales de Derechos Humanos.

- Se buscó un equilibrio en número de noticias entre los medios ya que se tuvo en cuenta que la periodicidad de publicación de los tres medios no es la misma, ya que los periódicos El Tiempo y El Espectador (diario) y la Revista Semana (Semanal).

El corpus de esta investigación se constituyó de la siguiente manera: Un total de 297 artículos, de los cuales 101 son del periódico El Tiempo, 109 del periódico El Espectador y 87 de la Revista Semana. Todos los artículos fueron publicados en entre los años de 2007 y 2010, teniendo en cuenta lo observado por los informes de Derechos Humanos que expresan que desde el 2007 se dio inicio a la desaparición sistemática de población joven de Soacha que se convirtió en víctima de este tipo de violencia.

\subsubsection{Clasificación temática de los artículos}

Los temas de los que se observó su aparición en las noticias de establecieron de acuerdo al interés de encontrar la relación de la violencia con las construcciones discursivas del joven, en los hechos concretos de la violencia que se denominó Falsos Positivos", a partir de la revisión teórica sobre el discurso mediático, violencia y juventud identificamos los siguientes ITEMS como relevantes en la investigación.

\subsubsection{Categoría violencia}

En este bloque se agrupan las noticias que aborden el tema específico de la violencia relacionada con el contexto y el tema de los "Falsos Positivos". En este marco se tendrá en cuenta los temas de violencia política, la violencia social y delincuencial y la violencia contra los jóvenes. Las cuales describiremos a continuación.

a) Violencia política

Al referirnos al concepto de violencia política estamos haciendo referencia a la agresión realizada por el Estado o fuerzas paraestatales (paramilitares) contra grupos sociales en razón a su pertenencia política, social o étnica. A través del seguimiento de los 
Organismos de Derechos Humanos se ha podido comprobar la persecución constante a los jóvenes del sector territorial del sur de Bogotá, por lo que la violencia de "falsos positivos" se enmarca dentro de la violencia política.

b) Violencia Social y delincuencia.

La violencia social y delincuencia, es entendida como aquella forma de violencia ejercida en los territorios, ya sea por la presencia de conflictos sociales no resueltos o por la participación de la juventud en expresiones de asociativas tales como: pandillas, bandas y otro tipo de grupos que tengan como fin actos de delincuencia.

\section{c) Violencia contra los jóvenes.}

La violencia contra los jóvenes es asumida como aquella forma de violencia directa ejecutada contra los jóvenes por parte de miembros de la fuerza pública u otras organizaciones de carácter paramilitar. Dicha violencia tiene como objetivo al sujeto joven, ya sea en la búsqueda de involucrarlo en el conflicto armado o de reprimirlo en razón de su pertenencia identitaria juvenil. El caso de "falsos Positivos" de Soacha se trata de una violación sistemática de Derechos Humanos contra un grupo específico de jóvenes, por parte de las fuerzas del Estado colombiano.

\subsubsection{Categoría de Discurso}

En esta categoría exploramos la presencia discursiva en el corpus proveniente de sectores como las víctimas, el gobierno, los militares, la oposición y los organismos internacionales. A continuación, mostramos cada una de las temáticas que pertenecen a esta categoría.

\section{a) El discurso de los familiares de las víctimas}

En este tema agrupamos el discurso proveniente de los familiares de las víctimas, que relatan que dan cuenta de los hechos de violencia contra los jóvenes; los testimonios sobre quienes eran las víctimas y la lucha de las madres y de otros familiares por la justicia y la recuperación del nombre de los jóvenes asesinados y hechos pasar por combatientes guerrilleros. 
b) El discurso del gobierno

Este tipo de discurso está referido a la posición de miembros del gobierno colombiano en relación a los graves hechos de violencia acontecidos contra la población joven. Con ello nos interesa explorar la respuesta gubernamental a tan graves hechos de violencia.

\section{c) El discurso militar}

En este discurso es de nuestro interés explorar los planteamientos públicos de las Fuerzas militares colombianas, responsables directos de la violencia ejercida contra los jóvenes en el marco de los "Falsos Positivos".

\section{d) El discurso de la oposición política.}

En este discurso se tiene en cuenta los pronunciamientos realizados por los miembros de partidos políticos opositores al gobierno de este periodo temporal. Quienes son críticos de su política de represión y representan una de las voces a favor de la búsqueda de justicia de este hecho de violencia contra los jóvenes.

\section{e) El Discurso de la Sociedad Civil}

En este discurso se engloban los pronunciamientos de miembros de organizaciones sociales y de Derechos humanos de índole nacional sobre los hechos de violencia sucedidos en el marco de los mal denominados "Falsos Positivos".

\section{f) El discurso de los Organismos Internacionales de Derechos Humanos}

La grave situación de Derechos Humanos en Colombia conllevó a la intervención de los Organismos internacionales como Naciones Unidas; la comisión de la Organización de los Estados Americanos (OEA), Amnistía internacional entre otros.

\subsubsection{Categoría de contexto político}

El análisis del discurso mediático se ha planteado en relación al contexto político y social del país, en el periodo de análisis de esta investigación, para lo cual se determinaron tres aspectos coyunturales de interés nacional: Estos temas son: Electoral, Seguridad democrática y Violación de Derechos Humanos. Presentamos una descripción de estos temas. 
a) Electoral.

La presencia de Elecciones parlamentarias y presidenciales en el 2010, hacen que los hechos se presenten en un contexto pre- electoral, en este sentido nos interesa observar la relación de esta particularidad del contexto en el discurso mediático de la violencia ejercida contra los jóvenes.

\section{b) Seguridad Democrática.}

El caso específico de los "Falsos Positivos" se realizó en el marco de la política Seguridad Democrática implementada por los gobiernos del presidente Uribe. En el contexto de dicha política se establecieron los estímulos económicos a los militares que obtuvieran resultados en la lucha contra los movimientos subversivos, en este sentido es nuestro interés por observar la presencia de este aspecto en el discurso mediático producido a la violencia de "falsos positivos".

\section{c) Violación de los Derechos Humanos.}

La violación de los Derechos Humanos trata sobre la información de la violación de Derechos Humanos presentes en los artículos de este Estudio; partiendo de la existencia una situación de violación sistemática de Derechos Humanos que se entrecruza con la violencia ejercida contra los jóvenes denominada "Falsos Positivos".

\subsubsection{Categoría de Representación social del joven}

De acuerdo con la revisión del marco teórico encontramos como dos conceptos importantes en dicha representación; víctimas y victimarios; son dos de las formas significativas de nombrar a los jóvenes en su relación con la violencia. En este sentido nos interesa observar la aparición de estos dos conceptos en los artículos de este estudio. Estos conceptos serán expuestos a continuación.

\section{a) Victima}

Este concepto reúne la aparición en el discurso del sujeto joven como víctima del ejercicio de la violencia tanto del Estado colombiano, como otras fuerzas paraestatales o miembros de organizaciones de la delincuencia. 


\section{b) Victimario.}

Bajo esta variable nos interesa agrupar las apariciones en el discurso mediático de representaciones del joven como actor de violencia, así como posibles hechos de violencia en los que el joven del sector de Soacha se haya visto involucrado como parte activa de la agresión.

\subsubsection{Categoría de Organización social juvenil y comunitaria}

Ante la importancia que el discurso mediático otorga la relación violencia y juventud, se consideró relevante para esta investigación abordar los temas de organización juvenil, dado que es ésta una de las estrategias utilizada por los jóvenes para contrarrestar los imaginarios que se producen alrededor las conceptualizaciones del joven como violento. En este marco se establecieron los temas: Cultural y artística, comunitaria y política, los cuales serán expuestos a continuación.

\section{a) Cultural y artística}

Dentro de ésta se consideran las experiencias que resaltan el arte y manifestaciones culturales juveniles, que aparecen nombradas en los artículos de este estudio. Así como aquellos artículos que abordan las manifestaciones culturales que hacen parte de las expresiones juveniles.

\section{b) Comunitaria.}

En este tema nos interesa observar la presencia en los artículos de aspectos como las apuestas de organización juvenil en pro de sus comunidades, así como aquellas acciones del sector poblacional joven que van encaminadas a la integración y el desarrollo comunitario.

c) Política.

Se trata de establecer en los artículos la aparición de experiencias de participación tanto en iniciativas locales como nacionales de carácter de decisión y acción política. En esta categoría tendrán cabida artículos relacionados con la participación de la juventud en espacios como los Concejos Locales de Juventud, las Juntas de Acción Comunal, los Comités de Planeación local o municipal, así como la participación en partidos políticos y asociaciones de la sociedad civil. 


\subsubsection{Categoría de Estigmatización}

De acuerdo a la revisión teórica se considera que el tema de la estigmatización es un aspecto relevante en las prácticas discursivas sobre los jóvenes y la violencia, por ello consideramos importante tener en cuenta los temas de estigmatización por territorio y estigmatización, estigmatización juvenil.

a) Estigmatización del Territorio.

En esta variable se reúnen las apariciones en el discurso de aspectos que asocian el territorio de esta investigación con violencia, ya sea desde las tipologías de violencia social, política y delincuencial. Se aborda la presencia en los discursos de constructos sociales que se califiquen negativamente el territorio de este estudio, desde aspectos como la asociación a la historia de violencia del país o con hechos derivados del conflicto armado interno.

\section{b) Estigmatización juvenil.}

En este tópico se recoge la presencia en el discurso de asociaciones del joven con la violencia o con elementos que lo pongan en desventaja con otros sectores sociales. De otra parte, también se observan aquellos artículos que tratan el tema de la estigmatización como un problema social.

\subsubsection{Categoría de Derechos Humanos}

Hace referencia a la aparición dentro de los artículos de este estudio de aspectos relacionados con el contexto de la violación de los Derechos Humanos, Para ello hemos establecido los siguientes aspectos: Violación de Derechos Humanos, justicia y procesos judiciales e impunidad.

\section{a) Violación de Derechos Humanos}

En este tema se recogen aspectos relacionados con las violaciones de los Derechos Humanos en el sector de investigación. No sólo que hagan referencia la violación de los derechos de los jóvenes sino contra la población en general. En esta variable se recogen los datos que estén relacionados con hechos de violencia ejercidos por miembros del Estado contra la población civil y que infrinjan los Derechos Humanos y el Derecho Internacional Humanitario. 


\section{b) Justicia}

En esta variable nos interesa abordar las apariciones en los diferentes artículos del discurso sobre el juicio y castigo a los responsables de los hechos de violencia contra los jóvenes, así como las lecturas a la administración de justicia presentes en los discursos de los diversos actores citados en los artículos de prensa que hacen parte de este corpus. De igual manera, se inscriben en esta variable los artículos relacionados con la sanción por parte de organismos de justicia internacional tales como la Corte Interamericana de Derechos Humanos y la Corte Penal internacional entre otros.

\section{c) Procesos judiciales.}

En este caso se hace referencia a la aparición en las noticias de los procesos penales de administración de justicia llevados por las autoridades judiciales en contra de los responsables de la violencia contra los jóvenes, específicamente en el tema de los Falsos Positivos.

\section{d) Impunidad.}

Este aspecto hace referencia a la aparición en las noticias que se expresen en relación con la falta de justicia o los pocos resultados de la misma para penalizar los hechos de violencia acontecidos en el caso que recoge esta investigación. Así como aquellos artículos que tengan como tema los obstáculos para construir la verdad sobre la violencia contra los jóvenes y los mecanismos de evasión de la justicia utilizados por perpetradores de violencia enmarcada en los "Falsos Positivos".

\subsubsection{Intencionalidad de los discursos mediáticos}

En el marco de este estudio comprendemos la intencionalidad como el mensaje contenido en los artículos, que tiene como finalidad la generación de una reacción de la opinión pública; partimos de lo expuesto en el marco teórico que hace parte de esta investigación donde se afirma que el discurso mediático está relacionado con las tendencias ideológicas de los medios de comunicación. Para la descripción y análisis de los datos sobre la intencionalidad se han construido las siguientes categorías. 
a) Ofrecer una información contextualizada sobre la violencia contra los jóvenes..

Se reconoce que existe está tendencia cuando el articulo presenta los hechos de violencia contra los jóvenes en relación con el contexto político, la violación sistemática de los Derechos Humanos, las políticas de seguridad democrática y la violencia histórica en contra del joven popular. Así como se tienen en cuenta aspectos de la violencia estructural y cultural que afectan al país.

b) Ofrecer una información incompleta y confusa sobre la violencia contra los jóvenes.

En esta categoría se consideran los artículos que no establecen relación alguna con aspectos como la violencia política, la violación sistemática de los Derechos Humanos de los jóvenes. Se observa la violencia de los "Falsos Positivos", como un caso que involucra algunos miembros de la fuerza pública y no se tienen en cuenta las relaciones con el conflicto armado interno ni con la política de seguridad democrática llevada a cabo por el gobierno del Presidente Uribe.

\section{c) Construir opinión pública de reconocimiento a las víctimas}

En esta categoría se inscriben los artículos que abordan el tema de las víctimas desde un discurso que reconoce su componente humano, además del reconocimiento de su estatus de joven como miembro de una comunidad, grupo social y familia. En este discurso tiene especial sentido los relatos de sus familiares que contribuyen a ver al joven en su contexto de humanización.

\section{d) Atraer audiencia a través del lenguaje sensacionalista.}

En este discurso se observa la exposición de los hechos acontecidos de manera dramática enfatizando en la atrocidad de los hechos violentos o en lo dramático de las historias del joven. Lo cual tiene como objetivo atraer lectores a través del sensacionalismo.

e) Denunciar ante la opinión pública los hechos de violencia contra los jóvenes.

En esta categoría se consideran los artículos que ponen de manifiesto la responsabilidad del Estado, las fuerzas militares y grupos paramilitares en la violencia contra los jóvenes, así como muestran la impunidad en que permanecen los hechos. 


\section{f) Construir Opinión pública a favor del Estado}

En esta categoría se inscriben los artículos que enfatizan en el papel de los procesos penales y judiciales como actos efectivos de justicia. Que el medio de comunicación con mayor número de noticias.

\subsection{Síntesis}

En este capítulo hemos expuesto la metodología que será utilizada en este estudio, especialmente hemos hecho énfasis en el análisis del discurso como método pertinente para dar sentido a los discursos de violencia contra los jóvenes, especialmente denominada violencia de "Falsos Positivos". Hemos presentado una discusión teórica sobre el análisis de discurso desde la perspectiva de la Escuela Francesa lo cual nos permite comprender que el abordaje de los discursos se enmarca tanto en elementos estructurales como coyunturales, así como en el análisis de las relaciones de poder y dominación.

En este diseño metodológico consideramos importante analizar la violencia de "falsos positivos" desde elementos expuestos por parte de la perspectiva de la Escuela Francesa, tales como: las condiciones de producción, reproducción de los discursos y circulación de los discursos, las relaciones de poder y las formaciones ideológicas.

En este capítulo se presentan las categorías de análisis para el análisis cualitativo, estructuradas a partir de las aportaciones teóricas y la primera lectura de los artículos pertenecientes al corpus de este estudio. Las categorías identificadas para el desarrollo de este análisis fueron las siguientes: Discurso mediático, Violencia contra los jóvenes, constructo social del joven popular en los medios de comunicación e Intencionalidades de discurso mediático.

En este estudio desarrollamos un análisis cuantitativo sobre el total de artículos analizados. A partir de dos categorías: Las temáticas expuestas en las noticias y las intencionalidades presentes en el discurso. La elaboración de subcategorías se realizó a partir del análisis de los artículos y la lectura a luz de la teoría de medios de comunicación y producción noticiosa.

El análisis del discurso desde la perspectiva de la Escuela Francesa nos permitió identificar y analizar las materialidades sociales, simbólicas y culturales que están 
presentes en el discurso mediático sobre la violencia contra los jóvenes en el marco de la violencia denominada "Falsos Positivos". De esta manera este método nos posibilitó hacer una reflexión teórica sobre la configuración del constructo del joven popular en el marco de esta violencia, asimismo reconocer el papel de este medio de comunicación en las construcciones de nociones de realidad en el marco del conflicto armado. 


\section{CAPITUlO V. DESARROLLO METODOLÓGICO DE LA}

INVESTIGACIÓN. APROXIMACIÓN CUANTITATIVA

5.1. Descripción y análisis de datos.

5.2. Configuración del Corpus.

5.3. Frecuencias de aparición temas.

5.4. Categorías.

5.6. Análisis de Frecuencia de Aparición Temática y Tendencias Ideológicas de los Medios de Comunicación.

5.7. Intencionalidad.

5.8. Síntesis. 



\section{CAPÍtulo V. DESARROLlo METOdológico DE LA INVESTIGACIÓN. APROXIMACIÓN CUANTITATIVA}

En este capítulo abordaremos desde una perspectiva cuantitativa la información del corpus de este estudio. A partir de categorías de análisis temáticas construidas desde el acercamiento académico al análisis del discurso y la lectura de las 297 noticias que hacen parte del corpus analítico de esta investigación. El análisis de la información se ha realizado desde una clasificación temática en la que nos interesa adentrarnos en las frecuencias de aparición de dichas temáticas y además el análisis intencionalidad a partir de la clasificación en siete categorías de análisis: violencia, discurso, contexto político, estigmatización, representación social del joven, organización social juvenil y derechos humanos. Todo ello nos permitirá observar la relación entre las tendencias política y la intencionalidad.

\subsection{Descripción y análisis de datos}

La descripción de datos se desarrollará a partir de la presentación de gráficas, las cuales agrupan los datos obtenidos por temas y el análisis se desarrollará a partir de los datos y su relación con el contexto político y las tendencias ideológicas de los medios de comunicación.

\subsection{Configuración del Corpus}

El corpus de esta investigación está constituido por 297 artículos pertenecientes a tres medios de comunicación escritos, la distribución de artículos por medio se señala en la Figura 1.

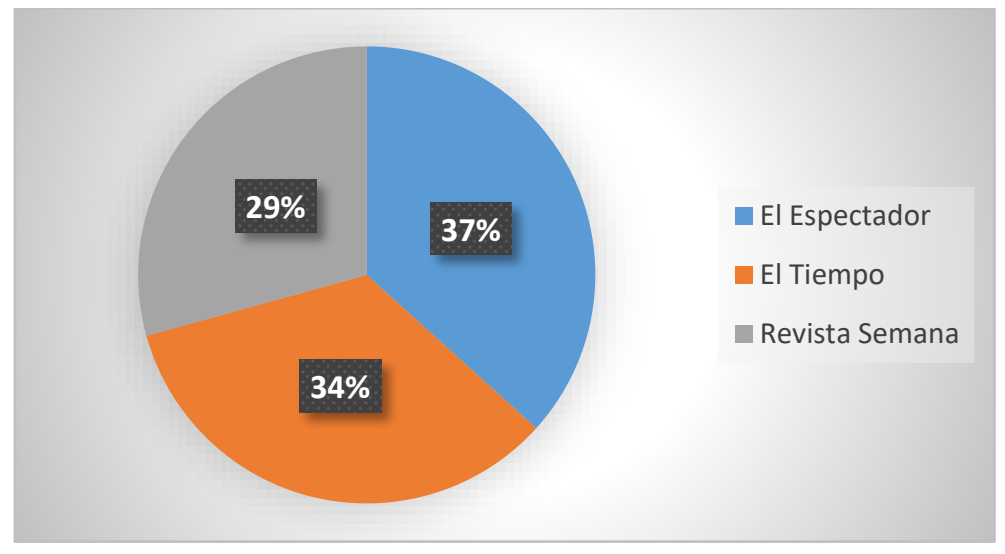

Figura 1. Distribución de artículos por medio 
El Espectador es el medio que mayor aporta datos al corpus con $37 \%$, seguido por El periódico El Tiempo con un 34\% y por último, la Revista Semana con un 29\% de noticias. La distribución de datos se da de acuerdo al número de noticias presentadas por cada uno de los medios de comunicación, es necesario tener en cuenta que los dos periódicos tienen publicaciones diarias y la Revista Semana es publicada semanalmente por lo que se explica el menor número de artículos de este medio de comunicación.

\subsection{Frecuencias de aparición temas}

Para el análisis de la información en este estudio nos interesa observar cuáles son las frecuencias de aparición en las noticias que hacen parte del corpus de esta investigación; con el fin de saber si existen prevalencias temáticas de acuerdo al medio de comunicación. A continuación, mostramos las frecuencias de aparición de acuerdo a las categorías de análisis distribuidas de la siguiente manera.

\subsection{Categorías}

\subsubsection{Categoría de violencia}

La categoría violencia está conformada por las variables: Violencia Política, Violencia Social y Violencia contra los jóvenes. La distribución de los datos de las frecuencias de aparición noticiosa se verá reflejada en la Figura 2.

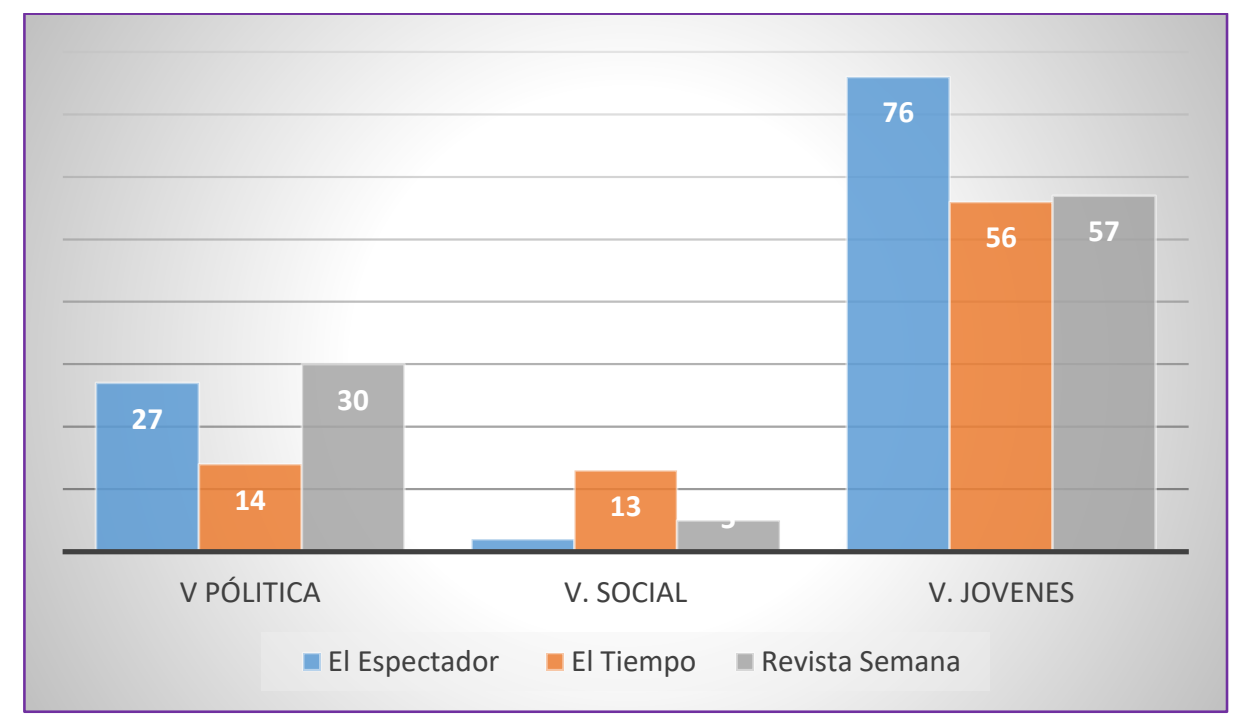

Figura 2. Frecuencia de aparición de violencia

En la Figura 2 podemos observar que con respecto a la Violencia Política el medio de comunicación con un número mayor de noticias en este tema es la Revista Semana con 
30 artículos, seguida por El Espectador y con una mayor diferencia el periódico El Tiempo. Estos datos indican la existencia de una relación entre tendencia ideológica y la frecuencia de publicación en este tema. Los datos reflejan que los dos medios de comunicación con mayor cercanía ideológica (El Espectador y La Revista Semana) también poseen mayor tendencia a la publicación en el tema de violencia política.

La publicación de noticias sobre Violencia Política presentó una restricción en el medio oficialista El Tiempo, dicha frecuencia coincide con la tendencia gubernamental de omitir la información sobre este tema dado que desde las fuentes gubernamentales se desconoció la presencia de un Conflicto Armado en el país, como una estrategia de ocultamiento de la verdad propias del periodo presidencias de Álvaro Uribe.

Con respecto a la variable violencia social y delincuencia observamos que el periódico El Tiempo con 13 artículos tiene el mayor número de publicaciones. Aunque el registro de publicaciones de este tema es baja en todos los medios; es llamativo que sea el periódico El Tiempo el que presente mayor número publicaciones en este tema.

Por último, el tema de Violencia contra los Jóvenes el periódico con mayor información sobre este tema es el periódico El Espectador con 76 noticias, de esta manera posee 20 artículos más que los otros dos medios de comunicación, mientras que los otros dos medios de comunicación (El Tiempo y la Revista Semana) se comportaron de manera muy similar en la producción noticiosa de este tema.

Con respecto a los datos generales llama la atención la preponderancia del tema de la Violencia contra los jóvenes, con respecto a las otras dos variables, como lo podemos observar en la Figura 3. 


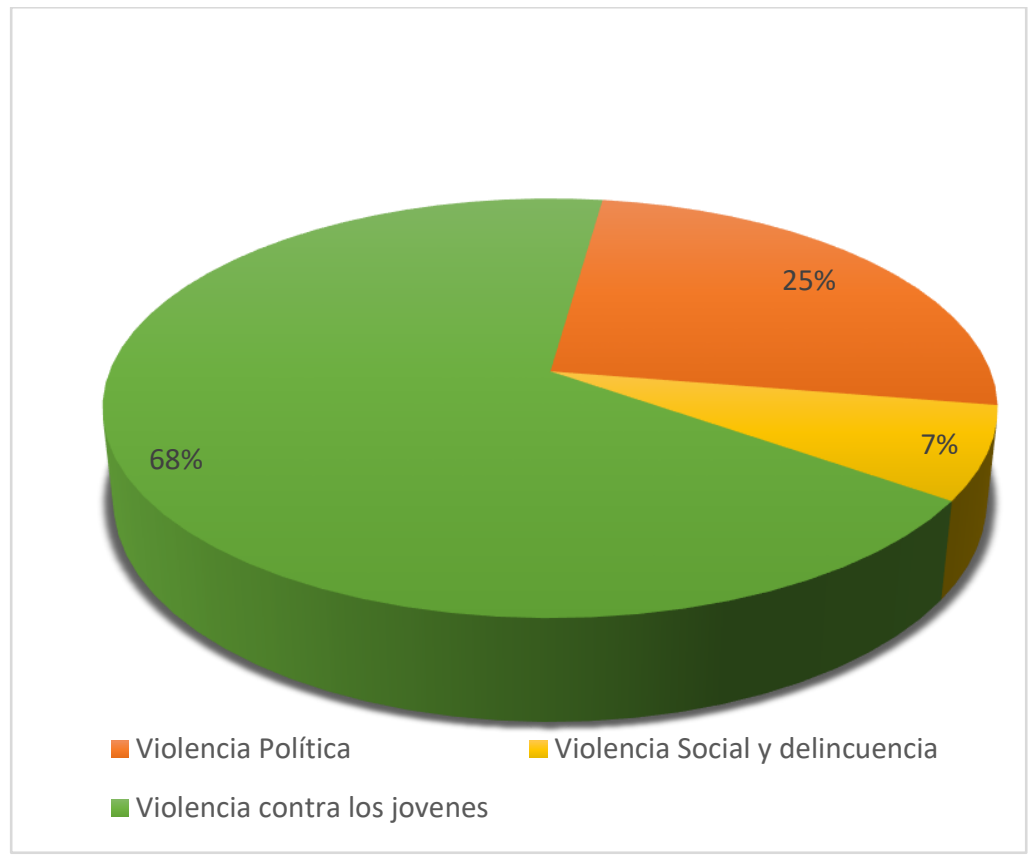

Figura 3. Porcentaje de aparición de violencia

La mayor frecuencia del tema de Violencia contra los jóvenes con un porcentaje del $68 \%$ frente a un $25 \%$ de la violencia política y un $7 \%$ en la violencia social. La preponderancia en el tema de la violencia contra los jóvenes adquirió una relevancia a partir del destape del escándalo de los “Falsos Positivos" al quedar en evidencia que la violencia sistemática de las Fuerzas Armadas colombianas contra los jóvenes en el marco de la política de Seguridad Democrática adelantada por el gobierno.

Con respecto a la Violencia Política observamos con interés el significativo menor número de publicaciones, dado que en el periodo de este estudio según los informes de las organizaciones de Derechos Humanos incrementó sustancialmente la violencia. Asimismo, podemos ver que las noticias sobre el tema Violencia Social y Delincuencia es muy baja, lo que puede explicarse desde la importancia que adquirió el tema de la Violencia contra los jóvenes a partir de los Falsos positivos.

\subsubsection{Categoría Discurso}

La categoría de Discurso está compuesta por los Discursos: Familiares de las víctimas, Sociedad Civil, Militar, Oposición política, Gobierno y Organismos Internacionales de Derechos Humanos. La distribución de los datos se ve reflejada en la Figura 4. 


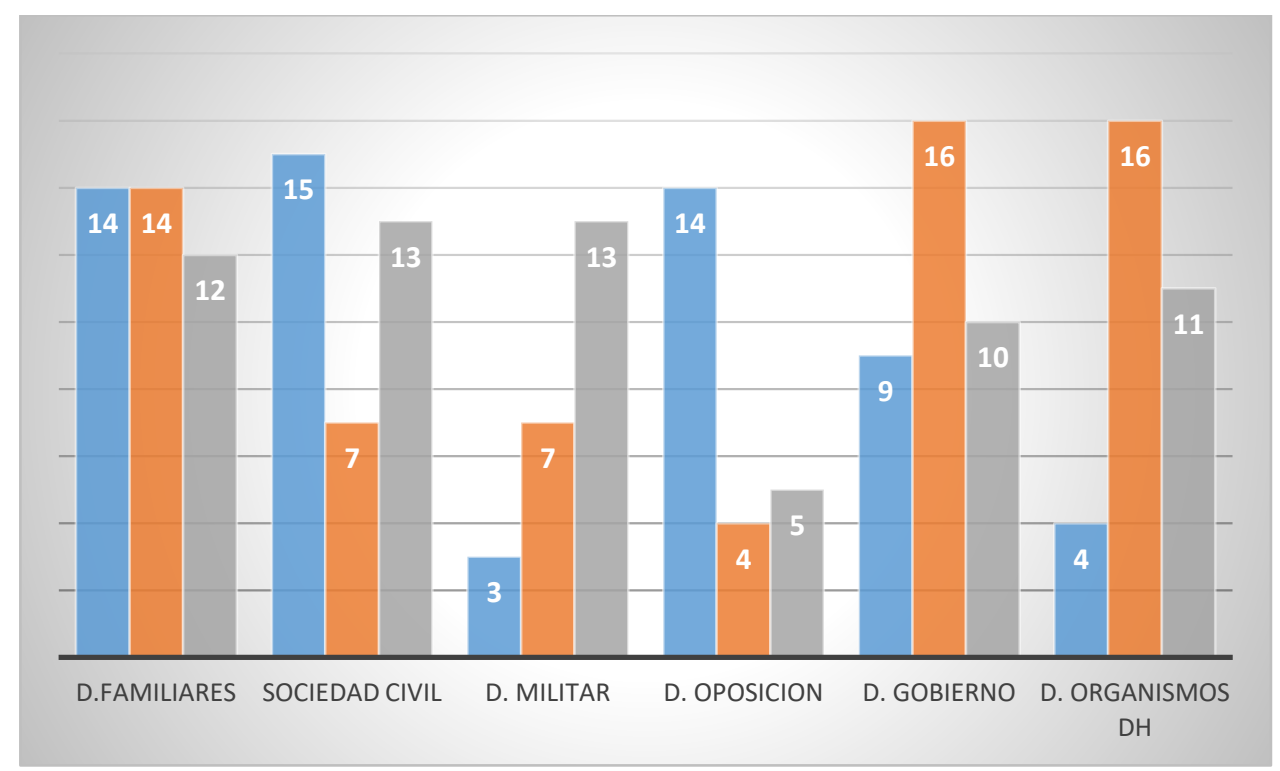

Figura 4. Frecuencia de aparición de discurso

En el Figura 4 podemos observar que con respecto a la variable Familiares de las víctimas, la distribución de los datos es muy similar en los tres medios de comunicación, La Revista Semana con 12 artículos es el medio con menor publicación en este tema, Los otros dos medios lo superan por sólo 2 puntos.

Estas frecuencias de aparición responden a la tradición del ejercicio periodístico sobre el tema de la guerra en el país, donde ha tenido muy poca visibilidad el testimonio de las víctimas, así como también es de anotar que como ya expusimos: el perfil de las víctimas hace referencia a jóvenes que excluidos socialmente, por tanto sus familiares han tenido que buscar el reconocimiento para que su voz tenga escucha.

Asimismo, es necesario tener en cuenta que en este hecho de violencia se hicieron pasar civiles por guerrilleros muertos en combate y que la versiones tanto del gobierno (en sus inicios) y las fuerzas militares trataron de que a nivel discursivo y simbólico fueran vistos como delincuentes, por tanto, no es relevante para estas posturas conocer la historia de los jóvenes víctimas y que se evidencie su condición de joven popular muy similar a los sectores que pertenecen a este grupo poblacional y que por tanto cualquier joven del territorio hubiese podido ser víctima de esta violencia en razón a su residencia en el sector y su situación de vulnerabilidad. 
Con respecto a la variable Discurso de la sociedad civil, podemos observar que el tema aparece con mayor frecuencia en el periódico El Espectador con15 datos, con mucha cercanía de la Revista Semana a tan sólo 2 artículos y en menor medida en el periódico El Tiempo con 7 registros en este tema. Esta distribución de los datos muestra una tendencia en la cercanía entre los dos medios afines ideológicamente: Revista Semana y El Espectador. Lo cual es acorde con la tendencia de los medios más oficialistas a dar poca importancia a fuentes que no se relacionen con el gobierno $\mathrm{u}$ órganos de poder económicos o políticos.

En la variable Discurso Militar observamos que la Revista Semana con 13 datos es el medio de comunicación con mayor número de artículos, seguido con una diferencia de 6 artículos por el periódico El Tiempo, es de anotar el reducido número de publicaciones del Espectador que sólo tiene 3 artículos. La existencia de una relación entre la tendencia ideológica de los medios de comunicación y producción noticiosa en este tema se ve reflejada en el mayor número de publicaciones de la Revista Semana medio de comunicación que se caracterizó por hacer visible la violación de Derechos Humanos realizada por este medio de comunicación.

Con respecto a la variable Discurso Oposición, El Espectador con 14 artículos tiene el mayor número de publicaciones en este tema superando con 9 artículos a la Revista Semana con 5 artículos. El periódico El Tiempo ocupa el último lugar con 4 publicaciones. En cuanto a la relación de la tendencia ideológica y frecuencia de publicación de este tema sólo se identifica claramente en el periódico El Espectador.

Con respecto al Discurso del Gobierno, el medio con mayores publicaciones en este tema es El Tiempo con 16 artículos, superando a la Revista Semana que cuenta con 10 artículos, mientras que El Espectador se encuentra en el último lugar con 9 artículos. El primer lugar del Tiempo puede estar ligada a la tendencia ideológica de este medio de carácter oficialista.

Por último, el Discurso de los Organismos internacionales de Derechos Humano observamos que el periódico El Tiempo con 16 artículos tiene el mayor número de publicaciones en esta variable, seguido por la Revista Semana con 11 publicaciones y por último el periódico El Espectador con 4 artículos. La frecuencia de aparición de esta variable nos revela que existe una marcada diferencia en estos tres medios y no se puede 
establecer una relación entre tendencia ideológica de los medios de comunicación y frecuencias de aparición de este tipo de discurso.

- Distribución datos según el tipo de Discurso

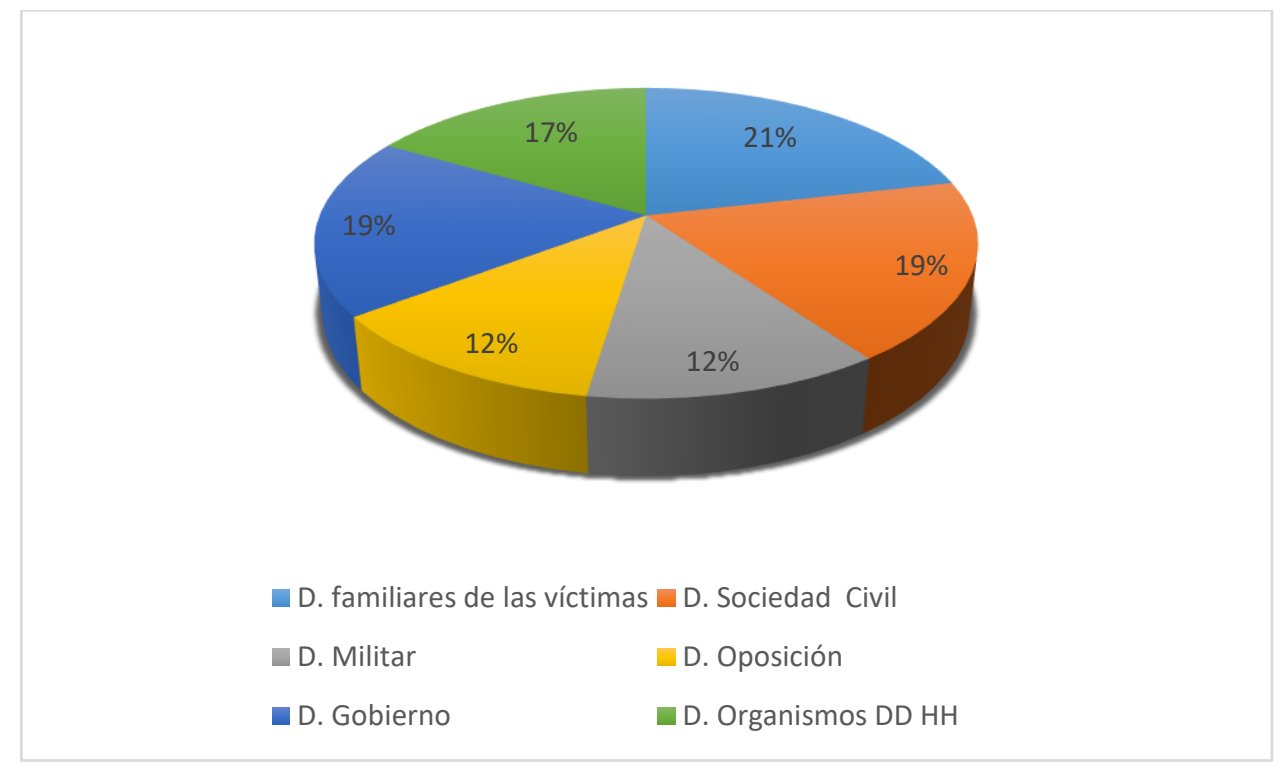

Figura 5. Porcentaje de aparición del tipo de discurso

En la Figura 5 podemos observar que los dos tipos de discurso que más se presentan son los de Familiares de las víctimas y Sociedad Civil con el 19\% del total de los datos encontrados en este tema, seguidos por el discurso de los organismos de Derechos Humanos con un $17 \%$ y por último se encuentran los discursos oposición y Militar con el $12 \%$ cada uno. Estos datos muestran que no hay una diferencia significativa en términos de frecuencias de aparición por tipo de discurso.

Llama la atención que los porcentajes más bajos se presenten en los discurso militar y de oposición, dado que a pesar de las graves violaciones de los Derechos Humanos por parte de las fuerzas militares los medios no dedicarán espacio a las opiniones de este sector y de otro lado, no hubiesen tenido tan en cuenta los discursos de los opositores al gobierno que históricamente han sido excluidos del gobierno. 


\subsubsection{Categoría de Contexto Político}

En esta categoría tendremos en cuenta las variables Electoral y Seguridad Democrática. Dos Temas relevantes en el periodo de investigación. Los datos estadísticos de esta categoría se reflejan en la Figura 6.

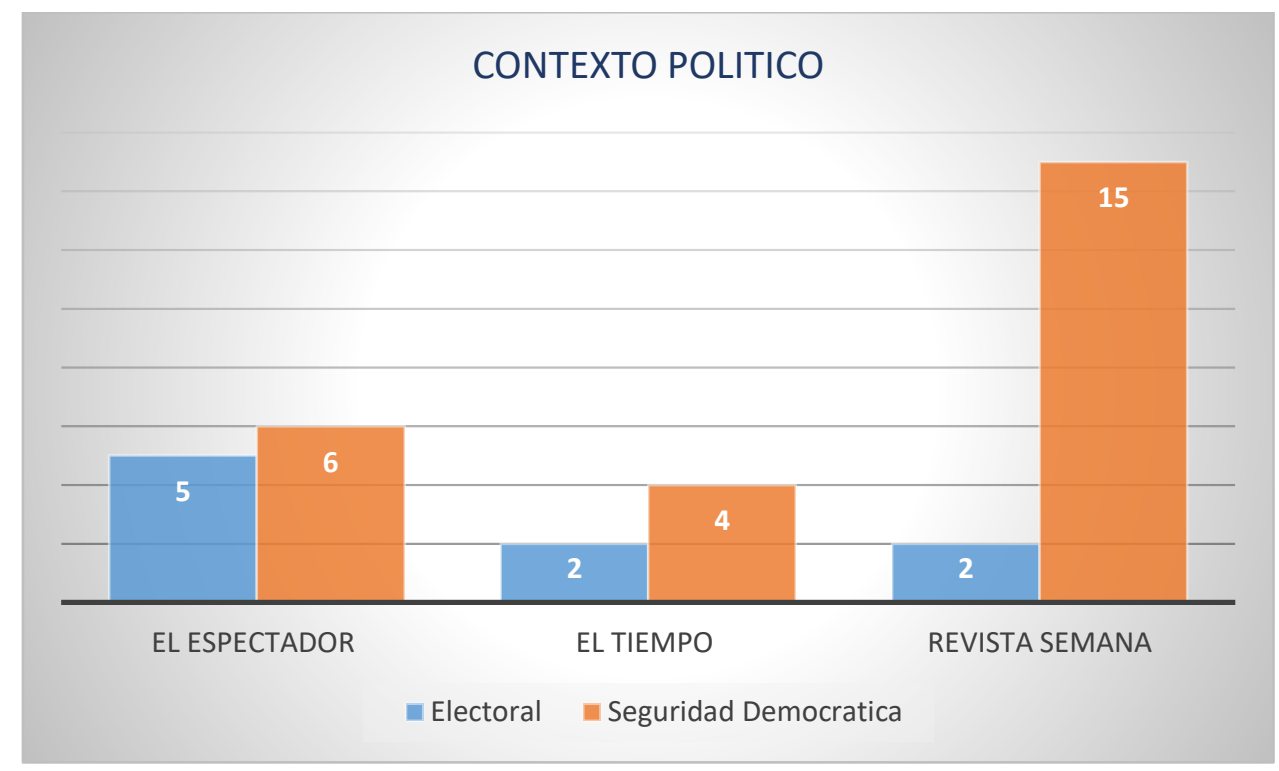

Figura 6. Frecuencia de aparición del contexto político

La aparición del tema electoral es mayor en el periódico El Espectador con 5 artículos y le siguen los otros medios de comunicación con 2 publicaciones cada uno, Resulta llamativo el bajo número de publicaciones que relacionan la violencia de "Falsos Positivos" con el tema electoral si estos temas estuvieron presentes en los debates de los candidatos tanto presidenciales como las parlamentarias.

La variable Seguridad Democrática aparece de manera significativa en la Revista Semana con 15 publicaciones sobre este tema, seguida por el periódico El Espectador con 6 publicaciones y por último el periódico El Tiempo con 5. La distribución de los datos es acorde con la tendencia de la Revista Semana de hacer análisis a la política de Seguridad Democrática y poner en el debate público la coyuntura política del país.

\subsubsection{Categoría de Estigmatización}

En esta categoría se analizarán las variables Estigmatización del joven y Estigmatización del territorio. Nos interesa el análisis de estos dos temas porque han sido identificados 
como los temas mayormente presentes en la categoría de Estigmatización. Podemos observar los datos en la Figura 7.

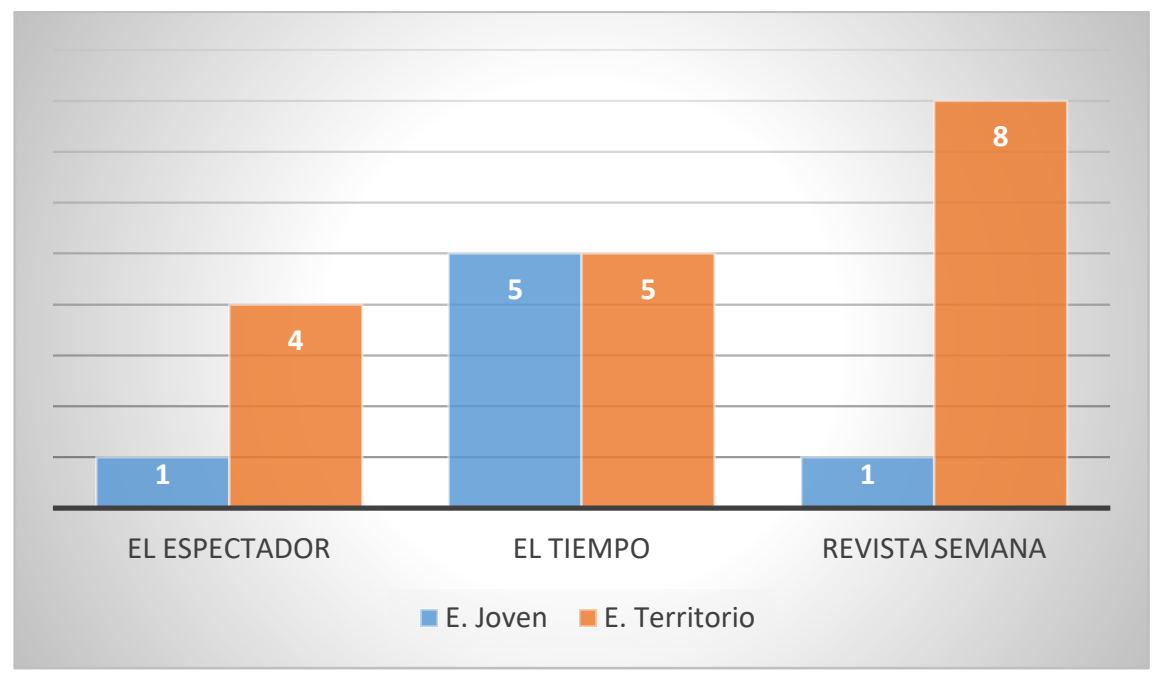

Figura 7. Frecuencia de aparición de estigmatización

La variable de Estigmatización del joven sólo se observa en 7 registros, el periódico El Tiempo con 5 artículos es el medio de comunicación con mayor publicación, mientras que los otros dos medios: La Revista Semana y El Espectador tan sólo presentan 1 publicación en este tema. Llama la atención la baja frecuencia de aparición de este tema, dado que la estigmatización del joven del sur de Bogotá es muy común en los imaginarios nacionales según lo afirmado por estudios académicos citados en el marco teórico de esta investigación.

Los estudios académicos sobre la estigmatización del joven en Colombia exponen la existencia de un lenguaje de estigmatización del joven en periodos anteriores, Al contrario en el periodo de este estudio las publicaciones son bajas esto puede ser interpretado por la importancia que tomo a nivel mediático de la violencia de los "Falsos Positivos".

La Estigmatización del territorio se encuentra en un número mayor de artículos en la Revista Semana con 8 artículos, seguida por El Tiempo y El Espectador con 4 y 5 publicaciones respectivamente. De la misma manera, que la variable anterior el bajo número de noticias en este tema llama la atención y sugiere un análisis del contenido de los discursos para una mayor comprensión del bajo número de publicaciones. 


\subsubsection{Categoría de Representación Social del joven}

La categoría de Representación social del joven presenta dos variables Víctima y Victimario, estos dos constructos sociales responden a las formas de nominación frecuentes en la nominación del joven en el contexto del conflicto Armado Colombiano. En la siguiente Figura 8 se presentan los datos estadísticos de este estudio.

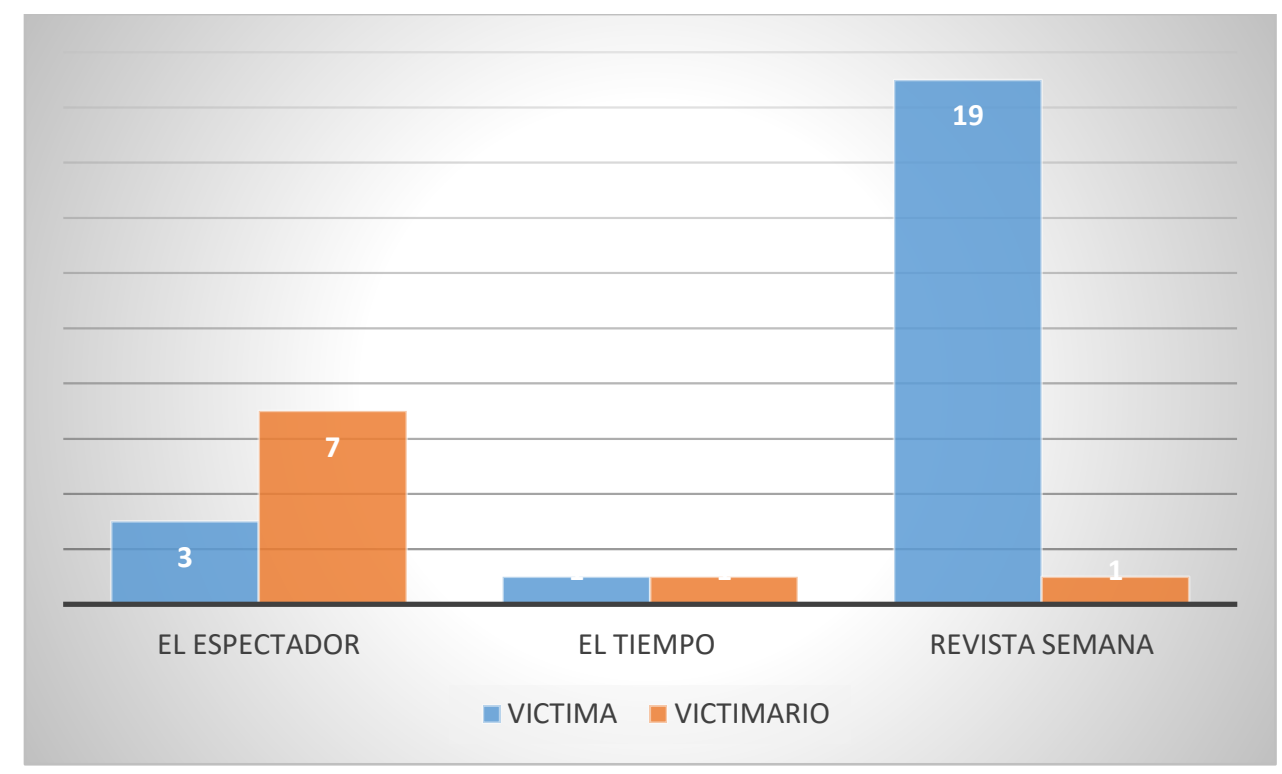

Figura 8. Frecuencia de representación social del joven

La variable víctima se encuentra en un mayor número en la Revista Semana con 19 artículos en este tema y con una significativa diferencia el siguiente medio que es el periódico El Espectador con 3 artículos y por último El Tiempo con 1 articulo. Los datos nos muestran una preponderancia de la Revista Semana acorde con la tendencia de este medio de comunicación por dar mayor relevancia a los sectores afectados por la violencia.

Con respecto a la variable denominada victimario observamos que El Espectador con 7 artículos es el medio de comunicación con más artículos sobre este tema, seguido por los otros dos medios de comunicación que tan sólo tienen 1 artículo en este tema. Los datos correspondientes a este tema son bajos con respecto a la muestra y nos permite identificar de una manera clara la relación entre tendencia ideológica y publicación en este aspecto.

\subsubsection{Categoría de organización social juvenil}

La categoría Organización Social Juvenil está compuesta de las variables: Organización Cultural y Artística, Organización Política y Organización Comunitaria. En la Figura 9 se presentan los datos estadísticos. 


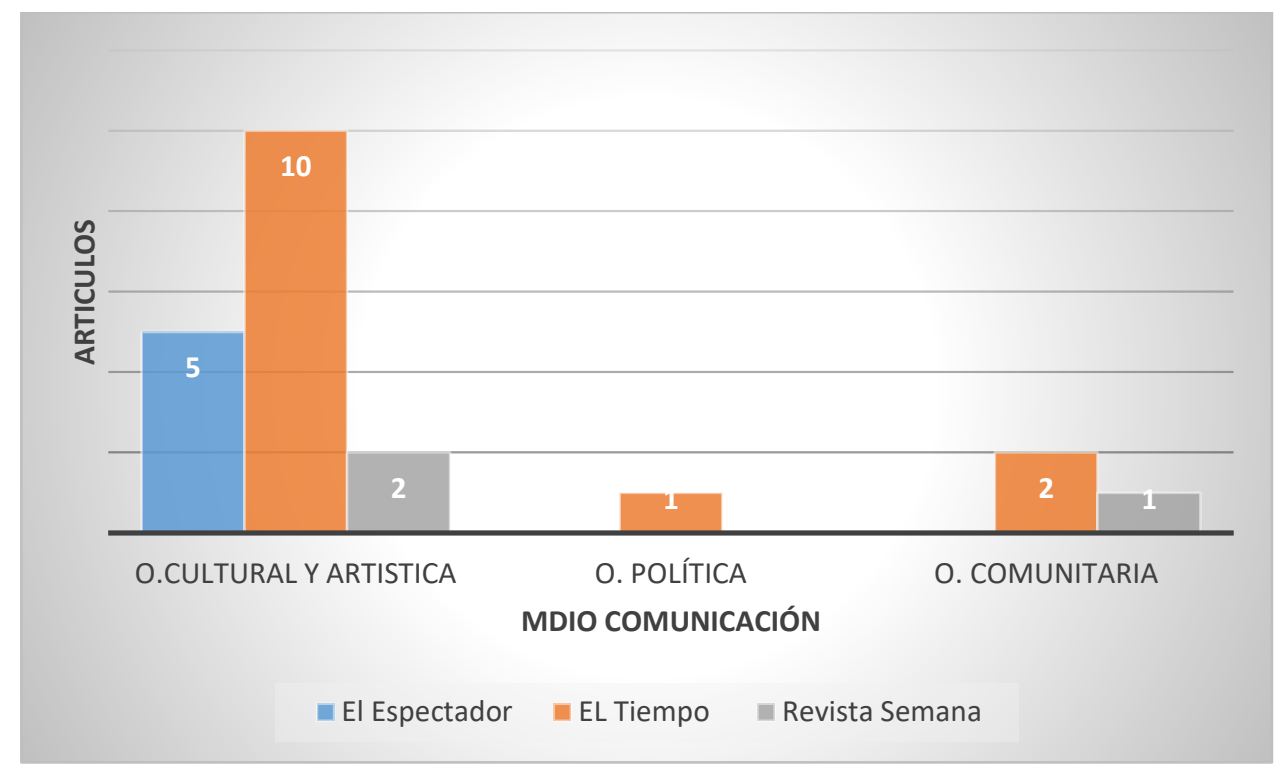

Figura 9. Frecuencia de organización social juvenil

La variable Organización Cultural y Artística aparece en primer lugar en el periódico El Tiempo con 10 artículos superando al periódico Espectador por 5 artículos. La organización comunitaria sólo posee 3 artículos distribuidos así: El Tiempo (2) y la Revista Semana (1). Por último, La variable Organización política sólo cuenta con un artículo publicado en el periódico El Tiempo.

En términos globales corresponde con la tendencia tradicional del discurso mediático de desconocer las diversas iniciativas que desarrollan para el reconocimiento de las acciones de reivindicación de la identidad juvenil emprendidas por jóvenes de sectores populares.

La distribución de los datos no da cuenta de la existencia de una relación entre las tendencias ideológicas y producción de noticias en este tema, por un lado, el número de datos en este aspecto no es significativo y de otra parte en los pocos registros no se muestra una correlación entre la tendencia ideológica de los medios y la publicación de noticias en este aspecto

\subsubsection{Categoría de Derechos Humanos}

\section{Derechos Humanos}

La categoría Derechos Humanos consta de las siguientes variables: Violación sistemática de los Derechos Humanos, Derechos de los Jóvenes, Proceso Judicial e Impunidad. La distribución por tema se puede observar en la Figura 10. 


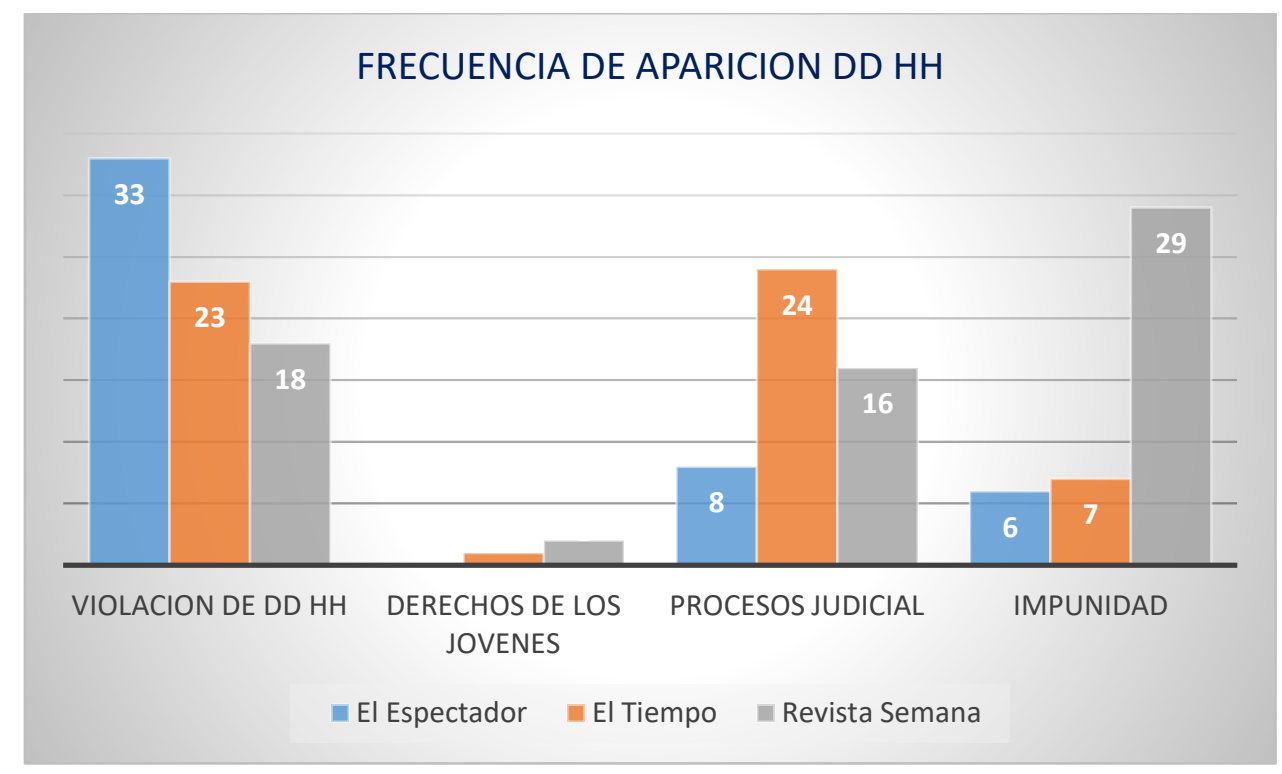

Figura 10. Frecuencia de aparición de DDHH

El tema de violación sistemática de los Derechos Humanos tiene el mayor número de registros se presenta en el periódico El Espectador con 33 artículos lo cual corresponde con una tendencia crítica de este medio al gobierno de este periodo, las publicaciones sobre este tema del periódico El Tiempo y la Revista Semana corresponden a 23 y 18 artículos respectivamente.

La variable Derechos de los jóvenes es muy baja no supera los dos artículos por medio de comunicación, incluso el Espectador no cuenta con ninguna publicación en este tema, por tanto, resulta significativo dada la ausencia de un factor esencial en el análisis de la violencia contra los jóvenes.

EL tema de los procesos judiciales aparece en primer lugar en el periódico El Tiempo con 24 artículos, seguido por la Revista Semana con 16 artículos y por el último el periódico El Espectador con 8 artículos, en la lectura realizada del total de artículos sobre el "Falsos positivos" en el contexto nacional, el periódico El Tiempo se presentan un alto número de artículos relacionados con este tema, en el caso específico de Soacha se mantiene esta tendencia.

La variable Impunidad tiene la frecuencia más alta en la Revista Semana con 29 artículos, dicho medio presenta una diferencia significativa en el siguiente medio que es El Tiempo con 7 artículos y por último El Espectador con 6 artículos, lo anterior evidencia una tendencia de la Revista Semana por este tema de impunidad no sólo en el tema de la 
violencia de los "Falsos Positivos" sino en otros temas de contexto político e interés nacional.

La distribución de las variables relacionadas con la categoría de Derechos Humanos se presentó tal como aparece en la Figura 11.

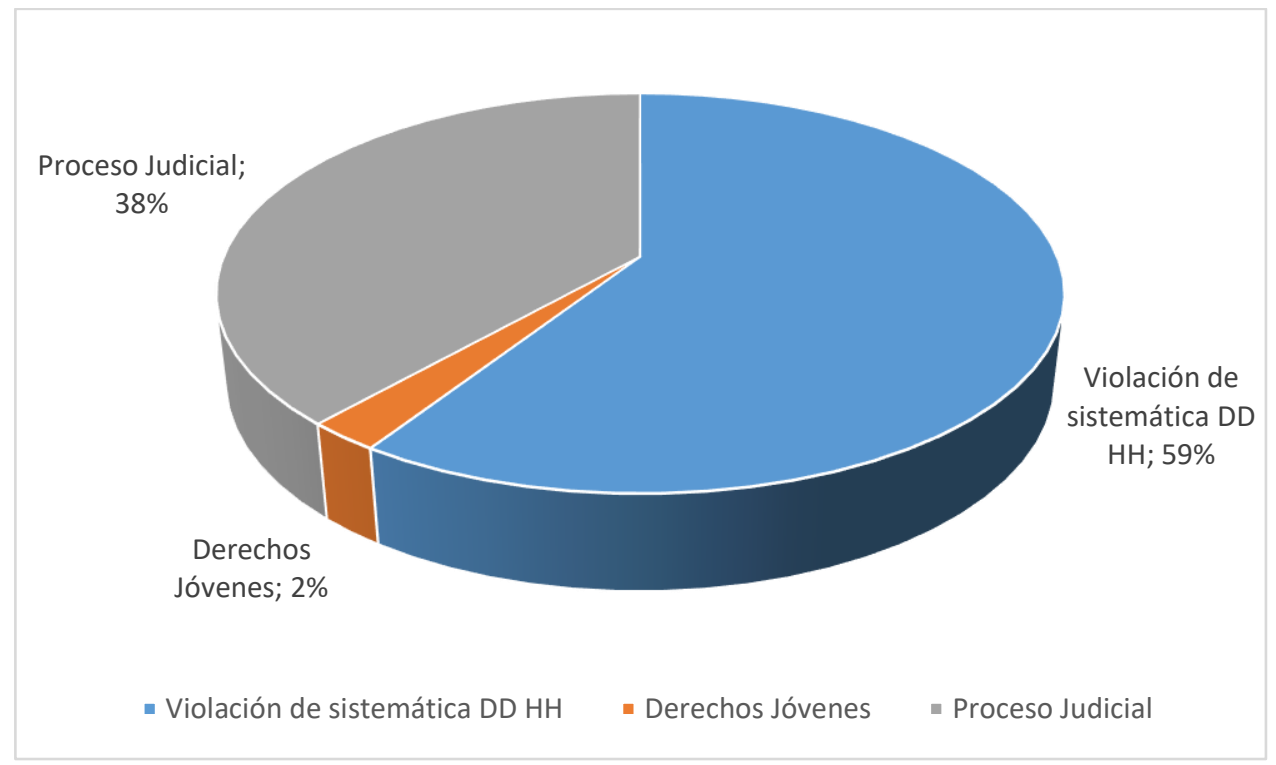

Figura 11. Porcentaje de distribución variables DDHH

La variable de Violación Sistemática de DD HH, con un porcentaje del 59\% el mayor porcentaje en esta variable puede explicarse por la violencia ejercida contra los jóvenes que se inscribe en la violación de los Derechos Humanos. Resulta llamativo el bajo porcentaje del tema de los Derechos de los jóvenes sólo el $2 \%$ de los artículos abordan este tema, en un contexto político marcado por la violencia contra los jóvenes.

\subsection{Frecuencias de aparición violencia por años $(2007-2010)$}

La frecuencia de aparición por años se realizó específicamente para las categorías de violencia y discurso. Este análisis está dirigido a observar si existe relación entre la producción noticiosa y algunos hechos sucedidos en el marco de violencia contra los jóvenes denominada "Falsos positivos". En la aparición por años de estas variables podemos distinguir los siguientes elementos. 
- Violencia por año.

En la Figura 12 se puede observar la frecuencia de aparición de las variables: Violencia política, Violencia social y Violencia contra los jóvenes por cada uno de los 4 años que hacen parte de la temporalidad de este estudio.

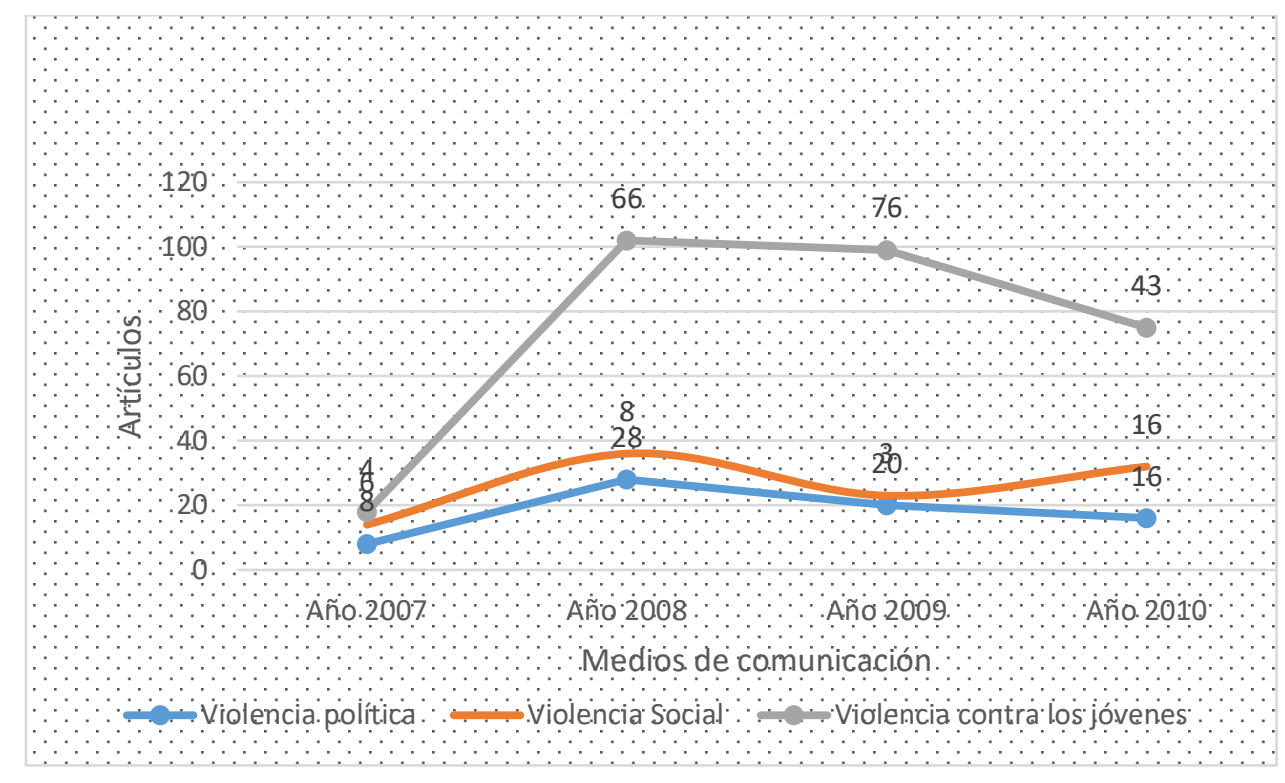

Figura 12. Frecuencia de aparición categoría violencia por año

La Figura 12 nos muestra que el comportamiento de las variables tiene similitud en el año 2007 , los datos de las tres variables no superan los 8 datos. Las variables que presentaron mayor cambio en los siguientes años fueron Violencia contra los jóvenes y Violencia Política. Lo cual se refleja de una manera más llamativa en el tema de violencia contra los jóvenes.

En el año 2008 se presenta un significativo cambio en el comportamiento de las variables de Violencia Política y Violencia contra los jóvenes, la primera incrementa en 20 registros y la segunda en 62 registros, como se puede observar en la Figura 12 el incremento es muy significativo en el tema de violencia contra los jóvenes. El comportamiento de estas dos variables en el año 2009 posee cambios importantes, el tema de Violencia política desciende en 8 registros mientras que el tema de violencia contra los jóvenes incrementa 10 registros con respecto al comportamiento de los datos en el 2008. En el año 2010 se presenta una reducción en el número de publicaciones tanto del tema de violencia política en 4 datos y en la variable violencia contra los jóvenes dicho descenso es notorio con más de 33 datos menos. 


\section{- Análisis de frecuencia de aparición por año}

Este incremento de datos entre 2008 y 2009 responde a lo que se denominó el destape de los "Falsos Positivos", en el mes de octubre de 2008, Hecho que hizo evidente el asesinato de 19 jóvenes del municipio de Soacha por parte de la fuerza pública.

A partir de estos datos podemos establecer que ante la evidencia de que los 19 jóvenes desaparecidos de Soacha, habían sido asesinados por el ejército colombiano, conllevó a que la noticia sobre esta violencia específica contra los jóvenes ocupará centralidad en los medios de comunicación. La gravedad de los hechos no pudo pasar por desapercibida por parte de las Organizaciones de Derechos Humanos nacionales e internacionales, por tanto se convirtió un hecho de debate político que no podía ser soslayado por los medios de comunicación.

La violencia contra la población joven en la zona colindante entre Bogotá y Soacha, ha sido una constante desde la década de 1990, las mal llamadas campañas de "limpieza social", en las cuales se asesinan jóvenes por parte de fuerzas paramilitares, el constante desplazamiento forzado ha sido un tema de denuncia tanto de organismos de Derechos Humanos como de los líderes sociales de la zona. Los informes de la Revista Semana (2005) entre los años de 1990 y 1992 se presentaron 500 asesinatos de jóvenes y entre los años de 2002 y 2005; 210 jóvenes fueron asesinados en el sector.

Dichos informes de los organismos de Derechos Humanos siempre reclamaron la acción de los medios de comunicación, sin embargo, pocos medios de comunicación se atrevieron hacerlo. En el caso de la violencia de "Falsos Positivos" se vio algo distinto, ya que se dio un incremento del número de noticias sobre estos casos.

- Frecuencias de aparición de los discursos por año.

La descripción de discursos por año nos pareció relevante dado que al observar que se produjo un cambio significativo en el comportamiento de la categoría violencia por años, nos interesó hacer el seguimiento del comportamiento de la categoría discurso por años que se ve expresada en la Figura 13. 


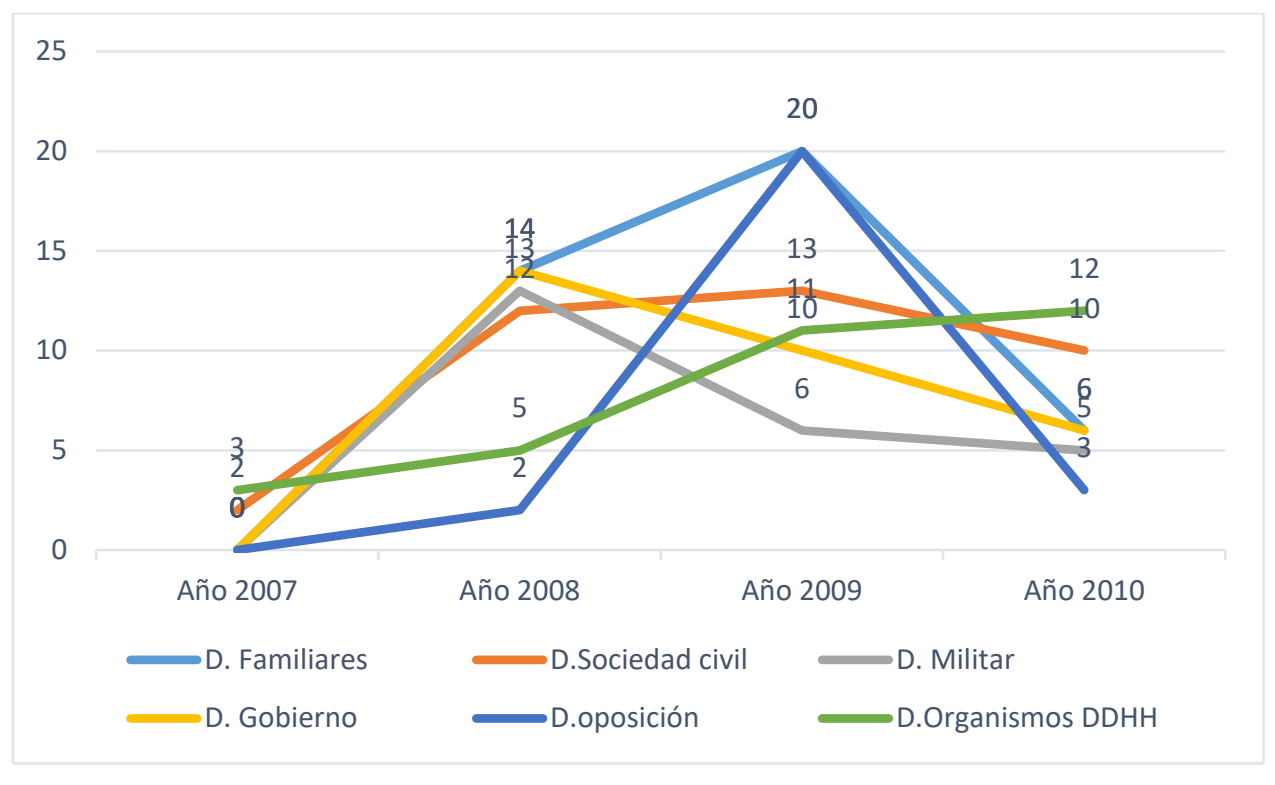

Figura 13. Frecuencia de aparición discursos por años

La frecuencia de aparición del Discurso por año podemos observar que para el año 2007 el comportamiento de las variables fue similar, la frecuencia de aparición más alta fue el discurso militar con 3 artículos, por tanto, la frecuencia de aparición de todos los discursos fue baja, para el año 2008, el comportamiento de la frecuencia de aparición tiene un significativo cambio, especialmente en los discursos de Familiares de las víctimas con 14 artículos, Sociedad Civil con 12 artículos, Militar con 13 artículos y el discurso del Gobierno con 14 publicaciones. En el año 2009 llama la atención el incremento en el discurso de Familiares y el discurso de la Oposición Política que llegaron a los 20 artículos, de igual manera, llama la atención la reducción de publicaciones con respecto al año inmediatamente anterior en los discursos Militar que se redujo en 7 artículos. En el año 2010 se observa que las frecuencias de aparición de los discursos tuvieron una tendencia significativa a la baja a excepción del discurso de organismos internacionales.

\section{- Análisis de frecuencia de aparición por año}

En definitiva, podemos observar que el escándalo de los "Falsos Positivos" se convirtió en uno de los hechos emblemáticos más representativos de la violencia contra la población juvenil en el territorio del sur de Bogotá, es importante resaltar que el año 2008 se puede identificar como un símbolo temporal de la violencia contra los jóvenes que obtuvo centralidad mediática en los años 2008 y 2009 y un decrecimiento en el año 2010. De esta manera, podemos observar que el comportamiento de la frecuencia de aparición de los discursos tiene relación directa con el comportamiento de la violencia. 
La centralidad que tuvo la violencia denominada "Falsos Positivos" conllevó a que los medios de comunicación le dieran mayor importancia a dos discursos que no han sido muy comunes en periodos anteriores, es así como el discurso de familiares de las víctimas y de oposición política fueron más frecuentes en este periodo. Asimismo, el discurso de los Organismos Internacionales ocupo un lugar en las noticias incluso en el año 2010 donde mantuvo una producción importante: Todo lo anterior puede explicarse por el interés que despertó los hechos de violencia contra los jóvenes en la comunidad nacional e internacional.

\subsection{Análisis de Frecuencia de Aparición Temática y Tendencias Ideológicas de los} Medios de Comunicación

La relación entre tendencias ideológicas de los medios de comunicación y frecuencia de aparición temática la expondremos a partir de las categorías elaboradas por tema. Con respecto a la violencia encontramos lo siguiente:

Los tres medios de comunicación presentaron mayor frecuencia de aparición en el tema de violencia contra los jóvenes, el medio con mayor número de noticias fue El Espectador que tuvo una diferencia significativa frente a los otros dos medios que mantuvieron datos similares. En este sentido El Espectador tuvo una frecuencia de aparición acorde con su tendencia ideológica de actuar en favor de las víctimas. Sobre los otros dos medios de comunicación no encontramos una diferencia notoria que nos permita asumir esta concordancia ideológica.

Frente a la Frecuencia de aparición de la producción noticiosa sobre Violencia Política se observa que la Revista Semana presenta el mayor número de publicaciones y muy cerca se encuentra El periódico El Espectador, por tanto en esta variable existe concordancia entre las tendencias ideológicas de los medios de comunicación y frecuencia de aparición ya que los dos medios de comunicación que son cercanos ideológicamente se encuentran en el primer lugar en número de publicaciones.

En cuanto a la variable de Violencia Social se encuentra en mayor medida en el periódico El Tiempo y los otros dos medios de comunicación registran un bajo número, lo que podría indicar la existencia de correlación entre tendencias ideológicas y la frecuencia de aparición en esta variable. 
Con respecto a la categoría Discursos encontramos que el periódico El Tiempo posee un mayor número de publicaciones en los discursos de Organismos de Derechos Humanos, Gobierno y Familiares de las víctimas. En Este sentido sólo podemos establecer que existe concordancia entre tendencia ideológica del medio de comunicación y la frecuencia de publicación en la variable Discurso de Gobierno.

La Revista Semana presenta mayor número de publicaciones en los discursos de la Sociedad Civil, Familiares de las víctimas, Organismos de Derechos Humanos y Discurso Militar. Estos datos indican que existe una relación entre tendencia ideológica y frecuencia de aparición noticiosa.

En la categoría contexto político se identificó una baja frecuencia de aparición, especialmente en la variable electoral, por tanto en este caso no es posible establecer la relación entre la tendencia ideológica de los medios de comunicación y la publicación noticiosa en este tema. La Revista Semana es el medio que más publicaciones posee sobre el tema de Seguridad Democrática, por tanto se puede establecer la concordancia entre su tendencia ideológica y la Frecuencia de aparición noticiosa en este tema.

En el caso de la categoría Estigmatización encontramos que la Frecuencia de Aparición es muy baja y por tanto, no contamos con los suficientes elementos para concluir que existe relación entre la tendencia ideológica y producción noticiosa en este tema.

La descripción de datos en el caso de la categoría Representación del joven nos muestra que en la variable Victima, la Revista Semana posee el mayor número de publicaciones con distancia significativa con respecto a los otros dos medios. Por tanto, es posible la existencia de relación entre tendencia ideológica y producción noticiosa. Mientras que la variable: Victimario presenta datos muy bajos que no nos permiten identificar relación entre estas dos variables.

La categoría de Derechos Humanos presenta las siguientes características: La variable de Violación Sistemática de Derechos Humanos se encuentra en primer lugar en el periódico EL Espectador, lo cual es acorde con la tendencia de este medio de comunicación de informar de forma contextualizada. En el caso del tema impunidad vemos que la Revista Semana tiene el primer lugar con una diferencia significativa con los otros dos medios de comunicación. Estos resultados son acordes con la tendencia ideológica de este medio de 
comunicación que se preocupa por poner en evidencia los hechos de violencia contra los colombianos.

\subsection{Intencionalidad}

La categoría de intencionalidad se encuentra divida en seis tipos de variables que representan los intereses tácitos de los medios de comunicación frente a lo esperado de sus lectores. El comportamiento de las variables lo vemos reflejado en la Figura 14.

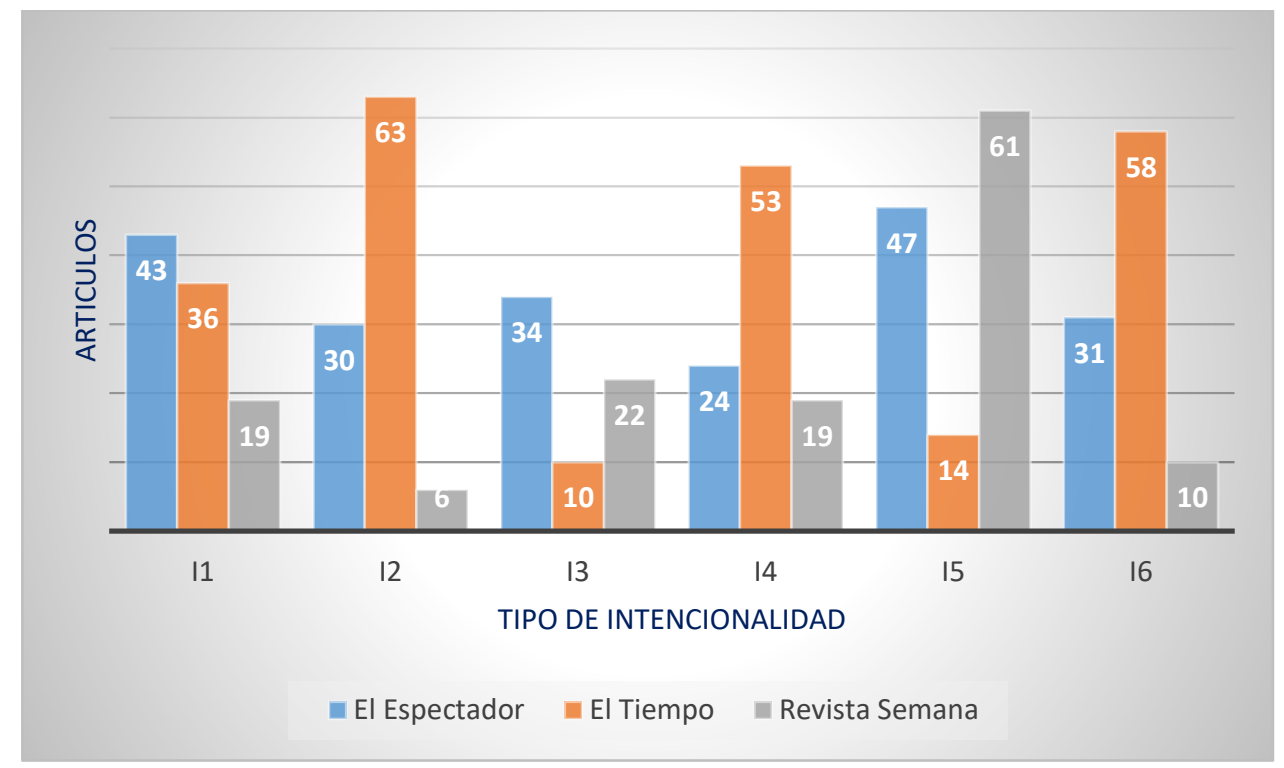

Figura 14. Frecuencia de aparición intencionalidad

El Figura 14 nos muestra los siguientes aspectos frente a la variable $I 1$ relacionada con ofrecer una información contextualizada de la violencia contra los jóvenes, observamos que el periódico con mayor número de noticias que cumplen esta variable fue el periódico El Espectador con 43 artículos, seguido por el periódico el Tiempo con una diferencia de 9 de artículos.

La distribución de los datos en la variable I2 la intencionalidad de ofrecer una información incompleta y confusa está presente en primer lugar 63 artículos, lo cual resulta muy significativo que representa más de la mitad de los artículos que aporta este periódico al Corpus. En Relación a los otros dos medios de comunicación se evidencia que El Tiempo mantiene con El Espectador una distancia que supera los 30 puntos, de 
igual manera, es muy llamativo el número de registros de la Revista Semana (6) que se encuentra muy distante de los otros medios de comunicación.

La variable I3 Construir una opinión pública a favor de la víctima, el periódico EL Espectador con 34 artículos, seguido por la Revista Semana con 22 publicaciones y por último el periódico El Tiempo con 10 artículos, como podemos observar en esta categoría se ve reflejada una diferencia del medio oficialista con respecto a los otros dos medios.

Con respecto a la variable I4 Atraer audiencia a través del lenguaje sensacionalista observamos que El periódico El Tiempo con 53 artículos es el medio de comunicación que se ubica en el primer lugar con una distancia notable al periódico El Espectador con 24 artículos y la Revista Semana con 19 noticias, por tanto, se observa que la frecuencia de publicación es mayor para el medio de comunicación oficialista y menor en los otros dos medios de comunicación.

La variable I5 Denunciar ante la opinión pública los hechos de violencia contra los jóvenes, se encuentra en primer lugar en la Revista Semana con 61 artículos, seguida por el periódico El Espectador con 47 artículos y por último el periódico El Tiempo con 14 noticias. De acuerdo a la tendencia ideológica podemos observar que los dos medios de comunicación con una tendencia ideológica crítica (El Espectador y La Revista Semana) mantienen mayor tendencia de publicación desde esta variable.

Por último, la variable I6 Construir opinión pública a favor del Estado se observa que el periódico El Tiempo con 58 publicaciones, seguido por el periódico El Espectador con 31 artículos y por último la Revista Semana con 10 artículos. Como se puede observar se mantiene la tendencia del periódico oficialista.

Con respecto a la hipótesis de que existía relación entre la tendencia ideológica de los medios de comunicación y la frecuencia de aparición de intencionalidad encontramos que a partir del análisis del Chi cuadrado, existe tal dependencia entre estas variables dado que el resultado de la prueba de Chi cuadrado proporciona un valor $\mathrm{p}<0.000$ en todos los tipos de intencionalidad observados en este estudio. Por tanto, sí existe una relación entre tendencia ideológica y producción noticiosa en el tema de intencionalidad. 


\subsubsection{Análisis tendencias ideológicas de los medios de comunicación y variables de intencionalidad}

Como ya hemos visto en el capítulo teórico la tendencia del periódico El Tiempo se ha inscrito en una tendencia oficialista, especialmente en las últimas tres décadas se ha mostrado inclinado a las posturas de los gobiernos. La relación de esta medio de comunicación y la intencionalidad podemos observar que la mayor frecuencia se encuentra en las variables Ofrecer una información incompleta y confusa sobre la violencia contra los jóvenes- I2, Atraer audiencias a través de un lenguaje sensacionalista.I4, Construir opinión pública a favor del Estado I6. Las tres variables más recurrentes refieren a temas que buscan la distorsión de la información y mantener la opinión pública en favor del Estado.

Por tanto, podemos observar que la tendencia ideológica tiene una relación directa con el tipo de publicaciones en este medio, prevalece la tendencia oficialista y conservadora que se preocupa por el mantenimiento de las relaciones políticas tradicionales.

En el periódico El Espectador se pudo observar que las frecuencias de aparición de acuerdo a las intencionalidades hicieron mayor presencia en las variables de Ofrecer una información contextualizada I1 y Denunciar ante la opinión pública los hechos de violencia contra los jóvenes I5, lo cual coincide con su tendencia crítica y liberal propia de todos los periodos de la historia de este medio.

En el caso de la Revista Semana pudimos observar una mayor centralidad en la variable Denunciar ante la opinión pública los hechos de violencia contra los jóvenes I5, donde tiene una publicación de 61 artículos, un alto valor si tenemos en cuenta que la Revista Semana aporta al corpus 87 artículos, es decir que el 70\% las noticias de este medio se inscriben en esta intencionalidad.

En la comparación de los datos sobre intencionalidad de los tres medios de comunicación observamos que existe una mayor cercanía entre el periódico El Espectador y la Revista Semana en la publicación de noticias inscritas en intencionalidades críticas al papel gubernamental y en favor de las víctimas. 


\subsection{Síntesis}

Las conclusiones que se desprenden del análisis de los datos son las siguientes:

Con respecto a la violencia se puede observar que existe una mayor tendencia a publicar sobre la violencia contra los jóvenes de los "Falsos positivos", debido a la puesta en escena pública de este tipo de violación de los Derechos Humanos. Lo cual es una situación particular de este periodo, ya que como vimos en el marco teórico la violencia política contra los jóvenes ha sido una constante en la historia nacional. La manera como los medios de comunicación abordaron el tema de la violencia nos da cuenta de que las tendencias ideológicas de los medios de comunicación corresponden con los enfoques ideológicos y políticos de los medios de comunicación.

La publicación de noticias sobre la violencia por años nos indicó que tuvo un incremento en los años 2008 y 2009, después del destape de los "Falsos positivos", en octubre de 2008, la evidencia irrefutable de una violencia sistemática en contra de los jóvenes, proveniente del Estado colombiano, específicamente de sus fuerzas militares.

La Frecuencia de aparición de los discursos se caracteriza por tener una frecuencia muy baja, con ligeras diferencias en la distribución por cada uno de los medios de comunicación, por consiguiente, no se puede distinguir una clara influencia de la tendencia ideológica y la frecuencia de publicación.

La frecuencia de aparición de discurso por años se observa algo muy similar con el tema de la violencia, con un mayor número de publicaciones en los años 2008 y 2009, a partir del destape de la violencia contra los jóvenes. Lo que nos confirma que el develar la violencia contra los jóvenes llevo a una mayor atención mediática y social.

Los datos estadísticos sobre el contexto político nos indican una frecuencia de aparición baja, llama la atención, el poco interés de los medios de comunicación abordar el tema de "Falsos Positivos" el marco electoral, así como el poco interés ofrecido al tema de la política de Seguridad Democrática que tan sólo se encuentra de manera significativa en la Revista Semana. En el marco de esta política se incrementó la violencia política y los hechos de violencia contra los "Falsos Positivos".

Las variables de estigmatización no contaron con mayor atención por parte de los medios de comunicación, la publicación de artículos que expresen directamente sobre este tema, 
es muy reducida, por tanto, lo más indicado es observar en el análisis del discurso, sí existe una aparición de estos constructos sociales en el uso del lenguaje de los medios de comunicación. Llama la atención que tradicionalmente ha existido una tendencia en los medios de comunicación a centralizar la información en ver al joven como victimario, pero en este caso, al parecer la violencia de "los Falsos positivos", ha tenido incidencia en que se haya dado mayor centralidad a ver a los jóvenes como víctimas.

El tema de la representación social del joven expresado en las dos variables: victimario y víctima, explícitamente no se encuentra de manera recurrente en los artículos, en los datos encontrados se ofrece mayor relevancia a la variable víctima, lo cual es esperado dado el contexto de violencia directa contra la juventud que es la centralidad de este estudio.

En el tema de Derechos Humanos observamos que existe un número de publicación y que aún en un grave contexto de la violación de los Derechos Humanos de la juventud, no contó con centralidad en los medios de comunicación. Las noticias enmarcadas dentro de esta categoría que tuvieron mayor impacto fueron las relacionadas con la violación sistemática de los Derechos Humanos. Dada la contundencia de los hechos de violencia contra los jóvenes

Los pocos datos encontrados con relación al tema de la organización social juvenil dan cuenta de la poca trascendencia de este tema para los medios de comunicación del tema de la organización, lo cual nos hace preguntarnos por las construcciones mediáticas de lo juvenil, ya que se niegan aspectos fundamentales en las construcciones de la identidad juvenil.

En cuanto a la categoría de intencionalidad y su relación con las tendencias ideológicas de los medios de comunicación se puede afirmar la existencia de cierta correlación entre las tendencias ideológicas de los medios de comunicación y los tipos de intencionalidad. Los argumentos que nos llevan a esta conclusión es la mayor cercanía en términos estadísticos entre los medios de comunicación: El Espectador y la Revista Semana en relación de la intencionalidad. Así como la tendencia del periódico El Tiempo a tener mayores publicaciones a la hora de registrar noticias favorables al oficialismo y al Estado y menos noticias en las intencionalidades relacionadas con el favorecimiento a las víctimas, la denuncia de la violación de los Derechos Humanos. 
La descripción y análisis de los datos cuantitativos le aportan elementos a este estudio para alimentar el análisis del discurso, en este sentido, podemos partir hacía un análisis cualitativo bajo la premisa de que existe una relación entre tendencia ideológica de los medios de comunicación y frecuencias de aparición de temáticas. No obstante será en análisis del discurso el que nos ofrecerá mayor claridad de esta afirmación a partir del análisis del lenguaje expuesto en los artículos.

Con respecto a la categoría intencionalidad donde realizamos un análisis del discurso para poder establecer las variables de intencionalidad queda clara la relación entre tendencia ideológica y frecuencia de publicación por tipo de intencionalidad. A través del método cuantitativo pudimos establecer la dependencia entre estas dos variables.

Este análisis cuantitativo nos abre perspectivas en el análisis cualitativo que conlleven a la identificación de los discursos que nombran al sujeto joven en estos contextos de violencia política, que nos permitan desentrañar los sentidos discursivos de los hechos emblemáticos de violencia contra los jóvenes, que nos den lucen en la identificación de las narrativas simbólicas y culturales que materializan la información periodística a través de la violencia.

Este análisis cuantitativo frente a las frecuencias de aparición temática y de intencionalidad en un tema específico como es el tema de los "Falsos Positivos", nos abre preguntas claves para analizar el papel de los medios de comunicación en la comprensión de la violencia en el país desde las relaciones del poder, y en este sentido, vale la pena preguntarnos:

¿Sí la Frecuencia de aparición en determinado tema está ligado a las presiones de poder que tienen los medios de comunicación para emitir al información periodística?

De igual manera, resulta importante para este estudio analizar como el dato cuantitativo puede estar ligado a unos marcos ideológicos construidos históricamente a partir de las luchas de poder presentes en el país desde su constitución como república.

En definitiva, el análisis cuantitativo contribuye al fortalecimiento del análisis del discurso que será el tema central del siguiente capítulo, donde nos interesa dar sentido a los discursos presentes en el corpus de la investigación y desde allí poder establecer de una manera más clara las construcciones sociales y simbólicas que se materializan en el discurso mediático en Colombia. 


\section{CAPITULO VI. LA CONSTRUCCIÓN SIMBÓLICA Y DISCURSIVA DEL JOVEN EN EL CONTEXTO DE LOS “FALSOS POSITIVOS.” ANÁLISIS DEL DISCURSO}

6.1. La construcción simbólica sobre joven víctima de la violencia de "falsos positivos" en el discurso mediático.

6.2. El constructo social de los jóvenes en los Medios de comunicación.

6.3. La construcción simbólica del joven desde el victimario.

6.4. Análisis del Discurso sobre el joven en los medios de comunicación a luz de la teoría.

6.5. Síntesis. 



\section{CAPÍTULO VI. LA CONSTRUCCIÓN SIMBÓLICA Y DISCURSIVA DEL JOVEN EN EL CONTEXTO DE LOS "FALSOS POSITIVOS." ANÁLISIS DEL DISCURSO}

En este capítulo abordaremos la significación del joven popular en el marco del conflicto armado interno del país, para dicho abordaje hemos escogido el caso específico de los jóvenes desaparecidos de Soacha como parte de la violencia mal denominada "falsos positivos." Este capítulo se dividirá en cuatro apartados los cuales se expondrán de la siguiente manera: En primer lugar, abordaremos la construcción simbólica y discursiva del joven en el contexto de la violencia de "falsos positivos," en segundo lugar, El constructo social de los jóvenes en los Medios de comunicación, en tercer lugar, La construcción simbólica del joven desde el victimario, en cuarto lugar, La construcción simbólica del joven desde el victimario y por último presentaremos una síntesis del capítulo.

\subsection{La construcción simbólica del joven víctima de la violencia de "falsos positivos" en el discurso mediático}

La violencia de "falsos positivos" llevada a cabo contra los jóvenes del sur de Bogotá fue uno de los tantos casos que sucedieron en el país, donde de una manera perversa se asesinaron civiles para ser mostrados como muertes en combate por parte de las fuerzas militares. Estas crueles estrategias usadas en el contexto de la guerra colombiana, muestran de manera irrefutable la degradación del conflicto colombiano, el cual llegó a extremos inimaginables de barbarie y crueldad.

La desaparición y el posterior asesinato de estos jóvenes fue un acto de negación de seres humanos perpetrado contra civiles. Se pretendió mediante estos hechos y la ubicación de los cuerpos de estos jóvenes en Fosas comunes como NN (Sin nombre), la total eliminación física y simbólica de seres humanos, con ello se despojó a las víctimas de sus vidas, su dignidad y sus identidades.

El caso de los jóvenes de Soacha es un caso de mal denominada violencia de "falsos positivos", que hace referencia al delito de "ejecuciones extrajudiciales," contemplado en el Derecho Internacional Humanitario y en la Declaración de Derechos Humanos. Las ejecuciones extrajudiciales se entienden como el delito de asesinar civiles y hacerlos pasar por combatientes. 
El caso de Soacha, se convirtió en un caso emblemático en septiembre de 2008, porque al descubrir la violencia desarrollada en el marco de las ejecuciones extrajudiciales contra jóvenes del sur de Bogotá y el municipio de Soacha, hacía parte de una violación sistemática de Derechos Humanos llevada a cabo por miembros de la Fuerzas Armadas Colombianas contra civiles. Dicho caso, cobró importancia porque mostró a la comunidad nacional e internacional la existencia de graves prácticas de violación de los Derechos Humanos. Es importante anotar que lo sucedido con los "jóvenes de Soacha" sólo refleja el $1 \%$ de la violencia acontecida bajo esta modalidad en el periodo comprendido entre el año 2006 y 2010, se considera que este periodo se presentaron al menos 1800 víctimas de ejecuciones extrajudiciales.

La violencia desarrollada en el contexto de los mal denominados "falsos positivos" pone de manifiesto que en los conflictos de larga duración se llega a los más cruentos y barbaros actos de agresión, que con frecuencia la guerra se deshumaniza y traspasa los límites éticos de las confrontaciones, llegando a producir sufrimiento extremo a la sociedad civil.

El conocimiento de los hechos mediante lo que se llamó los "falsos positivos" tuvo un alto abordaje mediático, la circulación de discursos sobre lo ocurrido estuvo en las principales páginas de los periódicos y medios televisivos y radiales, asimismo la crueldad de la violencia perpetrada se convirtió en un tema de debate y preocupación de los sectores políticos y sociales del país, de igual manera, atrajo el interés de la comunidad internacional. Y como se ha comentado se convirtió en un caso altamente difundido por los medios de comunicación.

En este estudio nos interesa observar desde el análisis académico y específicamente desde el análisis del discurso, los discursos mediáticos sobre las "víctimas" y especialmente como se construyeron socialmente y simbólicamente los imaginarios de jóvenes víctimas de esta violencia, en pocas palabras de que significaciones fueron dotadas sus identidades. Por ello las páginas que continúan estarán dedicadas a la construcción simbólica de los jóvenes por parte de los medios de comunicación, así como por los actores representativos de la política, la sociedad civil, las organizaciones políticas y los familiares de las víctimas. 


\subsubsection{Contextualización}

La investigación de Villamizar (2013) realizada en el marco del master de cooperación al desarrollo y que precede a este estudio trabajó sobre la construcción de las identidades juveniles en medio de la guerra, es decir dio cuenta de los procesos de apropiación de los sentidos de pertenencia y las identificaciones individuales y colectivas. En dicho trabajo se pudo concluir que la violencia proveniente del conflicto armado tiene impactos muy profundos en la construcción de las maneras de significar las identidades de estos jóvenes en relación a sí mismos y a los "otros."

La investigación aportó que la población juvenil del sector de Ciudad Bolívar y Cazuca en el sur de Bogotá, construye sus sentidos de identidad en medio del "miedo" y el terror impuesto por las persecuciones de los diferentes armados, especialmente el abuso de miembros de las fuerzas armadas colombianas y las amenazas y el terror impuesto por grupos paramilitares. La población juvenil de este sector se ve expuesta al control de sus dinámicas sociales y culturales, que son vigiladas por grupos de extrema derecha.

De igual forma, se identificó que existen profundos constructos de estigmatización del joven que operan como motivadores de violencia para grupos de ideología de extrema derecha y miembros de la Fuerza pública. El análisis realizado en dicho estudio nos llevó a explorar los constructos sociales de estigmatización sobre la población joven habitante en este territorio. De esta manera, hallamos que la estigmatización del joven popular del sur de Bogotá se ha dado de una manera constante en la historia del sector geográfico y que los constructos sociales de estigmatización estaban ligados a la existencia del conflicto armado interno y a la condición juvenil.

La revisión teórica que soportó la investigación nos aportó un elemento clarificador en el análisis de la estigmatización del joven y este fue el concepto del imaginario nacional del joven popular como amenaza social, acuñado por Martín-Barbero (1998) y desarrollado por Riaño (2000, 2006). Según Martin Barbero este imaginario tuvo su origen en la mitad de la década de 1980, a partir del involucramiento de la población joven en la violencia del narcotráfico y el manejo dado por los medios de comunicación del fenómeno del sicariato juvenil, especialmente en un caso emblemático el asesinato del Ministro de Justicia del país por un par de jóvenes sicarios a mediados de la década de 1980. 
En la experiencia en terreno se observó que la estigmatización sobre el joven popular actuaba como un elemento perverso de justificación por parte de actores del conflicto armado, muestra de ello, es la utilización de este discurso en las amenazas públicas de parte de grupos de extrema derecha a los jóvenes del sector. Lo cual demostró que el problema de la estigmatización del joven no sólo tenía efectos culturales y sociales sino que se articulaba a la violencia procedente del conflicto armado interno.

A partir de esta experiencia investigativa surge la preocupación por analizar el tratamiento dado por la prensa escrita al doloroso episodio de violencia contra los jóvenes, denominado "falsos positivos", específicamente en el "Caso de los jóvenes de Soacha". El análisis teórico y del corpus de esta investigación nos mostró la necesidad de abordar la construcción social del joven, víctima de esta violencia en la prensa escrita. Así como en los discursos de los familiares, la sociedad civil y los propios victimarios.

\subsubsection{El caso de "falsos positivos" Soacha}

Entre los meses de enero y septiembre de 2008, desaparecieron 14 jóvenes del Municipio de Soacha y de la localidad de Ciudad Bolívar en el sur de Bogotá. Los nombres de estos jóvenes son:

Julio César Mesa Vargas de 24 años, Jhonatan Orlando Soto Bermúdez de 17 años, Daniel Andrés Pesca Olaya de 27 años, Eduardo Garzón Páez de 32 años, Diego Alberto Tamayo Garcera de 22 años, Víctor Fernando Gómez Romero de 23 años, Andrés Palacio Bustamante de 22 años, Fair Leonardo Porras Bernal de 26 años. Elkin Gustavo Verano Hernández de 25 años Julián Oviedo Monroy de 19 años, Joaquín Castro Vásquez, Jaime Steven Valencia 16, Daniel Alexander Martínez, 22 años, Mario Alexander Arenas Garzón de 33 años y Jaime Castillo Peña de 42 años.

Después en el año 2009 se agregaron a esta lista los nombres de Alexander Quirama 31 años y Norbey Muñoz Gutiérrez de 22 años, desaparecidos en Bogotá y encontrados en Fosa común en Chivor Boyacá.

A inicios de septiembre de 2008 fueron hallados sus cuerpos en fosas comunes en el municipio de Ocaña Norte Santander, a cientos de kilómetros del lugar de donde desaparecieron. Las investigaciones iniciales de medicina forense establecieron que la muerte de estos jóvenes sucedió en periodo no superior a las 72 horas de su desaparición. 
A partir de septiembre de 2008, los familiares de estas víctimas iniciaron un largo proceso para conocer la verdad de lo sucedido. Proceso largo y lleno de obstáculos. De las investigaciones se ha logrado determinar que este grupo de jóvenes murieron en el marco de una violencia sistemática cometida por la Fuerzas Armadas de Colombia.

El caso de los "jóvenes de Soacha" se convirtió en un caso emblemático de la violencia de ejecuciones extrajudiciales, que reflejó una estrategia de muerte implementada por el Estado colombiano. El esfuerzo de los familiares de las víctimas, las organizaciones sociales, partidos políticos de oposición y Organismos Internacionales han reconstruido los hechos ocurridos en este caso.

\subsubsection{La desaparición de los jóvenes}

Se tiene conocimiento que los jóvenes fueron desaparecidos cerca a sus domicilios con la utilización de civiles que cumplieron el papel de reclutadores, en este sentido. La Fundación para la Educación y El Desarrollo FEDES (2011) afirmó que:

Estas personas encargadas del reclutamiento de los jóvenes tenían domicilio en el mismo municipio de Soacha, y establecieron los parámetros de elegibilidad de sus víctimas. Era común a la totalidad de las víctimas que se tratara de personas desempleadas, de extracción humilde, fáciles de atraer bajo el señuelo de promesas laborales. Fue común característico de los casos objetos de estudio que las víctimas alertaran a sus familiares cercanos sobre la existencia de una oferta laboral, hechos que no es de extrañar en condiciones de pobreza, y que por ello sus familiares no tuvieron sospecha alguna del ofrecimiento al menos al principio. (p.11)

Según FEDES, después de que los jóvenes aceptaban el ofrecimiento, se ponía en marcha un segundo paso, de este engranaje criminal que consistía en el traslado al lugar de la ocurrencia de los hechos, en esta ruta criminal los reclutadores se encargaban de entregarlos a las brigadas del ejército, quienes realizando un falso reten y los trasladaban a un lugar donde se había preparado la escena del crimen, para posteriormente ser asesinados a sangre fría bajo la simulación de un combate.

De las indagaciones, los testimonios de los familiares de las víctimas y supervivientes, así como de las pesquisas judiciales se conoce que la escena del crimen y los cuerpos eran 
manipulados para mostrar falsas evidencias de que se trataba de guerrilleros asesinados en combate.

\subsubsection{EI Escandalo de los falsos positivos}

Se denominó Escandalo de "falsos positivos" al conocimiento del hecho de que jóvenes desaparecidos en El sur de Bogotá y Soacha fueron hallados en fosas comunes en el municipio de Ocaña a 15 horas de la capital del país, la presión de los familiares, el acompañamiento del personero de Soacha y algunas organizaciones de la sociedad civil permitieron descubrir la suerte que habían corrido estos jóvenes y la implicación en la desaparición y muerte de miembros de la fuerza pública. El caso tuvo relevancia mediática y llamó la atención de la comunidad nacional e internacional.

Dicho caso fue muy importante porque puso de manifiesto una grave violación de Derechos Humanos, bajo la modalidad de Ejecuciones Extrajudiciales en el territorio nacional.

\subsection{El constructo social de los jóvenes en los Medios de comunicación}

Para analizar el constructo social de los jóvenes en los medios de comunicación escrita (El Espectador, El Tiempo y La Revista Semana), realizamos la revisión de artículos pertenecientes al corpus de esta investigación a la luz del análisis del discurso desde la perspectiva de la Escuela Francesa. De esta manera, se identificaron las construcciones sociales hechas de los medios sobre los jóvenes de dicha violencia. En este análisis del discurso realizado a los artículos de prensa encontramos que los medios de comunicación presentaron un perfil de las víctimas, en adelante abordaremos las construcciones sociales que se hicieron del sujeto joven en los medios de comunicación.

Un artículo que nos aporta elementos para este análisis es el presentado en la Revista Semana (2008a), donde se muestra el perfil de algunos los jóvenes víctimas del caso de Soacha.

Los jóvenes bogotanos tenían edades que oscilaban entre 17 y 32 años, casi todos eran desempleados o trabajaban en oficios como construcción y mecánica y, según la Defensoría del Pueblo, algunos tenían antecedentes como consumidores de drogas. Eran, en general, muchachos humildes que vivían en la marginalidad de 
Ciudad Bolívar, Altos de Cazucá, y Bosa. Del grupo de los 11, el primero en desaparecer fue Faír Leonardo Porras, de 26 años, que trabajaba como ayudante de construcción, quien fue reportado por su familia como desaparecido el 8 de enero. Cuatro días después, el CTI y el Ejército estaban haciendo el levantamiento de su cuerpo, muerto supuestamente en combate. Los segundos en desaparecer, el 13 de enero, fueron Elkin Gustavo Verano, de 25 años, y Joaquín Castro, de 27 años, ambos empleados en un taller de campanas para carros, y amigos inseparables. Según reportes oficiales, habrían muerto en combate.

El 15 de enero, es decir, dos días después de su llegada. En un tercer caso, Julio César Mesa, de 24 años, y Johnatan Orlando Soto, de 17 años, que habían sido reportados como desaparecidos el 26 de enero, aparecieron como dados de baja en combate dos días después. Lo mismo le ocurrió un mes después a Julián Oviedo, de 19 años, quien trabajaba en construcción. Más tarde, el 25 de agosto, fueron hallados muertos Diego Alberto Tamayo, de 25 años; Víctor Gómez, de 23, y Andrés Palacio, de 22 años. A estos tres últimos el Ejército los había reportado como miembros de bandas emergentes muertos en combate, y había dicho en su momento que se les había encontrado dos pistolas y una escopeta de repetición. Todos los jóvenes tienen en común que venían del sur de Bogotá y que fueron reportados como guerrilleros o bandoleros dados de baja por la Brigada Móvil XV, con sede en Ocaña. Otros dos de los muchachos, Daniel Pesca y Eduardo Garzón, murieron en jurisdicción de San Vicente de Chucurí. (p.1)

Como observamos en la presentación que hace la Revista Semana muestra un perfil básico en su artículo, muestra sus nombres, la actividad que realizaba, los hechos en los desaparecieron y las versiones del ejército. En este análisis discursivo son a resaltar las siguientes formas de nombrar a los jóvenes:

Los jóvenes son nombrados como "muchachos humildes que vivían en la marginalidad de Ciudad Bolivar. Altos de Cazuca y Bosa," de esta manera, se hace referencia a las 
condiciones socio-económicas de los jóvenes y el sector territorial en el que residían; no obstante es de anotar que no se trata sólo de determinaciones socio-económicas del sector, sino que es conocida la influencia que tienen estos aspectos en la discriminación de la zona. Dado algunas características del territorio: La ubicación periférica del sector de Cazuca y Ciudad Bolívar, el que estas zonas hayan sido construidas por procesos de invasión por migrantes y desplazados de la violencia ha conllevado a que en los imaginarios locales y nacionales se establezcan constructos de exclusión social.

Otro de las caracterizaciones que llaman la atención en este artículo es la de: “Todos los jóvenes tienen en común que venían del sur de Bogotá", lo cual es cierto todos pertenecían al sur de Bogotá, sin embargo, es importante resaltar que este sector ha sido significado en los imaginarios locales y nacionales como un sector "caliente" al que se le designan atributos relacionados con la violencia y la delincuencia.

En este artículo se describe que la justificación de los victimarios, es decir las Fuerzas Militares, al afirmar que las fuentes oficiales advierten que: Estos jóvenes "habrían muerto en combate" esta afirmación retomada de los discursos militares, hace referencia a otro concepto muy utilizado en estas concepciones estigmatización la de "bandoleros y guerrilleros." En el caso del conflicto colombiano hemos visto como las connotaciones de "bandoleros y guerrilleros, han sido utilizadas de manera recurrente para llamar el adversario. Y son numerosos los casos de líderes sociales, sindicalistas y activistas de Derechos Humanos que han sido procesados judicialmente con falsas acusaciones por cuenta de organismos de seguridad del Estado o lo que es peor asesinados o desaparecidos por fuerzas de ultraderecha en el país.

Un asunto a resaltar de este artículo de la Revista Semana es que presentó el nombre de los 11 jóvenes desaparecidos, asesinados y mostrados como muertos en combate en Ocaña al oriente del país, lo cual nos parece significativo porque en la mayor parte de los artículos esto no sucede, los textos de este corpus hicieron referencia a los "muchachos de Soacha” o los “jóvenes de Soacha”. El acto de llamar por el nombre a las víctimas es un acto que otorga identidad, que humaniza, puesto que le concede el sentido de que es un ciudadano colombiano, se contribuye a que pasen de ser parte de un grupo de edad a tener una individualidad. En el lenguaje mediático y cotidiano emitido sobre la guerra se hace uso de generalizaciones, se nombra a las víctimas como datos, asociadas a una 
cualidad y de tal manera, la generalización hace que el impacto social de lo sucedido también se vaya generalizando y aceptando.

El periódico El Tiempo (2009a), presenta el perfil de las víctimas basado en la versión de la fiscalía.

El caso de Soacha refleja, según la Procuraduría, cuál era el perfil de las víctimas para 'falsos positivos'. Ellas fueron contactadas inicialmente por civiles y entregadas a militares. Esta situación se ha repetido en varias zonas del país. En estos casos, las personas que resultaron muertas conocían o eran amigas del reclutador. Algunas habían estado involucradas en delitos menores y otras consumían droga. Además, no tenían empleos estables. Los reclutadores engañaron a los jóvenes con falsas promesas de trabajo en fincas. De esa forma consiguieron llevarlos de manera voluntaria hasta el sitio en que debían ser entregados a sus verdugos. En otros casos se encontró que las víctimas eran sindicalistas, líderes comunales o desmovilizados.

En este perfil presentado por el periódico El Tiempo no habla de los nombres, ni los datos que caracterizan a las víctimas, sino que expresa como sucedieron los hechos. Se afirma que eran civiles, que algunos de ellos habían cometido delitos menores y otras consumían droga. Llama la atención que el perfil presentado hable de los delitos menores, consumo de alucinógenos, los cuales son considerados aspectos con cargas negativas en los imaginarios sociales sobre los jóvenes. De la misma manera, llama la atención que no se hable de que entre las víctimas se encontraban menores de edad y personas con capacidades diferenciadas que les impedían cometer delitos.

En este artículo se hace alusión a dos estigmas que se han identificado en el estudio realizado en el sector cuando se expresa que: "Algunas habían estado involucradas en delitos menores y otras consumían droga", esto se relaciona con los estigmas de "delincuentes" y "drogadictos", identificados en el estudio que precedió esta investigación como formas de estigmatización utilizadas para llamar a los jóvenes del sur de Bogotá.

De la misma manera el periódico El Espectador (2009a), presenta el siguiente perfil. 
(...) y jóvenes asesinados, en general marcados por la falta de oportunidades y la pobreza. Vale decir, según los casos que se han conocido, habitantes de la calle, drogadictos y enfermos mentales. (p.1)

Este artículo enfatiza en la pobreza y la falta de oportunidades como características de los jóvenes, los tres elementos finales de este texto son mucho más llamativos como constructos de estigmatización: habitantes de la calle, drogadictos y enfermos mentales.

La información que tenemos de los jóvenes víctimas ninguno de ellos era habitante de la calle ni consumidor de sustancias psicoactivas. Y si bien es cierto que en el grupo se encontraban tres|jóvenes con capacidades diferenciadas a nivel físico y mental, el uso del término "enfermos mentales", tiene una connotación bastante negativa que afecta la dignidad de las víctimas.

En El Tiempo (2009a) se expresan elementos del perfil de los jóvenes, así como del modus operandi utilizado por victimarios.

El caso de Soacha refleja, según la Procuraduría, cuál era el perfil de las víctimas para 'falsos positivos'. Ellas fueron contactadas inicialmente por civiles y entregadas a militares. Esta situación se ha repetido en varias zonas del país. En estos casos, las personas que resultaron muertas conocían o eran "Los casos más recientes muestran mayor refinamiento. Mientras que antes las víctimas jóvenes pobres y desempleados- eran asesinadas cerca de sus domicilios, parecería ahora que son trasladadas lejos con el objetivo de retardar y obstaculizar investigaciones. Todo apunta a que solo una red organizada podría estar en condiciones de efectuar estos asesinatos Se necesita un reclutador para llevar a los muchachos a regiones apartadas, una persona que consiga las armas para depositar junto a los cuerpos y un colaborador que fabrique información -los antecedentes judiciales desconocidos para las familias y los allegados-. Existe un testimonio de compra de armas en el mercado negro para "plantar" en las escenas del crimen que, al parecer, está hoy en manos de la justicia. (p.1) 
En este fragmento se hace referencia de manera tacita a la violencia que ha tenido lugar en el sur de Bogotá contra los jóvenes, la denominada "Limpieza Social”. Cuando habla de los asesinatos cerca a sus domicilios de residencia. También aquí se habla de la necesidad de participación de varias personas en los asesinatos.

El uso de la expresión: "jóvenes pobres y desempleados-eran asesinados cerca de sus domicilios," que eran víctimas de la mal llamada "limpieza social” y después de las ejecuciones extrajudiciales; se utilizan las connotaciones de "pobres" y "desempleados," aunque el uso de estos términos no signifique en sí una estigmatización sino sean adjetivos para calificar a los jóvenes desde su situación económica, es importante reconocer las significaciones dadas en los imaginarios de ser joven, pobre y desempleado en Colombia, que remite a un joven potencialmente "peligroso." No se puede afirmar que en estas noticias esté la intencionalidad de estigmatizar a los jóvenes, pero si se observa que en estos perfiles de evidencia una mayor tendencia a descartar los aspectos negativos de la situación de los jóvenes.

Continuando con el formato presentado en el perfil observamos que el periódico, Morales, L (2009) presenta un perfil del caso de Alexander Quirama,
Alexander, de 31 años, difícilmente podía ser un 'reconocido delincuente'. En un reporte de la unidad siquiátrica del Hospital Meissen fechado el 29 de junio de 2005 queda constancia que Alexander sufría desde los 6 años de una desviación bipolar afectiva y por eso estaba bajo medicación de drogas siquiátricas fuertes como Sinogan, Lorazepam y Haloperidol, un antisicótico que se le da a los esquizofrénicos. (p.1)

El artículo nos muestra la situación de salud de este joven, razón por la cual era imposible que este joven pudiera dirigir un grupo armado. Como acusado por sus verdugos, de esta manera se pone en evidencia la gravedad de los hechos cometido contra este grupo de jóvenes. En este caso el periódico muestra una información más contextualizada ya que hace referencia a la enfermedad especifica que sufría, los medicamentos que debía tomar, en este caso no se hace una generalización, sino que con aspectos muy específicos se demuestra a la opinión pública, que en estas condiciones un joven no puede actuar de la manera que se le acusa. 
En la presentación del perfil de las víctimas hecha por los medios de comunicación se observó el uso del formato que mostraba testimonio, este caso fue muy común cuando se trató de la presentación de los familiares de las víctimas. La Revista Semana (2010c), se presenta un testimonio de una de las víctimas:

Su hijo pasó de ser un estudiante de sexto bachillerato, al que su familia llamaba de cariño 'Chivito', a ser parte de un supuesto combate, de una aparente victoria del Ejército. Él es uno de los mal llamados 'Falsos positivos'. Y María, de 52 años, una mujer que todos los días llora la muerte de su hijo. (p.1)

En este fragmento se observa un tratamiento de mayor cercanía a la realidad de las víctimas, de igual manera se pone en evidencia que un joven menor de edad que apenas se encontraba iniciando sus estudios secundarios no podría estar participando de un combate. Por ello sin nombrarse explícitamente el artículo muestra lo poco creíble de las versiones de las fuerzas militares sobre la muerte de los jóvenes.

La Revista Semana fue el medio que más utilizó el testimonio de los familiares de las víctimas para la presentación de las noticias, la dureza de los testimonios tiene un impacto muy alto para el lector, en este caso tomaremos algunos de ellos para mostrar la forma como fueron presentadas las noticias. García (2010):

Jhony quería ser militar y terminó de Falso Positivo

El sábado fue sepultado en Bogotá uno de los jóvenes presentados como muertos en combate con el Ejército en Ocaña. Tenía 22 años y quería ser militar. Su familia pide justicia.Jonny quería ser militar y terminó de 'falso positivo'

Jonny Duvián Soto salió de su casa una mañana de julio de 2008 y no regresó. Dos meses después su cuerpo apareció en Ocaña, Norte de Santander y fue presentado a la luz pública como muerto en combate con el Ejército colombiano. ¿Guerrillero? Se preguntan los familiares, mientras aseguran_que su hijo y hermano sólo era un vendedor de $\mathrm{CD}$ en las calles de Bogotá. 
El 23 de septiembre de 2008 investigadores del CTI de la Fiscalía llegaron hasta la casa de la familia Soto Muñoz en Ciudad Bolívar y les enseñaron unas fotografías en un computador portátil. César, el hijo mayor, reconoció instantáneamente a su hermano. Tenía una camisa amarilla, la cara ensangrentada y el lunar cerca de la oreja izquierda que siempre lo caracterizó. Era Jonny y había muerto el 12 de agosto.

¿Por qué lo mataron? Fue la primera pregunta que aún espera respuesta para 24 familias de jóvenes que fueron desaparecidos de sus barrios y presentados como guerrilleros muertos en Combate en una región del Norte de Santander. Año y medio después de su muerte, los restos de Jonny fueron entregados a sus familiares para ser sepultados en un cementerio el sur de la capital colombiana.

Después de prestar el servicio militar obligatorio en San José del Guaviare, Jonny regresó a su casa con la firme intención de continuar con la carrera como soldado profesional. Era una idea que lo trasnochaba cinco meses antes de su desaparición y que su familia le apoyaba, pero la ausencia de recursos económicos impidió continuar con los trámites, por lo que debió postergar su regreso a las filas del Ejército mientras conseguía un poco de dinero vendiendo CD's piratas en el Cafam de la Floresta.

-Allá tengo trabajo seguro-, le decía a su hermano César que lo acompañó hasta el aeropuerto militar de Catam, una madrugada de enero de 2008 cuando regresaba al batallón general Joaquín Paris, en el Guaviare, después de un permiso para visitar a su familia. Quería ser militar, pero sólo ingresaría a las listas del Ejército como uno más de sus 'falsos positivos'.

Culminado su servicio militar, Jonny trabajó en una tintorería y luego se dedicó al mercado informal como vendedor ambulante. $\mathrm{Su}$ familia dice que fue desde su lugar de trabajo desde donde se lo llevaron para la región donde lo asesinaron, quizás engañado con 
promesas de empleo, la misma teoría que sostienen las madres de los desaparecidos de Soacha.

“Su hijo era un guerrillero", fue la explicación que los agentes de la Fiscalía le dieron a don José Soto y que él refutó inmediatamente porque estaba convencido que esa afirmación era falsa. -Mi hijo era un muchacho normal, trabajador y de su casa-, apuntó el jefe de la familia Soto, de 62 años, quien trabaja vendiendo pinchos en la Plaza de las Américas.

Doña Zoraida Muñoz, de 57 años y líder de su comunidad, guardaba las esperanzas de una confusión y que su hijo entrara pronto por la puerta de su casa. Se aferró a su fe para que el dolor de la noticia de la supuesta muerte de uno de sus seis hijos no opacara su trabajo con los niños de Ciudad Bolívar, a quienes les consiguió zapatos y juguetes en diciembre pasado gracias a una donación de la Fundación Pies Descalzos. Hoy se siente sin fuerzas y afirma que ya no quiere vivir más.

Andrés, de 25 años y el tercer hijo de la familia Soto Muñoz, fue el elegido para ir a presenciar la macabra escena de la exhumación del cadáver de su hermano en Ocaña, quien yacía en una fosa con cuatro cuerpos más. Un capítulo de su vida que prefiere no recordar.

Una vez practicados los respectivos exámenes de ADN se confirmó el parentesco y 17 meses después fueron entregados los restos de Jonny a su familia para darle cristiana sepultura. Un peregrinaje para recuperar los restos que los tenía al borde de la locura y que terminó gracias a que la Secretaría de Gobierno de la Alcaldía Mayor de Bogotá tomó las riendas y asumió los gastos del traslado y sepelio.

-A Jonny lo mató el Ejército y fue publicado como guerrillero por el afán de mostrar resultados-, es la conclusión a la que llega la mayoría de la familia Soto. La única que aún no entiende por qué mataron a su hermano es Johanna, quien en su condición de sordomuda y pese al esfuerzo de sus cercanos por explicarle, no 
entiende el contexto de este episodio del conflicto armado colombiano. Ella tiene 31 años y es confeccionista, dicen sus vecinos que es la mejor del barrio. Algún día quisiera estudiar diseño de modas mientras ve crecer a su hijo Pablo, de 8 años.

César, el hermano mayor, tiene 34 años y trabaja como panadero. Tiene 4 hijos y son ellos quienes lo han llenado de fortaleza para ser el soporte de la familia en este "infierno de dolor y de martirio que le llaman "falso positivo"

Yenny tiene 28 años y trabaja como mesera en la cafetería de un centro comercial. Espera que el tiempo pueda regalarles un poco de resignación para afrontar la pérdida de su hermano Jonny y le preocupa el estado de salud física y mental de sus padres. Don José es diabético y la tensión de los últimos días lo llevó a ser internado en un hospital. Doña Zoraida, pese a que lo había abandonado hace muchos años, se refugió de nuevo en el cigarrillo.

Andrés teme por la seguridad de la familia y ya no quiere salir ni a jugar microfútbol en la cancha que está a seis cuadras de la casa. Intenta terminar sus estudios de tecnólogo en sistemas, pero confiesa que le da miedo andar en la calle. Aunque no han recibido amenazas como les sucede a las madres de Soacha, cree que la exposición del caso hace a su familia vulnerable y que podría suceder en cualquier momento, por eso cuida mucho en especial a Karen, su hermana menor, quien a sus 16 años se graduará de bachiller. (p.1)

En el relato se observa el impacto que tiene la violencia de esta magnitud, de esta manera, sin entrar en el análisis se expone la situación de las víctimas. El relato de manera sencilla muestra a la opinión pública como eran estos jóvenes, que hacían, cuáles eran sus sueños En este sentido, el artículo nos habla de la paradoja de la violencia, de como un joven que después de haber prestado el servicio militar obligatorio, quería ser militar y terminó siendo asesinado por los militares. 
En este testimonio se puede observar como en la guerra se construyen las justificaciones de muerte "guerrillero" y se consolida en el conflicto colombiano en una asignación que justifica cualquier atrocidad. De igual manera el relato nos muestra el sufrimiento causado a las familias, la interrumpible violación de sus derechos cuando todo queda en la impunidad.

Sin querer negar la importancia del testimonio queda faltando a estos artículos el análisis de la realidad, la conexión de esta violencia con el contexto socio- político, con los ciclos de violencia vividos en el país donde los jóvenes han sido los mayores afectados.

En definitiva los medios de comunicación hicieron la presentación de los jóvenes de este caso, mostrando perfiles generales, en los discursos se destacan los elementos que les asigna cualidades por su estatus socio-.económico, sobre su sector de residencia, y sólo en los casos en que se incluyó el testimonio pudimos observar que se mostraron elementos que les identificaban en su relación con sus familias, o aspectos particulares de cada uno de ellos.

\subsection{La construcción simbólica del joven desde el victimario}

Aunque en el discurso mediático recopilado anteriormente se presentan elementos que permiten observar las percepciones de los victimarios, ahora nos interesa retomar, los artículos que abordan de manera directa la construcción social del joven configurada por los victimarios. El artículo de la Revista Semana (2008b)

Mi hermano fue un falso positivo"

El escalofriante testimonio de Luis Esteban Montes, un soldado que se enteró de que sus compañeros de pelotón mataron a un campesino cualquiera para hacerlo pasar por guerrillero. Pero la víctima resultó ser su propio hermano.

Andrés teme por la seguridad de la familia y ya no quiere salir ni a jugar microfútbol en la cancha que está a seis cuadras de la casa. Intenta terminar sus estudios de tecnólogo en sistemas, pero confiesa que le da miedo andar en la calle. Aunque no han recibido amenazas como les sucede a las madres de Soacha, cree que la exposición del caso hace a su familia vulnerable y que podría suceder en cualquier momento, por eso 
cuida mucho en especial a Karen, su hermana menor, quien a sus 16 años se graduará de bachiller.

“Todo pasó el 30 de abril del año pasado. Yo estaba como soldado contraguerrilla en el Batallón de Infantería N.31 que opera en Córdoba. Mi compañía llevaba más de 15 días sin hacer mucho en un pueblito caluroso que se llama San Juan. No había operaciones ni patrullajes. Los soldados estábamos simplemente ahí, sin hacer nada. Pero el Día de la madre estaba cerca y los altos mandos empezaron a preocuparse porque no teníamos resultado para mostrar, ni méritos para que nos dieran los días y poder salir a visitar a las familias. Entonces se empezó a hablar de "legalizar" a alguien. Es decir, de matar a una persona para hacerla pasar por guerrillero y así ganarse el permiso para salir. No me sorprendió del todo, pues las 'legalizaciones' son un asunto cotidiano.

"Una noche, mientras yo hablaba con mi familia por teléfono, llegó mi cabo Jonathan Pineda y me dijo: "Guajiro, váyase para el cambuche que ya tenemos el 'man' al que le vamos a hacer la vuelta". Yo le pregunté que quién era, pero me mandó a callar y me advirtió que mi capitán Jairo Mauricio García había dado la orden de que no le habláramos para que no se diera cuenta de que lo iban a matar. Le pregunté: ¿¿De dónde es el 'man'?" y me dijo que de La Guajira. Siempre buscaban personas que fueran extrañas a la región para que ningún familiar los reclamara. De todas maneras, yo tenía mucha curiosidad porque también soy de La Guajira. Entonces me salí del cambuche, encendí un cigarro y escuché que el hombre me pidió otro. No le alcancé a ver el rostro porque no había luz ni luna. Estaba lloviznando. Le regalé el cigarro y nos pusimos a charlar. Al poco tiempo me di cuenta de que era mi hermano, Leonardo Montes. "Mi hermano se había ido de Maicao hacía mucho tiempo, cuando yo apenas era un pelao de 9 años. Por eso no lo reconocí. Pero cuando me dijo el nombre de mi papá, lo comprobé. Era mi hermano y era también al que habían elegido al azar para matarlo. No lo podía creer. Entonces me destapé. Le dije que yo era el 'niño', Luis Esteban, su hermano. Nos abrazamos y en medio de la emoción le advertí que lo iban a matar para hacerlo pasar por guerrillero. Le dije que se fuera, pero él no me creyó. Él 
se había hecho muy amigo de dos soldados de mi compañía que lo invitaron hasta el cambuche. Leonardo estaba seguro de que no le iban a hacer nada. Estaba engañado.

"Después de 20 minutos conversando con él afuera, me mandaron a llamar. Entonces me fui directo donde mi cabo Pineda y le dije: "Ustedes no pueden matar a ese hombre porque él es mi hermano". El cabo no me creyó y me dijo que mejor hablara con el capitán García, quien tampoco me creyó. Lo único que hizo fue insultarme. Le insistí. Le dije que le preguntara por el nombre de mi papá, de mis hermanos, de la familia, de la calle en Maicao donde habíamos nacido.

"A partir de ese momento todo fue un enredo. El capitán y yo discutimos varias horas y mi hermano lo escuchó todo. Al final, les dije que ya no me importaba si me creían o no, que ese hombre que iban a matar era mi hermano y primero tenían que matarme a mí. "Por qué no trae a un hermano suyo, capitán, o a su papá y así puede irse contento el Día de la madre. Pero con mi hermano no se pueden meter", le dije. Todos estaban muy alterados. No podían creer que la única persona que lograron conseguir para asesinar resultara ser el hermano de un soldado de su propio pelotón. El plan que tenían de buscar a alguien que no fuera de la zona, a alguien que no tuviera dolientes en el pueblo y que su muerte pasara inadvertida, se le había ido a la basura.

"Después de un rato, el Capitán me dijo: "A mí no me duele la mano pa matar a ese hijueputa". Tampoco era difícil encontrar quién lo hiciera porque cada compañía tiene sus dos o tres sicarios, que son siempre los que hacen esas vueltas y se ganan su millón de pesos.

"En un momento de descuido aproveché para decirle a mi hermano que se fuera corriendo, que saltara por unos alambres, que pasara la quebrada y se fuera para la casa porque lo iban a matar. Él decía que no se iba porque ahí sí era más fácil que lo asesinaran. Logramos salir un poco del cambuche, conseguimos una mototaxi y él se fue para el pueblo. Yo me quedé, pero, obviamente, esa noche no pude dormir. 
"Al otro día me di cuenta de que todo había cambiado para mí. Mis compañeros me odiaban. Entonces le pedí a un coronel que me trasladara porque yo no era capaz de patrullar con la misma gente. Además, estaba muy débil, pues me había atacado con fuerza el paludismo. Ese mismo día me mandaron para una compañía diferente en Puerto Libertador, un pueblo cercano a San Juan. Allá me sentí más tranquilo. Al menos no tenía miedo de que me mataran. La idea de denunciar a mis compañeros se me pasó por la cabeza, pero finalmente no lo hice en ese momento. Ya había liberado a mi hermano, que era lo más importante, y quería evitarme problemas con mis superiores.

"Como al tercer día de estar en Puerto Libertador escuché que la compañía donde yo estaba antes había "dado una baja". Me entró la duda por mi hermano y le pregunté a un soldado si sabía quién era el muerto. Él me contestó que no, pero que un carro lo estaba recogiendo para llevarlo al cementerio.

"De inmediato me fui para donde una tía que vive en Puerto Libertador y le conté todo. Le pedí que me acompañara al cementerio. Cuando íbamos caminando hacia allá, pasó el carro con el muerto pero tenía la carpa abajo y no pudimos verle la cara. Cuando llegamos al lugar, el muerto ya estaba en el piso envuelto en un plástico blanco. Yo me tiré sobre él, rompí la bolsa y me di cuenta de que era mi hermano, Leonardo. El hueco ya estaba listo y dos soldados lo agarraron de los pies y de las manos y lo tiraron así, sin ataúd ni nada. Supuestamente, le encontraron una granada y un arma en las manos. Pero ya hay un testigo en el pueblo que dice que él le vendió esa pistola al Ejército y yo me acuerdo cómo, días antes al 30 de abril, dos soldados de mi pelotón la estaban limpiando con orina para borrarle las huellas.

"Después de ver todo esto llamé a mi familia en Maicao. Les conté todo y ellos vinieron por él hasta Córdoba para darle cristiana sepultura. Fue entonces cuando decidí demandar al Estado. Pero el mundo se me vino encima. Estoy en permanente estado de alerta porque pienso que me puede pasar algo. Me da miedo comer lo que me dan en el Ejército y aunque ya completé tres años en la institución y hoy estoy en el Batallón Juan del Corral, en Rionegro, Antioquia, la única función que puedo cumplir es 
recoger la basura de todos. No puedo ir a zonas de combate porque tengo medidas especiales de protección. Además, muchos me tienen la mala porque saben de la demanda y de mi historia. Yo espero que todo esto pase muy rápido. El caso lo tiene una fiscal de derechos humanos, quien está investigando a los siete militares implicados en mi caso. El día que se haga justicia veré qué otro rumbo le doy a mi futuro. Lo que pasó con mi hermano me cambió completamente la vida y creo que ya merezco un poco de tranquilidad".

En este artículo vemos que la Revista Semana presenta una radiografía de "los falsos positivos", al mostrar a través del propio testimonio de un soldado que nos permite conocer hasta donde se puede degradar la guerra; en el discurso de este soldado se observa que tenía conocimiento de lo que sucedida en torno a los "falsos positivos", que eran llamados por parte del ejército como "legalizaciones":

Este testimonio habla de la forma como se planeaba a "sangre fría" los asesinatos y como estaban sistemáticamente planeados, se trataba de que las víctimas no tuvieran dolientes en las zonas donde eran asesinados, por ello se puede entender que los jóvenes de Soacha fueran llevados a un lugar lejano.

Al observar el relato entre líneas podemos ver algunos aspectos de los victimarios como de las víctimas, el principal aspecto que podemos observar en este caso es la deshumanización a la que se lleva la víctima y además en la que entra el victimario, el victimario se vuelve calculador, asume el asesinar como una acción cualquiera, los miembros del ejército sabían lo que pasaba, hasta quienes eran los encargados de cumplir con los asesinatos.

El doloroso testimonio recogido por la Revista Semana, brinda luces sobre la forma como la violencia de "los falsos positivos", pasó hacer parte de la cotidianidad del ejercicio militar, la utilización de un lenguaje propio de este actuar, el uso del término "legalizar" era conocido por los soldados, al parecer aunque no toda la tropa participará directamente en el asesinato, conocían como era el funcionamiento y era una estrategia aceptada, tal vez por el miedo y el terror impuesto por parte de sus superiores. 
En este sentido, es donde analizar la deshumanización en la guerra, la condición necesaria para llegar a este punto de barbarie, es que se pierda la sensibilidad, la aceptación de la "legalización" por parte de los soldados a los que se les ha obligado a perder su humanidad y empatía sino nos damos cuenta, el soldado reacciona ante esta crueldad sólo al comprobarse que es su hermano.

En definitiva, este testimonio ofrece elementos claves para entender el drama de la guerra en Colombia, que terminó enfrentando a las propias familias, a los propios vecinos y amigos. Así como enfrenta a los dramas de los combatientes y cuestiona profundamente los principios, éticos y humanitarios de los ejércitos combatientes.

La violencia de "los falsos positivos" fue efectuada por organismos del Estado colombiano, no obstante, en esta violencia participaron civiles, específicamente en la función de reclutadores de los jóvenes, de esta manera registró El Tiempo (2009b), la versión de dos de las personas que entregaron jóvenes a las brigadas del ejército.

Las dos víctimas, Camilo Andrés y Daniel Suárez Martínez, fueron enganchados por Víctor Manuel López Manosalva, quien el 21 de noviembre del año pasado confesó en la Fiscalía que los entregó a un grupo de militares encabezados por Ríos. "Por esos manes me dieron una chichigua, como cien mil pesos. Eso fue en diciembre del 2007”, confesó el reclutador. (p.1)

La versión dada por el reclutador confirma la utilización de civiles para entregar a las víctimas a las brigadas que posteriormente cometerían el asesinato, el reclutador reconoce que recibió un pago de cien mil pesos; más o menos como 30 Euros. Para el reclutador esta fue una transacción como si se tratara de una mercancía. Cuando afirma "Por esos manes me dieron un chichigua", el uso de este término en lenguaje coloquial se refiere a muy poco dinero, algo así como un poco de monedas. En este contexto vemos que la vida se convirtió en una mercancía. En esta violencia se implementó un mercado de la muerte, de esta manera lo publicó El Tiempo (2009b)

Cuando la Fiscalía le preguntó a López Manosalva qué ocurría con los muchachos que él conseguía y entregaba a militares, respondió: “Obvio que iban a estar muertos, porque a mí no me iban a pagar por llevarlos nada más". (p.1) 
El texto nos muestra como existía un conocimiento, de quienes hicieron el reclutamiento de cuál sería el destino final de estos jóvenes, sin embargo, realizaron la tarea solicitada por los miembros de las Fuerzas Armadas cruzando los límites morales y éticos de una sociedad como lo hacían los asesinos que los contrataban. Un importante punto para la reflexión es ¿cómo se ven afectados los principios éticos en los conflictos de larga duración?

En otro discurso artículo de la Revista Semana se observa como este medio de comunicación cuestiona el papel de las fuerzas militares, pero también se pregunta por el papel de los periodistas en la trasmisión de las noticias. En el artículo "Así no se gana la guerra," refiriéndose a los militares destituidos y judicializados por la participación en la violencia de "falsos positivos," la periodista Duzan (2008) afirma que:

Ninguno de ellos se refirió al dolor de las madres de los jóvenes de Soacha e incluso uno de ellos insistió en que se trataba de muertos en combate que le hacían mal a la sociedad porque eran personas al margen de la ley, casi dando a entender que aun si hubiera habido irregularidades -que según todos ellos, no las hubo-, había que agradecerles porque nos libraron de esa escoria. Pero tampoco ninguno de nosotros, los periodistas, fue capaz de preguntarle a alguno de ellos cuál era la razón por la cual no había tantos falsos positivos en los enfrentamientos contra las Águilas Negras, hecho que debería poner en tela de juicio los resultados que muestra el Ejército en la lucha que libra contra las poderosas bandas emergentes. (p.1)

El artículo muestra como para los victimarios siguen siendo "muertos en combate", esta noción lleva a reflexionar ¿En cómo se construyen las nociones del "enemigo", en estos conflictos de larga duración?

La noción del "enemigo" en este caso actúa como justificante de atrocidades inimaginables, tal como afirma la periodista, no se observó arrepentimiento, ni compasión hacia el dolor de las madres, por parte de los agresores, en este artículo se le designa a los victimarios, el significar a sus víctimas como "escorias", este término con alto contenido negativo, al tratarse de algo impuro, que hay que desechar, quizás muestra la degradación del concepto del contrincante en la cotidianidad de los conflictos armados. 
En definitiva, podemos afirmar que la construcción simbólica y social que tiene el victimario se establece en una profunda deshumanización del otro, a tal punto que seres humanos pasaron a ser objetos de un mercado ilegal de personas. Los testimonios recolectados en este tema nos confirman que estos hechos estuvieron fría y sistemáticamente planeados y ejecutados de la misma manera, lo cual emana preocupaciones muy profundas por el valor de la vida y el respeto por el "otro" en el marco de la guerra.

\subsection{Análisis del Discurso sobre el joven en los medios de comunicación a luz de la teoría}

Los discursos mediáticos contenidos en estos artículos del corpus de esta investigación nos muestran la existencia de constructos sociales de las víctimas de violencia, asociados a los imaginarios sociales del sector territorial, la juventud y el conflicto armado interno. En este sentido, observamos la existencia de una relación de constructos sociales sobre el joven popular con el discurso mediático.

Villamizar (2013) observan que el constructo social que estigmatiza al joven popular del sur de Bogotá, es una configuración altamente enraizada, en los imaginarios de los ciudadanos, no podemos afirmar que se trata de un discurso producido únicamente por los medios masivos de comunicación, pero si podemos señalar que existe un lenguaje mediático que alude a dicha representación y que profundiza los imaginarios ya existentes. En este caso, vemos como este discurso contiene lenguaje discriminante sobre dos elementos: territorio y jóvenes.

El surgimiento de estos constructos sociales de estigmatización está ligado a la configuración de estos barrios a partir de procesos irregulares de urbanización causados por la violencia estructural y política, que obligó a cientos de familias a desplazarse a la capital del país y constituir asentamientos informales. Durante más de tres décadas dichos territorios han sido receptores de población expulsada por la violencia política existente en el país.

Estos procesos de urbanización han sido altamente conflictivos con el Estado que se ha caracterizado por su papel ausente para garantizar los Derechos Humanos de la población residente en este sector y que de manera ambigua ha ejercido una represión sobre estos pobladores a través de las fuerzas armadas. Desde los primeros años de historia del sector 
han circulado discursos de estigmatización de la zona tanto por parte de las instituciones militares como de algunos medios de comunicación, prácticas discursivas que se mantienen hasta el día de hoy. Citaremos algunos ejemplos que dan cuenta de esto.

Navia (1996) observa que:

Antes de que amanezca, los habitantes de Ciudad Bolívar comienzan a bajar de los cerros hacia la urbe sembrada de luces titilantes. Vienen en colectivos destartalados o apretujados en los buses que bordean las lomas llenas de ranchos y de casas a medio terminar. Son construcciones de madera y ladrillo desnudo, levantadas en escalones junto a senderos de tierra que serpentean desde la de la montaña. (p.1)

Un trabajo periodístico realizado por El Espectador (2014) afirma que

En diciembre de 2013 decidí internarme en la Comuna 4 de Soacha, también conocida como Altos de Cazucá, uno de los sectores más peligrosos y abandonados de Soacha, y límite fronterizo de este municipio con Bogotá. (p.1)

La utilización de un lenguaje cargado de adjetivos, el uso de la metáfora, el empleo de la negrilla y un mayor tamaño de la letra, son mecanismos que buscan llamar la atención de los lectores, a través del sensacionalismo y el dramatismo. La adjetivación como peligrosa.

De otra parte, la utilización de títulos con un lenguaje asociado a la guerra es otra de las características presentes en el discurso mediático, es así como por ejemplo, el periódico El Tiempo (1996), titula un artículo “Cazucá bomba de tiempo”. El Espectador (2014) Pasamos la noche en Cazuca y descubrimos como opera la limpieza social, Montoya (2007) Somos generadores de violencia.

Los titulares resultan más significativos en razón de comprender la construcción de imaginarios, si observamos, la existencia de una representación social del sector como escenario de la guerra, en no pocas ocasiones, el discurso mediático pone de manifiesto, la existencia de esta conexión.

El abordaje de la violencia contra la población conserva el mismo formato, además de enfatizar las condiciones de pobreza, el sujeto joven, es descrito con el uso del 
dramatismo: La Revista Semana (2005) en su artículo Cazuca de luto, observa en su párrafo de inicio:

(...) Afuera están dos de sus hijos. El uno es un adolescente tan escuálido que tiene los pantalones a punto de caérsele. (p.1)

El tratamiento que se le da a la violencia contra la población joven en el sector recae, en la presentación de historias de jóvenes protagonistas de la violencia, historias cargadas de dramatismo y dolor donde la exacerbación del dolor, pareciera llevar irremediablemente a la violencia; de manera confusa se habla de actores del conflicto y las economías ilegales, que involucran a la población joven en el exterminio contra sus propios pares. El Espectador (2014) afirma:

(...) Y nadie sabe, en una comuna de $\mathbf{1 7 . 0 0 0}$ desplazados, cuándo la víctima se convirtió en victimario. (p.1)

No obstante, es de anotar que los artículos de la Revista Semana plantean una diferencia en el tratamiento de la violencia contra la juventud de este sector del sur de Bogotá. La revisión realizada, Encontramos que se dio una amplia divulgación a las noticias sobre la violencia contra los jóvenes recurriendo al análisis contextualizado dentro del contexto del conflicto armado colombiano, así como tuvieron un mayor lugar los familiares de las víctimas de la violencia política contra los jóvenes.

Los constructos sociales locales de discriminación del joven popular asociados a aspectos como: Territorio y juventud están presentes en el discurso mediático sobre las víctimas de la violencia de "falsos positivos," de la misma manera, que circularon en los discursos sobre el sicariato juvenil y la violencia juvenil urbana vivida en las décadas de 1980 y 1990 en el contexto de las grandes ciudades colombianas. Por tanto, se pone de manifiesto persistencia de atributos negativos asociados a las nociones de territorio y juventud en las prácticas discursivas mediáticas sobre el joven popular y por lo mismo se corrobora la existencia de un imaginario de discriminación social del joven popular. Por esta razón es necesario mostrar los principales aspectos que reproducen estas significaciones del joven popular y por ello son descritos a continuación. 
a) Pobreza y marginalidad.

Las circunstancias en las que se dieron los poblamientos de estos sectores expuestas anteriormente y las características socio-económicas de sus pobladores son elementos que se anclan en los imaginarios locales y nacionales, como atributos de desventaja y se materializan en el lenguaje en dos palabras pobreza y marginalidad. De esta manera, estos sectores han sido nominados como "marginales," este concepto está ligado a varias acepciones, en éstas es común llamar marginal aquello que está más allá del límite en referencia a las fronteras geográficas, pero en otro sentido, se dice marginal aquello que se ha construido en condiciones de anormalidad.

b) Territorios violentos y" zonas rojas."

Los constructos sociales sobre Soacha y especialmente sobre la comuna de Cazuca se expresa en la utilización de conceptos como los de "zonas rojas," esta expresión surgida en los Estados Unidos en 1890, para nombrar barrios y sectores dedicados a los negocios de prostitución, se utiliza en Colombia para denominar a sectores marcados por una fuerte violencia del conflicto, especialmente a sectores territoriales con enfrentamientos armado o alta presencia de actores armados.

En el imaginario social sobre los territorios urbanos existe la nominación a ciertos territorios como "zonas rojas" o "territorios calientes," para asignar atributos violentos este es el caso de Cazuca y Ciudad Bolívar en el sur de Bogotá, dichas connotaciones también están presentes en los pobladores locales, incluso ellos han construido mapas simbólicos del territorio donde se ubican los territorios más "calientes" o "bravos" por la intensidad de la violencia manifestada en hechos como los asesinatos, los atracos o la aparición de cadáveres o las masacres ocurridas como producto de la violencia derivada del conflicto armado interno y la delincuencia.

Estas configuraciones simbólicas y sociales; pobreza, marginalidad, zonas rojas y territorios calientes, están muy presentes en la manera de nombrar a los jóvenes víctimas de la mal llamada violencia de "falsos positivos", como lo pudimos observar en los discursos presentes en este apartado. Aunque dichas configuraciones no se nombran de manera explícita en los discursos mediáticos, se observa una reiterada nominación en estos sectores de estas características, que a su vez se asignan para los jóvenes. 
De esta manera, observamos que el discurso sobre las víctimas se enfatiza en su pertenencia a sectores "jóvenes pobres", "muchachos humildes". Es importante tener en cuenta que el sector geográfico de este sector ha vivido la estigmatización precisamente por las condiciones socioeconómicas, estas concepciones estigmatizantes se trasladan a sus habitantes y en especial a la juventud, dado que a los jóvenes se les asignan otras connotaciones como la de violentos.

La forma como se presenta en los medios de comunicación el perfil de los jóvenes refleja un poco conocimiento de las víctimas en muy pocas ocasiones se hace referencia a sus nombres, se utiliza un lenguaje generalizador, la caracterización se basa en estereotipos tales como "desempleados" e incluso aspectos relacionados con la salud que se expresan de forma descontextualizada como el término: "enfermos mentales."

En otras ocasiones se dieron otras expresiones mucho más cargadas de estigmatización como cuando se aseguró que entre las víctimas hubo "delincuentes", "habitantes de calle," la primera nominación es muy peligrosa, ya que en el contexto de violencia colombiano, el término "delincuente" ha sido utilizado por fuerzas paramilitares para justificar asesinatos y masacres. En este mismo sentido, las afirmaciones generalizadoras tales como: "algunos de ellos habían cometido delitos menores," la generalización en estos casos deja una sensación en la audiencia de que existe algún tipo de justificación para la violencia acontecida.

Los constructos sociales que relacionan al joven popular con la delincuencia son recurrentes en el país; tal como lo exponen autores como Martín-Barbero (1998), Perea (2004), Riaño (2006) y Serrano (2005), y se asocian a la existencia de un constructo social sobre el joven en escenario nacional que surgió en la década de 1980.

En este orden de ideas es necesario recordar que estos constructos sociales se constituyen en un acto violento hacia un sector particular, es una forma de representación social, asumida por la mayor parte de la sociedad, lo que el grupo denomina como "la marca", es una forma de nombrar al otro, que genera rechazo, la aceptación de la sociedad del joven popular produce en él un profundo sufrimiento y le obstaculiza la construcción de un sentido de pertenencia con sus comunidades locales y con la nación.

Una de las comprobaciones de este estudio es la aparición de imaginarios sociales que circulan en los contextos cotidianos presentes en el discurso mediático sobre el joven 
popular y que aparecen en el discurso mediático sobre los jóvenes víctimas de la violencia "falsos positivos", esta continuidad en el discurso nos hace preguntarnos por la continuidad de estos imaginarios.

Las construcciones discursivas sobre los jóvenes de este estudio nos demuestran la persistencia de imaginarios sociales de discriminación del joven popular del ámbito nacional, donde el joven aparece como amenaza social, pero también los imaginarios locales, del sector.

En los artículos de prensa aparecen alusiones a que algunos jóvenes habían cometido delitos menores y otros eran "drogadictos, "estas dos connotaciones han estado muy presentes en la estigmatización del joven popular. De igual manera, en el estudio de Villamizar (2013) se observó que existe en los imaginarios sociales sobre los jóvenes del sector, delincuentes y drogadictos y que estos actúan como justificantes de la violencia contra los jóvenes, especialmente la mal denominada "limpieza social", la cual se puede definir como como una violación sistemática de los derechos humanos, a partir del asesinato o masacre a grupos de personas que se caracterizan por una situación marginal y la concepción de los actores homicidas de que las víctimas se encuentran por fuera de un orden social, se trata de una expresión aberrante de discriminación social, de ciertos actores armados.

La mal llamada "limpieza social" posee un elemento que la caracteriza, éste es el estigma, el cual se configura como una forma de discriminación social, lo que en palabras de Goffman (1970):

La fuerza de un estigma radica entonces en un atributo que se percibe sobre un individuo, como una diferencia capaz de causar rechazo, por parte de las personas que también pertenecen a la misma sociedad. (p.474)

En este caso el rechazo es llevado a una situación que sirve como dispositivo de justificación de la eliminación de un sector de la población, así nos surge la pregunta por cómo se construyen estas formas de negación en la sociedad colombiana. Una de las respuestas que nos atrevemos a formular es que lo que opera allí, es la invención de un orden social dominado por una concepción de lo autoritario, ha existido una tendencia mediática en el país que infunde el miedo, se dice en todos los lugares que se está 
"desprotegido" y se advierte que no se puede confiar en el otro, porque este puede ser un "delincuente", se nos dice por todos los medios que tenemos que acudir a las autoridades, que se requiere de un ser supremo que nos pueda "proteger".

Este discurso llevó al país a solicitar un gobierno de "mano dura", que durante dos periodos instauró uno de los regímenes más autoritarios desde su programa "La Seguridad Democrática”. En esta noción del caos se instala como lo plantea Castillejo, (2000) "una incesante e impaciente necesidad de orden en medio de la incertidumbre" (p.88)

Desde el discurso del caos se profundiza en la resolución de nuestros conflictos vía la fuerza, se instala una representación del otro, que deviene del peligro de ser jóvenes, ya que representan el riesgo, lo cual se configura en un estigma, en una representación social que los ubica en desventaja y lo que es peor, en un sistema autoritario, se justifica como la eliminación de lo que causa malestar.

\subsubsection{Constructo social del joven en los medios de comunicación}

El constructo social del joven en los medios de comunicación lo hemos definido a partir del análisis del discurso de los artículos que hacen parte del corpus. Entre las connotaciones que han recibido los jóvenes en este contexto se pueden anotar las siguientes.

\section{a) Víctimas.}

El concepto de víctimas hace referencia a personas que han sufrido daños en su integridad física y/o emocional que se constituyan en una violación de los Derechos Humanos. La Comisión Nacional de Reparación y Reconciliación. CNRR (2006) considera como víctimas:

A todas aquellas personas o grupos de personas que, en razón o con ocasión del conflicto armado interno que vive el país desde 1964 hayan sufrido daños individuales o colectivos ocasionados por actos $\mathrm{u}$ omisiones que violan los derechos consagrados en normas de la Constitución Política de Colombia, del Derecho Internacional de los Derechos Humanos, del Derecho Internacional Humanitario y del Derecho Penal Internacional, y que constituyan una infracción a la ley penal nacional. 
El concepto expuesto por la CNRR, se aplica claramente para el caso de la violencia de "falsos positivos" con el agravante de que los hechos aquí sucedidos fueron ejecutados por miembros de las fuerzas armadas y por tanto revisten de mayor gravedad por ser una violación del Estado, instancia garante de la protección de los derechos de los colombianos.

En el análisis del discurso realizado a los artículos de este corpus observamos que en la construcción social del joven, está muy marcada la concepción de víctima. Es de anotar la existencia de una marcada tendencia a afirmar que eran "víctimas inocentes." En razón a que los jóvenes no eran combatientes. Desde luego, es verdad que los jóvenes no eran miembros de grupos armados y las condiciones en que fueron llevados para ser asesinados agravan aún más la violación de sus derechos.

Sin embargo, es necesaria una discusión sobre el clasificar a las víctimas por si son inocentes o culpables, ya que nos queda la sensación de que sí las víctimas hubiesen sido combatientes se hubiese aceptado tal tratamiento y esto nos lleva a una reflexión por los principios éticos que se manejan en contextos de guerra. En un Estado de Derecho como es el colombiano, la vida y la dignidad de los ciudadanos tiene el mismo valor no importa si es subversivo, delincuente común, sigue siendo un ser humano y por tanto sujeto de derechos.

La larga historia del conflicto armado en Colombia, ha llevado a una especie de acostumbramiento a la existencia de un clima recurrente de noticias de acciones de guerra que terminan convirtiéndose en un aspecto cotidiano al que las audiencias se ven sometidas, esto conlleva a un acostumbramiento que no permite el análisis de la información que se nos transmite.

Este concepto de víctimas en los artículos de prensa no sólo es significado desde la perspectiva de quien ha sufrido daño en su integridad, sino que además ha re- significado con el uso de adjetivos, tales como "pobres" referidos a alguien que sufre, a alguien por el que se generan sentimientos de compasión.

\section{b) De jóvenes a "muchachos de Soacha"}

El "caso de Soacha" tuvo una significativa importancia mediática, por tanto ha permanecido en la prensa colombiana desde que se destapó el escándalo hasta la actualidad. En este recorrido las significaciones del joven en el discurso se fueron 
transformando, especialmente la Revista Semana y El Espectador se utilizó el término "muchachos para referirse a los jóvenes víctimas de esta violencia. El uso de esta connotación tiene varias acepciones; se utiliza para nombrar a personas que están haciendo el tránsito de adolescentes a jóvenes, al igual se utiliza en relaciones más cercanas o también para nombrar grupos de jóvenes del barrio o la localidad. La connotación dada por la prensa, se refiere a una especie de cercanía con las víctimas de esta violencia, entre líneas se observa que el término "muchachos" es usado para expresar que tan sólo se trataba de un grupo de jóvenes que no tenía la capacidad para realizar los delitos de los cuales se les acusan.

La utilización de la connotación "muchachos de Soacha" contiene una carga simbólica, que se puede explicar desde dos sentidos, primero, el municipio de Soacha es muy representativo en el tema de la violencia por ser el mayor receptor de población de personas en situación de desplazamiento y segundo, la carga simbólica de este caso por ser emblemático en el tema de la violencia de las ejecuciones extrajudiciales.

En definitiva, el discurso expresado por los medios de comunicación ubicamos que a los jóvenes se les significó como víctimas, lo cual es absolutamente cierto, ellos fueron víctimas de violación sistemática de los Derechos Humanos ejercida por el Estado colombiano en cabeza de sus Fuerzas Militares; Esta violencia se enmarcó en delitos como : La desaparición forzada, la tortura, la ejecución extrajudicial y el homicidio agravado, procederes que muestran la crueldad utilizada en estos dolorosos hechos, que sin duda abrieron una profunda herida en sus familias y en la sociedad. Con dinero del Estado, de los impuestos pagados por los colombianos se mantuvo un mercado ilegal de vidas.

No obstante, en el discurso mediático la categoría víctimas fue significada con el uso de adjetivos como; pobres y humildes que restan el contenido político al concepto de víctimas y trasladan la obligación de reparación del Estado a la generación de compasión por parte de las audiencias.

Aunque no identificamos que se hayan creado constructos sociales de estigmatización sobre los jóvenes de este caso, si observamos la existencia de estigmas y estereotipos juveniles anclados en los discursos, como son los estereotipos de jóvenes desempleados, o desescolarizados que la prensa utiliza para explicar porque los jóvenes eran vulnerables a ser engañados con oportunidades de trabajo y de otra algunos estigmas como los de 
drogadictos, delincuentes, aparecen en el discurso y dejan una sensación de que estas son características de los jóvenes que habitan estos territorios.

\subsubsection{El discurso de los victimarios}

Un eje central en este análisis es la concepción de quienes cometieron los hechos, en tanto el despojar de la dignidad y la vida de seres humanos, requiere de haber configurado una construcción simbólica del "otro" que justifique su muerte. Es decir requiere de despojar al otro de su dignidad y su humanidad. En este caso que se trató de crímenes planeados a sangre fría, por ello se crearon perfiles de quienes serían reclutados y posteriormente asesinados. Es evidente que existió una sistematicidad en los hechos, ya que existe un modos operandi, que presenta elementos comunes en todos los casos, entonces por esto sugiere la existencia de una imagen de la potencial víctima cargada de un sentido simbólico que le hace merecedora de su eliminación.

Del análisis que hemos realizado observamos que las construcciones simbólicas que se expresaron en estos discursos son:

\section{a) guerrilleros y bandoleros"}

En la mayor parte de los artículos se mostró que las Brigadas del ejército colombiano que participaron en esta violencia crearon un lenguaje justificador de la muerte, en la imagen del "combatiente", pero no quiere decir que así lo creyeran, porque como comprobamos en las narraciones hechas por testigos e implicados en el hecho, el mostrar a civiles como muertos en combate fue una intención fríamente calculada, por tanto la construcción discursiva del combatiente sería racionalmente fabricada.

Sin embargo, es conocida la existencia de este imaginario de "guerrilleros" y “delincuentes", para denominar a los jóvenes de los sectores populares. En el estudio de Villamizar (2013) se comprobó que la Fuerza Pública que realiza el control en estos sectores ha demostrado tener imaginarios de discriminación contra los jóvenes, que se manifiestan en el trato diferenciado que se hace de estos jóvenes, la constante requisa y solicitud de documentación, el trato degradante y el señalamiento público hacía los jóvenes con la utilización de palabras como. "guerrillos”, “drogos” y “delincuentes." Este trato de abuso de autoridad enuncia la existencia de identificaciones preconcebidas que asignan atributo negativo sobre el joven que es utilizado para justificar la agresión por el joven. 
Es necesario apuntar en esta reflexión que el imaginario social de la guerrilla de los colombianos, presenta un profundo rechazo y que está cargada de atributos negativos del "mal", en este sentido en un análisis de las representaciones del conflicto realizado por Pardo (2005) afirma que:

En primer lugar, la nominación de la guerrilla se puede rastrear en un conjunto de expresiones asociadas a la construcción de un actor delincuente que es incapaz de reconocer normas, interactúa de forma irresponsable, impulsiva, insensible y calculada; este tipo de actor es agresivo, incapaz de compasión, carente de límites, todo lo cual lo formula como un sujeto cuya conducta es amoral y antisocial. (p.182)

En este análisis realizado sobre la representación de la guerrilla colombiana en la prensa colombiana, se muestra como está imagen está cargada de adjetivos que le asignan una identidad calculadora, insensible y capaz de perpetrar cualquier acción maléfica contra la sociedad civil.

Así en los imaginarios sociales de los colombianos, la guerrilla es portadora del mal, especialmente, la imagen de las FARC, han sido profundamente satanizadas en el país, en mayor medida a partir de la década del 2000. El discurso del Expresidente Uribe desde su candidatura a la presidencia y la llegada a la misma en el año 2002, agudizó las connotaciones negativas sobre la subversión y polarizó mucho más al país.

Es de notar que en estos periodos de gobierno del señor Uribe, se enfatizó en la construcción de una imagen que calificaba a los movimientos insurgentes y se desvirtuó su estatus de combatiente. Sin lugar a dudas esto tuvo asidero en los imaginarios sociales sobre las guerrillas, que si bien es cierto son ejércitos combatientes que habrían perdido reconocimiento ante la sociedad civil; en este periodo se enraizaron sentimientos de rechazo y odio.

En estas condiciones utilizar un discurso de "guerrilleros" para justificar la muerte de civiles indefensos en manos de militares, resulta un acto instrumental en búsqueda de que la sociedad acepte tan inmensa crueldad. Sólo mediante la construcción de una imagen del "enemigo" en abstracto despojada de toda dignidad se puede actuar sin límites desde la violencia. Por tanto, es pertinente preguntarse. ¿Cómo se construyó la imagen del 
enemigo en Colombia? Y ¿Hasta qué punto la sociedad colombiana ancló en los imaginarios estas imágenes de eliminación del otro?

Estas preguntas no pueden ser resueltas en este estudio, lo único que podemos es esbozar unas posibles respuestas que quedaran abiertas para el análisis en otras investigaciones. La primera respuesta, se funda en que la construcción de la imagen del enemigo en Colombia, ha estado marcado por los ciclos de violencia en el país, Blair (2005) afirma que dicha construcción tiene asidero en la historia partidista, la autora pone de manifiesto la imposibilidad de la construcción de la validez del adversario y la aceptación de la diferencia,

Según la citada autora, la identidad nacional se construyó alrededor de los partidos políticos, que a su vez construyeron sus identidades en relación a la exclusión del adversario. En este sentido, Blair (1999) afirma que cuando el otro es el que nos niega, la única posibilidad de afirmación es su destrucción.

\section{Mercancía}

La violencia ejercida en el marco de los "falsos positivos", es una de las más aberrantes vivida en el marco del conflicto armado que vive el país, seres humanos, fueron tratados como una "mercancía", como objetos que se pueden comprar y vender, los testigos de los hechos mostraron como las vidas de estos jóvenes tuvieron un precio pagado tanto a los reclutadores, como a los miembros de la Fuerza Pública que recibieron prebendas por asesinar a supuestos miembros de los grupos de subversivos.

\subsection{Síntesis}

Este capítulo exploró y analizó los constructos sociales sobre el joven y la violencia de los "falsos positivos" contenidos en los artículos que hacen parte de esta investigación. Mediante el análisis del discurso se identificaron las principales características del lenguaje utilizado por los tres medios de comunicación objeto de esta investigación (El Espectador, El Tiempo y la Revista Semana), además identificamos los principales constructos utilizados para nombrar los jóvenes víctimas del denominado "Caso de Soacha". De igual forma, en este capítulo se identificaron y analizaron los constructos sociales presentes en el discurso del "victimario," causante directo de la desaparición y muerte de los jóvenes del sur de Bogotá y Soacha. 
De la exploración realizada al corpus se identificó que: en el constructo social del joven víctima de la violencia de "falsos positivos", emitido por los medios de comunicación, se encuentran reflejados estereotipos y estigmas que circulan sobre el joven popular. Estos constructos están relacionados con los lugares de procedencia y su condición juvenil.

Otros constructos sociales sobre los jóvenes del caso de Soacha es el de víctimas, este concepto se acompaña de adjetivos tales como: pobres, humildes e inocentes. La adjetivación realizada al concepto le proporciona diversos sentidos desde los que se centran en el componente político como los que inspiran compasión.

En la construcción social en los medios de comunicación sobre el joven del "Caso de Soacha" enfatiza en su condición de "inocentes" y es totalmente cierto, se comprobó que estos jóvenes no realizaban ninguna actividad ilegal y por tanto merecen que se reconozca su inocencia. El asunto problemático que nos queda al leer el discurso, es que parecería que en el discurso mediático aceptaría que la violencia perpetrada tendría alguna justificación si se tratará de "combatientes" o de quien infringiera la ley, en este caso nos encontramos ante una de las graves consecuencias de la guerra y es la deshumanización del adversario y la no comprensión que es merecedor de un trato digno, el consagrado en las normas constitucionales.

En este capítulo observamos el constructo social del joven para el victimario esta cimentada en la deshumanización del "otro," al punto de verlo como alguien que merece la destrucción. Este imaginario de construye en el marco del discurso del "enemigo" configurado en el contexto de un conflicto de larga duración, en este sentido para el Estado colombiano la noción de guerrillero es asumida como depositaria del mal. Los victimarios justificaron la desaparición y asesinato de los jóvenes a partir de nominarlos como guerrilleros.

Otro constructo social que identificamos es ver el joven como "mercancía" como objeto de intercambio de un mercado ilegal, dados los incentivos económicos ofrecidos a los militares por mostrar resultados con número de "bajas" en combate. Se dio inicio a un macabro plan de comprar vidas humanas como objetos con precio.

El análisis de los textos contenidos en el corpus de este estudio posibilita concluir que la violencia perpetrada en el marco de "falsos positivos," además asesinar y desaparecer a civiles, fue la expresión de un lenguaje horror y negación de las víctimas, puesto que estas 
personas fueron despojadas de su dignidad e identidad, dado los tratos crueles y el engaño a que fueron sometidos antes de su asesinato y la supresión de sus nombres e historias de vida después de su muerte al convertirlos en NN (Personas sin nombre) y acusarlos de delincuentes; la memoria de las víctimas fue maltratada causando profundo sufrimiento a sus familias y comunidades e infringiendo un acto de re-victimización de quienes fueron asesinados al no sólo destruir sus vidas físicas sino afectar negativamente su memoria. 


\section{CAPITULO VII. JUVENTUD Y VIOLENCIA. DISCURSOS}

HEGEMÓNICOS Y CONTRA HEGEMÓNICOS. LOS "FALSOS POSITIVOS” EN EL DISCURSO DE DIFERENTES ACTORES DE LA POLÍTICA Y LA SOCIEDAD CIVIL

7.1. Practicas discursivas sobre la violencia de "falsos positivos." Representantes del Gobierno, los familiares de las víctimas y la sociedad civil.

7.2. Análisis del Discurso de los medios de comunicación a la luz de la teoría.

7.3 Síntesis. 


\section{CAPÍTULO VII. JUVENTUD Y VIOLENCIA. DISCURSOS HEGEMÓNICOS Y CONTRA HEGEMÓNICOS. LOS "FALSOS POSITIVOS” EN EL DISCURSO DE DIFERENTES ACTORES DE LA POLÍTICA Y LA SOCIEDAD CIVIL}

En este capítulo analizaremos los principales discursos publicados sobre: la violencia de "falsos positivos" y las representaciones sociales de estos actores políticos y sociales sobre la juventud víctima de esta violencia. En este sentido, describiremos el discurso del gobierno, los familiares de las víctimas y los organismos de Derechos Humanos y la Sociedad Civil. La presentación de este capítulo se distribuirá en dos apartados, el primero, Practicas discursivas sobre la violencia de "falsos positivos." Representantes del Gobierno, los familiares de las víctimas y la sociedad civil y el segundo, Análisis del Discurso de los medios de comunicación a la luz de la teoría.

\subsection{Practicas discursivas sobre la violencia de "falsos positivos." Representantes del} Gobierno, los familiares de las víctimas y la sociedad civil

La violencia ocurrida en el marco de los "falsos positivos" presenta múltiples interpretaciones, las prácticas discursivas de lo sucedido están influenciadas por formaciones ideológicas y relaciones de poder entre los diferentes actores discursivos. A continuación, describimos los discursos de actores representativos del Gobierno colombiano, los militares, los familiares de las víctimas y los Organismos de Derechos Humanos.

\subsubsection{El discurso del gobierno}

Al considerar la violencia de "falsos positivos" como una grave violación de los Derechos Humanos, efectuada por las fuerzas armadas colombianas se hace necesario conocer cuál fue la postura del gobierno nacional a tan semejante agravio contra la población civil, en este sentido es muy importante conocer el discurso emitido desde el ejecutivo en cabeza del presidente de la república. La revisión a los artículos de prensa nos mostró que el Gobierno colombiano se convirtió en un interlocutor permanente en los medios de comunicación y es así como una vez destapado el escándalo de "falsos positivos", El Espectador (2016) afirmó que: 
El 8 de octubre de 2008 entonces presidente Álvaro Uribe Vélez manifestó en una locución que los jóvenes de Soacha que habían sido reportados como bajas en combate "no estaban recogiendo café" sino que estaban adelantando acciones ilegales que fueron atacadas por el Ejército Nacional y la Fuerza Pública.

En este comunicado el presidente Uribe afirmó que, según el informe de la fiscalía general de la nación, los jóvenes habían muerto en combate. Resulta preocupante que el señor Presidente de la República, representante del Estado colombiano, quien por mandato popular y constitucional tiene encargado la protección de los ciudadanos, se expresé en los medios masivos de comunicación, con tanta ligereza e irresponsabilidad.

Es de anotar que, en los primeros días del mes de septiembre de 2008, los organismos de Derechos Humanos y el propio personero de Soacha, representante del Ministerio Público, habían dado a conocer la violación de Derechos Humanos que habían sufrido estos jóvenes, así como se conocía como habían ocurrido los hechos.

Al siguiente día tuvo que hacer la rectificación de lo sucedido, tal como lo registró el periódico El Espectador (2008a)

Muy fuerte, repito, ver al Presidente desencajado y furibundo reconociendo la barbarie oficial, que no otra cosa es lo sucedido con esos pobres muchachos de Soacha y de muchos otros lugares del país, convertidos en guerrilleros por decisión de unos regulares.

Hacia las 8 de la mañana el Presidente llamó al Fiscal para escuchar de su propia voz el estado de las investigaciones. Iguarán le sostuvo entonces lo que había explicado en la tarde del martes: que los 11 muchachos murieron a manos del Ejército, pero que aún no se ha establecido si fue en medio de un enfrentamiento.

Tan pronto como terminó la conversación, Uribe ordenó redactar un comunicado en el que dio cuenta de la charla y reafirmó lo dicho por Iguarán: "La Fiscalía aún no ha establecido la afirmación del Ejército de que fueron dados de baja en combate". 
El martes Uribe había atribuido a Iguarán una información distinta: “El Fiscal General de la Nación aseguró que los jóvenes desaparecidos de Soacha fueron dados de baja en combate", dijo en medio de la Asamblea de la ANIF.

Un funcionario del círculo presidencial le aseguró a este diario que a Uribe "le informaron eso altas fuentes militares nutridas por altas fuentes de la misma Fiscalía".

En el comunicado de ayer se insiste en otros aspectos de la investigación que han sido corroborados por la Fiscalía, como que los jóvenes fueron reclutados con fines criminales y que estos "no salieron con el propósito de trabajar o recoger café".

Iguarán también se apresuró a dejar aclarado el tema: “¿Fueron muertos en combate? No sabemos, estamos investigando. No puede la Fiscalía afirmar que fueron muertos en combate", dijo desde un simposio internacional sobre investigaciones criminalísticas, en la sede de la DIPOL.

El pronunciamiento del señor presidente se limitó a afirmar que aún no existía claridad de sí estas personas habían sido asesinadas en Combate, pero su discurso continúa mostrando una sombra de duda sobre la inocencia de los jóvenes. Estas afirmaciones del expresidente Uribe no eran nuevas, puesto que era acostumbrado por el presidente de la república el emitir discursos sesgados cuando se trataba de defender las Fuerzas Militares o desvirtuar las versiones de organizaciones de la sociedad civil y Derechos Humanos.

La presentación que hace el medio de comunicación también carece de claridad, pues dice que: Muy fuerte, repito, ver al Presidente desencajado y furibundo reconociendo la barbarie oficial. Si se vio al señor presidente muy alterado como lo registraron las imágenes de los medios de televisión, lo que no hizo fue reconocer que se trató de un crimen de la Fuerza Pública, como lo afirma el medio de comunicación, lo único que señala es que no se tiene claridad de que fueron muertos en Combate.

La contundencia de los hechos le obligó al señor presidente a transformar los discursos sobre lo sucedido con los jóvenes, de esta manera lo afirma el periódico El Espectador (2009a): 
Ahora, cuando las investigaciones han avanzado y todo indica que estamos ante un caso de "falsos positivos", la situación y el tono de las declaraciones oficiales han dado, por fortuna, un vuelco de 180 grados. El ministro de Defensa, Juan Manuel Santos, advirtió que habrá “cero tolerancia con cualquier comportamiento (de la Fuerza Pública) que no esté ajustado al respeto por los derechos humanos".

Ante las evidencias de que lo sucedido se trataba de una ejecución extrajudicial cometida por las fuerzas armadas colombianas, el gobierno fue cambiando sus discursos, de manera moderada y sin reconocer en ninguno de ellos, que se había equivocado en las primeras declaraciones que había emitido sobre este tema.

En este artículo El Espectador continúa expresando:

Si bien el discurso oficial se ha endurecido frente a tan flagrante violación de los derechos humanos, seguimos sin hacer una reflexión de fondo sobre el sentido de tan macabras acciones. El testimonio, dado a conocer por la revista Semana, de un soldado contraguerrilla del Batallón de Infantería $N^{\circ} 31$, que opera en Córdoba, quien presenció el asesinato de su propio hermano, a quien los altos mandos hicieron pasar por guerrillero muerto en combate para ganar unos días de vacaciones, es ilustrativo de hasta dónde hemos llegado. La vida misma del colombiano parece haber perdido sentido en medio de la rutinización de una guerra que se asegura vamos ganando, al tiempo que altos oficiales del Ejército son primero condecorados y después señalados de ser las manzanas podridas de la institución. Por lo demás, nadie se pregunta por las circunstancias sociales que mueven a que los jóvenes hayan sido enganchados en un grupo al margen de la ley.

La invitación que se hace a la reflexión que se hace en este artículo, desde luego que se hace muy necesario el debate sobre como la guerra llegó a extremos de barbarie, hasta qué punto en el prolongado conflicto se naturalizaron las más graves agresiones y el impacto de la violencia estructural en el agravamiento, de la guerra no obstante, se requería en ese momento que más que un discurso que promete la investigación y la justicia se dieran acciones para superar la impunidad, que incluso al día de hoy se está pendiente de esto. 
Parecería el momento para detener la carrera enloquecida de la muerte y la degradación y encontrar un camino más humano juntos. En este punto ya no parece suficiente pedir solamente, y otra vez, que se juzgue a los responsables”.

La afirmación que se hace en este artículo: " nadie se pregunta por las circunstancias sociales que mueven a que los jóvenes hayan sido enganchados en un grupo al margen de la ley. Nos muestra como en este texto se filtran constructos de estigmatización que asocian al joven popular con la violencia, ya que se pregunta por las condiciones sociales que llevaron a las víctimas a involucrarse en un grupo armado. En este caso específico está demostrado que no hubo vinculación de los jóvenes a grupos ilegales.

Además del expresidente Uribe y el Ministro de Defensa de ese entonces, también fue portavoz del Gobierno, para referirse sobre el caso de Soacha, Amat, Y (2008) publicó sus explicaciones sobre las sanciones impuestas a miembros de la fuerza pública involucrados esta violencia. El Ministro afirmó que:

(...) si usted sospecha o teme que algunos de sus hombres atropellan los derechos humanos, ¿trataría de comprobar plenamente los hechos, o la sola duda de alguna actuación pone su civilidad por encima de la defensa de sus hombres?

Nuestra política, como ya lo dije, es de cero tolerancia con la violación de los derechos humanos y esto es lo que estamos poniendo en práctica, pero todo hombre o mujer de las Fuerzas Militares tiene el mismo derecho al debido proceso que cualquier ciudadano común, y estamos también haciendo grandes esfuerzos para establecer un sistema de defensa adecuado para las Fuerzas Militares.

El discurso del entonces Ministro de Defensa Juan Manuel Santos, expresa que la posición del gobierno, es la de "tolerancia cero" a la violación de los Derechos Humanos, no expresa cuáles son las medidas que se tomaron en su momento, para evitar que se siguieran repitiendo estos hechos vergonzosos, no se le dijo al pueblo colombiano que se estaba haciendo para sancionar y castigar a quienes cometieron delitos extralimitándose en sus funciones y mucho menos se dijo como se iba a reparar a las víctimas. En este mismo artículo, el ministro se refirió a los aspectos que habrían motivado dicha violencia. 
En su opinión, ¿qué está provocando los llamados falsos positivos? En esto hay de todo: desde indisciplina, falta de control y corrupción, hasta falsas denuncias. Hay que saber distinguir, pero lo importante es que no le tenemos miedo a coger al toro por los cachos y resolver el problema, para proteger la institución militar y el honor de la inmensa mayoría de soldados y policías que tanto se sacrifican por la seguridad de todos los colombianos.

En el anterior párrafo el discurso del ministro de entonces que resume las afirmaciones que hizo el gobierno se trató de hechos llevados a cabo por la indisciplina, la corrupción de unos pocos miembros de la Fuerza Pública, aún más llamativo que haya hablado de falsas denuncias. Parece que a los funcionarios públicos les queda difícil reconocer las graves dimensiones de los hechos acontecidos y la opinión pública se quedó callada ante la magnitud de los hechos contra la población civil y tampoco se pronunció ante la demanda de los familiares por la búsqueda de justicia.

Las prácticas discursivas efectuadas por el Gobierno colombiano se mantuvieron a favor de los militares y para ello se fueron generando discursos que desviaban la atención con la utilización de lenguajes sutiles se trató de contrarrestar la responsabilidad del Estado en esta violencia. Así se construyó la teoría de las manzanas podridas que describiremos a continuación.

\subsubsection{Discurso militar: "Manzanas podridas" e impunidad}

Los discursos de los representantes del gobierno y los militares giraron en torno a la metáfora de las "manzanas podridas," expresión con la que se explica que: La violencia sucedida en el marco de los "falsos positivos", fue realizada por unos pocos, que se trató de un hecho aislado, protagonizado por un grupo de militares que cayeron en actos de corrupción e indisciplina. De Esta manera lo reporta El Espectador (2008a):

\section{(...) Suma y ofrece un panorama desolador: es verdad lo que los} defensores de derechos humanos del mundo denuncian e internamente se viene negando y descalificando ad infinitum. Y la nueva actitud no puede ser otra que asumir, poner pecho y corregir, dejando de lado el estribillo de las manzanas podridas, porque no son pocas sino una cosecha completa. 
En este artículo El Espectador se muestra como el discurso de las "manzanas podridas" produce se desvié la aplicación de la justicia. Usar la metáfora de " las manzanas podridas", significa que si apartan aquellos oficiales que participaron en estos hechos es suficiente para parar el problema, se desconoce que el sistema de recompensas establecido en el marco de la política de Seguridad Democrática es totalmente inadecuado en un Estado de Derecho, como pretende serlo el Estado colombiano, pero lo que es peor desconoce los graves problemas éticos y humanitarios a los que llegó al conflicto colombiano, tanto en los ejércitos combatientes, como los civiles involucrados en acciones bélicas.

Las declaraciones del expresidente Uribe sobre las sanciones adelantadas contra los militares fueron publicadas por El Espectador (2008b), textualmente afirmó:

Estos hallazgos muestran que en algunas instancias ha habido negligencia, falta de cuidado con los procedimientos que tienen que observarse $\mathrm{y}$ eso ha permitido que algunas personas puedan estar implicados en crímenes resultado de la confabulación entre delincuentes e integrantes del ejército", dijo Uribe.

"Crímenes que algunas regiones tienen por interés...asesinar inocentes para dar la sensación de que se está enfrentado a los criminales en esas regiones, cuando son los verdaderos criminales los asociados con integrantes del ejército para cometer estos crímenes, para desorientar y para mantener esos criminales intacto el teatro de acción de su actividad delictiva", agregó el mandatario.

En este artículo observamos que El expresidente Uribe reconoce que la violación de Derechos Humanos fue llevada a cabo por miembros de la Fuerza Pública, sin embargo, es un reconocimiento a medias, ya que se mantiene en que fue un acto cometido por algunos miembros del ejército que se aliaron con delincuentes. No obstante, este reconocimiento está precedido de una afirmación de le existencia de negligencia y falta de cuidado en los procedimientos que debe observar las Fuerzas Armadas. Negligencia y falta de cuidado, palabras de contenido benevolente cuando están implicadas las vidas de personas. 
En definitiva, el discurso del gobierno presentado por la prensa se centró en las intervenciones del presidente Uribe. Dicho discurso tuvo varios matices, cuando se conoció lo que se denominó el "destape del escándalo de los "falsos positivos", fue un discurso arrogante y en contra de las víctimas que estuvo cargado de adjetivos que culpaban a los jóvenes de realizar actividades ilegales.

Sin embargo, con las evidencias que se presentaron por parte de familiares de las víctimas, las organizaciones de Derechos Humanos y el Ministerio público, se dio un giro discursivo en el gobierno que determinó, la aceptación de una verdad a regañadientes por parte del ejecutivo, No obstante, el discurso se centró en la metáfora de las "manzanas podridas" y enfatizó en la tesis de que lo sucedido era un acto de indisciplina de algunos miembros de la fuerza pública.

El discurso emitido por el gobierno nunca reconoció y se retractó de los excesos del lenguaje cometidos contra el buen nombre y la dignidad de los jóvenes que fueron asesinados por militares, tampoco se expresó claramente sobre la culpabilidad de los responsables, se limitó a definir una de las violaciones más graves de los Derechos Humanos en el marco de conflicto armado colombiano como un acto de indisciplina y corrupción de un pequeño grupo de militares.

Los discursos del Ministro de Defensa de la época, hoy presidente del país Juan Manuel Santos, sobre tolerancia cero con las violaciones de los Derechos Humanos en el interior de las Fuerzas Armadas Colombianas, se quedaron en palabras que no demostraron acciones contundentes para sancionar y castigar a los culpables y adelantar acciones para que estos actos no se siguieran cometiendo, los informes de Derechos Humanos registran que entre el 2006 y 2015 se cometieron 4.700 ejecuciones extrajudiciales en el país.

Por último, es de anotar que nunca el Gobierno colombiano se refirió a aspectos estructurales como los problemas de la política de Seguridad Democrática que con su estrategia de incentivos a militares por resultados en muertes y detenciones de subversivos motivaron esta violencia, así como tampoco a los problemas de formación de las tropas en los Derechos Humanos que habrían contribuido a tan grave lesión a la sociedad civil. Mucho menos tomó medidas al respecto para corregir los graves problemas de la fuerza pública en temas de Derechos Humanos. 


\subsubsection{El discurso militar}

Los pronunciamientos públicos de las fuerzas militares sobre el "caso de Soacha" fueron muy similares a los del Gobierno, en un principio sostuvieron la tesis de que las víctimas eran muertos en combate y posteriormente se apoyó la tesis de las manzanas podridas, en medio de estas dos versiones se mostraron varios matices.

A finales de 2008 se hicieron 27 destituciones de miembros del ejército colombiano, acusados de ser responsables de las ejecuciones extrajudiciales de Soacha. A partir de este hecho se pusieron en circulación diversas versiones sobre lo sucedido, mientras el Gobierno sostenía la tesis de las "manzanas podridas," para los militares se trataba de un hecho de conspiración de las FARC, tal como lo expresó el general Cortés, uno de los generales destituidos por este caso, así quedaron registradas sus versiones en El Espectador (2009b).

Mi análisis es que ahí hubo infiltración de los terroristas de las FARC. Porque el Ejército está arrollador en esta guerra, las está acabando. La población quiere al Ejército, y Alfonso Cano sabe que un Ejército que se gana el cariño y el corazón de la población, gana la guerra. Entonces, ¿qué hace Cano? Nos infiltra con el propósito de hacer estos falsos positivos y dañar la imagen del Ejército.

La versión de la infiltración de las fuerzas militares, incluso fue apoyada por el Ministro de Defensa del momento, estas versiones fueron una muestra de una práctica común en los discursos militares y los sectores oficialistas; cargar la responsabilidad sobre el grupo insurgente lo cual era oportuno dada las configuraciones imaginarias de la sociedad colombiana de asignar a las FARC, la depositaria de todos los males. Una configuración simbólica originada desde discursos hegemónicos y apropiados por la sociedad.

Tanto los militares destituidos, como los activos y hasta los militares retirados en sus pronunciamientos públicos enfatizaron en la defensa de los miembros de la fuerza pública y manifestaron que las sanciones eran una ofensa contra la tropa que sólo había cumplido con su deber de proteger a los colombianos. De esta manera lo afirmó el general Cortés en entrevista en El Espectador (2009b).

A mí me llegaron también esos correos. Mis soldados se sacrificaron, se esforzaron, muchos perdieron la vida o salieron heridos y ahora 
quedaron todos como criminales. Porque si es señalado su comandante como criminal, como asesino, como responsable de esos asesinatos, pues fueron señalados esos 26 mil hombres, porque el comandante los está representando. Nunca he cuestionado mi salida, porque uno tiene a cargo a mucha gente y por ellos toca dar la cara. Ese era mi trabajo y ahí se dio mi salida. Pero no acepto que me hayan sacado en esa rueda de prensa, en ese espectáculo mediático en el que nos tildaron de asesinos.

Como podemos ver los militares no reconocieron la participación en los hechos, además de asumirse como víctimas de falsas acusaciones y de un desprestigió en los medios de comunicación. Además, se mostraron muy críticos a las posibilidades de que los crímenes cometidos en el marco de la violencia de ejecuciones extrajudiciales fueran juzgados por la justicia ordinaria y no por la justicia militar. Así como se refleja en la Revista Semana (2010a):

Es la primera vez en la historia que los ex comandantes del Ejército se reúnen para poner sobre la mesa una realidad: los soldados, los suboficiales y oficiales están preocupados por el manejo que se le ha dado a la justicia penal militar, al fuero militar y al tema de los famosos 'falsos positivos' que los han explotado políticamente, afectando la moral del Ejército. La moral de las tropas es algo bastante delicado.

Ningún ejército del mundo está enfrentando una guerra con tantos obstáculos, con tantas normas, con tantos reglamentos como los que le han impuesto a este. El soldado no sabe si combatir o no, porque esos documentos consignan pautas que prácticamente impiden su actuación. Y a la incertidumbre se suma la sensación de desprotección total, porque el oficial que se ve expuesto a una investigación penal no cuenta con ningún tipo de defensa desde la institución. (p.1)

Como se observa en este artículo los militares no aceptan la normatividad que regulan los conflictos, consideran que son obstáculos para su actuación. Así como rechazan que crímenes como estos sean juzgados por la justicia penal ordinaria, porque los consideran crímenes de guerra. De lo expresado en este artículo se deduce que los límites éticos y 
humanitarios que deben regir cualquier conflicto armado están desdibujados en la fuerza pública.

En el texto se puede ver el uso de un lenguaje excluyente y descalificador, así por ejemplo, el uso del término el tema de los famosos 'falsos positivos, el adjetivo famosos, puede estar

Siendo usado por el alto impacto mediático que tuvo esta violencia, y en lenguaje coloquial este término puede ser usado para referirse a algo que se le da mucha importancia sin tenerlo. Hablar en estos términos de un hecho de violencia tan grave muestra que no existe arrepentimiento de la violencia ejercida contra los jóvenes.

Una de las características de las prácticas discusivas de determinado grupo no es homogéneas y en el discurso militar encontramos estas diferencias, por ejemplo, el discurso expuesto por el general Padilla comandante del ejército presenta algunas particularidades. En Revista Semana (2010b) se publicaron las siguientes opiniones:

En varias declaraciones, Padilla de León calificó las ejecuciones extrajudiciales como "una vergüenza" y aseguró que colaboraría con la justicia ordinaria para que los culpables recibieran castigo. Sin embargo, las críticas por ese hecho aún hoy lo persiguen.

A lo largo de su tarea en el alto mando, Padilla de León reclamó en más de una oportunidad a sus oficiales la necesidad de que todas las acciones estuvieran enmarcadas en el respeto a los derechos humanos. Y les inculcó la necesidad de "ganar la guerra" dentro de la legalidad, porque en caso contrario, solía decirlo, no era obtener el triunfo. Quizás por eso, lamentó en público y en privado ese inmenso lunar.

"Para mí es una página pasada, es algo del pasado, sucedió lamentablemente, es una situación dolorosa que deshonró el uniforme con las personas comprometidas, pero se actuó con todo el peso de la ley. El gobierno y nosotros tomamos unos correctivos de manera inteligente. Hoy es un asunto del pasado", indicó Padilla de León recientemente. 
Sí bien el general Padilla en su discurso expresó el reconocimiento de la responsabilidad de los militares en este caso, lo nombro como un lunar, restando importancia a la gravedad a los acontecimientos. De igual manera, afirma que se trataba de asuntos del pasado, y que ya se habían tomado los correctivos por parte del Gobierno y las Fuerzas militares.

\subsubsection{El discurso de los familiares víctima}

Las implicaciones de la violencia de los "falsos positivos" son muy profundas en las fibras emocionales en los familiares de la víctimas, en sus amigos, allegados y aunque no se reconozca de manera explícita a la sociedad, sin lugar a duda quienes más lo han sufrido son sus familiares, sus madres que después de tan abominable hechos, han tenido que ponerle la cara al dolor y convertir una de las heridas más profundas; la perdida de sus hijos" en la fortaleza de su lucha: por la justicia, recuperar el nombre de sus hijos y sobre todo para que actos del tal magnitud no se vuelvan a repetir. En las siguientes páginas le daremos lugar a los discursos de estas mujeres recogidos por los medios de comunicación que hacen parte de este estudio.

a) Que rectifiquen, que le devuelvan su nombre.

Al revisar la información sobre las madres de Soacha, encontramos un reiterado llamado de sus familiares y una profunda insistencia porque se clarifique que sus hijos no se encontraban haciendo actividades ilegales. En El Tiempo (2010)

Que si alguna vez el Gobierno tildó a nuestros jóvenes de guerrilleros, rectifique y diga la verdad, que fueron inocentes, que intentaron hacer de ellos un resultado y que por eso le mataron. Y claro que estén tras las rejas los culpables. (p.1)

En tan corto fragmento vemos como se ve reflejado las necesidades de las víctimas. Verdad, justicia y no repetición. Este grupo de familiares encabezados por las madres, se une al llamado que hacen todas las víctimas del país, quienes se anclan sus luchas en tres elementos: Saber lo que pasó, Castigo a los responsables y que nunca los hechos se repitan.

Recordamos su memoria de bien, queremos limpiar sus nombres pues no son guerrilleros, son inocentes, porque no pertenecían a ningún grupo armado, ellos dependían de nosotros. Pedimos justicia al 
Gobierno se aclare todo, porque en esto tiene que ver el ejército, que los hicieron pasar por guerrilleros muertos en combates (Impunidad acarrea más "falsos positivos")

En este artículo se muestra también la necesidad de los familiares de las víctimas de que se reconozca públicamente la inocencia, significa que se sepa la verdad y se haga justicia. La violencia ejercida contra este grupo de jóvenes les arrebato su identidad, en el discurso de los victimarios y representantes del Estado sus nombres fueron cambiados por NN combatientes, para sus seres amados es importante que se les devuelvan sus nombres y sus identidades. Sus familias saben que sus vidas no podrán ser devuelta, pero sí exigen se les devuelva la "dignidad.", el derecho a ser recordados en la memoria del país, por quienes eran.

En la Revista Semana (2009a) se observó que:

Los familiares no han visto, ni siquiera, que el nombre de los muchachos que han sido desaparecidos y luego ejecutados hayan sido resarcidos públicamente. Se debe resarcir su derecho a la honra y el buen nombre", aseguró el activista.

En los discursos de los familiares está muy presente el reclamo por la impunidad, dada, la falta de respuesta de las instancias judiciales y políticas para identificar, sancionar y castigar tan atroces delitos.

La lucha por la justicia, la verdad y recuperar el nombre de sus hijos se inició a finales del año 2008, ante la desaparición de sus hijos y ha continuado a lo largo de este tiempo, como se ve reflejado cuatro años más tarde. Revista Semana (2012) mostró el siguiente testimonio:

Luz Marina Bernal, una de las "madres de Soacha", progenitora de Fair Leonardo Porras Bernal, un joven especial, dada su deficiencia mental, dijo a EFE que la concentración de este domingo busca "recordar al país que esos crímenes del Ejército no se olvidan, y para exigir". (p.1)

Las prácticas discursivas de este grupo de madres tienen la intencionalidad de ser una fuente de memoria para el país, que los hechos no se olviden y en este sentido encontramos otro punto de reivindicación el de la "memoria." 
Las madres de Soacha siguen en su búsqueda de justicia en contra de la impunidad que ha reinado hasta el día de hoy. Así quedaron registrado en la Revista Semana (2012)

(...) Según Bernal, hay inquietud en el colectivo por cuanto solo hay una condena, que ha sido apelada, y por cuanto el principal inductor de la matanza, en el caso de su hijo, un mayor del Ejército, "está evadido". (p.1)

Las madres han sufrido amenazas, pero dicen continuar con su lucha. La Revista Semana (2010c) muestra unos los testimonios:

Pero no porque vea lejos lo que desde hace dos años anhela o porque haya sido blanco de amenazas se va a quedar quieta. María seguirá buscando justicia. "Las intimidaciones que algunas mamás hemos recibido son precisamente para que nos callemos. Pero eso no va a pasar.

El proceso de búsqueda de justica por sus hijos llevado a cabo por las madres de Soacha en medio de un conflicto degradado, donde las normas humanitarias han sido atropelladas por todos los ejércitos en confrontación, incluido el Estado; que en este caso es el responsable de esta violación de los Derechos Humanos y la persecución en contra de las víctimas de solicitar justicia.

Al referirse a los sueños de sus hijos, truncados por las acciones del ejército, su hijo que había prestado el servicio militar obligatorio, y deseaba continuar su carrera militar quedó truncado al ser desaparecido y asesinado por miembros de la institución a la que deseaba ingresar. Reyes \& Guillen (2009) publicó su testimonio.

Pero no le alcanzó la vida”, afirmó su madre, Blanca Nubia Monroy al explicar que el mismo ejército se la truncó. "Jamás me pasó por la mente que mi hijo lo había matado el ejército.” (P.1)

La violencia emanada de un conflicto de larga duración siempre está llena de paradojas, contradicciones, como por ejemplo, el interés de los jóvenes por entrar a las filas de los ejército, y un ejército que a su vez se lleva sus sueños. En este sentido es importante ver como la cotidianidad de la violencia se ve expuesta a innumerables hechos contradictorios. 


\section{b) La relación con el Gobierno colombiano.}

Desde que las madres de estos jóvenes se enteraron del destino de sus hijos, solicitaron al presidente de la república que les recibiera para plantear sus necesidades de justicia y limpiar el nombre de sus hijos, sin embargo, durante casi 2 años, el Gobierno se negó a tener una reunión con ellas.

Sólo en el 2010 en época preelectoral el presidente Uribe decidió recibirlas, hecho que fue tomado por las madres de jóvenes asesinados como acto oportunista del presidente, y por ello la mayoría de las víctimas no se presentaron, y estas fueron sus declaraciones publicadas por El Espectador (2010a)

Nosotros radicamos una carta recién que sucedieron estos hechos, y no nos atendió, entonces, ¿por qué ahora, que se está haciendo lo de la reelección, lo de las elecciones, por qué nos quiere utilizar en estos momentos?" precisó Luz Marina Beltrán Porras, una de las madres, en compañía de representantes de la Corporación Colectivo de Abogados José Alvear Restrepo. (p.1)

¿Ahora sí tiene tiempo para nosotras?, pues nosotras no tenemos tiempo para él. Entonces, si él quiere, yo, Carmenza Gómez, lo puedo atender, pero después de las elecciones", dijo una de las madres.

Los discursos de las madres y el presidente de la Republica, no tienen puntos de encuentro, mientras ellas se basan en la búsqueda de la verdad y justicia, El Gobierno pasó de la negación absoluta de los hechos a las verdades a medias, no hubo en este periodo un verdadero reconocimiento de la violencia de Estado llevado contra civiles y por ello la relación se planteó en un profundo desencuentro.

El ofrecimiento de una reunión en el año 2010 por parte del mandatario fue interpretado por las madres de Soacha; activistas de Derechos Humanos y analistas políticos como un hecho proselitista.

Al terminar el mandato del presidente Uribe las relaciones empeoraron, ya que el presidente Uribe volvió afirmó el 25 de junio de 2015. Así lo expuso la Revista Semana (2016): 
En reunión con las madres de Soacha varias me expresaron que sus hijos estaban infortunadamente involucrados en actividades ilegales, lo cual no es excusa para asesinarlos, pero la hipótesis no fue examinada por la justicia.

Por esta razón las madres pusieron una denuncia y el caso se está tramitando de manera judicial. En este sentido observamos que las afirmaciones del presidente Uribe responden a sus propias concepciones ideológicas, ya que después de su mandato siguió emitiendo las mismas opiniones de forma personal.

El 17 de noviembre de 2016 se emitió fallo condenatorio contra 21 militares adscritos al Batallón Móvil de Ocaña (Norte de Santander) por la ejecución extrajudicial de cuatro jóvenes provenientes de Soacha quienes fueron presentados como guerrilleros abatitos en combate.

Después de tener la sentencia por parte del Juez Primero especializado, las madres siguieron solicitando que se les devuelva el nombre a sus hijos tal como lo afirma el periódico; El Espectador (2016).

Que los muchachos no eran ningunos guerrilleros y entonces con eso diciendo el presidente: 'esos muchachos sí eran hijos de familia, no eran ningunos zánganos por ahí, ningunas personas malas porque mi hijo era una persona muy buena", aseguró Garcera -cuyo único hijo fue asesinado por la Fuerza Pública- a Noticias Uno.

En este sentido vemos que después de ocho años el presidente Uribe sigue refiriéndose en los mismos términos, aun cuando ya dejo el cargo de presidente de la república, por tanto, se nota la intencionalidad personalizada del exmandatario en lo que respecta a este tema. De igual manera, las madres de los jóvenes después de ocho siguen esperando que se les devuelva el buen nombre a sus hijos.

El discurso de los familiares de las víctimas se centró en tres ejes: la verdad, la justicia y la no repetición de tan graves hechos de violencia. La búsqueda de la verdad a su vez tiene en eje muy importante, la recuperación del nombre de sus hijos, hermanos, esposos, el reconocimiento de que no eran combatientes, ni estaban cometiendo actividades ilícitas, es sin lugar a dudas la bandera de su lucha por los Derechos Humanos. 
La búsqueda de justicia de los familiares, especialmente, las madres es una constante discursiva, es decir el juicio y castigo para los responsables de la violencia contra sus hijos, aún en los momentos más dolorosos como lo fueron: el conocer el destino de sus hijos después de meses de su desaparición, la exhumación de sus cuerpos y el escuchar las atrocidades confesadas por los reclutadores y testigos de tal violencia; siempre su reivindicación fue y sigue siendo el juicio y castigo de los culpables dentro de los marcos jurídicos y penales que establece la ley colombiana y los principios internacionales de los Derechos Humanos propios de un Estado de Derecho como lo pretende ser el colombiano.

La no repetición de los hechos, después de tan dolorosos actos de violencia contra sus hijos, estas mujeres populares, asumieron otra identidad la de: "madres de Soacha" y convirtieron sus profundas heridas en la búsqueda de que hechos como los que sufrieron sus hijos no se volvieran a repetir y que "nunca más," las madres tuvieran que pasar por algo similar a sus historias. Tan valiente y digna respuesta de estas mujeres y sus familias es el reflejo de la profunda capacidad sanadora y de la generosidad de las víctimas del conflicto armado en Colombia. Quienes han mantenido la consigna por la búsqueda de la paz.

\subsubsection{Discurso de los Organismos de Derechos Humanos}

Retomamos el discurso de los organismos nacionales e internacionales de Derechos Humanos, dada la importancia que tuvo la intervención de dichos organismos en el esclarecimiento de estos hechos y en la presión a las instancias judiciales para adelantar las respectivas investigaciones.

La presencia del Relator de Naciones Unidas en Colombia sin duda alguna tuvo una gran incidencia en el conocimiento de los hechos en los escenarios nacionales y especialmente en los internacionales. En las declaraciones ofrecidas después de su primera visita dejo ver su preocupación por los hechos y el reconocimiento de que se trataba de un hecho digno de la atención internacional.

Es de recordar que en el momento de la visita se vivía en el país un clima de contradicción con respecto a lo sucedido, por un lado, las versiones de los militares y apoyadas por el gobierno de que se trataba de personas muertas en combates y en unos reducidos casos, de crímenes cometidos por algunos militares y de otro lado, las víctimas, las 
organizaciones de Derechos Humanos nacionales y miembros de partidos de oposición asegurando que se trataban de graves violaciones de Derechos Humanos. En este sentido, contribuyó a que se reconociera nacional e internacionalmente, los graves hechos sucedidos. Así lo reportó la Revista Semana en su artículo, Relator de ejecuciones extrajudiciales llega a Colombia.

Desde su primera visita expuso sus diferencias con la posición del gobierno, así lo publicó la Revista Semana (2009a).

No puedo descartar la posibilidad de que algunos falsos positivos fueran, de hecho, guerrilleros, pero aparte de las afirmaciones contundentes, el gobierno no me ha dado prueba alguna en ese sentido", dijo Alston, en la rueda de prensa que ofreció antes de abandonar el país. (p.1)

En el discurso del representante de las Naciones Unidas se observa que, en su visita al país, no conoció información que lo llevará a corroborar las versiones del gobierno, sino que por el contrario por las características de las víctimas apuntaba a una tesis contraria. En la Revista Semana (2009b), El Relator afirmó que:

Con base en lo investigado, dijo que "entre los 'peligrosos guerilleros' que fueron dados de baja hay adolescentes de 16 y 17 años, un hombre joven con una edad mental de 9 años, un padre de familia abnegado, cuyos cuñados están en servicio militar activo, y un joven soldado de licencia por vacaciones, que visitaba a su familia. (P.1)

El uso del término "peligrosos guerrilleros," refiriéndose a la descripción hecha por los militares y el gobierno y ponerlo en duda con las características de las víctimas que no pueden hacer o ser lo que allí se dice.

Además, afirma la Revista Semana (2009a) que para el relator de Naciones Unidas si es claro que fueron manipulados los cuerpos de las victimas presentarlos como "guerrilleros", de manera expresa de refiere:

(...) contrario a lo que suele ocurrir aquí en el país, él sí le dio crédito a pruebas que hablan de "víctimas vestidas con ropa de camuflaje recién planchada (cuando se dijo que habían muerto en combate), o calzando 
botas de campo cuatro tallas más grandes que su tamaño, o zurdos llevando una pistola en su mano derecha, $\mathrm{u}$ hombres con una única bala disparada en el cuello". Para Alston, estos hechos "menoscaban aún más la sugerencia de que se trata de guerrilleros muertos en combate". (P.1)

Posteriormente el señor relator de Naciones Unidas, en su informe sobre ejecuciones extrajudiciales, hizo énfasis en los siguientes puntos:

La conceptualización del concepto de "falsos positivos", frente al uso del término para dirigirse a la muerte de civiles, según la Revista Semana (2009c), el relator de Naciones Unidas expreso que:

(..) el uso de la expresión 'falsos positivos', ya que "brinda una suerte de aura técnica para describir una práctica que se caracterizaría mejor como el asesinato a sangre fría y premeditado de civiles inocentes, con fines de beneficio. (p.1)

La utilización del eufemismo "falsos positivos" es una manera de restar importancia a la violencia ejercida, de esta manera, el señor relator de las Naciones Unidas llama a darle el verdadero nombre a las acciones cometidas por la fuerza pública. No obstante, el llamado de atención del Diplomático a la no utilización de ese término, hasta el día de hoy se sigue usando tanto por las instituciones del Estado como por la sociedad en general.

Un segundo aporte del relator de los Derechos Humanos es: El establecimiento de la existencia de un "patrón de ejecuciones extrajudiciales," en Revista Semana (2010d), el Relator expreso que:

Mis investigaciones encontraron que miembros de las fuerzas de seguridad de Colombia perpetraron un número significativo de ejecuciones extrajudiciales en un patrón que se fue repitiendo a lo largo del país (P.1)

El informe declara la existencia de elementos similares en las desapariciones forzadas y posteriores asesinatos, lo cual le lleva a concluir la existencia de un patrón común en estas violaciones de Derechos humanos. 
Un tercer elemento tiene que ver con la Política de Seguridad Democrática y su estrategia de incentivos, al respecto aclara en la Revista Semana (2010d) que:

Aunque estos asesinatos no fueron cometidos como parte de una política oficial, encontré muchas unidades militares comprometidas con los llamados "falsos positivos", en los cuales las víctimas eran asesinadas por militares, a menudo por beneficio o ganancia personal de los soldados.

Aunque el Philip Alston, relator especial de la ONU para las ejecuciones arbitrarias, expone que dichos hechos no fueron cometidos como parte de una política oficial, si deja ver que encontró la participación de muchas unidades militares en estos hechos por beneficio personal; lo cual abre la posibilidad a que el sistema de incentivos a militares por resultados de acción contra combatientes subversivos pudo ser motivador de estos hechos de violencia.

Un cuarto elemento expuesto por el señor relator es la existencia de impunidad en el 98,5\% de los casos de esta violencia, de esta manera lo observó en Revista Semana (2010d):

La actual tasa de impunidad en relación con presuntas ejecuciones por parte de las fuerzas de seguridad, que llega hasta el 98,5\% según fuentes creíbles, es demasiado alta.

Si tenemos en cuenta el impacto que tiene una afirmación de las Naciones Unidas a un país, por tratarse del organismo internacional de mayor importancia en Derechos Humanos, la afirmación de un 98,5\% de impunidad se constituye en un fuerte llamado de atención al Estado colombiano.

En quinto lugar, informe "Refutó la tesis de que las matanzas eran obra de unas "manzanas podridas". Para el diplomático, los crímenes "fueron llevados a cabo de una manera más o menos sistemática, por una cantidad significativa de elementos dentro del Ejército".

La intervención del relator de Naciones Unidas hizo evidente que la metáfora de las "manzanas podridas," presente en el discurso del gobierno y los militares era utilizada para desviar la atención y ocultar a los verdaderos responsables de estos hechos. 
Entre las recomendaciones del señor relator se encuentra la exhortación al Estado colombiano a investigar y castigar a los responsables de estas violaciones de los Derechos Humanos. Incluso advirtió que la justicia penal internacional podría actuar en caso de que el Estado colombiano no lo hiciera, estas fueron sus palabras publicadas en la Revista Semana (2009c): "si no castigan ejemplarmente a los responsables, otros lo harán por ustedes

Organizaciones internacionales como Human Rights Watch; Amnistía Internacional entre otras, manifestaron su preocupación al Estado Colombiano por las violaciones de Derechos Humanos en el marco de la violencia de "falsos positivos," en la información de prensa que hace parte del corpus encontramos que más que reseñar las recomendaciones de estos organismos sobre la situación de Derechos Humano, en el periodo de (2007-2010), sin embargo a partir de 2012, tuvo centralidad en los medios reseñados el debate sobre el fuero militar y el tema de la justicia sobre los "falsos positivos", por lo cual en retomaremos algunas de las reacciones expuestas en la prensa .

El gobierno nacional en cabeza del señor Presidente de la Republica siempre tuvo una respuesta negativa a las observaciones hechas por dichas organizaciones, las solicitudes de estos organismos fueron resultas con discursos públicos de rechazo. Tal como lo afirma el periódico Rodríguez (2008):

Cuando todo el mundo aplaudía, con razón, la decisión del Gobierno de retirar a los militares involucrados en los falsos positivos, el presidente Uribe salió a despotricar de Human Rights Watch, Amnistía Internacional y las ONG que hace rato venían advirtiendo sobre esos abusos y pidiendo esas medidas sin que nadie escuchara en la Casa de Nariño. (p. 1)

En este caso, el primer mandatario del país hizo uso de una práctica común en él, rechazar los informes de todas las ONGS de Derechos Humanos y acusarlos de amigos del terrorismo o de intervención en asuntos internos. La labor de las Organizaciones Derechos Humanos en el país ha sido muy valiosa y el caso que nos ocupa no fue la excepción, sin embargo, la respuesta del gobierno fue de rechazo a las recomendaciones y solicitudes, así quedo registrado en De la Torre (2008) 
No acababa de declarar que los desaparecidos de Soacha habían muerto en combate, que las denuncias de Amnistía Internacional y Human Rights Watch sobre crímenes de Estado en Colombia eran ardid de la subversión, cuando se destapó un tenebroso mercado de cadáveres de inocentes activado por redes de uniformados, mafiosos y paramilitares. Seis años de guerra comandada por una política oficial que reclama, compulsiva, bajas a granel, descuidando controles sobre la tropa y la oficialidad, resultaron en una mar de falsos positivos que escandalizan al mundo. (P.1)

En definitiva, el Discurso de los Organismos de Derechos Humanos y de las organizaciones de la sociedad civil giró alrededor a la presión del Estado por el esclarecimiento de los hechos, la sanción y castigo a los responsables. La intervención más importante en este sentido, fue la realizada por El relator de Naciones Unidas para ejecuciones Extrajudiciales.

Las observaciones y recomendaciones expresadas por el Diplomático son un llamado de atención al Gobierno colombiano para que: Aclaré los hechos, investigue y haga Justicia y tenga en cuenta las reclamaciones tanto de las víctimas, como de la organización civil. Los aportes más significativos de este discurso son: El rechazo a llamar la violencia de ejecuciones extrajudiciales; "falsos positivos" y hacer una definición de esta expresión como un eufemismo para nombrar asesinatos a sangre fría de civiles; de igual manera aclara la efectiva participación de militares en esta violencia de una manera más o menos sistemática, establece que la violencia sucedida contra civiles no se trata de casos aislados de corrupción sino que se ha presentado en todas las regiones del país con la participación de un bueno número de brigadas y con un patrón criminal común, hace un llamado a garantizar la integridad de los derechos de los supervivientes y los familiares de las víctimas; por último, advierte que si el gobierno colombiano no aplica la debida Justicia se expone a que estos casos tengan que ser juzgados por la Justicia Penal Internacional.

Las observaciones y recomendaciones de las Naciones Unidas sobre la violencia ocurrida contra civiles en Colombia en el marco de los mal denominados "falsos positivos" se expresan en un lenguaje diplomático, por ello, es importante anotar que el discurso del señor relator es un llamado muy fuerte al Estado colombiano por encontrar una violación grave de los Derechos Humanos y la insistencia en la aplicación de justicia. El 
seguimiento de las Naciones Unidas a la violencia ocurrida en marco de las ejecuciones extrajudiciales pone de manifiesto la profunda preocupación de la comunidad internacional por la situación de los Derechos Humanos en el país.

\subsection{Análisis del Discurso de los medios de comunicación a la luz de la teoría}

Hemos descrito los elementos más importantes de los discursos del Gobierno, los familiares de las víctimas y los organismos internacionales sobre la violencia de "falsos positivos" y de esta manera, hemos podido observar la existencia de diferencias entre prácticas discursivas dependiendo de la fuente de la que provine el discurso, se puede afirmar que las narrativas discursivas sobre la violencia de "falsos positivos" contiene una multiplicidad de sentidos, que en ocasiones se niegan, excluyen, contradicen, contraponen o se complementan.

El discurso mediático expuesto por estos tres medios escritos sobre la violencia de "falsos positivos" se comporta dentro de marco de una lucha por significar tanto la violencia como la juventud en torno a los hechos sucedidos, pero también en relación con las representaciones sociales del joven y específicamente el proveniente del sector popular, así como de matizar la violencia a partir de las propias concepciones e intencionalidades.

En estudio asumimos el discurso como una práctica social y cultural, tal como lo expone Los discursos deben ser entendidos como prácticas discursivas, como lo expone Haidar (1992) al considerar el discurso como prácticas sociales particulares, dado que están constituidos por diversas materialidades y no sólo su componente lingüístico textual, por tanto, su análisis interdisciplinar.

Vimos como el discurso del gobierno estuvo liderado por el señor presidente de la República de esa época a quien se le asigna el poder del portavoz autorizado, en los términos propuestos por Bourdieu (2001), cuando se refiere a quien tiene la autoridad para hablar de un campo determinado, autoridad que es dada en relación al poder, no importa si el portavoz es el más indicado para expresarse sobre este tema, lo importante es que posea el reconocimiento de los otros. En este caso el presidente Uribe tiene este reconocimiento porque en ese momento era el primer mandatario del país y además comandante en jefe de las fuerzas militares. Este estatus le abre los canales de comunicación, le permite emitir un discurso que es recibido no sólo por la prensa nacional 
sino también la prensa internacional, y por una buena parte de los colombianos que le otorgan un reconocimiento simbólico y político.

El presidente Uribe es conocedor del poder que tiene su palabra, aún si ésta no expresa la verdad, porque sin ningún problema dio sus primeras declaraciones afirmando que los jóvenes de Soacha eran delincuentes, "dados de baja" por el ejército en su función constitucional, ni siquiera consultó al fiscal por el estado de las investigaciones y lo que es peor habló en nombre de la fiscalía para institucionalizar una mentira. Sin lugar a dudas este actor político actúo motivados por sus tendencias ideológicas guerristas y su interés de aniquilar todo lo que pueda ser visto como el "enemigo", actuó motivado por la defensa de su proyecto de gobierno basado en "ganar la guerra" en el campo militar sin importar el precio que los colombianos tengan que pagar por ello.

El Gobierno colombiano, y especialmente, el Presidente de este periodo poseían la viabilidad para expresar y publicar estos discursos con facilidad, ya que si analizamos las condiciones de producción, reproducción del discurso nos damos cuenta que el poder político, económico y social le permitían hacer uso de los medios de comunicación de manera recurrente, es más el estatus de primer mandatario le permite ser requerido por los medios de comunicación constantemente y por encima de otras fuentes. Además de contar con medios oficialistas y los escenarios políticos para circular estos discursos.

Los discursos del señor presidente se fueron transformando un poco, a partir de los avances de las investigaciones sobre los "falsos positivos" y la presión de las organizaciones de los Derechos Humanos, este tránsito discursivo, continúo promulgando un manto de duda, sobre los hechos, sin el reconocimiento de las falsas acusaciones hechas a las víctimas y la grave ofensa a sus familiares.

Posteriormente vimos que el señor presidente se limitó en sus discursos a expresar la necesidad de investigación de los hechos, distanciándose un poco de los medios de comunicación y dando mayor relevancia al discurso al Ministro de Defensa de entonces, el señor Juan Manuel Santos.

El discurso del ministro Santos giro entorno al lema de "tolerancia cero" para la violación de Derechos Humanos por parte de las fuerzas Militares, asegurando la investigación de los hechos, pero también enfatizando en la necesidad de garantizar a los militares implicados el debido proceso. Aunque el discurso del señor Ministro se mostró un poco 
más sosegado y no contradijo de manera explícita a los familiares de las víctimas, no mostró de manera contundente y clara cuáles eran las estrategias del gobierno para el cumplimiento de su slogan de "tolerancia cero".

La postura del Ministro estuvo muy centrada en la defensa de las instituciones castrenses, las cuales representa, su leguaje con un tono más diplomático que el del presidente Uribe, no se dirigió a las víctimas, no dio respuesta a las reivindicaciones de las madres de Soacha ni a las organizaciones de los Derechos Humanos que reclamaban por una respuesta del Gobierno que reconociera la verdad de los hechos y la sanción para los responsables.

El lenguaje utilizado por el Ministro de la época estuvo cargado de generalizaciones que hablan de "simples" actos de indisciplina y corrupción de unos pocos miembros de la institución. Esta generalización posibilita que un asesinato a "sangre fría de civiles" se le llame un "acto de indisciplina" o un "acto de corrupción", en este caso se hace una instrumentalización del lenguaje que no resulta para nada inocente.

Tal como lo expresa Abad (2008) en un artículo del periódico El Espectador:

LAS PALABRAS QUE ESCOGEMOS PARA hablar sobre cualquier asunto no son neutras, ni siempre inocentes. Al usar una expresión en vez de otra, lo que estamos revelando es una actitud mental, bien sea censura, de complacencia, o bien como en el caso que voy analizar, un intento por disminuir y casi minimizar la gravedad de los hechos. (p.1)

En este caso, el ministro habló de militares que cometieron crímenes atroces que contemplan los delitos de desaparición forzada y asesinato, como si se tratará de faltas de indisciplina de un adolescente. En este sentido, si bien el discurso del ministro no se expresa de manera responsable sobre las víctimas de esta violencia, sí deja ver que la vida de estos jóvenes y otros miles de ciudadanos en el país asesinados premeditadamente y a sangre fría no tiene el valor suficiente para ser más que "acto de indisciplina".

El discurso del primer mandatario de la época sólo habló de las reivindicaciones de los familiares de las víctimas en el año 2010, cuando estaba entre sus intereses acceder a una tercera reelección; en ese momento sus declaraciones tuvieron un tono más conciliador con respecto a las solicitudes de las víctimas y por ello hizo llamado al dialogo no sólo con las familiares de los jóvenes asesinados en Soacha sino los familiares de víctimas de 
otras regiones del país. Esta actitud del primer mandatario fue interpretada como una instrumentalización por parte de la mayoría de los familiares de las víctimas que se rehusaron a asistir.

Evidentemente, el tiempo les daría la razón a los familiares de las víctimas en tanto, el periodo electoral finalizó con negativos resultados para la corriente política del expresidente Uribe, el volvió a los discursos estigmatizadores de las víctimas, aún después de haber terminado su periodo de gobierno.

Al parecer el lenguaje del Gobierno y los militares es un lenguaje cargado de eufemismos, por ejemplo, se le denominó a la cruel violencia de ejecuciones extrajudiciales "falsos positivos" y a sus victimarios directos "manzanas podridas" acudiendo al lenguaje coloquial se minimizó la responsabilidad del Estado en la violación de los Derechos Humanos.

En este sentido, retoma importancia el planteamiento de Gonzales (2009), quien planteó que el lenguaje se transforma en los contextos de guerra, específicamente, expresa que en escenarios se crean nuevos léxicos cargados de eufemismos, disfemismos y nominalismos.

Con respecto al Discurso de los familiares de las víctimas, representa de manera simbólica a las víctimas del conflicto armado colombiano. La emergencia de estos discursos se produce a partir de una experiencia dolorosa tras un grave hecho de violencia que afecto a un alto número de familias de este país, en este caso específico, se trata de uno de los casos emblemáticos de la violencia de ejecuciones extrajudiciales. Es importante resaltar que la exposición pública y mediática de este caso conocido como el "Caso de Soacha", conllevó al surgimiento de un discurso público y masivo de sus protagonistas, las madres de Soacha.

De esta manera, el análisis las condiciones de posibilidad de producción, circulación del discurso necesariamente tiene que tener en cuenta los siguientes elementos:

a) Que el surgimiento del discurso de las "Madres de Soacha" tiene su origen un dramático hecho de violencia derivado del Conflicto Armado interno.

El "caso de Soacha" propició el surgimiento de un sujeto político y comunitario que ha recobrado una fuerza en la historia contemporánea del país, se trata de las "madres de 
Soacha," Mujeres populares, madres de familias a quienes les sorprendió una experiencia límite de sufrimiento, en términos de lo planteado por Riaño (2006), con ello se define el profundo sufrimiento causado a un sector social por la violencia, esta experiencia se da en la exacerbación de la violencia y la producción de un sufrimiento que accede a los límites del dolor imaginable.

La respuesta personas llevadas a estos extremos del sufrimiento humano son diversas, pero la mayoría de éstas se basan en la potenciación las capacidades resilientes de los seres humanos sometidos a tal sufrimiento, las "madres de Soacha" generaron un discurso de resistencia, resiliencia y reivindicación, este discurso entendido en los términos conceptualizados por Arendt (2003), un discurso que es acción.

Las condiciones de producción, circulación del discurso de las "madres de Soacha deben verse desde los siguientes aspectos:

a) El discurso de las madres no contaba con el reconocimiento de muchos sectores de la sociedad y que este reconocimiento tuvo que construirlo en el proceso de búsqueda de la verdad y la justicia.

Las madres de Soacha eran mujeres populares que vivieron las luchas por la sobrevivencia y los avatares de vivir en medio del conflicto armado más largo de la región latinoamericana, en este sentido, sus luchas eran cotidianas y locales. Sus vidas se transformaron a partir de la desaparición y el asesinato de sus hijos, ya que la búsqueda de la verdad y justicia las llevó necesariamente a la esfera pública y la exposición en los medios de comunicación. De esta manera se vieron abocadas a la defensa de sus hijos en las luchas simbólicas, sociales y discursivas. Ellas tuvieron que generar un contra discurso para afrontar las acusaciones hechas a la memoria de sus hijos desde sectores hegemónicos y de poder (Gobierno, Fuerzas Armadas, partidos políticos oficialista, medios de comunicación especialmente televisivos).

b) Los familiares de las víctimas no tienen el mismo acceso al uso de los medios de comunicación que otros sujetos discursivos que intervinieron este caso.

El análisis de las condiciones de producción, circulación y recepción del discurso desde la perspectiva de la Escuela Francesa, se deben tener en cuenta los mecanismos de control y exclusión propuestos por Foucault (1970) y el concepto del lenguaje de autoridad de 
Bourdieu (2001). Tanto el concepto de control y exclusión como el lenguaje de autoridad están directamente relacionados con el poder social, político y económico.

En esta línea, el discurso de los familiares de las víctimas tuvo mayores dificultades para acceder a los medios de comunicación, mientras que el Gobierno, los militares y las corrientes del oficialismo contaban con el uso de aparatos ideológicos como medios de comunicación, para las "madres de Soacha" era necesario que algún periodista se interesará por sus reclamaciones o la utilización de otros canales como la denuncia y protesta pública.

Asimismo, los voceros del Gobierno; las Fuerzas Militares y los partidos políticos oficialistas son actores discursivos, con reconocimiento social y político para hablar sobre los temas relacionados del conflicto armado, mientras que para las víctimas las posibilidades de acceso a los medios de circulación siempre han sido reducidas.

En relación a las relaciones de poder que posibilitan o que obstruyen la producción, circulación y recepción de este discurso se observa que este grupo de víctimas del conflicto armado se encuentra en desventaja frente a los poderes institucionales de actores que son los contradictorios, así como se ven con menos posibilidades de acceso a los medios; en este sentido su poder, radica en el uso del testimonio y a través de apelar a los organismos de Derechos Humanos y Organizaciones humanitarias nacionales e internacionales. De esta manera, lograron que su versión de los hechos llegará a ser de interés de la comunidad internacional y legitimar sus acciones discursivas.

Con respecto al discurso de los organismos internacionales de los Derechos Humanos, y especialmente, el del relator de Naciones Unidas, posee las características de un discurso de autoridad, con un lenguaje específico diplomático y el reconocimiento de la comunidad internacional como observador de la situación de los Derechos Humanos. Por tanto, la presencia del relator de la Naciones Unidas fue registrada por los medios de comunicación y tuvo una significativa importancia para presionar la investigación sobre este hecho.

El discurso del represente de las Naciones Unidad corroboró las versiones dadas tanto por los familiares como Organizaciones sociales y Derechos Humanos nacionales sobre la violencia de las ejecuciones extrajudiciales. Y obtuvo una mayor recepción del Gobierno que ante el llamado de otras organizaciones como Amnistía Internacional, Human Rights 
Wactch y otras organizaciones locales, que fueron rechazadas y descalificadas por el gobierno.

La autoridad que posee las Naciones Unidas para emitir observaciones recomendaciones sobre la situación de Derechos Humanos en el mundo, le permitió al relator expresar de manera pública: versiones sobre la violencia de Ejecuciones Extrajudiciales contradictorias a las expuestas por el Gobierno nacional y más cercanas a lo expuesto por los familiares de las víctimas, de esta manera, se puso de manifiesto la preocupación del máximo organismo de Derechos Humanos en cuanto a:

- La violación de Derechos Humanos cometida por el Estado colombiano, bajo la modalidad de ejecuciones extrajudiciales que se desarrolló de manera, más o menos sistemática bajo un patrón común de actuación.

- La existencia de impunidad en la mayoría de los casos de ejecuciones extrajudiciales.

- La necesidad de protección de los supervivientes y los familiares de las víctimas, dada su persecución por la búsqueda de verdad y de justicia.

- El llamamiento al Estado colombiano a la investigación y judicialización de los responsables de estos hechos y la advertencia de que estos preceptos no se cumplen podrían ser juzgados por la Justicia Penal Internacional.

Ante el informe del relator de la ONU, el Gobierno colombiano emitió un discurso de agradecimiento por las recomendaciones y enfatizó en el único punto del informe que afirmaba que el gobierno había hecho algunos esfuerzos por el esclarecimiento de los hechos.

\subsubsection{Relación inter-discursivas}

En definitiva, las posibilidades del discurso de estos sujetos discursivos tienen relación con los aspectos como el poder, las formaciones ideológicas y la coyuntura. La tabla 3 nos muestra los principales elementos que constituyen estos discursos 
Tabla 3. Relación comparativa entre discursos actores políticos y sociales.

\begin{tabular}{|c|c|c|c|c|c|c|}
\hline $\begin{array}{l}\text { Sujeto del } \\
\text { discurso }\end{array}$ & $\begin{array}{l}\text { C. } \\
\text { producción, } \\
\text { circulación } \\
\text { de los } \\
\text { discursos }\end{array}$ & $\begin{array}{l}\text { Formación } \\
\text { ideológicas }\end{array}$ & $\begin{array}{l}\text { Representac } \\
\text { ión Social } \\
\text { del joven. }\end{array}$ & $\begin{array}{l}\text { Relaciones } \\
\text { de poder }\end{array}$ & $\begin{array}{l}\text { Coyuntur } \\
\text { a }\end{array}$ & \begin{tabular}{l}
\multicolumn{2}{l}{ Característic } \\
as del \\
Discurso.
\end{tabular} \\
\hline $\begin{array}{l}\text { Gobierno. } \\
\text { Conformad } \\
\text { o por el } \\
\text { Presidente } \\
\text { de la } \\
\text { República, } \\
\text { Ministros e } \\
\text { Institucione } \\
\text { s del Estado. } \\
\text { Las } \\
\text { funciones } \\
\text { de portavoz } \\
\text { fueron en } \\
\text { Mayor } \\
\text { medida } \\
\text { asumidas } \\
\text { por El } \\
\text { presidente, } \\
\text { con menos } \\
\text { protagonism } \\
\text { o el } \\
\text { Ministro de } \\
\text { Defensa. }\end{array}$ & $\begin{array}{l}\text { Portavoz } \\
\text { autorizado: } \\
\text { poder } \\
\text { político y } \\
\text { militar como } \\
\text { primer } \\
\text { mandatario y } \\
\text { comandante } \\
\text { en jefe de las } \\
\text { Fuerzas } \\
\text { Militares. } \\
\text { Acceso a los } \\
\text { aparatos } \\
\text { ideológicos } \\
\text { (Medios de } \\
\text { comunicació } \\
\text { n) }\end{array}$ & $\begin{array}{l}\text { Guerrista } \\
\text { Derecha. }\end{array}$ & $\begin{array}{l}\text { Delincuente } \\
\text { Guerrillero }\end{array}$ & $\begin{array}{l}\text { Poder } \\
\text { político } \\
\text { Poder } \\
\text { simbólico } \\
\text { Poder de } \\
\text { representació } \\
\text { n. }\end{array}$ & $\begin{array}{l}\text { Seguridad } \\
\text { democráti } \\
\text { ca. } \\
\text { Brusqueda } \\
\text { d de } \\
\text { reelección. } \\
\text { Uribismo }\end{array}$ & $\begin{array}{l}\text { Lenguaje en } \\
\text { ocasiones } \\
\text { irónicas y } \\
\text { satíricas. } \\
\text { "No estaban } \\
\text { cogiendo } \\
\text { Café" } \\
\text { Desconocimie } \\
\text { nto del } \\
\text { contexto de } \\
\text { guerra } \\
\text { colombiano. } \\
\text { Discurso } \\
\text { estigmatizado } \\
\text { r. }\end{array}$ \\
\hline $\begin{array}{l}\text { Familiares } \\
\text { de las } \\
\text { víctimas. } \\
\text { Sujeto } \\
\text { colectivo: } \\
\text { Madres de } \\
\text { Soacha. } \\
\text { Madres, } \\
\text { padres, } \\
\text { hermanos, } \\
\text { esposos. } \\
\text { Portavoz } \\
\text { autorizado }\end{array}$ & $\begin{array}{l}\text { No acceso a } \\
\text { los medios de } \\
\text { comunicació } \\
\text { n. }\end{array}$ & $\begin{array}{l}\text { Derechos } \\
\text { Humanos } \\
\text { Resistencia } \\
\text { Resiliencia } \\
\text { Paz } \\
\text { Búsqueda de } \\
\text { reconocimiento. }\end{array}$ & $\begin{array}{l}\text { Hijos } \\
\text { Víctimas } \\
\text { re } \\
\text { victimizado } \\
\mathrm{s} \\
\text { inocentes }\end{array}$ & $\begin{array}{l}\text { Poder } \\
\text { comunitario. } \\
\text { Organización } \\
\text { social. } \\
\text { Movimiento } \\
\text { nacional de } \\
\text { víctimas } \\
\text { Reconocimie } \\
\text { nto } \\
\text { internacional }\end{array}$ & $\begin{array}{l}\text { Persecució } \\
\text { n política a } \\
\text { defensores } \\
\text { de DDHH. } \\
\text { Política de } \\
\text { Seguridad } \\
\text { Democráti } \\
\text { ca. }\end{array}$ & $\begin{array}{l}\text { Discurso } \\
\text { político } \\
\text { Discurso de } \\
\text { reivindicación } \\
\text { de las } \\
\text { víctimas. }\end{array}$ \\
\hline $\begin{array}{l}\text { Organismos } \\
\text { internaciona } \\
\text { les de DD } \\
\text { HH y } \\
\text { sociedad } \\
\text { civil. } \\
\text { Portavoz } \\
\text { autorizado: } \\
\text { Relator de } \\
\text { Naciones } \\
\text { Unidas }\end{array}$ & $\begin{array}{l}\text { Acceso a } \\
\text { medios de } \\
\text { comunicació } \\
\text { n. } \\
\text { Reconocimie } \\
\text { nto } \\
\text { internacional } \\
\text {. }\end{array}$ & $\begin{array}{l}\text { Liberal. } \\
\text { Diplomática } \\
\text { Paz } \\
\text { Derechos } \\
\text { Humanos.(neutrali } \\
\text { dad, } \\
\text { universalidad) }\end{array}$ & Víctimas & $\begin{array}{l}\text { Poder } \\
\text { Político } \\
\text { Poder } \\
\text { diplomático }\end{array}$ & & $\begin{array}{l}\text { Discurso } \\
\text { diplomático. } \\
\text { Discurso de } \\
\text { DD HH. }\end{array}$ \\
\hline
\end{tabular}


La información que encontramos en la tabla 3, nos permite sintetizar los aspectos que hacen parte de estos discursos: se puede deducir las siguientes relaciones entre discursos.

Los puntos más conflictivos en las prácticas discursivas sobre las jóvenes víctimas de "falsos positivos" se encuentran en la oposición radical de los planteamientos de los familiares de las víctimas y los discursos oficialistas (la tendencia política del Gobierno). En estas dos narrativas se encuentra un total desencuentro. Dado que la significación del joven para el gobierno se basa en una representación social negativa (delincuentes, guerrilleros, bandoleros y de otra parte sus familias piden en reconocimiento de las víctimas como lo que son: "hijos," jóvenes y víctimas de Estado. Estas diferencias no sólo son nominaciones lingüísticas se trata de las luchas sociales por la verdad y la justicia. La versión del Gobierno fue claramente refutada por las investigaciones judiciales y académicas, se demostró desde elementos facticos que los jóvenes no eran delincuentes y que fueron engañados y llevados a la muerte de manera perversa.

No obstante, tal demostración las prácticas discursivas del Gobierno de ese periodo y de los militares siguió siendo la versión presentada y ante la prominencia de la verdad por lo menos se siguió poniendo en duda la inocencia de las víctimas. Que hace que este discurso de mantenga a pesar de la contundencia de la verdad, necesariamente tenemos en que centrarnos aquí en tres elementos de análisis del discurso; las formaciones ideológicas, el poder y la coyuntura.

En este análisis es necesario tener en cuenta la coyuntura de guerra y además que se trata de una guerra prolongada, una guerra en la que se libran luchas ideológicas, en este sentido, históricamente el Estado ha tenido una postura ideológica centrada en ideas de derecha y en contra de cualquier manifestación popular que disienta de los principios conservadores, en esta formación ideológica se priorizó el ganar la guerra en el campo militar sin importar los costos económicos, sociales y humanos, los Gobiernos colombianos han actuado desde estos principios ideológicos y de ahí los pocos esfuerzos para búsqueda de salidas negociadas o el repetitivo fracasos de los mismos.

Si bien estas tendencias ideológicas guerristas han permanecido en el contexto gubernamental, no necesariamente se dan de manera homogénea en los diferentes periodos de gobierno y los periodos del presidente Uribe comprendidos entre el año 2002 y 2008 fueron especialmente centrados en la ideología guerrerista y afianzamiento de la ideología de derecha por tanto las practicas discursivas se polarizaron a favor del 
mantenimiento de las instituciones militares, en esta coyuntura se reafirmó la criminalización de la sociedad civil.

Las formaciones discursivas generan una representación del "otro," en el caso del contexto de conflicto armado que vive el país, la construcción social del "enemigo," es un acto de negación absoluta; donde sólo existe la posibilidad de ser destruido. En este sentido los discursos aquí analizamos se debaten en dos perspectivas sobre el joven verlo como "enemigo" y verlo como un ser humano. La diferencia entre estos discursos se encuentra en la significación de vida y muerte. Puesto que la violencia es un acto de destrucción configurado en primera instancia en los campos discursivos.

Con respecto a las formaciones ideológicas, es necesario anotar aquí que las formaciones ideológicas del Gobierno no son constructos exclusivamente institucionales sino que en éstas están permeadas las ideologías individuales de quienes hacen parte de una instancia gubernamental, prueba de ello es que por ejemplo las practicas discursivas del Expresidente Uribe no se transformaron con la culminación de su periodo presidencial, los discursos de discriminación en contra de los jóvenes continuaron al punto de que en la actualidad existe una denuncia pública en contra del exmandatario por las acusaciones hechas en contra de los jóvenes de Soacha.

Antes de hacer este análisis es necesario decir que no existe un único discurso de estos organismos, que se pueden observar algunas prácticas discursivas con algunas similitudes y algunas diferencias. Estas diferencias están dadas entre otros asuntos por relaciones de poder, sobre todo por el poder de reconocimiento dado a organismos como las Naciones Unidas, con esto queremos decir que no es lo mismo el lenguaje de autoridad de las Naciones Unidas, al de las Organizaciones de DD HH Internacionales como: Anmistia Internacional y mucho menos al discurso de Organizaciones locales, en estas relación se estructura una línea vertical basado en el reconocimiento, el poder político, social y simbólico.

El discurso de las Organizaciones internacionales de Derechos Humanos presenta una mayor cercanía a los discursos de los familiares de las víctimas. En este sentido, las practicas discursivas del relator de Naciones que es un discurso basado en los principios liberales de los Derechos Humanos en la neutralidad, la universalidad y la igualdad, Así la ONU puso de manifiesto, las observaciones y recomendaciones sobre la violencia de la Ejecuciones extrajudiciales en base a la necesidad del respeto por los Derechos 
Humanos y la sanción de del cumplimiento de los culpables, recordando así la responsabilidad del Estado colombiano en la garantía de respeto de los Derechos Humanos de sus ciudadanos.

Las prácticas de otros organismos de los Derechos Humanos internacionales como Amnistía Internacional, Human Rights Wactch, que poseen un reconocimiento Internacional, pero no en la misma medida que las Naciones Unidas, el discurso de estas organizaciones es más fuerte en términos de la denuncia de los hechos, y hace afirmaciones relacionadas con el tema de la impunidad y el fuero militar, dos temas que resultan álgidos para las instancias gubernamentales.

Por último, el discurso de las organizaciones locales de Derechos Humanos es el más cercano al de las víctimas, puesto que está anclado en los temas de verdad, justicia, reparación y no repetición, que son también los ejes del discurso de víctimas.

En definitiva, las prácticas discursivas sobre la violencia de los "falsos positivos" se originan, producen y circulan de acuerdo al poder que poseen los sujetos discursos, en términos de las posibilidades de acceder a los medios de circulación. De otra parte, el sentido discursivo está altamente mediado por las formaciones ideológicas que sostienen las prácticas discursivas, y que contribuyen a la definición del cómo proceder en la guerra.

Los constructos sociales del joven en estas prácticas discursivas se configuran a partir de elementos ideológicos, sociales e históricos, son las tendencias ideológicas las que contribuyen a clasificar a las personas o grupos en determinadas categorías; según cuales son los imaginarios de guerra o de paz, de víctimas o victimarios. En este sentido, la construcción social del joven se encuentra en una disputa simbólica, ideológica, política y social, en razón a las posiciones de los diferentes sujetos discursivos.

\subsubsection{Principales discursos sobre el joven en el marco de la violencia de "falsos positivos"}

En el análisis sobre los discursos encontramos la presencia de las siguientes prácticas discursivas:

a) El discurso gubernamental.

Materialidades ideológicas: 
- Defensa de la Seguridad Democrática, a su vez esta política se encuentra inscrita en marcos ideológicos guerrerista cuyo eslogan es ganar la guerra con las armas y el todo vale.

- Concepciones políticas de Derecha. Los dos periodos gubernamentales del Presidente Uribe (2002-2010) son reconocidos por la implementación de un modelo conservador y afín a los intereses económicos de la clase alta.

- La polarización política del país. El periodo comprendido entre (2002-2010) se caracterizó por un marcado conflicto entre los partidarios de "mano dura" contra cualquier manifestación en contra de cualquier muestra de oposición a la ideología guerrista y la defensa de las posibilidades de oposición.

b) El discurso militar

Las materialidades de este discurso se basan en:

- El triunfalismo bélico: Ganar la guerra ha sido el principal emblema de las Fuerzas Armadas de Colombia, y este ganar la guerra significa ganarla en términos militares.

- $\quad$ La destrucción del enemigo.

La destrucción del "enemigo" en las instituciones castrenses es común, en el caso colombiano esto se hizo muy fuerte, ya que por ser un conflicto de larga duración se fueron enraizando los odios y la noción del adversario se negó y se construyó una imagen macabra del Enemigo a quien se le dotó simbólicamente de ser portador del mal y por tanto digno de eliminación.

c) Discursos de los familiares de las Víctimas.

Las materialidades presentes en este discurso.

- Política. En el caso de Soacha, los familiares de las víctimas emergieron como sujetos sociales y sus prácticas discursivas giran en torno a la búsqueda de justicia y el reconocimiento de su lucha social. Así como sus discursos están centrados en la búsqueda la reivindicación de los derechos negados a sus hijos.

- Simbólica. El reconocimiento del buen nombre de sus hijos es la mayor fuerza que contiene este discurso. Y desde allí se configura la necesidad de resemantizar el discurso expresado por el gobierno y las fuerzas militares sobre sus hijos y significar la memoria de los jóvenes desde la construcción de la verdad. 
- Resistencia y resiliencia: El discurso de las víctimas se construye en contradicción con el gobierno y se basa en el rechazo a las formas de concebir la guerra y la política.

d) El discurso de Derechos Humanos internacionales

Una perspectiva institucional hegemónica, las bases ideológicas del discurso de los Derechos humanos se encuentran en una ideología liberal, si bien actúan en favor del respeto a los principios de igualdad y universalidad para los ciudadanos, no cuestionan las estructuras de poder y exclusión propias del modelo tradicional de hacer política.

Los principios humanitarios: El respeto a las normas de la guerra consagradas en los protocolos de actuación en caso de conflictos. En este sentido, es actuar dentro del marco de una guerra, no abordar las condiciones estructurales que originan las confrontaciones bélicas.

El papel diplomático: este rol lleva a que se asuma una supuesta neutralidad en el marco del conflicto, y con ello sus observaciones no pueden obstruir las acciones del Estado.

e) Discurso de Derechos Humano comunitario: Los principios ideológicos de estos discursos se basan:

La reivindicación de los derechos de la sociedad civil y especialmente los sectores populares.

La reafirmación de las identidades contra hegemónicas, es decir sus discursos están atravesados por la diferencia y en contradicción con los esquemas tradicionales de poder. Especialmente, el cuestionamiento al poder del Estado y los organismos de poder.

La reivindicación el derecho a la justicia en favor las víctimas de Estado.

\subsubsection{Las formaciones discursivas en contextos de guerra}

Hemos analizado hasta el momento los discursos más representativos de los sujetos políticos y sociales sobre la violencia de "falsos positivos" y encontramos que sus prácticas discursivas responden a las formaciones ideológicas, las relaciones de poder y la coyuntura. Además, apreciamos la influencia del conflicto armado en estas prácticas discursivas. 
En este sentido de acuerdo con Bonilla (2003) las guerras no sólo son luchas armadas, también son disputas discursivas. Por los actores implicados generan estrategias no sólo bélicas sino además semánticas. En medio de una confrontación armada como la colombiana el lenguaje ha sufrido transformaciones ya sea por la aparición de nuevos léxicos o por el uso de eufemismos o disfemismos.

En la violencia ejercida contra los jóvenes resulta muy llamativo, el uso de las malas denominaciones, tales como los mal denominados "falsos positivos y la mal denominada "limpieza social," nominaciones que encubren el verdadero sentido que tiene una violencia cruel y bárbara contra un sector poblacional.

En la violencia de las ejecuciones extrajudiciales se recurrió al uso de otros términos como; legalizaciones, para indicar el acto de asesinar a alguien y hacerlo pasar como combatiente, o el uso de un término "dar de baja" usado por las fuerzas del Estado para referirse a la muerte de combatientes, en este sentido, observamos que las palabras cobran un contenido, simbólico y social que no es neutro, sino que se ancla en las formas ideológicas por la guerra.

Ademán en los contextos bélicos asistimos a una serie de luchas por el sentido, es así como en los discursos vemos una lucha por las palabras. En el caso de la violencia llevada a cabo en el marco de las ejecuciones extrajudiciales vemos la disputa por nombrar lo sucedido, Así para el Estado fueron crímenes de guerra o falsos positivos, para las Naciones Unidas ejecuciones Extrajudiciales y para las madres y las víctimas: crímenes de lesa humanidad.

No se trata sólo de diferencias lingüísticas, sino que el nombrar de determinada manera implica un contenido político distinto, una actuación de la justicia distinta y sobre todo abre o cierra las posibilidades de reparación a quienes han sufrido la violencia. Si, por ejemplo, los mal llamados "falsos positivos" son considerados crímenes de lesa humanidad, implican una aplicación distinta de la justicia penal, pero lo más importante es que se reconoce que se causó un daño a la sociedad y por tanto tenemos que sanar estas heridas sociales.

Así como contribuiría a la reconciliación tan necesaria para la paz, pero esta no se construye con el olvido de lo sucedido, sino con el reconocimiento de los hechos, la justicia y la solicitud del perdón sentido. Así lo observó una de las madres de Soacha, en 
Padilla \& Sampietro (2012): “El proceso de perdón y reconciliación es un proceso largo de asimilación y ayudaría que el gobierno colombiano y el ejército pidieran perdón”. (p.3).

En definitiva, la violencia emanada del conflicto armado transforma las prácticas sociales, través del lenguaje, la aparición de nuevos léxicos, el uso de la metáfora es muestra de que, en contextos de guerra, las palabras cambian, se transforman o se restringen en favor de uno u otro interés, en este sentido, no sólo se disputa en una confrontación armada, sino que también se una confrontación semántica.

\subsection{Síntesis}

Este capítulo abordó las prácticas discursivas sobre la violencia de "falsos positivos" de diversos sujetos políticos, sociales y comunitarios. Hemos identificado las principales características de los discursos y la relación existente entre los mismos. De esta manera, observamos que las prácticas discursivas sobre la violencia de "falsos positivos" se encuentran en disputa y que contienen múltiples contradicciones en torno al sujeto joven víctima de esta violencia.

El análisis de los discursos de los diversos sujetos políticos y sociales sobre la violencia de "falsos positivos", mostró que existen diferencias de acuerdo a las formaciones ideológicas, el poder y la coyuntura. Los discursos del Gobierno, los militares tienen similitudes y se basan en ideologías de derecha, guerrerista y en este sentido, la significación de las víctimas se encajan en la noción del "enemigo" o el "combatiente" mientras que para los familiares de la víctimas la significación se construye a partir del concepto de víctima, hijos y jóvenes populares y para las organizaciones de Derechos Humanos, las representaciones sociales del joven se enmarcan en el concepto de víctima desde los marcos del derecho internacional.

Las prácticas discursivas del Gobierno y los familiares son las que presentan mayor distancia, las acusaciones realizadas por el Gobierno de entonces sobre la vinculación de los jóvenes a actividades ilegales fue recibido por los familiares de las víctimas como un acto de re-victimización de quienes fueron asesinados y desaparecidos. Las prácticas discursivas del Gobierno se centraron en la exclusión, estigmatización y poco respeto por las víctimas y las prácticas de los familiares en la reivindicación del buen nombre de los jóvenes, así como la búsqueda de la verdad y la justicia. 
Las prácticas discursivas del Gobierno y los militares se centraron en la defensa de las Fuerzas Armadas, aun cuando las pruebas demostraron la responsabilidad en la desaparición y asesinato de estos jóvenes y miles civiles en el país, se limitaron a asumirlo como un acto de indisciplina de un puñado de militares que se convirtieron en un lunar en la institución. Esta postura del Gobierno entró en contradicción con las prácticas discursivas de los familiares y las organizaciones de Derechos Humanos.

A partir del análisis del Discurso realizado en este capítulo observamos que: las prácticas discursivas sobre la violencia de "falsos positivos" se producen, circulan y reproducen con la influencia de la coyuntura política, las formaciones ideológicas, así como las luchas por el poder político y simbólico. Los elementos coyunturales presentes en estas prácticas discursivas son : La política de Seguridad Democrática, la radicalización de un discurso de derecha en el Gobierno colombiano y la polarización política en la sociedad civil; asimismo, los elementos ideológicos inscritos en estos discursos son: El fortalecimiento de las ideologías de extrema derecha y guerristas, de la misma manera, la profundización el constructo social del “ enemigo interno” en la clase política y la sociedad civil; así como la luchas entre actores armados por ganar la guerra en los terrenos discursivos, políticos y bélicos.

Por último, este estudio estableció que en las prácticas discursivas analizadas en este estudio se ven reflejados elementos de estigmatización sobre el joven popular asociadas a la violencia del conflicto armado y la delincuencia. Por tanto, observamos que en el discurso mediático analizado se encuentra presente el imaginario social del joven popular como amenaza. 


\section{CAPÍTULO VIII. SÍNTESIS Y PROPUESTAS DE ACTUACIÓN}

8.1. Síntesis.

8.2. Aportaciones a la construcción de paz en contexto del post- conflicto.

8.3. Futuras líneas de investigación. 



\section{CAPÍTULO VIII. SÍNTESIS Y PROPUESTAS DE ACTUACIÓN}

En este estudio hemos analizado el discurso mediático de la violencia de "falsos positivos" y se han expuesto las principales representaciones sociales sobre la joven víctima de la violencia de "falsos positivos," específicamente el "caso de Soacha" presentes en el discurso mediático analizado. Se han identificado y analizado las principales características del discurso desde diferentes actores discursivos: familiares de las víctimas, Gobierno, militares y Organismos de Derechos Humanos. En este capítulo exponemos los principales logros obtenidos en este estudio en el campo teórico, metodológico y del análisis empírico.

\subsection{Síntesis}

a) El campo Teórico

Esta investigación fue realizada a través del análisis del discurso desde la perspectiva de la Escuela Francesa, por lo cual retomamos los conceptos de lenguaje, poder e ideología como ejes teóricos para realizar este análisis. Estos tres elementos fueron de gran importancia para analizar las prácticas discursivas mediáticas en contexto del conflicto armado colombiano; específicamente para el abordaje de las concepciones de la juventud víctima de los mal denominados "falsos positivos.

La comprensión del lenguaje desde la relación con el poder simbólico planteado por Bourdieu $(1982,2001)$ contribuyó a la comprensión de las especificidades del discurso en los medios de comunicación y la búsqueda de reconocimiento por parte de las audiencias. En este sentido podemos afirmar que los medios de comunicación aquí analizados realizaron la presentación de la noticia de acuerdo a intereses específicos. La Revista Semana se interesó por un reconocimiento como portavoz de un lenguaje especializado y una audiencia especializada. El periódico El Espectador se mantuvo en su papel crítico y oposición al Gobierno, especialmente a la política de Seguridad Democrática. Por último, el periódico El Tiempo se centró en su tendencia oficialista cercana a la posición del Gobierno.

Estas búsquedas de reconocimiento simbólico también están marcadas por las formaciones ideológicas, en este el lenguaje se crea y recrea constantemente y se producen en dos sentidos, por un lado un leguaje de exclusión, negación y muerte y por otro lado un lenguaje de la reivindicación, la solidaridad y la vida, el primero representado 
en los estereotipos estigmatización y las representaciones de rechazo social sobre los jóvenes y el segundo en los discursos de reivindicación de los familiares de las víctimas y las organizaciones sociales. En definitiva, la violencia genera una disputa simbólica por los imaginarios de vida y muerte, que a su vez está mediada por los intereses de poder presentes en los escenarios bélicos, así se observó que las producciones discursivas estuvieron muy asociadas a las tendencias políticas, los intereses por mantener la guerra o la paz, y en este sentido pudimos confirmar que la guerra es una disputa armada y una confrontación discursiva.

La violencia en Colombia generó un lenguaje de exclusión y negación del otro, dicho lenguaje se materializó en la "noción del enemigo," esta construcción ha permanecido en los imaginarios nacionales a lo largo del conflicto armado y se convirtió en uno de elementos justificador de la muerte del otro, no sólo presente en los ejércitos armados sino también en los diferentes sectores de la sociedad.

El discurso en contra del "enemigo" se agudizó en el Gobierno del presidente Uribe, éste se materializó en la política de Seguridad Democrática. Esta política, que más que una serie de lineamientos para contrarrestar el avance de los movimientos subversivos, se configuró en un mecanismo para el involucramiento de la población civil en la guerra y la toma de partido en relación al conflicto armado. Giraldo (2005) afirma que desde las directrices de esta política se invitaba e incentivaba a la población civil para combatir al "enemigo interno," y con la puesta en marcha de las medidas de esta política se empezarían a borrar las fronteras del Estado de derecho y un Estado autoritario. La influencia de la política de Seguridad Democrática sobre la población civil agudizó los conflictos entre los colombianos y de esta manera se profundizaron las divisiones entre los partidarios del Gobierno y los opositores del mismo. En este clima de confrontación se configuraron los imaginarios sociales "patriotas" para denominar la corriente oficialista y "terroristas;" para nombrar a los opositores y desde estos dos constructos sociales se potencializó la fragmentación social y se instó a la sociedad civil a la lucha contra el "enemigo interno," quien era representado por los opositores a la política de Seguridad Democrática.

En este sentido, la política de Seguridad Democrática enfatizó la construcción de relaciones de rechazo social, al profundizar los imaginarios sociales sobre todo aquello 
que se oponía a la ideología de derecha y se fortalecieron las representaciones sociales del "enemigo"

asociado a la imagen del "terrorista" y con ello se instalaron discursos que abogaban por el uso de la violencia.

La inmersión del país en un contexto de guerra como el caso colombiano ha conllevado a transformaciones linguiísticas y simbólicas, las maneras de nominar a los combatientes se han venido transformado paulatinamente, así los constructos sociales de los actores armados fueron cambiando de "bandoleros" a "guerrilleros" y luego a "terroristas." Estos cambios semánticos, si bien son expuestos e impulsados por el Gobierno, los grupos de poder económicos y los partidos políticos tradicionales a través de sus aparatos ideológicos (medios de comunicación e instituciones sociales), se van anclando en la sociedad y se establecen como formas de nominación del otro.

Los aportes teóricos sobre la configuración de imaginarios en la estigmatización del joven en medio del Conflicto Armado contribuyeron al análisis de las representaciones sociales del joven víctima de "falsos positivos". Hemos observado que en los imaginarios sociales de discriminación de la población juvenil están presentes las prácticas discursivas sobre los imaginarios de las víctimas de "falsos positivos." De esta manera, tanto la prensa como los diferentes actores discursivos establecen las imágenes de la población joven en base en estereotipos y estigmas asociados a la pertenencia territorial, la situación socioeconómica y la condición juvenil.

Uno de los mayores aportes teóricos, en relación al análisis de la diada juventud y violencia en Colombia, es el concepto que aporta Martín-Barbero (1998) sobre la existencia de un imaginario nacional del joven popular como amenaza, este constructo teórico nos permitió dilucidar la permanencia de este imaginario en los discursos de actores tales como: El Gobierno, las fuerzas militares y los victimarios directos de los jóvenes del caso de Soacha, lo cual nos permite hacer una comprobación teórica y empírica de la persistencia de este constructo social no sólo en las prácticas discursivas sino en las formaciones imaginarias de lo juvenil en el caso colombiano.

La presencia del imaginario social del joven como amenaza en el discurso de los medios de comunicación se dio de manera distinta según el medio de comunicación. Este tipo de constructo fue más notorio en el periódico El Tiempo, sin embargo, las asociaciones del 
joven popular con la delincuencia o la violencia del conflicto armado no están exentas en los otros dos medios de comunicación donde aparecen de forma más sutil. No observamos que la publicación de dicho imaginario se produzca por una intencionalidad directa y específica de los medios de comunicación, sino que estas concepciones están ancladas en los imaginarios nacionales sobre el joven y de éstos no están libres los periodistas ni los medios de comunicación.

b) Componente metodológico.

Este estudio se realizó a partir del análisis del discurso desde la perspectiva de la Escuela Francesa del discurso, los principales aportes de esta metodología de este estudio se detallan a continuación.

El análisis del discurso desde la perspectiva de la Escuela Francesa fue una perspectiva válida para el examinar los constructos sociales del joven víctima de la violencia de "falsos positivos". Los elementos como la interdisciplinaridad, las relaciones de poder, las formaciones ideológicas permitieron desentrañar los sentidos contenidos en los discursos aquí analizados.

Las prácticas discursivas sobre la violencia de "falsos positivos" se construyen en medio de procesos históricos de violencia, en transformaciones culturales e ideológicas que sólo pueden ser analizadas desde una perspectiva interdisciplinaria. En esta línea la perspectiva de análisis de la Escuela Francesa combina elementos de la sociología, la historia, la ciencia política y el análisis lingüístico.

La vinculación al análisis de discurso desde variables como: el poder, las formaciones ideológicas y la coyuntura. Tuvo una gran importancia para el logro de resultados, ya que las prácticas discursivas generadas en medio del conflicto armado se crean y recrean en el marco de las luchas por el poder y las disputas por ganar la guerra, que no sólo posee intereses militares, sino que además es una confrontación económica, política, social y simbólica.

El análisis del componente ideológico propuesto por la Escuela Francesa tiene gran pertinencia cuando se trata del análisis del discurso mediático sobre la violencia en Colombia, dado que las producciones discursivas de la prensa están directamente relacionadas con las filiaciones ideológicas de los medios de comunicación y de los sujetos del discurso. Así las representaciones sociales sobre el joven víctima de la 
violencia del caso de Soacha, están profundamente mediatizadas por las formaciones ideológicas de los productores y receptores del discurso.

c) Análisis del discurso y resultados

El análisis del corpus de este estudio se llevó a cabo desde dos perspectivas: cuantitativa y cualitativa. Con el desarrollo de la primera describimos las características del corpus en relación a las frecuencias de aparición temática y así como las frecuencias de intencionalidad de cada uno de los medios de comunicación que hace parte de este estudio. Con la perspectiva cualitativa analizamos las prácticas discursivas sobre el joven víctima de la violencia de "falsos positivos" en el caso de Soacha.

El análisis cuantitativo dio cuenta de la existencia de una concordancia entre las tendencias ideológicas de los medios de comunicación y las frecuencias de aparición temática. La publicación de las temáticas de violencia política y violencia contra los jóvenes obtuvieron una mayor frecuencia de aparición en la Revista Semana y el periódico El Espectador los dos medios de comunicación más críticos a la corriente del Gobierno del momento.

En cuanto a las frecuencias de aparición del discurso de los actores discursivos analizados (Gobierno, militares, familiares de las víctimas y la sociedad civil), se comprobó que estuvieron acorde a los lineamientos ideológicos de los medios de comunicación. La Revista Semana y el Periódico El Espectador dieron mayor importancia a los discursos familiares de las víctimas, a las críticas del discurso del gobierno y a los discursos de la sociedad civil, mientras que el periódico El Tiempo se centró más en el discurso gubernamental.

El análisis cuantitativo permitió determinar la existencia de una mayor producción de noticias en torno a la violación de los Derechos Humanos, la violencia política y la violencia contra los jóvenes en el periodo temporal comprendido entre finales de 2008 y el año 2009. Esta circunstancia nos llevó a deducir la influencia de este hecho de violencia en la producción noticiosa y lo llamativo que resultó para los medios de comunicación por el denominado escándalo de los "falsos positivos."

El análisis del discurso mediático sobre la violencia de "falsos positivos" nos permitió concluir la existencia de constructos sociales del joven víctima de la violencia de los "falsos positivos" relacionados con el imaginario nacional del joven como amenaza 
social. El discurso mediático consignado en el corpus retoma las asociaciones semánticas sobre el joven con elementos productores de la estigmatización tales como la delincuencia, la violencia política y las características del ser juvenil. Además, en este discurso se retoman aspectos tales como los constructos sociales negativos asignados al territorio "el sur de Bogotá" y los atributos negativos a este sector joven residente en la zona.

Las connotaciones mediáticas sobre los jóvenes del denominado caso de Soacha se centran en nominar al joven como víctima, sin embargo esta connotación está dotada de adjetivaciones que revictimizan a los jóvenes, dado que se les asignan atributos como "humildes" y "pobres." Estos atributos despojan de sentido político al concepto de víctimas y lo connotan de un sentido que inspira compasión.

Las prácticas discursivas analizadas en este contexto de violencia también nos mostraron una marcada tendencia a enfatizar en el discurso de las víctimas inocentes esta cualidad asociada a que no participaban en ningún grupo ilegal. La necesidad de nominar a las víctimas como inocentes se produce entre dos discursos política y semánticamente contradictorio. El primero de ellos enfatiza que las víctimas no participaban en actividades ilegales, aspecto totalmente justo y necesario de realzar y reconocer por el respeto a la dignidad de los jóvenes asesinados, a la memoria de las víctimas, sus familiares y el país. El segundo discurso enfatiza su inocencia como elemento necesario para rechazar la violencia ejercida contra este grupo de jóvenes.

El asunto problemático del discurso que presupone la no participación de las víctimas en actividades ilegales como punto central para rechazar la violencia infringida a seres humanos, muestra uno de los aspectos más complejos de los constructos sociales configurados en la guerra; puesto que se presume que habría víctimas que se "merecen" la violación de Derechos Humanos y otras no; según las concepciones de inocencia o culpabilidad. Y se niega un principio fundamental; la existencia de un orden constituido donde el Estado posee los mecanismos legales para sancionar las conductas ilegales de sus ciudadanos siempre en el marco de los Derechos Humanos.

Estas formas de significar la violencia ponen de manifiesto el desafío de asumir que las normas sociales y los principios de los Derechos Humanos deben ser aplicables a todas las personas sin excepción y, son además, una prioridad para superar los efectos de la 
guerra así como para transformar un lenguaje justificador de violencia configurado a lo largo del conflicto.

En las prácticas discursivas de los diferentes actores: Gobierno, militares, familiares de víctimas y Organismos de Derechos Humanos, observamos que existe una disputa entre las versiones de estos actores motivada por sus filiaciones ideológicas, relaciones de poder y la lucha ganar la guerra en los terrenos discursivos. Las prácticas discursivas sobre la violencia de los "falsos positivos" se encuentran polarizadas. Por un lado, el discurso del Gobierno y los militares se centraron en mostrar a las víctimas de esta cruel violencia como "guerrilleros" o "delincuentes" y del otro lado, los familiares y organizaciones sociales y Derechos Humanos enfatizaron en defender la memoria y el buen nombre de las víctimas. La otra corriente discursiva fue la expresada por las Naciones Unidas, que a través de un lenguaje diplomático cuestionó las versiones del Gobierno colombiano y sus fuerzas militares e indicó que se trataba de una práctica más o menos sistemática de violación de los Derechos Humanos denominada ejecuciones extrajudiciales.

El análisis de las prácticas discursivas sobre el caso de Soacha y la mal llamada violencia de "falsos positivos" nos mostró que las significaciones acerca de dicha violencia se encuentran en contradicción. Mientras que para el Gobierno colombiano y los militares la nombraron como "falsos positivos," para organismos internacionales se trató de una violación de Derechos Humanos llamada "Ejecuciones Extrajudiciales" y para los familiares de las víctimas y organizaciones de la sociedad civil son crímenes de lesa humanidad. Estas tres nominaciones: "falsos positivos," ejecuciones extrajudiciales y crímenes de lesa humanidad no sólo representan una diferencia lingüística, sino que sobre todo representan diferencias políticas y jurídicas amplias.

\subsection{Aportaciones a la construcción de paz en contexto del post- conflicto}

En el contexto del conflicto armado colombiano se expresaron innumerables formas de violencia y una sistemática violación de los Derechos Humanos intensificada por la profunda degradación de tan largo conflicto. La violencia de los "falsos positivos" fue una muestra contundente del daño que puede producir una guerra. Los resultados de esta investigación nos muestran como la violencia sistemática que han soportado los colombianos ha dejado profundas heridas emocionales y sociales. 
Después de más de cinco décadas de guerra, Colombia tiene la Esperanza de construir la paz, los acuerdos logrados con el movimiento insurgente de las FARC y las actuales negociaciones con el ELN, nos ubican en un escenario de post- conflicto. Este es uno de los momentos más importantes en la historia del país porque nos enfrentamos a una situación paradójica, la inmensa posibilidad de ganar la paz y el mayor reto de nuestra historia: ganar el postconflicto. Si llegar acuerdos con los movimientos guerrilleros fue un camino largo y difícil, lleno de contradicciones, dada las graves grietas sociales y políticas abiertas con una dolorosa y degradada guerra; superar el postconflicto aún contiene mayores desafíos y será el logro de los procesos de reconciliación entre los colombianos lo que nos encaminará hacia la construcción de la paz.

Este estudio, desde el análisis del discurso mediático de la violencia de los "falsos positivos", propone aportar la construcción de herramientas para la reconstrucción de los vínculos sociales en la sociedad, vínculos fracturados a partir de actos de violencia extrema y la convivencia cotidiana con la violencia. En esta apuesta partimos de la existencia de profundas heridas individuales, familiares y sociales que requieren ser reconocidas y sanadas.

\subsubsection{Puntos clave para trabajar en una propuesta en la construcción de paz}

Los principales elementos identificados para abordar en esta propuesta son los siguientes:

a) Lenguajes de deshumanización en contexto de conflicto armado.

La violencia perpetrada contra los jóvenes del caso de Soacha evidenció uno de los mayores impactos de la guerra; la negación absoluta del "otro." La vida de los seres humanos quedó sin valor tanto en las narrativas como en las acciones contra los adversarios y la sociedad civil. En este escenario bélico de reafirmó la noción del “enemigo" por encima de la del adversario, en este sentido, el "otro" es un ser que merece ser aniquilado simbólica y físicamente: Esta representación del "enemigo" se agudizó en los imaginarios nacionales a partir del año 2002, en el marco de la política de Seguridad Democrática donde se radicalizó un discurso de "odio" a la subversión y rechazo a cualquier apuesta diferente a la gubernamental. En este escenario, la sociedad civil se apropió de estos discursos y se generalizó una noción del enemigo y con ello se justificó la exclusión del otro. 
Estas transformaciones en las prácticas discursivas polarizadas por el agotamiento de un largo conflicto, la degradación del mismo, el fortalecimiento de ideologías de derecha en el poder y la vinculación de la sociedad civil al conflicto con las estrategias de la política de Seguridad Democrática, generaron un clima de aceptación de acciones de violencia inimaginables.

Las prácticas discursivas de los victimarios analizadas en este estudio nos demostraron que el conflicto armado en Colombia llegó a extremos de violencia donde los principios mínimos de humanidad, tanto el victimario se despojó de la humanidad para cometer tales crímenes como su representación de la víctima fue despojada de todo sentido de dignidad.

b) La transgresión de los límites éticos y morales en la guerra

El análisis de la violencia de "falsos positivos" y específicamente el caso de Soacha nos mostró que en el conflicto colombiano se llegó a la transgresión de los principios éticos y morales y se traspasó los límites humanitarios que deben regir los conflictos armados. No sólo se desdibujaron las normas y códigos humanitarios, sino que se transgredieron los principios éticos de cualquier convivencia.

Los análisis realizados a la violencia de "falsos positivos" expresan que, a partir de la estrategia de estímulos económicos y de reconocimiento ofrecidos a los militares en el marco de la política de Seguridad Democrática, se generó la violencia de los "falsos positivos". Sin embargo, la existencia de estímulos para mostrar resultados no puede explicar la producción de tal magnitud, tal como lo expresa Wills (2008):

Pero pensar en términos de estímulos es insuficientes, porque las personas no sólo responden a ellos, sino que también se inscriben en climas morales donde ciertas acciones se tornan socialmente admisibles y otras por el contrario son vistas como inadmisibles (p.11).

El comerciar y asesinar a seres humanos por estímulos económicos pone de manifiesto un grave problema ético y moral y cuestiona profundamente cuáles son los procesos de formación que están recibiendo las fuerzas armadas, cuales son los valores sociales que permiten que civiles engañen y entreguen jóvenes para ser asesinados y por supuesto qué pasa con una sociedad que observa este tipo de crueldad y permanece indiferente. 
Los principios que regulan si una acción es o no aceptable no sólo se trata de criterios individuales, sino que también se adhieren a lo socialmente consensuado como el deber ser, en este sentido, podemos observar que existen grietas en esos marcos éticos que regulan las relaciones sociales y que en contextos de guerra se está bajo amenaza de pasar los límites de lo socialmente aceptable.

c) Las heridas abiertas a partir del conflicto.

La violencia sucedida en el marco de los "falsos positivos" es una expresión del daño que puede causar un conflicto de larga duración llevado al extremo máximo de degradación, lo cual, sin lugar a dudas, deja abiertas heridas no sólo a sus seres queridos sino a la sociedad. Los impactos de esta violencia generaron sufrimiento extremo a las familias, grupos sociales y sociedad en general.

Los principales efectos psicosociales de esta violencia fueron: la destrucción de la confianza en los miembros de la sociedad civil, el sufrimiento causado a sus familiares, el incremento de la fractura entre Estado y Sociedad Civil; la agudización de los conflictos entre la juventud y otros sectores de la sociedad. La impunidad presente alrededor de este caso dejó en la sociedad una profunda de incertidumbre y dolor.

d) Los lenguajes de resiliencia y la resistencia civil

El dolor causado por la violencia suele generar diversas respuestas en quien la sufre, en el caso de la violencia de los "falsos positivos" se infringió mucho dolor tanto a las víctimas, a sus familiares y sus comunidades. Este sufrimiento tuvo respuestas que potenciaron lenguajes de resiliencia y resistencia, la búsqueda de las madres por dignificar el nombre de sus hijos, la justicia y la no repetición generaron una prácticas discursivas de solidaridad y acciones para la construcción de paz, que dotaron de nuevos sentidos el dolor convirtiéndolo en un potenciador de procesos de resistencia civil confirmando que en situaciones de sufrimiento extremo, las personas y las comunidades potencializan sus propios recursos emocionales y sociales para tramitar las experiencias de dolor.

\subsubsection{Posibles caminos hacia la construcción de la paz}

Colombia tiene, en la actualidad, la mayor probabilidad de construir la paz en su historia, asistimos a uno de los momentos más importantes en la búsqueda, para las nuevas 
generaciones, de la cotidianidad de un país sin conflicto armado. Esta es una oportunidad no sólo para los colombianos sino para toda la humanidad. El país ha vivido un proceso de seis años con muchas contradicciones y grandes disputas discursivas y políticas. La firma de los acuerdos de paz con el movimiento insurgente más importante: Las Fuerzas Armadas Revolucionarias de Colombia. Ejército del Pueblo (FARC- EP), ha conllevado a que en el país exista un clima de esperanza en un futuro mejor en la mayor parte de la población, con excepción de sectores radicalizados en ideologías de ultraderecha que no ven con buenos ojos la negociación llevada a cabo.

En la sociedad colombiana impera un optimismo frente al momento histórico que vivimos, pero también existe la preocupación por los retos que impone un postconflicto; no es para menos; dar cierre a más de cinco décadas de guerra conlleva tareas y costos muy importantes. Las preocupaciones por los costos económicos, la garantía de la integridad de los excombatientes, la seguridad de los territorios dejados por la subversión, las políticas de reintegración de tierras, la participación política de los ejércitos desarmados, la garantía de justicia y reparación de las víctimas, entre otros temas son prioridades en la política del postconflicto, los cuales van a requerir del mayor compromiso de los colombianos y sus gobernantes.

Sin embargo, es de anotar que uno de los riesgos que tiene el post-conflicto es que nos centremos en los macro problemas y no demos lugar a asuntos problemáticos derivados de las dimensiones culturales, emocionales y simbólicas presentes en este conflicto. En el caso particular la producción discursiva en contextos de guerra no supone actuar para deconstruir prácticas de negación y exclusión, lenguajes de horror y terror que lastimosa se produjeron y reprodujeron en medio de la violencia propia de un conflicto de larga duración.

Desde este estudio aportamos posibilidades de construcción de paz para responder a los cuatro puntos planteados anteriormente. Los resultados obtenidos en este análisis permiten concluir la necesidad de transformar los lenguajes de deshumanización. Los medios de comunicación requieren ser regulados en relación a los contenidos expuestos sobre la violencia y la paz.

De igual manera, se requiere avanzar en la construcción de lenguajes de reconocimiento del otro, de solidaridad en los espacios cotidianos y políticos, incluir en la formación 
educativa en todos los niveles la comprensión de valores éticos que lleven a diseñar nuevas formas de tramitación de los conflictos.

Un elemento fundamental para abordar la deshumanización del lenguaje en el contexto de la guerra es la construcción de la verdad de lo sucedido. Para las víctimas este es un elemento constitutivo de los procesos de reconstrucción, en este estudio observamos que para las víctimas y los supervivientes de esta violencia es necesario saber lo ocurrido con sus seres queridos, pero también es necesario que la verdad sobre los hechos acontecidos sea reconocida y apropiada por la sociedad. Este es un elemento que en el caso del postconflicto se encuentra en mayor disputa, como es sabido se institucionalizó la mentira, no sólo en los campos mediáticos, políticos y sociales sino en la cotidianidad del discurso; por ello la construcción de paz requiere de generar procesos de verdad unidos a la búsqueda de justicia.

Uno de los puntos más problemáticos que presentó la negociación de acuerdos de paz estuvo alrededor de la Justicia Especial de Paz, la cual asumió como camino la construcción de la verdad de lo sucedido no sólo por parte de los movimientos subversivos sino por todos los actores que hacen parte de este conflicto; esto implica poner de manifiesto en los campos de lo público la participación de diversos sectores de la sociedad en la guerra.

Además se requiere potenciar los lenguajes de resistencia civil y empoderamiento social, en este estudio comprobamos que la violencia y específicamente la violencia de los "falsos positivos" no sólo se configuró en medio de lenguajes de exclusión y negación absoluta de la dignidad de seres humanos mediante la creación de metáforas del horror y la crueldad sino que a la par se construyeron prácticas discursivas dotadas de sentido de la solidaridad, la dignidad y la reivindicación de la vida sobre la muerte. Estas prácticas discursivas deben ser reconocidas en su potencialidad creadora y recreadora de escenarios de paz. El lenguaje de quienes son sometidos a experiencias límites de sufrimiento son en su mayoría lenguajes del perdón y la búsqueda de que el inmenso dolor producido por la guerra no se repita. Este lenguaje sanador y esperanzador no ha contado con el absoluto reconocimiento en los medios de comunicación y estamos en mora de que estas prácticas discursivas tengan centralidad en los escenarios públicos y cotidianos ya que son una muestra de la gran capacidad de reconstruir a partir del dolor. 


\subsection{Futuras líneas de investigación}

Este estudio abre las puertas a futuras investigaciones. Las principales líneas de investigación que surgen en este estudio son las siguientes:

1. Se requiere seguir profundizando sobre las transformaciones del lenguaje en el contexto de guerra, sobre aquellas que centran en la exclusión del otro y actúan como prácticas justificadoras de la violencia. Asimismo, en las prácticas discursivas de resiliencia, solidaridad y paz que emergen tras la experiencia dolorosa de violencia.

2. El análisis comparativo de los discursos mediáticos sobre la violencia entre medios escritos y medios televisivos. Este estudio se centró en la prensa escrita, sin embargo, es necesario observar el discurso de medios televisivos que son producidos desde formatos distintos y cuentan con mayor audiencia que la prensa escrita.

3. Las prácticas discursivas en torno a la paz. En este trabajo investigativo identificamos la existencia de discursos de negación y exclusión en el contexto de violencia a la par se fortalecieron prácticas discursivas de paz, es necesario construir conocimiento sobre estas prácticas para potenciarlas en escenarios de postconflicto.

4. Las construcciones de los principios éticos y morales en contextos de conflictos de larga duración. Se hace necesario abordar la discusión sobre la influencia de la guerra en los marcos normativos sociales y las relaciones de convivencia ciudadana.

En este sentido, consideramos necesario seguir trabajando en el campo de las prácticas discursivas a través de estas líneas de investigación propuestas complementando así el estudio presentado. 



\section{BIBLIOGRAFÍA}

Abad, H. (2008, 1 Noviembre). Fallas, lunares y orejas. El Espectador. Recuperado de http://www.elespectador.com/opinion/columnistasdelimpreso/hector-abadfaciolince/columna87342-fallas-lunares-orejas

Acevedo, A., \& Castaño, S. (2001, Junio). El Frente Nacional Una reflexión histórica de su legitimidad política. Revista Ciencias Humanas (28). Recuperado de http://www.utp.edu.co/ chumanas/revistas/revistas/rev28/acevedo.htm.

Ahumada, M. A. (Ed.) (2007). El enemigo interno en Colombia. Quito: Abya Yala.

Ahmed-Ali, F., Galán, M., Ignacio, J., \& Nos-Aldás, E. F. (Eds.). (2011). Comunicación para la paz en acción: Periodismos, conflictos, alfabetización mediática y Alianza de Civilizaciones (Vol. 8). Publicacions de la Universitat Jaume I.

Alape, A. (Ed.) (1985). Ciudad Bolívar la hoguera de las ilusiones. Bogotá: Planeta.

Alape, A. (2006, Agosto). Voces en el taller de memoria. Recuperado de http://es.scribd.com/doc/22853539/Alape-Arturo-Voces-en-el-taller-de-la-memoria-2006.

Amat, Y. (2008, Noviembre 2008). Esta es la decisión más dolorosa que hemos tomado: MInidefensa. Recuperado de http://www.eltiempo.com/archivo/documento/MAM$\underline{3168820}$

Arendt, H., \& Cruz, M. (Eds.) (1993). La condición humana (Vol. 3). Barcelona: Paidós.

Auge, M. (Ed.) (1993). Los no lugares. Espacios de anonimato. Barcelona: Gedisa.

Austin, J. L. (1995). Cómo hacer cosas con palabras. Barcelona: Paidós.

Bañón, A. (2010, Abril). Comunicación destructiva y agresividad verbal en la Red. Notas en torno al discurso sobre las enfermedades raras. Discurso \& Sociedad, 4(4). Recuperado de http://www.dissoc.org/ediciones/v04n04/DS4(4)Banon.pdf.

Benveniste, E. (Ed) (2004). Problemas de lingüística general. México: Siglo XXI.

Biblioteca Luis Ángel Arango (2016). Reseñas de la Revista Semana y Cambio 1998-2004.

Recuperado de

http://www.banrepcultural.org/blaavirtual/todaslasartes/monografia/mono2a.htm 
Blair, E. (Ed.) (1999). Conflicto Armado y militares en Colombia. Cultos, símbolos e imaginarios. Bogotá: CINEP.

Bonilla, J. I. (2003). Calidad informativa y cubrimiento del conflicto. En C. Tamayo y M. Ruiz (Eds.), Calidad informativa y cubrimiento del conflicto: estándares de calidad periodística en el cubrimiento del conflicto armado en Colombia, (pp.22-49) Bogotá. Bogotá: Cerec.

Bourdieu, P. (Ed.) (1982). Qué significa hablar, Economía de los Intercambios Lingüísticos. Torrejón de Ardoz: Akal.

Bourdieu, P., \& Passeron, J. C. (2001). Fundamentos de una teoría de la violencia simbólica. Bourdieu, Pierre y Passeron, Jean-Claude. La Reproducción. Elementos para una teoría del sistema de enseñanza. Recuperado de http://s3.amazonaws.com/academia.edu.documents/40947891/Bourdieu_y_Passeron.pdf

Botero, P., Pinilla, V., Lugo, N., \& Calle, D. (2011, Enero). Narrativas del conflicto en contextos locales de Colombia. Revista Universidad de Manizales. Recuperado de http://revistaumanizales.cinde.org.co/index.

Buitrago, F. L. (2003). La doctrina de seguridad nacional: materialización de la Guerra Fría en América del Sur. Revista de estudios sociales, (15), 74-87. .

Cerbino, M. (2007, Marzo). Imaginarios de conflictividad juvenil en Ecuador. Las maras. Identidades. Nueva Sociedad. 2008, 82-102

Cerbino, M. (2006). Jóvenes en la calle: cultura y conflicto. Barcelona: Anthropos

Centro de Investigación y Educación Popular (CINEP) y La Comisión Intereclesial de Justicia y Paz (2009, Marzo). Panorama de Derechos Humanos y Violencia Política. Banco de Datos de Violencia Política. Recuperado: Recuperado de www. nocheyniebla.org. co.

Collins, J., \& Glover, R. (2003). Lenguaje Colateral. Claves para justificar la guerra. Madrid: Páginas de Espuma.

Costa, P., Pérez, T. J., \& Tropea, F. (1996). Tribus urbanas. El ansia de la identidad juvenil: entre el culto a la imagen y la autoafirmación a través de la violencia. Barcelona: Paidós.

Courtine, J. J. (Ed.) (1981). Análisis del discurso político (el discurso comunista dirigido a los cristianos). Langages, 62. 
De Hincapié, M. T. U. (2004). Las palabras de la guerra. Estudios Políticos. Recuperado de http://aprendeenlinea.udea.edu.co/revistas/index.php/estudiospoliticos/article/view/1397/ 1457

De La Roche, F. L. (2005, Febrero). Aprendizajes y encrucijadas del periodismo. Entre la paz de Pastrana y la seguridad democrática de Uribe. Bogotá: Palabra Clave, (13), 7- 45.

De la Torre, C. (2008, Noviembre). Purgando culpas, El Espectador, Recuperado de http://www.elespectador.com/search/Purgando\%20Culpas.

Duncan, G. (2005, Enero). Del Campo a la Ciudad en Colombia. La infiltración Urbana de los Señores de la Guerra. Recuperado de https://core.ac.uk/download/pdf/6516973.pdf

Duranti, A. (Ed.) (2000). Antropología lingüística. Cambridge: University Expres.

Duzan; M, J. (2008). Así no se gana la guerra. Revista Semana. Recuperado de http://www.semana.com/opinion/articulo/asi-no-gana-guerra/96895-3

Echeverría, R. (Ed.) (2003). Ontología del lenguaje. Santiago de Chile: Comunicaciones: Noreste.

Escola de Cultura de Paul (2003, Julio). Barómetro sobre conflictos derechos humanos y $\begin{array}{llll}\text { construcción de paz. } & \text { Recuperado de }\end{array}$ http://escolapau.uab.cat/img/programas/alerta/barometro/barometre3.pdf

El Espectador (2016, 23 Mayo). Nuestros hijos fueron revictimizados: Falsos positivos de Soacha. El Espectador. Recuperado de http://www.elespectador.com/noticias/judicial/nuestroshijos-fueron-revictimizados-madres-de-los-fals-articulo-633814

El Espectador (2014, Febrero 27). Pasamos la noche en Cazuca y descubrimos como opera la limpieza social. Recuperado de http://www.elespectador.com/noticias/bogota/pasamosnoche-cazuca-y-descubrimos-opera-limpieza-socia-articulo-477668

El Espectador (2009a, 28 octubre). Los desaparecidos de Soacha. Recuperado de http://www.elespectador.com/opinion/editorial/articulo86620-los-desaparecidos-desoacha cambiar año 2008

El Espectador (2009b, 2 Marzo). Fuimos carne de Buitre. Recuperado de http://www.elespectador.com/impreso/tema-del-dia/articuloimpreso123316-fuimoscarne-de-buitre 
El Espectador (2008a, Octubre 31). Los Falsos Positivos. Recuperado de http://www.elespectador.com/opinion/los-falsos-positivos-columna-87226

El Espectador (2008b). Purga histórica en el ejército por desapariciones. Recuperado de http://www.elespectador.com/node/86671/articulo-213798-sobre-el-sitp

El Tiempo (2010). Madre víctima de un "falso positivo" expone su caso en Estados Unidos. Recuperado de http://www.eltiempo.com/archivo/documento/CMS-8039200

El Tiempo (2009 a, Octubre 17). El drama de las familias de Soacha no termina. Recuperado de http://www.eltiempo.com/archivo/documento/CMS-6378707

El Tiempo (2009b, 18 Abril). Así se asesinaron a dos víctimas de 'falsos positivos "; cabo que participó en los homicidios confesó. Recuperado de http://www.eltiempo.com/archivo/documento/CMS-5011553

El Tiempo (1954, Noviembre 1). Portada. El Tiempo. Recuperado de https://news.google.com/newspapers/p/eltiempo?nid=N2osnxbUuuUC\&dat=19541101\& printsec $=$ frontpage $\& h l=e$

FEDES (2011) Soacha. "falsos positivos" la punta del iceberg. Recuperado de http://www.justiciaporcolombia.org/node/160

Fisas, V. (Ed) (1998). Cultura de paz y gestión de conflictos. Barcelona: Icaria.

Flórez, V. (2012, Agosto 25). Así Nació la Revista Semana, Recuperado de https://vladdomania.com/2012/08/25/asi-nacio-la-revista-semana/

Foucault, M. (Ed) (1970). EI orden del discurso. Barcelona: Pre-textos.

Foucault, M. (Ed) (1972). La arqueología del Saber y el discurso del lenguaje. FCE. Fromm E (1968) “Ética y psicoanálisis”. México: FCE.

Foucault, M. (1987). El orden del discurso. Barcelona: Tusquets

Foucault, M., \& Poster, M. (Eds.) (1987). Foucault, marxismo e historia: Modo de producción versus modo de información. México: Paidós Ibérica

García, C. (2010). Johnny quería ser militar y terminó de los "falsos positivos". Revista Semana. Recuperado de http://www.semana.com/nacion/conflicto-armado/articulo/jonny-queria$\underline{\text { militar-termino-falso-positivo/113467-3 }}$ 
Giraldo, J. C. G. (2005, Octubre 24). Del régimen de comunicación política del presidente de Colombia Álvaro Uribe Vélez. Recuperado de http://palabraclave.unisabana.edu.co/index.php/palabraclave/article/view/1461

Geertz, G. (1973). La descripción densa: hacia una teoría interpretativa de la cultura. Barcelona: Gedisa

Goffman, E. (Ed.) (1970). Estigma: Identidad deteriorada. Buenos Aires: Amorrortu.

González, M. T. S., \& Bermúdez, L. C. R. (2009, Julio). El lenguaje como instrumento de poder. Cuadernos de Lingüística Hispánica, (14), 35-58. Recuperado de file:///C:/Users/rosa/Downloads/Dialnet-ElLenguajeComoInstrumentoDePoder3618761.pdf

Habermas, J. (1981). Historia y crítica de la opinión pública: la transformación estructural de la vida pública (pp. 1-171). Barcelona: Gustavo Gili.

Habermas, J. (1990, Mayo). La soberanía popular como procedimiento. Recuperado de http://www.bolivare.unam.mx/cuadernos/cuadernos/contenido/CP.57/CP57.7JurgenHabe rmas.pdf

Habermas, J. (ed.) (1989). Discurso filosófico de la modernidad. Doce lecciones. Madrid: Tauros.

Haidar, J. \& Rodríguez, L. (1996, Mayo). Funcionamientos del poder y de la ideología en las prácticas discursivas. Recuperado http://www.dimensionantropologica.inah.gob.mx/?p=1456

Haidar, J. (1992, Diciembre). Las materialidades Discursivas. Un problema Interdisciplinario. Recuperado de http://seer.fclar.unesp.br/alfa/article/view/3914

Haidar, J. (1997). Las propuestas de Lotman para el análisis cultural y su relación con otras tendencias actuales. In En la esfera semiótica lotmaniana: estudios en honor de Iuri Mijailovich Lotman (pp. 194-207). Episteme.

Haidar, J. (1998). Análisis del discurso. En Galindo, L J (Ed.) Técnicas de investigación en sociedad y cultura (pp. 117-164). México: Addison.

Hall, S. (2010). Representación: representaciones culturales y prácticas significantes. En Textos de antropología contemporánea (pp. 59-74). Universidad Nacional de Educación a Distancia, UNED.

Hall, S. (1997). Representation. Cultural representations and signifying practices. London: Sage 
Henderson, H. (2006). La Ejecución extrajudicial o el homicidio en las legislaciones de América Latina. Recuperado de http://www.corteidh.or.cr/tablas/R08060-7.pdf

Ignatieff, M. (2003). Los derechos humanos como política e idolatría, Barcelona: Paidós.

Jodelet, D. (Ed.) (1984). La representación social: fenómenos, concepto y teoría. En S. Moscovici (comp.), Pensamiento y vida social. Psicología social y problemas sociales (vol. II). Barcelona: Paidós

Lechner, N. (Ed) (1990). Los patios interiores de la democracia. Subjetividad y Política. Santiago de Chile: Fondo de Cultura Económica.

Margulis, M., \& Urresti, M. (1998). La construcción social de la condición de juventud. En M, C. Laverde et al (Eds), Viviendo a toda: jóvenes, territorios culturales y nuevas sensibilidades. (pp.3-21). Bogotá: editorial Siglo del Hombre.

Martín-Barbero, J. (1998). Jóvenes Desorden Cultural y Palimpsestos de Identidad. En M, C. Laverde et al (Eds), Viviendo a toda: jóvenes, territorios culturales y nuevas sensibilidades. (pp.27-37). Bogotá: Siglo del Hombre. Ediciones.

Martín-Baró, I. (1990). De la guerra sucia a la guerra psicológica: el caso de El Salvador. Psicología social de la guerra. El Salvador: UCA

Matarán, B. (2001). El Lenguaje. Recuperado de https://es.bebee.com/bee/begona-mataran-lorite0VXync

Maturana, H. (2001, Mayo). Emociones y lenguaje en educación y política. Recuperado de http://www. systac. cl/emociones. pdf.

Medina, M. I, Vargas E. P., Medina, N., \& Jaramillo, L. E. (2011, Abril). Autorretrato del Sicario. Recuperado de http://hdl.handle.net/10785/628

Mirié, M. (2003). Estigma, vinculación y demarcación. Recuperado de tps://reflexionesdecoloniales.files.wordpress.com/2014/08/mmiric_estigma_disciminacion.pdf

Montoya, L. F. (2007, Noviembre 2007). Somos generadores de violencia. El Espectador. Recuperado de http://www.elespectador.com/opinion/somos-generadores-de-violenciacolumna-714 
Morales, L. (2009, Enero 16). Desaparecidos en Bogotá, muertos en Boyacá. Revista Semana. Recuperado de http://www.semana.com/nacion/conflicto-armado/articulo/desaparecidosbogota-muertos-combate-boyaca/99137-3

Movimiento de Reconciliación \& La Coordinación Colombia Europa (2014, Junio). Falsos positivos en Colombia y el papel de la asistencia militar de Estados Unidos, 2000-2010. Recuperado de https://www.colectivodeabogados.org/IMG/pdf/1 inform.pdf

Navia, J, R. (1996, Junio 23.) Cazucá una bomba de tiempo. El Tiempo. Recuperado de http://www.eltiempo.com/archivo/documento/MAM-456808

Negro, M. A. (2010, Abril). Lenguaje, palabra, discurso en la enseñanza de Jacques Lacan. Recuperado http://aprendeenlinea.udea.edu.co/

Osorio, F, E (1993). La violencia del silencio. Desplazados del campo a la ciudad, Bogotá: CODHES. Universidad Javeriana.

Padilla, S., \& Sampietro, L. (2012, Mayo 27). Yo no parí hijos para la guerra. Entrevista a Luz Marina Bernal, lideresa de las Madres de Soacha, Recuperado de http://iberoamericasocial.com/yo-no-pari-hijos-para-una-guerral

Pardo, N. (2005, Enero). La Representación de los Actores armados en la prensa colombiana. Recuperado de http://www.redalyc.org/articulo.oa?id=219201807

Pardo, N. G. (2013). Violencia simbólica, discursos mediáticos y reproducción de exclusiones sociales. Discurso \& Sociedad, (2), 416-440.

Paredes, Z. \& Díaz, N. (2007). Los Orígenes del Frente y Nacional en Colombia. Recuperado de www.saber.ula.ve/bitstrea

Pecaut, D. (Ed.) (2004). Guerra, Proceso de Paz y Polarización Política. Bogotá: Norma.

Pécaut, D., \& Gonzáles. L, (1996). Pasado, presente, futuro de la violencia. En Desarrollo Económico, 36 (144) 891-930. DOI 10.2307/3467131

Pechêux, M. (Ed) (1969). Análisis del contenido y teoría del discurso. Análisis Automático del Discurso. París: Dunod

Perea, C, M. (2014). Pandillas, muerte y sentido. Gangs, death and logic. Recuperado de http://flacsoandes.org/dspace/bitstream/10469/1491/3/RFLACSO-U04-05-Rubio.pdf

Perea, C, M. (2008, Abril). Pandillas, muerte y sentido. Gangs, death and logic. Recuperado de http://www.flacsoandes.edu.ec/biblio/catalog/resGet.php?resId=9056 
Perea C. M. (2004). Pandillas y conflicto urbano en Colombia. Desacatos, (14), 15-35 http://www.scielo.org.mx/scielo.php?pid=S1405-92742004000100002\&script=sci_arttext

Perea, C, M. (2001). Pandillas Urbanas al Suroriente de Bogotá. Recuperado Marzo 13 de 2012. http://www.tandfonline.com/doi/abs/.

Perea, C, M. (1998). Somos Expresión, No subversión. Juventud e identidades. Esfera Pública en el Suroriente Bogotano. En M.C Laverde et al (Eds), Viviendo a toda: jóvenes, territorios culturales y nuevas sensibilidades. (pp.129-150). Bogotá: Siglo del Hombre. Ediciones.

Pizarro, E. (2002, Enero). La Atomización Partidista en Colombia: El Fenómeno de las Microempresas Electorales. Recuperado de https://www.nd.edu/ kellogg/publications/workingpapers/WPS/292.pdf

Red Nacional de Organismos de Derechos Humanos (2008). Todos los Derechos para todos y todas. Campaña Nacional: La protesta es un derecho, la represión es un delito. Recuperado abril 11 de 2012. http://www.redtdt.org.mx/

Rebellato, J. L. (1998). Paulo Freire: educación y proyecto ético-político de transformación. Documentación Social, 110.

Reboul. O (Ed.) (1980). Lenguaje e Ideología. México: Fondo de Cultura Económica.

Reguillo, R. (2000a). Emergencia de culturas juveniles estrategias de desencanto. Buenos Aires: Norma. Ediciones.

Reguillo, R. (2000b). Las culturas Juveniles Un Campo de Estudio Para la Discusión. Recuperado de http://www.scielo.br/pdf

Reguillo, R. (2008). Las múltiples fronteras de la violencia: jóvenes latinoamericanos entre la precarización y el desencanto. Pensamiento iberoamericano, (3), 205-225.

Reguillo, R. (2004). La performatividad de las culturas juveniles. Recuperado de www.injuve.es/sites/default/files/culturasjuvenilesBibliografia.pdf

Revista Semana (2012, 24 Septiembre). Madres de Soacha recordaron 4 años de "falsos positivos." Revista Semana, Recuperado de http://www.semana.com/nacion/articulo/madres-soacha-recordaron-cuatro-anos-falsospositivos/265282-3 
Revista Semana (2010a, Mayo 23). La Tropa tiene la moral baja. Revista Semana. Recuperado de http://1www.semana.com/nacion/articulo/la-tropa-tiene-moral-baja/116949-3

Revista Semana (2010b, 27 Julio). Inteligencia militar, la marca de Fredy Padilla de León. Recuperado de http://www.semana.com/nacion/articulo/inteligencia-militar-marcafreddy-padilla-leon/119806-3

Revista Semana (2010c, Julio 14). ¡No tenemos por qué callarnos!” Revista Semana. Recuperado de http://www.semana.com/nacion/articulo/no-tenemos-que-callarnos/119304-3

Revista Semana (2010d, Mayo 27). ONU denuncia patrón de "ejecuciones extrajudiciales" e Impunidad en Colombia. Recuperado de http://www.eltiempo.com/archivo/documento/CMS-7727623

Revista Semana (2009a, Agosto 6) Relator de ejecuciones extrajudiciales llega a Colombia. Recuperado de http://www.semana.com/nacion/relaciones-exteriores/articulo/relatorejecuciones-extrajudiciales-onu-llega-colombia/103957-3

Revista Semana (2008a, Septiembre 27). ¿Falsos positivos mortales? Recuperado de http://www.semana.com/nacion/articulo/falsos-positivos-mortales/95607-3

Revista Semana (2008b, Octubre 25). Mi hermano fue un falso positivo. Revista Semana. Recuperado de http://www.semana.com/nacion/articulo/mi-hermano-falsopositivo/96639-3

Revista Semana (2005, Junio 12). Cazuca de luto. Recuperado de http://www.elespectador.com/opinion/somos-generadores-de-violencia-columna-714

Reyes, G., \& Guillen, G. (2009). La tragedia de las madres de Soacha desata escándalo de falsos positivos. El Nuevo Herald. Recuperado de http://www.elnuevoherald.com/Copiniones/opin-col-blogs/article1996408.html

Riaño, P. (2000). La memoria viva de las muertes. Lugares e identidades juveniles en Medellín. Revista Análisis Político del Instituto de Estudios Políticos y Relaciones Internacionales. IEPRI. 41, 23-38.

Riaño, P. (2006). Jóvenes, memoria y violencia en Medellín. Una antropología del recuerdo y el olvido. Medellín: Universidad de Antioquia.

Rodríguez, C. R. (2011). ¿Conflicto armado interno en Colombia? Más allá de la guerra de las palabras. Magistro, 4(7), 111-125. 
Rueda, M, J. (2012, Marzo). Los "falsos positivos" y el tratamiento de la cuestión de las ejecuciones extrajudiciales en Colombia en el sistema interamericano de Derechos Humanos. Recuperado de file:///C:/Users/rosa/Desktop/Adobe\%20Acrobat/documentos\%20personales/Falsos\%20p ositivos.pdf

Reguillo, R. (1998). Imaginarios globales, miedos locales. La construcción social del miedo en la ciudad. Ponencia presentada en el IV Encuentro de la Asociación Latinoamericana de Investigadores de la Comunicación. ALAIC. Recife: Universidad Católica de Pernambuco. Recuperado de http://antigua.mamacoca.org/docs_de_base/La_Representacion_Social_del_narcotrafico/ Rossana_Reguillo_Imaginarios_la_construccion_social_del_miedo_en_la_ciudad_ALAI C 11-16 de septiembre de 1998.pdf (11 septiembre)

Ricoeur, P. (Ed) (1996). Sí mismo como otro. Madrid: Siglo XXI.

Ricoeur, P. (Ed) (2001). La metáfora viva. Madrid: Ediciones Cristiandad.

Robin, R. (Ed) (1973). Histoire et linguistique, París: Librairie Armand Colin.

Rodríguez, C. R. (2011, Febrero). ¿Conflicto armado interno en Colombia? Más allá de la guerra de las palabras. Recuperado de http://revistas.usta.edu.co/index.php/magistro/article/view/593/879'

Rodríguez, C. (2008). Halcones, palomas y derechos humanos. El Espectador. Recuperado de http://www.elespectador.com/opinion/halcones-palomas-y-derechos-humanos-columna$\underline{87810}$

Rojas, D.M. (2006). La Internacionalización de la guerra: Estados Unidos y la guerra Colombia. En Gutiérrez, F, Wills. M. E y Sánchez, G. (Eds). Bogotá: Norma.

Romero, M. (2000, Julio). Democratización política y contra reforma paramilitar en Colombia. Recuperado de //redalyc.uaemex.mx/redalyc/pdf/126/12629304.pdf

Sabucedo, J.M., y Alzate, M. (2005). Conflicto terrorismo y cultura de Paz, en Blanco, A., del Águila, R., y Sabucedo, J.M. Madrid, 11-M. Un análisis del mal y sus consecuencias (pp. 221-253). España: Trotta

Salazar, A. (Ed.) (1990). No nacimos pa' semilla. Bogotá: CINEP. Ediciones.

Samayoa, J. (1990). Guerra y deshumanización: una perspectiva psicosocial. Psicología social de la guerra: trauma y terapia, 41-64. 
Sánchez, F; Díaz, M. \& Formisano, M. (2003, Junio).Conflicto y violencia criminal en Colombia: Un análisis especial. Recuperado de economia.uniandes.edu.co

Sánchez, G. (Ed) (1986). Los estudios de la violencia balance y perspectiva Pasado y presente de la violencia en Colombia. (pp.14-38).Bogotá: CEREC. Ediciones.

Sánchez, G. (2004, Junio). Violencias y Estrategias Colectivas en la Región Andina. Recuperado de http://books.openedition.org/ifea/3814

Sánchez. G. (Ed) (2006).Guerras, memorias e historia. Bogotá. Abril 2006. Bogotá: La carreta histórica. Ediciones.

Schlenker, H. A. (2008). Escrituras de violencia: relato y representación del sicario (Master's thesis, Universidad Andina Simón Bolívar, Sede Ecuador).

Serrano, J. F. (2005). La cotidianidad del exceso: Representaciones de la violencia entre jóvenes colombianos. Jóvenes sin tregua: culturas y políticas de la violencia. Barcelona, Antrophos, 129-143

Serrano, Y. (2006). Conflicto armado e información: una reflexión sobre las reglas de conducta profesional periodística que dicta el Acuerdo por la discreción. Diversitas, 2(1), 105-123.

Sierra, J. (2001, noviembre). Incidencia de los medios de comunicación en el conflicto colombiano. Siden: Sistema de información de la defensa nacional.

Smith D. (2000) Tendencias y Causas del Conflicto Armado. Recuperado de http://www.bivipas.unal.edu.co/handle/10720/643

Stangor, C., \& Crandall, C. S. (2000). Threat and social construction of stigma. In T. F. Heatherton, R. E. Kleck, M. R. Hebl, \& J. G. Hull (Eds.), The social psychology of stigma (pp. 62-87). New York: Guilford Press.

Taylor, S. J. y Bogdan, R.O (Ed.) (1987). Introducción a los métodos cualitativos de investigación: La búsqueda de significados. Barcelona: Paidós. Ediciones.

Thompson, J. B. (1996). La teoría de la esfera pública. Recuperado de http://campusmoodle.proed.unc.edu.ar/file.php/113/Biblioteca/thompson_la_teoria.pdf

Turbay, C. (2009). Estatuto de seguridad. Un estudio de caso. Recuperado de. http://dialnet.unirioja.es/servlet/

Uribe, M. T. \& López, L. (2006). Las palabras de la guerra. Un estudio sobre las memorias de las guerras civiles en Colombia. Medellín: La Carreta. 
Valenzuela, J, M. (1998). Somos Expresión, No subversión. Juventud e identidades. Esfera Pública en el Suroriente Bogotano. En M.C Laverde et al (Eds), Viviendo a toda: jóvenes, territorios culturales y nuevas sensibilidades. (pp.38-46). Bogotá: Siglo del Hombre. Ediciones.

Van Dijk, T. A. (Ed.) (2008). Semántica del discurso e ideología. Discurso \& Sociedad, 2(1), 201-261.

Vigostki, L. S (Ed,) (1995). Pensamiento y lenguaje. Barcelona: Paidós.

Villamizar, R. (2013). Jóvenes, Identidad y Violencias. Una Aproximación Etnográfica Al Caso Colombiano. Tesis de Máster no publicada. Instituto Interuniversitario de Desarrollo local. Universidad de Jaume I. Castellón.

Von der Walde, E. (2001, Septiembre). La novela de sicarios y la violencia en Colombia. Iberoamericana. Recuperado de http://www.jstor.org/stable/41672670

Wills, M, E. (2008, Nov 8). Estímulos Perversos y Laxitud Moral, El Espectador. Recuperado de http://www.elespectador.com/opinion/estimulos-perversos-y-laxitud-moral-columna89058

Zecchetto, V. (Ed) (2002). La danza de los signos: nociones de semiótica general. Quito: AbyaYala.

Zuluaga, J. (2004). La Guerra interna $\mathrm{Y}$ el desplazamiento forzado. Recuperado de. www.virtual.unal.edu.co/cursos/humanas/.../Jaime_zuluaga.pdf 
ANEXOS 

ANEXO 1. Tablas de artículos de Prensa (Corpus)

Tabla 1. Periódico: El Espectador

\begin{tabular}{|c|c|c|}
\hline Titulo & Link & Fecha \\
\hline $\begin{array}{l}\text { Soacha. } \\
\text { ritmo del Hip } \\
\text { Hop }\end{array}$ & http://www.elespectador.com & $1 / 12 / 21007$ \\
\hline $\begin{array}{l}\text { Los Falsos } \\
\text { positivos }\end{array}$ & http://www.elespectador.com & $31 / 10 / 2008$ \\
\hline $\begin{array}{l}\text { Falsos positivos } \\
\text { y otros }\end{array}$ & $\begin{array}{l}\text { http://www.elespectador.com/search/site/los } \\
\% 20 \text { falsos\%20positivos } \% 20 \% 20 \mathrm{en} \% 20 \text { colo } \\
\text { mbia? }\end{array}$ & $9 / 05 / 2008$ \\
\hline $\begin{array}{l}\text { Por un año } \\
\text { nuevo sin falsos } \\
\text { positivos }\end{array}$ & $\begin{array}{l}\text { http://www.elespectador.com/columna10317 } \\
\text { 6-un-ano-nuevo-sin-falsos-positivos }\end{array}$ & $30 / 12 / 2008$ \\
\hline $\begin{array}{lr}\text { Los } & \text { familiares } \\
\text { de } & \text { los } \\
\text { desaparecidos } \\
\text { pidieron cárcel } \\
\text { para Montoya }\end{array}$ & $\begin{array}{l}\text { http://www.elespectador.com/columna10317 } \\
\text { 6-un-ano-nuevo-sin-falsos-positivos }\end{array}$ & $4 / 11 / 2008$ \\
\hline $\begin{array}{l}\text { Presidente } \\
\text { confirma que } \\
\text { desaparecidos } \\
\text { murieron en } \\
\text { combate. }\end{array}$ & $\begin{array}{l}\text { http://www.elespectador.com/noticias/judici } \\
\text { al/video-presidente-confirma-desaparecidos- } \\
\text { de-soacha-murieron-combate }\end{array}$ & $7 / 10 / 2008$ \\
\hline $\begin{array}{l}\text { Falsos } \\
\text { copretéritos }\end{array}$ & $\begin{array}{l}\text { http://www.elespectador.com/columna90749 } \\
\text {-falsos-copreteritos }\end{array}$ & $15 / 11 / 2008$ \\
\hline Falsos Rumores & $\begin{array}{l}\text { http://www.elespectador.com/opinion/colum } \\
\text { nistasdelimpreso/mario- } \\
\text { morales/columna89280-falsos-rumores }\end{array}$ & $9 / 11 / 2008$ \\
\hline $\begin{array}{l}\text { Requien por el } \\
\text { NN }\end{array}$ & $\begin{array}{l}\text { http://www.elespectador.com/opinion/colum } \\
\text { nistasdelimpreso/uriel-ortiz- } \\
\text { soto/columna88445-requiem-los-nn }\end{array}$ & $5 / 11 / 2008$ \\
\hline
\end{tabular}




\begin{tabular}{|c|c|c|}
\hline $\begin{array}{l}\text { Peligro. Guerra } \\
\text { Sucia }\end{array}$ & $\begin{array}{l}\text { http://www.elespectador.com/opinion/colum } \\
\text { nistasdelimpreso/uriel-ortiz- } \\
\text { soto/columna88445-requiem-los-nn }\end{array}$ & $3 / 11 / 2008$ \\
\hline El sistema & $\begin{array}{l}\text { http://www.elespectador.com/opinion/colum } \\
\text { nistasdelimpreso/ivan-cepeda- } \\
\text { castro/columna89069-el-sistema }\end{array}$ & $8 / 11 / 2008$ \\
\hline $\begin{array}{l}\text { Guerra } \\
\text { ardides }\end{array}$ & $\begin{array}{l}\text { http://www.elespectador.com/columna92557 } \\
\text {-guerra-de-ardides }\end{array}$ & $22 / 11 / 2008$ \\
\hline $\begin{array}{ll}\text { Derecho } & \text { a } \\
\text { preguntar }\end{array}$ & $\begin{array}{l}\text { http://www.elespectador.com/columna92557 } \\
\text {-guerra-de-ardides }\end{array}$ & $4 / 11 / 2008$ \\
\hline $\begin{array}{lcl}\text { El } \quad 25 & \mathrm{de} \\
\text { septiembre }\end{array}$ & $\begin{array}{l}\text { http://www.elespectador.com/noticias/nacion } \\
\text { al/imagen-25-de-septiembre }\end{array}$ & $13 / 12 / 2008$ \\
\hline $\begin{array}{l}\text { Uribe denuncia } \\
\text { relación del } \\
\text { ejército con } \\
\text { desapariciones }\end{array}$ & $\begin{array}{l}\text { http://www.elespectador.com/noticias/nacion } \\
\text { al/imagen-uribe-denuncia-relacion-del- } \\
\text { ejercito-desapariciones }\end{array}$ & $29 / 10 / 200$ \\
\hline $\begin{array}{l}\text { ¿le alcanza a } \\
\text { Uribe para otra } \\
\text { reelección }\end{array}$ & $\begin{array}{l}\text { http://www.elespectador.com/opinion/colum } \\
\text { nistasdelimpreso/luis-carvajal- } \\
\text { basto/columna88931-le-alcanza-uribe-otra- } \\
\text { reeleccion }\end{array}$ & $7 / 11 / 2008$ \\
\hline $\begin{array}{l}\text { Guerra limpia, } \\
\text { Guerra sucia }\end{array}$ & $\begin{array}{l}\text { http://www.elespectador.com/columna89532 } \\
\text {-guerra-limpia-guerra-sucia }\end{array}$ & $10 / 11 / 2008$ \\
\hline $\begin{array}{l}\text { Blanca Nubia } \\
\text { Monroy, madre } \\
\text { de uno de los } \\
\text { desaparecidos } \\
\text { de Soacha. }\end{array}$ & $\begin{array}{l}\text { http://www.elespectador.com/columna89532 } \\
\text {-guerra-limpia-guerra-sucia }\end{array}$ & $22 / 04 / 2009$ \\
\hline $\begin{array}{l}\text { Estímulos } \\
\text { perversos } \\
\text { laxitud moral }\end{array}$ & $\begin{array}{l}\text { http://www.elespectador.com/search/site/los } \\
\% 20 f a l s o s \% 20 \text { positivos\%20en\%20colombia } \\
\text { ?page=4\&f[0]=ds_created\%3A\%5B2008- } \\
\text { 01-01T00\%3A00\%3A00Z\%20TO\%202009- } \\
\text { 01-01T00\%3A00\%3A00Z\%5D }\end{array}$ & $8 / 11 / 2008$ \\
\hline Madres de dolor & $\begin{array}{l}\text { http://www.elespectador.com/noticias/bogot } \\
\text { a/imagen-madres-del-dolor }\end{array}$ & $15 / 11 / 2008$ \\
\hline $\begin{array}{l}\text { El Estado } \\
\text { delincuente }\end{array}$ & $\begin{array}{l}\text { http://www.elespectador.com/opinion/colum } \\
\text { nistasdelimpreso/felipe-zuleta- } \\
\text { lleras/columna89068-el-estado-delincuente }\end{array}$ & $10 / 11 / 2008$ \\
\hline
\end{tabular}




\begin{tabular}{|c|c|c|}
\hline $\begin{array}{l}\text { El escándalo } \\
\text { por las muertes }\end{array}$ & $\begin{array}{l}\text { http://www.elespectador.com/imagen-el- } \\
\text { escandalo-muertes }\end{array}$ & $24 / 11 / 2008$ \\
\hline $\begin{array}{l}\text { Fallas, lunares y } \\
\text { orejas }\end{array}$ & $\begin{array}{l}\text { http://www.elespectador.com/opinion/colum } \\
\text { nistasdelimpreso/hector-abad- } \\
\text { faciolince/columna87342-fallas-lunares- } \\
\text { orejas }\end{array}$ & $1 / 11 / 2008$ \\
\hline $\begin{array}{lr}\text { El } & \text { Estado } \\
\text { contra } & \text { los } \\
\text { jóvenes } & \end{array}$ & $\begin{array}{l}\text { http://www.elespectador.com/columna90399 } \\
\text {-el-estado-contra-los-jovenes }\end{array}$ & $13 / 11 / 2008$ \\
\hline $\begin{array}{l}\text { El caso de los } \\
\text { muchachos de } \\
\text { Soacha }\end{array}$ & $\begin{array}{l}\text { http://www.elespectador.com/imagen-el- } \\
\text { caso-de-los-muchachos-de-soacha }\end{array}$ & $7 / 11 / 2008$ \\
\hline $\begin{array}{l}\text { Los que pecan } \\
\text { por la paga }\end{array}$ & $\begin{array}{l}\text { http://www.elespectador.com/opinion/colum } \\
\text { nistasdelimpreso/ramiro-bejarano- } \\
\text { guzman/columna87349-los-pecan-paga }\end{array}$ & $1 / 11 / 2008$ \\
\hline $\begin{array}{l}\text { Jóvenes en } \\
\text { riesgo }\end{array}$ & $\begin{array}{l}\text { http://www.elespectador.com/columna- } \\
\text { jovenes-riesgo }\end{array}$ & $1 / 10 / 2008$ \\
\hline $\begin{array}{l}\text { Jóvenes en } \\
\text { Riesgo }\end{array}$ & $\begin{array}{l}\text { http://www.elespectador.com/columna- } \\
\text { jovenes-riesgo }\end{array}$ & $7 / 10 / 2008$ \\
\hline $\begin{array}{ll}\begin{array}{l}\text { Son } 19 \\
\text { cadáveres }\end{array} & \\
\text { hallados } & \text { en } \\
\text { Ocaña } & \end{array}$ & $\begin{array}{l}\text { http://www.elespectador.com/fiscalia/video- } \\
\text { son-19-los-cadaveres-hallados-ocana-fiscalia }\end{array}$ & $24 / 09 / 2008$ \\
\hline $\begin{array}{l}\text { Familiares de } \\
\text { desaparecidos } \\
\text { presencian } \\
\text { exhumación de } \\
\text { los cuerpos }\end{array}$ & $\begin{array}{l}\text { http://www.elespectador.com/noticias/judici } \\
\text { al/video-familiares-de-desaparecidos- } \\
\text { presenciaron-exhumacion-de-los-cuerpos }\end{array}$ & $26 / 09 / 2008$ \\
\hline $\begin{array}{lr}\text { Madres } & \text { piden } \\
\text { medidas } & \text { más } \\
\text { drásticas } & \end{array}$ & $\begin{array}{l}\text { http://www.elespectador.com/noticias/judici } \\
\text { al/video-madres-piden-medidas-mas- } \\
\text { drasticas }\end{array}$ & $29 / 10 / 2008$ \\
\hline $\begin{array}{l}\text { Aumenta el } \\
\text { reclutamiento } \\
\text { en el sur y } \\
\text { nororiente de } \\
\text { Bogotá }\end{array}$ & $\begin{array}{l}\text { http://www.elespectador.com/noticias/judici } \\
\text { al/video-aumenta-reclutamiento-forzado-el- } \\
\text { sur-y-nororiente-de-bogota }\end{array}$ & $22 / 9 / 2008$ \\
\hline $\begin{array}{l}\text { ONU pide a } \\
\text { Colombia que } \\
\text { ni cesen las } \\
\text { investigaciones }\end{array}$ & $\begin{array}{l}\text { http://www.elespectador.com/noticias/politic } \\
\text { a/audio-onu-le-pide-al-gobierno-no-cesen- } \\
\text { investigaciones-sobre-desaparecidos }\end{array}$ & 11/20/2008 \\
\hline
\end{tabular}




\begin{tabular}{|c|c|c|}
\hline $\begin{array}{l}\text { sobre } \\
\text { desaparecidos }\end{array}$ & & \\
\hline $\begin{array}{l}\text { Concejal } \\
\text { denuncia } \\
\text { pandillismo en } \\
\text { Bogotá }\end{array}$ & $\begin{array}{l}\text { http://www.elespectador.com/noticias/politic } \\
\text { a/audio-onu-le-pide-al-gobierno-no-cesen- } \\
\text { investigaciones-sobre-desaparecidos }\end{array}$ & $19 / 8 / 2008$ \\
\hline $\begin{array}{l}\text { Falsos positivos } \\
\text { en Colombia }\end{array}$ & $\begin{array}{l}\text { http://www.elespectador.com/search/site/fals } \\
\text { os\%20positivos\%20en\%20Colombia?f }\end{array}$ & $\begin{array}{l}29 / 10 / 2009 \\
(35)\end{array}$ \\
\hline $\begin{array}{l}\text { A santos le } \\
\text { gustaba salir en } \\
\text { los positivos } \\
\text { pero no en los } \\
\text { falsos positivos }\end{array}$ & $\begin{array}{l}\text { http://www.elespectador.com/noticias/cultur } \\
\text { a/audio-santos-le-gustaba-salir-los-positivos- } \\
\text { no-los-falsos-positivos }\end{array}$ & $7 / 10 / 2009$ \\
\hline $\begin{array}{l}\text { Aplazada } \\
\text { audiencia de } \\
\text { falso positivos }\end{array}$ & $\begin{array}{l}\text { http://www.elespectador.com/video- } \\
\text { aplazada-audiencia-de-falsos-positivos }\end{array}$ & $10 / 06 / 2009$ \\
\hline $\begin{array}{ll}\text { Marcha contra } \\
\text { los } & \text { falsos } \\
\text { positivos } & \end{array}$ & $\begin{array}{l}\text { http://www.elespectador.com/noticias/judici } \\
\text { al/video-marcha-contra-los-falsos-positivos- } \\
\text { bogota }\end{array}$ & $6 / 3 / 2009$ \\
\hline $\begin{array}{l}\text { Marcha en } \\
\text { contra de los } \\
\text { falsos positivos. }\end{array}$ & $\begin{array}{l}\text { http://www.elespectador.com/imagen- } \\
\text { marcha-contra-falsos-positivos }\end{array}$ & $5 / 3 / 2009$ \\
\hline $\begin{array}{l}\text { Cerca de } 300 \\
\text { uniformados } \\
\text { tiene orden de } \\
\text { captura por } \\
\text { falsos positivos }\end{array}$ & $\begin{array}{l}\text { http://www.elespectador.com/noticias/judici } \\
\text { al/video-cerca-de-300-uniformados-tienen- } \\
\text { orden-de-captura-falsos-positivos }\end{array}$ & $7 / 8 / 2009$ \\
\hline $\begin{array}{l}\text { De nuevo los } \\
\text { falsos positivos }\end{array}$ & $\begin{array}{l}\text { http://www.elespectador.com/columna10995 } \\
\text { 7-de-nuevo-los-falsos-positivos }\end{array}$ & $20 / 1 / 2009$ \\
\hline $\begin{array}{l}\text { Otras } \\
\text { modalidades de } \\
\text { falsos positivos }\end{array}$ & $\begin{array}{l}\text { http://www.elespectador.com/columna11715 } \\
\text { 3-otras-modalidades-de-falsos-positivos }\end{array}$ & $11 / 2 / 2009$ \\
\hline $\begin{array}{l}\text { Tras las rejas } \\
\text { responsables de } \\
\text { Falsos positivos }\end{array}$ & $\begin{array}{l}\text { http://www.elespectador.com/noticias/judici } \\
\text { al/video-tras-rejas-responsables-de-falsos- } \\
\text { positivos-de-soacha }\end{array}$ & $22 / 5 / 2009$ \\
\hline $\begin{array}{l}\text { Falsos positivos } \\
\text { podrían ir a la } \\
\text { justicia Militar }\end{array}$ & $\begin{array}{l}\underline{\text { http://www.elespectador.com/noticias/judici }} \\
\text { al/audio-falsos-positivos-de-soacha-podrian- } \\
\underline{\text { ir-justicia-militar }}\end{array}$ & $27 / 10 / 2009$ \\
\hline
\end{tabular}




\begin{tabular}{|c|c|c|}
\hline $\begin{array}{l}\text { Impunidad de } \\
\text { los falsos } \\
\text { positivos }\end{array}$ & $\begin{array}{l}\text { http://www.elespectador.com/noticias/politic } \\
\text { a/imagen-impunidad-falsos-positivos }\end{array}$ & $27 / 5 / 2009$ \\
\hline $\begin{array}{l}\text { Falsos positivos } \\
\text { en Soacha }\end{array}$ & $\begin{array}{l}\text { http://www.elespectador.com/falsos- } \\
\text { positivos/imagen-falsos-positivos-soacha }\end{array}$ & $14 / 5 / 2009$ \\
\hline $\begin{array}{l}\text { Petro Asegura } \\
\text { que los falsos } \\
\text { positivos son } \\
\text { delitos contra } \\
\text { los Derechos } \\
\text { Humanos }\end{array}$ & $\begin{array}{l}\text { http://www.elespectador.com/noticias/judici } \\
\text { al/audio-petro-aseguro-falsos-positivos-son- } \\
\text { delitos-contra-los-derechos-humanos }\end{array}$ & 23/9/2009 \\
\hline $\begin{array}{l}\text { Aparecen más } \\
\text { falsos positivos }\end{array}$ & $\begin{array}{l}\text { http://www.elespectador.com/imagen- } \\
\text { aparecen-mas-falso-positivos }\end{array}$ & $7 / 5 / 2009$ \\
\hline $\begin{array}{l}\text { El rostro de los } \\
\text { falsos positivos }\end{array}$ & $\begin{array}{l}\text { http://www.elespectador.com/noticias/judici } \\
\text { al/galeria-el-rostro-de-los-falsos-positivos }\end{array}$ & $26 / 1 / 2009$ \\
\hline $\begin{array}{l}\text { Manifestación } \\
\text { contra los falsos } \\
\text { positivos }\end{array}$ & $\begin{array}{l}\text { http://www.elespectador.com/falsos- } \\
\text { positivos/imagen-manifestacion-contra-los- } \\
\text { falsos-positivos }\end{array}$ & $20 / 4 / 2009$ \\
\hline $\begin{array}{l}\text { Cifras de Falsos } \\
\text { positivos }\end{array}$ & $\begin{array}{l}\text { http://www.elespectador.com/noticias/judici } \\
\text { al/imagen-cifras-de-falsos-positivos }\end{array}$ & $26 / 1 / 2009$ \\
\hline $\begin{array}{l}\text { Falsedades } \\
\text { sobre los falsos } \\
\text { positivos }\end{array}$ & $\begin{array}{l}\text { http://www.elespectador.com/columna12015 } \\
\text { 4-falsedades-sobre-los-falsos-positivos }\end{array}$ & $21 / 09 / 09$ \\
\hline $\begin{array}{lr}716 & \text { denuncias } \\
\text { de } & \text { Falsos } \\
\text { positivos }\end{array}$ & $\begin{array}{l}\text { http://www.elespectador.com/search/site/fals } \\
\text { os\%20positivos\%20en\%20Colombia? }\end{array}$ & $26 / 1 / 2009$ \\
\hline $\begin{array}{l}\text { Nolbeiro } \\
\text { Muñoz }\end{array}$ & $\begin{array}{l}\mathrm{http}: / / \text { www.elespectador.com/noticias/judici } \\
\text { al/imagen-nolbeiro-munoz-victima-de-un- } \\
\text { falso-positivo }\end{array}$ & $26 / 1 / 2009$ \\
\hline $\begin{array}{l}\text { Camina } \\
\text { ta contra los } \\
\text { falsos positivos }\end{array}$ & $\begin{array}{l}\text { http://www.elespectador.com/noticias/politic } \\
\text { a/imagen-caminata-contra-los-falsos- } \\
\text { positivos }\end{array}$ & $6 / 3 / 2009$ \\
\hline $\begin{array}{l}\text { Colombia } \\
\text { denomina la } \\
\text { cultura del falso } \\
\text { desaparecido }\end{array}$ & $\begin{array}{l}\text { http://www.elespectador.com/video- } \\
\text { colombia-domina-cultura-del-falso- } \\
\text { desaparecido } \\
\text { video ya no está }\end{array}$ & $29 / 12 / 2009$ \\
\hline $\begin{array}{l}\text { Por Falsos } \\
\text { positivos }\end{array}$ & $\begin{array}{l}\text { http://www.elespectador.com/opinion/caricat } \\
\text { urista/chocolo/imagen-falsos-positivos }\end{array}$ & $7 / 5 / 2009$ \\
\hline
\end{tabular}




\begin{tabular}{|c|c|c|}
\hline $\begin{array}{l}\text { Uribe habló de } \\
\text { los falsos } \\
\text { positivos }\end{array}$ & $\begin{array}{l}\text { http://www.elespectador.com/imagen-uribe- } \\
\text { hablo-de-los-falsos-positivos }\end{array}$ & $8 / 5 / 2009$ \\
\hline $\begin{array}{l}\text { Aumentan los } \\
\text { falsos positivos }\end{array}$ & $\begin{array}{l}\text { http://www.elespectador.com/imagen- } \\
\text { aumentan-los-falsos-positivos }\end{array}$ & $4 / 3 / 2009$ \\
\hline $\begin{array}{l}5 \text { meses para el } \\
\text { informe } \\
\text { definitivo }\end{array}$ & $\begin{array}{l}\text { http://www.elespectador.com/falsos- } \\
\text { positivos/video-5-meses-el-informe- } \\
\text { definitivo }\end{array}$ & $19 / 6 / 2009$ \\
\hline $\begin{array}{l}\text { El senador } \\
\text { Gustavo Petro } \\
\text { Habló de Falsos } \\
\text { positivos }\end{array}$ & $\begin{array}{l}\text { http://www.elespectador.com/noticias/paz/i } \\
\text { magen-el-senador-gustavo-petro-hablo-de- } \\
\text { falsos-positivos }\end{array}$ & $27 / 1 / 2009$ \\
\hline $\begin{array}{l}\text { Alexander } \\
\text { Quirama }\end{array}$ & $\begin{array}{l}\text { http://www.elespectador.com/imagen- } \\
\text { alexander-quirama-victima-de-un-falso- } \\
\text { positivo }\end{array}$ & $26 / 1 / 2009$ \\
\hline $\begin{array}{lr}\text { Existen fallas } \\
\text { en } \\
\text { desempeño de } \\
\text { los algunos } \\
\text { comandantes }\end{array}$ & $\begin{array}{l}\text { http://www.elespectador.com/noticias/judici } \\
\text { al/audio-existen-fallas-el-desempeno-de-los- } \\
\text { comandantes }\end{array}$ & $23 / 1 / 2009$ \\
\hline $\begin{array}{l}\text { Son asesinatos } \\
\text { cometidos por } \\
\text { funcionarios } \\
\text { públicos }\end{array}$ & $\begin{array}{l}\text { http://www.elespectador.com/noticias/paz/vi } \\
\text { deo-son-asesinatos-cometidos-funcionarios- } \\
\text { publicos }\end{array}$ & $27 / 1 / 2009$ \\
\hline Un país de risa & $\begin{array}{l}\text { http://www.elespectador.com/columna17512 } \\
\text { 3-pais-de-risa }\end{array}$ & $30 / 09 / 2009$ \\
\hline $\begin{array}{l}\text { El derecho en } \\
\text { ruinas }\end{array}$ & $\begin{array}{l}\text { http://www.elespectador.com/columna12645 } \\
\text { 4-el-derecho-ruinas }\end{array}$ & $11 / 03 / 2009$ \\
\hline $\begin{array}{l}6 \text { de Marzo por } \\
\text { las víctimas de } \\
\text { crímenes de } \\
\text { Estado }\end{array}$ & $\begin{array}{l}\text { http://www.elespectador.com/opinion/colum } \\
\text { nistasdelimpreso/ivan-cepeda- } \\
\text { castro/columna124967-6-de-marzo-victimas- } \\
\text { de-los-crimenes-d }\end{array}$ & $7 / 3 / 2009$ \\
\hline $\begin{array}{l}\text { Amenazas a las } \\
\text { madres de } \\
\text { Soacha }\end{array}$ & $\begin{array}{l}\text { http://www.elespectador.com/columna16723 } \\
\text { 7-amenazas-madres-de-soacha }\end{array}$ & $17 / 09 / 2009$ \\
\hline $\begin{array}{ll}\text { El } & \text { Estado } \\
\text { asesino } & \end{array}$ & $\begin{array}{l}\text { http://www.elespectador.com/columna15135 } \\
\text { 0-el-estado-asesino }\end{array}$ & $18 / 07 / 2009$ \\
\hline
\end{tabular}




\begin{tabular}{|c|c|c|}
\hline $\begin{array}{l}\text { El rastro del } \\
\text { horror }\end{array}$ & $\begin{array}{l}\text { http://www.elespectador.com/columna11313 } \\
\text { 7-el-rastro-del-horror }\end{array}$ & $29 / 01 / 2009$ \\
\hline $\begin{array}{lr}\text { La madre de } \\
\text { John } \quad \text { Fredy } \\
\text { Muñoz }\end{array}$ & $\begin{array}{l}\text { http://www.elespectador.com/search/site/fals } \\
\text { os\%20positivos\%20en\%20Colombia?page= }\end{array}$ & $8 / 06 / 2009$ \\
\hline $\begin{array}{l}\text { Exhumación de } \\
\text { jóvenes }\end{array}$ & $\begin{array}{l}\text { http://www.elespectador.com/noticias/judici } \\
\text { al/imagen-exhumacion-de-jovenes }\end{array}$ & $24 / 1 / 2009$ \\
\hline $\begin{array}{l}\text { Intocables } \\
\text { también } \\
\text { equivocan }\end{array}$ & $\begin{array}{l}\text { http://www.elespectador.com/columna17843 } \\
\text { 2-los-intocables-tambien-se-equivocan }\end{array}$ & $20 / 12 / 2009$ \\
\hline $\begin{array}{lr}\text { La rra } \\
\text { encrucijada de } \\
\text { Uribe }\end{array}$ & $\begin{array}{l}\text { http://www.elespectador.com/columna14584 } \\
\text { 6-otra-encrucijada-de-uribe }\end{array}$ & $14 / 6 / 2009$ \\
\hline $\begin{array}{l}\text { Seguridad } \\
\text { antidemocrática }\end{array}$ & $\begin{array}{l}\text { http://www.elespectador.com/alvaro- } \\
\text { uribe/columna141625-seguridad- } \\
\text { antidemocratica }\end{array}$ & $19 / 5 / 2009$ \\
\hline $\begin{array}{l}\text { Las madres de } \\
\text { Soacha }\end{array}$ & $\begin{array}{l}\text { http://www.elespectador.com/falsos- } \\
\text { positivos/imagen-madres-de-soacha }\end{array}$ & $17 / 6 / 2009$ \\
\hline $\begin{array}{l}\text { Fernando } \\
\text { Escobar } \\
\text { Personero }\end{array}$ & $\begin{array}{l}\text { http://www.elespectador.com/falsos- } \\
\text { positivos/imagen-fernando-escobar- } \\
\text { personero }\end{array}$ & $13 / 7 / 2009$ \\
\hline $\begin{array}{l}\text { Familiares de } \\
\text { las victimas }\end{array}$ & $\begin{array}{l}\text { http://www.elespectador.com/imagen- } \\
\text { familiares-de-victimas- }\end{array}$ & $29 / 09 / 2010$ \\
\hline $\begin{array}{l}\text { La } \\
\text { discriminación } \\
\text { de las víctimas } \\
\text { de agentes de } \\
\text { Estado }\end{array}$ & $\begin{array}{l}\text { http://www.elespectador.com/columna14708 } \\
\underline{\text { 0-discriminacion-de-victimas-de-agentes-de- }} \\
\underline{\text { estado }}\end{array}$ & $22 / 06 / 2009$ \\
\hline $\begin{array}{l}\text { Ivan Cepeda } \\
\text { insiste en que } \\
\text { habría más } \\
\text { falsos positivos } \\
\text { en fosas }\end{array}$ & $\begin{array}{l}\text { http://www.elespectador.com/noticias/politic } \\
\text { a/ivan-cepeda-insiste-habria-victimas-de- } \\
\text { falsos-positivos-audio-224343 }\end{array}$ & $14 / 9 / 2010$ \\
\hline
\end{tabular}




\begin{tabular}{|c|c|c|}
\hline $\begin{array}{l}\text { ONU pide a } \\
\text { justicia } \\
\text { ordinaria que } \\
\text { investigan. } \\
\text { "falos } \\
\text { positivos" }\end{array}$ & $\begin{array}{l}\text { http://www.elespectador.com/search/site/fals } \\
\text { os\%20positivos\%20en\%20Colombia?f[0] }\end{array}$ & $9 / 9 / 2010$ \\
\hline $\begin{array}{l}\text { Mockus } \\
\text { advierte } \\
\text { preocupación } \\
\text { por falsos } \\
\text { positivos }\end{array}$ & $\begin{array}{l}\text { http://www.elespectador.com/search/site/fals } \\
\text { os\%20positivos\%20en\%20Colombia? }\end{array}$ & $16 / 5 / 2010$ \\
\hline $\begin{array}{ll}\text { Militares } & \text { libres } \\
\text { por } & \text { falsos } \\
\text { positivos } & \end{array}$ & $\begin{array}{l}\text { http://www.elespectador.com/video- } \\
\text { militares-libres-falsos-positivos }\end{array}$ & $7 / 01 / 2010$ \\
\hline $\begin{array}{lr}\text { Uribe } & \text { reunido } \\
\text { con las } & \text { Madres } \\
\text { de } & \text { Falsos } \\
\text { positivos } & \end{array}$ & $\begin{array}{l}\text { http://www.elespectador.com/noticias/nacion } \\
\text { al/imagen-uribe-reunido-madres-de-falsos- } \\
\text { positivos }\end{array}$ & $12 / 2 / 2010$ \\
\hline $\begin{array}{l}\text { Juan Manuel } \\
\text { Santos: Nos } \\
\text { inventamos los } \\
\text { falsos positivos, } \\
\text { los acabamos }\end{array}$ & $\begin{array}{l}\text { http://www.elespectador.com/noticias/politic } \\
\text { a/juan-manuel-santos-no-nos-inventamos- } \\
\text { los-falsos-positiv-articulo-205486 }\end{array}$ & $29 / 5 / 2010$ \\
\hline $\begin{array}{l}\text { ¿Falsos } \\
\text { positivos? Que } \\
\text { va }\end{array}$ & $\begin{array}{l}\text { http://www.elespectador.com/opinion/colum } \\
\text { nistasdelimpreso/reinaldo- } \\
\text { spitaletta/columna194479-falsos-positivos- } \\
\text { va }\end{array}$ & $22 / 3 / 2010$ \\
\hline $\begin{array}{lr}\text { Por falsos } \\
\text { positivos } \\
\text { condenan } \\
\text { años } 2 \\
\text { excomandante } \\
\text { del Casanare }\end{array}$ & $\begin{array}{l}\text { http://www.elespectador.com/noticias/judici } \\
\text { al/falsos-positivos-condenan-32-anos-de- } \\
\text { carcel-ex-comandan-articulo-237924 }\end{array}$ & $1 / 12 / 2010$ \\
\hline $\begin{array}{l}\text { Petro y Falsos } \\
\text { positivos }\end{array}$ & $\begin{array}{l}\text { http://www.elespectador.com/video-petro-y- } \\
\text { falsos-positivos }\end{array}$ & $10 / 3 / 2010$ \\
\hline $\begin{array}{ll}\text { Marcha } & \text { contra } \\
\text { los } & \text { falsos } \\
\text { positivos } & \end{array}$ & $\begin{array}{l}\text { http://www.elespectador.com/noticias/judici } \\
\text { al/marcha-contra-los-falsos-positivos- } \\
\text { imagen-230479 }\end{array}$ & $19 / 10 / 10$ \\
\hline $\begin{array}{l}\text { Uribe denuncia } \\
\text { infiltración de } \\
\text { narcos para los } \\
\text { falsos positivos }\end{array}$ & $\begin{array}{l}\text { http://www.elespectador.com/search/site/fals } \\
\text { os\%20positivos\%20en\%20Colombia? }\end{array}$ & $29 / 9 / 2010$ \\
\hline
\end{tabular}




\begin{tabular}{|c|c|c|}
\hline $\begin{array}{l}\text { Continua } \\
\text { polémica por } \\
\text { falsos positivos }\end{array}$ & $\begin{array}{l}\text { http://www.elespectador.com/search/site/fals } \\
\text { os\%20positivos\%20en\%20Colombia? }\end{array}$ & $18 / 03 / 2010$ \\
\hline $\begin{array}{l}\text { Divertimiento } \\
\text { político y falsos } \\
\text { positivos }\end{array}$ & $\begin{array}{l}\text { http://www.elespectador.com/columna18196 } \\
\text { 4-divertimento-politico-y-falsos-positivos }\end{array}$ & $13 / 1 / 2010$ \\
\hline $\begin{array}{l}\text { Las caras de los } \\
\text { Falsos positivos }\end{array}$ & $\begin{array}{l}\text { http://www.elespectador.com/columna } 18136 \\
\text { 2-caras-de-los-falsos-positivos }\end{array}$ & $10 / 01 / 2009$ \\
\hline $\begin{array}{ll}\text { Marcha } & \text { contra } \\
\text { los } & \text { falsos } \\
\text { positivos } & \end{array}$ & $\begin{array}{l}\text { http://www.elespectador.com/noticias/judici } \\
\text { al/marcha-contra-los-falsos-positivos- } \\
\text { imagen-203694 }\end{array}$ & $17 / 3 / 2010$ \\
\hline Falsos positivos & $\begin{array}{l}\text { http://www.elespectador.com/opinion/caricat } \\
\text { urista/magola/falsos-positivos-imagen- } \\
202336\end{array}$ & $9 / 5 / 2010$ \\
\hline $\begin{array}{l}\text { ONU presenta } \\
\text { el informe de } \\
\text { Derechos } \\
\text { Humanos }\end{array}$ & $\begin{array}{l}\text { http://www.elespectador.com/audio-onu- } \\
\text { presenta-informe-de-ddhh-colombia }\end{array}$ & $5 / 3 / 2009$ \\
\hline $\begin{array}{lr}\text { No hay cifras } \\
\text { exactas } & \text { de } \\
\text { violaciones } & \text { de } \\
\text { DD HH en } & \text { Colombia } \\
\text { Cola }\end{array}$ & $\begin{array}{l}\mathrm{http}: / / \text { www.elespectador.com/noticias/judici } \\
\text { al/video-no-hay-cifras-exactas-de- } \\
\text { violaciones-de-derechos-humanos-colombia }\end{array}$ & $19 / 1 / 2009$ \\
\hline $\begin{array}{lr}\text { La ley } & \text { de } \\
\text { víctimas o el } \\
\text { mensaje } \\
\text { enderezado }\end{array}$ & $\begin{array}{l}\text { http://www.elespectador.com/columna14652 } \\
\text { 1-ley-de-victimas-o-el-mensaje-enderezado }\end{array}$ & $18 / 6 / 2009$ \\
\hline
\end{tabular}

Tabla 2: Periódico El Tiempo

\begin{tabular}{|l|l|l|}
\hline Titulo & Link & Fecha \\
\hline $\begin{array}{l}\text { Delgado de la ONU destaca lucha } \\
\text { contra falsos positivos }\end{array}$ & $\begin{array}{l}\text { http://www.eltiempo.com/archivo/docu } \\
\text { mento/MAM-2788077 }\end{array}$ & $9 / 1 / 2008$ \\
\hline $\begin{array}{l}\text { Relator de la ONU sobre ejecuciones } \\
\text { extrajudiciales, } \\
\text { Escucha a víctimas en el congreso. }\end{array}$ & $\underline{\underline{\text { http://www.eltiempo.com/archivo/docu }}}$ & $8 / 6 / 2009$ \\
\hline
\end{tabular}




\begin{tabular}{|c|c|c|}
\hline $\begin{array}{l}\text { Debe reconocerse la magnitud del lio de } \\
\text { los falsos positivos. }\end{array}$ & $\begin{array}{l}\text { http://www.eltiempo.com/archivo/docu } \\
\text { mento/MAM-3491749 }\end{array}$ & $19 / 6 / 2009$ \\
\hline $\begin{array}{l}\text { Relator de ONU dice que no centrará } \\
\text { sólo en las ejecuciones extrajudiciales }\end{array}$ & $\begin{array}{l}\text { http://www.eltiempo.com/archivo/docu } \\
\text { mento/CMS-5397647 }\end{array}$ & $9 / 6 / 2009$ \\
\hline $\begin{array}{l}\text { ONU Contra la impunidad en los falsos } \\
\text { positivos }\end{array}$ & $\begin{array}{l}\text { http://www.eltiempo.com/archivo/docu } \\
\text { mento/MAM-3986555 }\end{array}$ & $26 / 05 / 2010$ \\
\hline $\begin{array}{l}\text { ONU documenta la existencia de falsos } \\
\text { positivos }\end{array}$ & $\begin{array}{l}\text { http://www.eltiempo.com/archivo/docu } \\
\text { mento/CMS-7585168 }\end{array}$ & $13 / 04 / 2010$ \\
\hline $\begin{array}{l}\text { Crear unidad especial de investigación } \\
\text { de los falsos positivos }\end{array}$ & $\begin{array}{l}\text { http://www.eltiempo.com/archivo/docu } \\
\text { mento/CMS-12490962 }\end{array}$ & $9 / 01 / 2010$ \\
\hline $\begin{array}{l}\text { Así se tejió la trampa de los falsos } \\
\text { positivos }\end{array}$ & $\begin{array}{l}\text { http://www.eltiempo.com/archivo/docu } \\
\text { mento/MAM-3456789 }\end{array}$ & $24 / 3 / 2009$ \\
\hline $\begin{array}{l}\text { Así se asesinaron a dos víctimas de } \\
\text { falsos positivos }\end{array}$ & $\begin{array}{l}\text { http://www.eltiempo.com/archivo/docu } \\
\text { mento/MAM-3406872 }\end{array}$ & $20 / 4 / 2009$ \\
\hline $\begin{array}{l}\text { Falsos positivos han provocado orden } \\
\text { contra } 17 \text { militares }\end{array}$ & $\begin{array}{l}\text { http://www.eltiempo.com/archivo/docu } \\
\text { mento/CMS-5108768 }\end{array}$ & $30 / 4 / 2009$ \\
\hline $\begin{array}{l}\text { El drama de las familias de Soacha aún } \\
\text { no termina }\end{array}$ & $\begin{array}{l}\text { http://www.eltiempo.com/archivo/docu } \\
\text { mento/MAM-3674087 }\end{array}$ & $18 / 10 / 2009$ \\
\hline $\begin{array}{l}\text { Madres de victimas de falsos positivos } \\
\text { piden cita con el presidente Santos }\end{array}$ & $\begin{array}{l}\text { http://www.eltiempo.com/archivo/docu } \\
\text { mento/CMS-7894699 }\end{array}$ & \\
\hline $\begin{array}{l}\text { Madres reciben } 5000 \text { rosas y } 20000 \\
\text { mensajes de apoyo durante la cumbre } \\
\text { en Madrid }\end{array}$ & $\begin{array}{l}\text { http://www.eltiempo.com/archivo/docu } \\
\text { mento/CMS-7714922 }\end{array}$ & $18 / 5 / 2010$ \\
\hline $\begin{array}{l}\text { Las fosas comunes convirtieron los } \\
\text { sicarios las montañas de tres barrios de } \\
\text { cazuca. }\end{array}$ & $\begin{array}{l}\text { http://www.eltiempo.com/archivo/docu } \\
\text { mento/CMS-3935621 }\end{array}$ & $27 / 1 / 2008$ \\
\hline También en Cazuca hay fosas & $\begin{array}{l}\text { http://www.eltiempo.com/archivo/docu } \\
\text { mento/MAM-2807284 }\end{array}$ & $28 / 1 / 2008$ \\
\hline Soacha marchó por sus jóvenes & $\begin{array}{l}\text { ww.eltiempo.com/archivo/documento/ } \\
\text { MAM-3164382 }\end{array}$ & $30 / 10 / 2008$ \\
\hline Los dinosaurios si existen & $\begin{array}{l}\text { http://www.eltiempo.com/archivo/docu } \\
\text { mento/CMS-4639714 }\end{array}$ & $30 / 10 / 2008$ \\
\hline $\begin{array}{l}\text { Jóvenes y familiares de desaparecidos } \\
\text { se encuentran en la plaza }\end{array}$ & $\begin{array}{l}\text { http://www.eltiempo.com/archivo/docu } \\
\text { mento/CMS-4632410 }\end{array}$ & $30 / 10 / 2008$ \\
\hline $\begin{array}{l}\text { Tres coroneles a dar respuesta sobre el } \\
\text { caso de Soacha }\end{array}$ & $\begin{array}{l}\text { http://www.eltiempo.com/archivo/docu } \\
\text { mento/MAM-3156127 }\end{array}$ & $25 / 10 / 2008$ \\
\hline
\end{tabular}




\begin{tabular}{|c|c|c|}
\hline $\begin{array}{l}\text { Máxima condena para los militares en } \\
\text { la responsabilidad de la desaparición de } \\
11 \text { jóvenes }\end{array}$ & $\begin{array}{l}\text { http://www.eltiempo.com/archivo/docu } \\
\text { mento/CMS-4623984 }\end{array}$ & $24 / 10 / 2008$ \\
\hline Uribe pide máximas condenas & $\begin{array}{l}\text { http://www.eltiempo.com/archivo/docu } \\
\text { mento/MAM-3157032 }\end{array}$ & $24 / 10 / 2008$ \\
\hline $\begin{array}{l}\text { Fiscalía investiga } 780 \text { casos de } \\
\text { presuntas ejecuciones extrajudiciales }\end{array}$ & $\begin{array}{l}\text { http://www.eltiempo.com/archivo/docu } \\
\text { mento/CMS-4632140 }\end{array}$ & $29 / 10 / 2008$ \\
\hline $\begin{array}{l}\text { La impunidad acarrea los casos de } \\
\text { falsos positivos }\end{array}$ & $\begin{array}{l}\text { http://www.eltiempo.com/archivo/docu } \\
\text { mento/CMS-4685078 }\end{array}$ & $24 / 11 / 2008$ \\
\hline $\begin{array}{l}\text { Senado espera que el gobierno asuma } \\
\text { responsabilidad política en casos de } \\
\text { falsos positivos }\end{array}$ & $\begin{array}{l}\text { http://www.eltiempo.com/archivo/docu } \\
\text { mento/CMS- } \\
\text { 4642008http://www.eltiempo. }\end{array}$ & $3 / 11 / 2008$ \\
\hline $\begin{array}{l}\text { ¿Usted si nos puede explicar que pasó } \\
\text { con el ejército? }\end{array}$ & $\begin{array}{l}\text { http://www.eltiempo.com/archivo/docu } \\
\text { mento/CMS-4642430 }\end{array}$ & $3 / 11 / 2008$ \\
\hline $\begin{array}{l}\text { Por falsos positivos de Soacha son } \\
\text { procesados } 44 \text { militares }\end{array}$ & $\begin{array}{l}\text { http://www.eltiempo.com/archivo/docu } \\
\text { mento/CMS-6235890 }\end{array}$ & $29 / 9 / 2008$ \\
\hline A propósito de inocentes & $\begin{array}{l}\text { http://www.eltiempo.com/archivo/docu } \\
\text { mento/MAM-3253384 }\end{array}$ & $28 / 11 / 2008$ \\
\hline Alarma por niñas pandilleras & $\begin{array}{l}\text { http://www.eltiempo.com/archivo/docu } \\
\text { mento/MAM-3591021 }\end{array}$ & $28 / 8 / 2 \mathrm{O} 09$ \\
\hline $\begin{array}{l}\text { Concentración para recibir respuesta } \\
\text { por falso positivo }\end{array}$ & $\begin{array}{l}\text { http://www.eltiempo.com/archivo/docu } \\
\text { mento/CMS-5923472 }\end{array}$ & $23 / 08 / 2009$ \\
\hline $\begin{array}{l}\text { Niñas de Soacha están cogiendo las } \\
\text { rejas de la delincuencia }\end{array}$ & $\begin{array}{l}\text { ww.eltiempo.com/archivo/documento/ } \\
\text { MAM-3644303 }\end{array}$ & $27 / 9 / 2009$ \\
\hline $\begin{array}{l}\text { El drama de los familiares de Soacha } \\
\text { aún no termina }\end{array}$ & $\begin{array}{l}\text { http://www.eltiempo.com/archivo/docu } \\
\text { mento/CMS-6378707 } \\
\text { Ver el perfil de las víctimas }\end{array}$ & $17 / 09 / 2009$ \\
\hline ¿Dar la vida por nosotros? & $\begin{array}{l}\text { http://www.eltiempo.com/archivo/docu } \\
\text { mento/CMS-6699895 }\end{array}$ & $29 / 09 / 2009$ \\
\hline $\begin{array}{l}\text { ONU preocupados por la libertad de las } \\
\text { víctimas }\end{array}$ & $\begin{array}{l}\text { http://www.eltiempo.com/archivo/docu } \\
\text { mento/MAM-3787239 }\end{array}$ & 09/01/2010 \\
\hline Son hechos que envilecen al ejercito & $\begin{array}{l}\text { http://www.eltiempo.com/archivo/docu } \\
\text { mento/MAM-3801283 }\end{array}$ & $20 / 1 / 2010$ \\
\hline $\begin{array}{l}\text { Demora en juicio permitió la libertad de } \\
17 \text { militares de falsos positivos }\end{array}$ & $\begin{array}{l}\text { http://www.eltiempo.com/archivo/docu } \\
\text { mento/MAM-3786427 }\end{array}$ & $8 / 1 / 2008$ \\
\hline $\begin{array}{l}\text { Declaraciones del presidente Uribe } \\
\text { durante su reunión con madres de } \\
\text { víctimas de falsos positivos }\end{array}$ & $\begin{array}{l}\text { http://www.eltiempo.com/archivo/docu } \\
\text { mento/CMS-7191868 }\end{array}$ & $12 / 2 / 2010$ \\
\hline
\end{tabular}




\begin{tabular}{|c|c|c|}
\hline Los falsos positivos. La película & $\begin{array}{l}\text { http://www.eltiempo.com/archivo/docu } \\
\text { mento/MAM-3849355 }\end{array}$ & $21 / 2 / 2010$ \\
\hline $\begin{array}{l}51 \text { militares libres en caso de falsos } \\
\text { positivos }\end{array}$ & $\begin{array}{l}\text { http://www.eltiempo.com/archivo/docu } \\
\text { mento/CMS-7444248 }\end{array}$ & $19 / 3 / 2010$ \\
\hline $\begin{array}{l}\text { Madre de falso positivo expone caso en } \\
\text { Estados Unidos }\end{array}$ & $\begin{array}{l}\text { http://www.eltiempo.com/archivo/docu } \\
\text { mento/CMS-8039200 }\end{array}$ & $1 / 10 / 2010$ \\
\hline Madres de falsos positivos de gira & $\begin{array}{l}\text { http://www.eltiempo.com/archivo/docu } \\
\text { mento/CMS-8039200 }\end{array}$ & $3 / 11 / 2010$ \\
\hline $\begin{array}{l}\text { Tropiezos en los procesos de falsos } \\
\text { positivos }\end{array}$ & $\begin{array}{l}\text { http://www.eltiempo.com/archivo/docu } \\
\text { mento/MAM-2390538 }\end{array}$ & $16 / 2 / 2007$ \\
\hline $\begin{array}{l}\text { Violación de Derechos por parte del } \\
\text { ejército en Colombia, dice informe de } \\
\text { la ONU }\end{array}$ & $\begin{array}{l}\text { http://www.eltiempo.com/archivo/docu } \\
\text { mento/CMS-347849 }\end{array}$ & $15 / 03 / 2007$ \\
\hline $\begin{array}{l}\text { Quejas sobre violación de derechos } \\
\text { humanos por la fuerza pública } \\
\text { aumentan en Colombia }\end{array}$ & $\begin{array}{l}\text { http://www.eltiempo.com/archivo/docu } \\
\text { mento/CMS-3478050 }\end{array}$ & $15 / 03 / 2007$ \\
\hline La Guerra, la justicia y la tierra & $\begin{array}{l}\text { http://www.eltiempo.com/archivo/docu } \\
\text { mento/CMS-4468239 }\end{array}$ & $26 / 08 / 2008$ \\
\hline $\begin{array}{l}30 \text { menores cometen un delito en } \\
\text { Bogotá }\end{array}$ & $\begin{array}{l}\text { ww.eltiempo.com/archivo/documento/ } \\
\text { CMS-4466971 }\end{array}$ & $25 / 08 / 2008$ \\
\hline ONU pedirá doble reparación & $\begin{array}{l}\text { ww.eltiempo.com/archivo/documento/ } \\
\text { MAM-3118253 }\end{array}$ & $1 / 10 / 2008$ \\
\hline $\begin{array}{l}\text { Serían cuatro los reclutadores de } \\
\text { Soacha y ofrecían hasta " } 10.000 .000 \\
\text { por vuelta }\end{array}$ & $\begin{array}{l}\text { ww.eltiempo.com/archivo/documento/ } \\
\text { CMS-4570577 }\end{array}$ & $27 / 9 / 2008$ \\
\hline $\begin{array}{l}\text { Advertencia de mini defensa por falsos } \\
\text { positivos }\end{array}$ & $\frac{\text { http://www.eltiempo.com/archivo/docu }}{\underline{\text { mento/MAM-3112250 }}}$ & $27 / 9 / 2008$ \\
\hline $\begin{array}{l}\text { Minidefensa insiste en dudas sobre } \\
\text { desaparecidos de Soacha. }\end{array}$ & $\begin{array}{c}\text { http://www.eltiempo.com/archivo/docu } \\
\text { mento/MAM-3112229 }\end{array}$ & $27 / 9 / 2009$ \\
\hline $\begin{array}{l}\text { Otras } 30 \text { denuncias de jóvenes en } \\
\text { Bogotá son investigadas por las } \\
\text { autoridades } 1\end{array}$ & $\begin{array}{c}\text { http://www.eltiempo.com/archivo/docu } \\
\text { mento/CMS-4633197 }\end{array}$ & $29 / 10 / 2008$ \\
\hline Muertos para legalizar & $\begin{array}{l}\text { ww.eltiempo.com/archivo/documento/ } \\
\text { CMS-4621201 }\end{array}$ & $23 / 10 / 2008$ \\
\hline & $\begin{array}{c}\text { http://www.eltiempo.com/archivo/docu } \\
\text { mento/MAM-3164444 }\end{array}$ & $30 / 10 / 2008$ \\
\hline
\end{tabular}




\begin{tabular}{|c|c|c|}
\hline Purga histórica & & \\
\hline $\begin{array}{l}\text { Soacha y Medellín piden } \\
\text { Militares invol para } \\
\text { positivos. }\end{array}$ & $\begin{array}{l}\text { ww.eltiempo.com/archivo/documento/ } \\
\text { CMS- } 4633200\end{array}$ & $29 / 10 / 2008$ \\
\hline $\begin{array}{l}535 \text { Personas fueron ejecutadas } \\
\text { extrajudicialmente de enero de } 2007 \text { a } \\
\text { junio de } 2008\end{array}$ & $\begin{array}{c}\text { http://www.eltiempo.com/archivo/docu } \\
\text { mento/CMS-4632458 }\end{array}$ & $29 / 10 / 2008$ \\
\hline $\begin{array}{l}\text { Proteger los derechos humanos es } \\
\text { obligación moral del ejército dice } \\
\text { comandante de las fuerzas militares. }\end{array}$ & $\begin{array}{c}\text { http://www.eltiempo.com/archivo/docu } \\
\text { mento/CMS-4605701 }\end{array}$ & $16 / 972008$ \\
\hline $\begin{array}{l}\text { Serian } 100 \quad \text { los } \quad \text { reportados como } \\
\text { muertos en combate en } 9 \text { regiones del } \\
\text { país. }\end{array}$ & $\begin{array}{c}\text { http://www.eltiempo.com/archivo/docu } \\
\text { mento/CMS-4601931 }\end{array}$ & $14 / 10 / 2008$ \\
\hline Mi hijo no sabía ni casar pájaros & $\begin{array}{c}\text { http://www.eltiempo.com/archivo/docu } \\
\text { mento/MAM-3127782 }\end{array}$ & $7 / 10 / 2008$ \\
\hline $\begin{array}{l}\text { Coroneles a dar explicaciones sobre el } \\
\text { caso de Soacha }\end{array}$ & $\begin{array}{l}\text { ww.eltiempo.com/archivo/documento/ } \\
\text { MAM-3156127 }\end{array}$ & $25 / 10 / 2008-$ \\
\hline Foro del lector. & $\begin{array}{c}\text { http://www.eltiempo.com/archivo/docu } \\
\text { mento/MAM-3164452 }\end{array}$ & $30 / 10 / 2008$ \\
\hline $\begin{array}{l}\text { Esta es la decisión más dolorosa que } \\
\text { hemos tomado. }\end{array}$ & $\begin{array}{c}\text { http://www.eltiempo.com/archivo/docu } \\
\text { mento/CMS-4639802 }\end{array}$ & $1 / 11 / 2008$ \\
\hline $\begin{array}{l}\text { Máxima condena para militares con } \\
\text { responsabilidad en la desaparición de } \\
11 \text { jóvenes en Soacha. }\end{array}$ & $\begin{array}{c}\text { http://www.eltiempo.com/archivo/docu } \\
\text { mento/CMS-4623984 }\end{array}$ & $24 / 10 / 2008$ \\
\hline $\begin{array}{l}\text { Uribe avala la versión del fiscal del caso } \\
\text { de Soacha. }\end{array}$ & $\frac{\text { http://www.eltiempo.com/archivo/docu }}{\text { mento/MAM-3131295 }}$ & $9 / 10 / 2008$ \\
\hline $\begin{array}{l}\text { Denuncian amenazas de muerte en } \\
\text { Ciudad Bolívar }\end{array}$ & $\begin{array}{c}\frac{\text { http://www.eltiempo.com/archivo/docu }}{\text { mento/MAM-3164637 }} \\
\text { nal }\end{array}$ & $30 / 10 / 2008$ \\
\hline $\begin{array}{l}\text { Así asesinaron a dos víctimas de falsos } \\
\text { positivos }\end{array}$ & $\frac{\text { http://www.eltiempo.com/archivo/docu }}{\text { mento/MAM-3406872 }}$ & $20 / 4 / 2009$ \\
\hline $\begin{array}{l}\text { Ciudadanos por la vida lanza campaña } \\
\text { no más falsos positivos }\end{array}$ & $\frac{\underline{\text { http://www.eltiempo.com/archivo/docu }}}{\text { mento/CMS-4746491 }}$ & $8 / 1 / 2009$ \\
\hline
\end{tabular}




\begin{tabular}{|c|c|c|}
\hline Falsos positivos & $\frac{\text { http://www.eltiempo.com/archivo/docu }}{\underline{\text { mento/MAM-3308839 }}}$ & $9 / 2 / 2009$ \\
\hline El falso positivo de Fernando Londoño & $\frac{\text { http://www.eltiempo.com/archivo/docu }}{\underline{\text { mento/MAM-3319632 }}}$ & $16 / 2 / 2009$ \\
\hline Sin imaginación & $\frac{\text { http://www.eltiempo.com/archivo/docu }}{\underline{\text { mento/MAM-3357492 }}}$ & $13 / 3 / 2009$ \\
\hline Asesinato de joven de 15 años & $\frac{\text { http://www.eltiempo.com/archivo/docu }}{\underline{\text { mento/MAM-3353275 }}}$ & $10 / 3 / 2009$ \\
\hline $\begin{array}{l}\text { No hay pruebas determinantes en } \\
\text { presuntos falsos positivos }\end{array}$ & $\frac{\text { http://www.eltiempo.com/archivo/docu }}{\underline{\text { mento/CMS-4881018 }}}$ & $16 / 3 / 2009$ \\
\hline La seguridad integral & $\frac{\text { http://www.eltiempo.com/archivo/docu }}{\underline{\text { mento/MAM-3375108 }}}$ & $26 / 03 / 2009$ \\
\hline Gobierno responde a estudio ONU & $\frac{\text { http://www.eltiempo.com/archivo/docu }}{\text { mento/MAM-3349782 }}$ & $7 / 3 / 2009$ \\
\hline $\begin{array}{l}\text { Con marcha de luz conmemoraron } \\
\text { memoria de } 11 \text { jóvenes }\end{array}$ & $\frac{\text { http://www.eltiempo.com/archivo/docu }}{\underline{\text { mento/CMS-6296388 }}}$ & $7 / 10 / 2009$ \\
\hline $\begin{array}{l}\text { Un año de incertidumbre por la muerte } \\
\text { de Camilo }\end{array}$ & $\frac{\text { http://www.eltiempo.com/archivo/docu }}{\underline{\text { mento/MAM-3406873 }}}$ & $20 / 4 / 2009$ \\
\hline $\begin{array}{l}\text { Soacha revivió el drama de los falsos } \\
\text { positivos }\end{array}$ & $\frac{\text { http://www.eltiempo.com/archivo/docu }}{\underline{\text { mento/MAM-3413598 }}}$ & $24 / 4 / 2009$ \\
\hline $\begin{array}{l}\text { Felicitaciones llegaron antes de las } \\
\text { bajas }\end{array}$ & $\frac{\text { http://www.eltiempo.com/archivo/docu }}{\underline{\text { mento/MAM-3455081 }}}$ & $22 / 5 / 2009$ \\
\hline Los 27 del 29 & $\frac{\text { http://www.eltiempo.com/archivo/docu }}{\underline{\text { mento/MAM-3490068 }}}$ & $18 / 6 / 2009$ \\
\hline Al extirpar este cáncer & $\frac{\text { http://www.eltiempo.com/archivo/docu }}{\underline{\text { mento/MAM-3448927 }}}$ & $11 / 5 / 2009$ \\
\hline $\begin{array}{l}\text { Los correctivos que se tomaron han } \\
\text { sido efectivo }\end{array}$ & $\begin{array}{c}\text { http://www.eltiempo.com/archivo/docu } \\
\text { mento/MAM-3674240 }\end{array}$ & $18 / 10 / 2009$ \\
\hline Un año de falsos positivos & $\frac{\text { http://www.eltiempo.com/archivo/docu }}{\text { mento/MAM-3674325 }}$ & $18 / 10 / 2009$ \\
\hline Práctica sistemática & $\frac{\text { http://www.eltiempo.com/archivo/docu }}{\underline{\text { mento/MAM-3491877 }}}$ & $19 / 6 / 2009$ \\
\hline $\begin{array}{l}\text { Denuncian aumento de amenazas } \\
\text { contra familias de Soacha }\end{array}$ & $\begin{array}{c}\text { http://www.eltiempo.com/archivo/docu } \\
\text { mento/CMS-5408129 }\end{array}$ & $10 / 6 / 2009$ \\
\hline
\end{tabular}


Tabla 3. Revista Semana.

\begin{tabular}{|c|c|c|}
\hline TITULO & Link. & fecha \\
\hline Falsos positivos al cine. & $\begin{array}{l}\text { http://www.semana.com/gente/articulo/los-falsos- } \\
\text { positivos-cine/118208-3 }\end{array}$ & $21 / 06 / 2010$ \\
\hline $\begin{array}{l}\text { Cortometraje sobre falsos } \\
\text { positivos de Soacha aspira a } \\
\text { premio en Alemania. }\end{array}$ & $\begin{array}{l}\text { http://www.semana.com/vida- } \\
\text { moderna/articulo/cortometraje-sobre-falsos- } \\
\text { positivos-soacha-aspira-premio-alemania/1254 }\end{array}$ & $31 / 12 / 2010$ \\
\hline $\begin{array}{l}\text { Condenan a ocho militares por } \\
\text { falsos positivos. }\end{array}$ & $\begin{array}{l}\text { http://www.semana.com/nacion/articulo/condenan } \\
\text {-ocho-militares-falsos-positivos/125316-3 }\end{array}$ & $1 / 12 / 2010$ \\
\hline $\begin{array}{l}\text { Los jóvenes más solos que } \\
\text { nunca }\end{array}$ & $\begin{array}{l}\text { http://www.semana.com/vida- } \\
\text { moderna/articulo/los-jovenes-mas-solos- } \\
\text { nunca/117096-3 }\end{array}$ & $25 / 5 / 2010$ \\
\hline $\begin{array}{l}\text { Ciudad Bolívar alerta por } \\
\text { organización paramilitar }\end{array}$ & $\begin{array}{l}\text { ww.semana.com/Buscador?query=Violencia\%20j } \\
\text { uvenil\%20en\%20Ciudad\%20Bolívar\%20y\%20Ca } \\
\text { zuca\&post=semana\&limit }\end{array}$ & $14 / 08 / 2007$ \\
\hline De la calle al Parque & $\begin{array}{l}\text { http://www.semana.com/Buscador?query=Violen } \\
\text { cia. }\end{array}$ & $11 / 09 / 2009$ \\
\hline Cazuca de Luto. & $\begin{array}{l}\text { http://www.semana.com/nacion/articulo/cazuca- } \\
\underline{\text { luto/73064-3 }}\end{array}$ & $12 / 06 / 2007$ \\
\hline El sur también existe. & $\begin{array}{l}\text { http://www.semana.com/on-line/articulo/el-sur- } \\
\text { tambien-existe/77818-3 }\end{array}$ & $12 / 03 / 2006$ \\
\hline Falsos positivos mortales & $\begin{array}{l}\text { http://www.semana.com/Buscador?query=\%20Ci } \\
\text { udad\%20Bol\%C3\%ADvar\%20y\%20Cazuca\&pos } \\
\underline{\mathrm{t}=\text { semana\&limit=10\&offset=10 }}\end{array}$ & $27 / 9 / 2008$ \\
\hline Hechos aislados & $\begin{array}{l}\text { http://www.semana.com/opinion/articulo/hechos- } \\
\text { aislados/79843-3 }\end{array}$ & $8 / 7 / 2006$ \\
\hline Las dos caras de Bogotá & $\begin{array}{l}\text { http://www.semana.com/opinion/articulo/las-dos- } \\
\text { caras-bogota/60887-3 }\end{array}$ & $29 / 09 / 2003$ \\
\hline $\begin{array}{l}\text { Bajó la victimización y mejoró } \\
\text { la percepción de Seguridad. }\end{array}$ & $\begin{array}{l}\text { http://www.semana.com/nacion/seguridad/articul } \\
\text { o/bajo-victimizacion-mejoro-percepcion- } \\
\text { seguridad/96102-3 }\end{array}$ & $10 / 10 / 2008$ \\
\hline $\begin{array}{l}\text { Los falsos positivos son una } \\
\text { práctica vieja del ejército }\end{array}$ & $\begin{array}{l}\text { ww.semana.com/opinion/articulo/los-falsos- } \\
\text { positivos-practica-vieja-ejercito/98864-3 }\end{array}$ & $17 / 172009$ \\
\hline
\end{tabular}




\begin{tabular}{|c|c|c|}
\hline Derrumbe Moral & $\begin{array}{l}\text { semana.com/opinion/articulo/derrumbe- } \\
\text { moral/103302-3 }\end{array}$ & $20 / 05 / 2009$ \\
\hline $\begin{array}{l}\text { Castigo para responsables de } \\
\text { falsos positivos }\end{array}$ & 1. ww.semana.com/Busador? & $29 / 09 / 2008$ \\
\hline $\begin{array}{l}\text { Primer cara a cara entre } \\
\text { Mockus y Santos }\end{array}$ & $\begin{array}{l}\text { http://www.semana.com/politica/articulo/primer- } \\
\text { cara-cara-entre-mockus-santos/117539-3 }\end{array}$ & $3 / 6 / 2010$ \\
\hline $\begin{array}{l}\text { Responsables de Falsos } \\
\text { positivos libres, Por decisión } \\
\text { desenfocadas de jueces. }\end{array}$ & $\begin{array}{l}\text { http://www.semana.com/nacion/articulo/responsa } \\
\text { bles-falsos-positivos-libres-decisiones- } \\
\text { desenfocadas-jueces-fiscal-general/1 }\end{array}$ & $19 / 8 / 2010$ \\
\hline $\begin{array}{l}\text { Capturados } 12 \text { militares } \\
\text { acusados de ejecuciones } \\
\text { extrajudiciales }\end{array}$ & $\begin{array}{l}\text { ww.semana.com/nacion/articulo/capturados-doce- } \\
\text { militares-colombianos-acusados-ejecuciones- } \\
\text { extrajudiciales/120164-3 }\end{array}$ & $6 / 08 / 10$ \\
\hline Relator ONU en Colombia & $\begin{array}{l}\text { http://www.semana.com/enfoque/articulo/relator- } \\
\text { onu-colombia/104144-3 }\end{array}$ & $13 / 06 / 2009$ \\
\hline No tenemos por qué callarnos. & $\begin{array}{c}\text { http://www.semana.com/nacion/articulo/no- } \\
\text { tenemos-que-callarnos/119304-3 }\end{array}$ & $14 / 07 / 2010$ \\
\hline $\begin{array}{l}\text { Que Estados Unidos no ayude } \\
\text { más a la cuarta división del } \\
\text { ejército. Piden familiares de } \\
\text { falsos positivos. }\end{array}$ & $\begin{array}{l}\text { w.semana.com/nacion/conflicto- } \\
\text { armado/articulo/que-eeuu-no-ayude-mas-cuarta- } \\
\text { division-del-ejercito-piden-familiares-falsos- } \\
\text { positivos/97279-3 }\end{array}$ & $13 / 11 / 2008$ \\
\hline $\begin{array}{l}\text { Mockus no ve responsabilidad } \\
\text { penal pero si moral en " falsos } \\
\text { positivo" }\end{array}$ & $\begin{array}{l}\text { http://www.semana.com/elecciones- } \\
\text { 2010/actividad-politica/articulo/mockus-no- } \\
\text { responsabilidad-penal-pero-si- }\end{array}$ & $25 / 5 / 10$ \\
\hline La manera extraña & $\begin{array}{l}\text { http://www.semana.com/cartas/articulo/la- } \\
\text { manera-extrana/95929 }\end{array}$ & $4 / 10 / 2008(24)$ \\
\hline $\begin{array}{l}\text { Los casos olvidados de los } \\
\text { falsos positivos }\end{array}$ & $\begin{array}{l}\text { www.semana.com/nacion/articulo/los-casos- } \\
\text { olvidados-falsos-positivos/119416-3 }\end{array}$ & $17 / 7 / 2010$ \\
\hline $\begin{array}{l}\text { Uribe denuncia alianza entre } \\
\text { miembros de brigada y el } \\
\text { narcotráfico para cometer } \\
\text { ejecuciones extrajudiciales. }\end{array}$ & $\begin{array}{l}\text { http://www.semana.com/nacion/articulo/uribe- } \\
\text { denuncia-alianza-entre-miembros-brigada- } \\
\text { narcotrafico-para-cometer-ejecuciones- }\end{array}$ & $25 / 03 / 2010$ \\
\hline $\begin{array}{l}\text { Capturados } 12 \text { militares doce } \\
\text { militares colombianos acusados } \\
\text { de falsos positivos. }\end{array}$ & $\begin{array}{l}\text { http://www.semana.com/nacion/articulo/capturad } \\
\text { os-doce-militares-colombianos-acusados- } \\
\text { ejecuciones-extrajudiciales/120164-3 }\end{array}$ & $08 / 06 / 2010$ \\
\hline
\end{tabular}




\begin{tabular}{|c|c|c|}
\hline $\begin{array}{l}\text { Próximo viernes marcha por } \\
\text { crímenes de Estado }\end{array}$ & $\begin{array}{l}\text { http://www.semana.com/nacion/justicia/articulo/p } \\
\text { roximo-viernes-marcha-victimas-crimenes- } \\
\text { estado/100698-3 }\end{array}$ & $3 / 3 / 2009$ \\
\hline $\begin{array}{l}\text { Relator de la ONU encontró } \\
\text { patrón de ejecuciones } \\
\text { extrajudiciales }\end{array}$ & $\begin{array}{l}\text { http://www.semana.com/nacion/articulo/relator- } \\
\text { onu-encontro-patron-ejecuciones-extrajudiciales- } \\
\text { colombia/117194-3 }\end{array}$ & $28 / 05 / 10$ \\
\hline La tropa tiene la moral baja & $\begin{array}{l}\text { http://www.semana.com/nacion/articulo/la-tropa- } \\
\text { tiene-moral-baja/116949-3 }\end{array}$ & $23 / 05 / 2010$ \\
\hline $\begin{array}{l}\text { Las cuentas de los falsos } \\
\text { positivos. }\end{array}$ & $\begin{array}{l}\text { http://www.semana.com/Buscador?query=falsos } \\
\% 20 \text { positivos\&post=semana\&limit=10\&offset=2 } \\
\text { 70\&from=2006\%2F01\%2F01\&to }\end{array}$ & $27 / 01 / 2009$ \\
\hline $\begin{array}{l}\text { Familiares de desaparecidos de } \\
\text { Soacha reclaman nuevamente } \\
\text { justicia. }\end{array}$ & $\begin{array}{l}\text { ww.semana.com/Buscador?query=falsos\%20posit } \\
\text { ivos\&post=semana\&limit=10\&offset=270\&from } \\
=2006 \% 2 \mathrm{~F} 01 \% 2 \mathrm{~F} 01 \& \text { to }\end{array}$ & $22 / 04 / 2009$ \\
\hline $\begin{array}{l}\text { ¿Por qué mataron a nuestros } \\
\text { hijos? }\end{array}$ & $\begin{array}{l}\text { http://www.semana.com/nacion/justicia/articulo/p } \\
\text { or-que-mataron-nuestros-hijos/100701-3 }\end{array}$ & $5 / 3 / 2009$ \\
\hline Así no se gana la guerra & $\begin{array}{l}\text { http://www.semana.com/opinion/articulo/asi-no- } \\
\text { gana-guerra/96895-3 }\end{array}$ & \begin{tabular}{|l|}
$1 / 11 / 2008$ \\
\end{tabular} \\
\hline $\begin{array}{l}\text { El 75\% de asesinatos y } \\
\text { desapariciones en Colombia es } \\
\text { por responsabilidad de agentes } \\
\text { del Estado. Comisión Colombia } \\
\text { de Juristas. }\end{array}$ & $\begin{array}{l}\text { http://www.semana.com/on-line/articulo/el-75- } \\
\text { ciento-asesinatos-desapariciones-colombia- } \\
\text { responsabilidad-agentes-del-estado-c }\end{array}$ & $31 / 1 / 2007$ \\
\hline Oh confusión, oh caos. & $\begin{array}{l}\text { http://www.semana.com/nacion/articulo/oh- } \\
\text { confusion-oh-caos/81004-3 }\end{array}$ & 16/092006 \\
\hline $\begin{array}{l}\text { Familiares de las víctimas de } \\
\text { falsos positivos alertan jóvenes. }\end{array}$ & $\begin{array}{l}\text { http://www.semana.com/nacion/multimedia/famil } \\
\text { iares-victimas-falsos-positivos-alertan-jovenes- } \\
\text { soacha/143123-3 }\end{array}$ & $20 / 11 / 2009$ \\
\hline $\begin{array}{l}\text { El dossier secreto de los falsos } \\
\text { positivos }\end{array}$ & $\begin{array}{l}\text { ww.semana.com/nacion/articulo/el-dossier- } \\
\text { secreto-falsos-positivos/99466-3 }\end{array}$ & 25/1/2009 \\
\hline $\begin{array}{l}\text { En la impunidad pueden quedar } \\
\text { los falsos positivos }\end{array}$ & $\begin{array}{l}\text { http://www.semana.com/politica/multimedia/en- } \\
\text { impunidad-podran-quedar-falsos-positivos- } \\
\text { soacha-felipe-zuleta/143295-3 }\end{array}$ & $8 / 1 / 2010$ \\
\hline $\begin{array}{l}\text { El gobierno no ha reconocido } \\
\text { que el número de falsos } \\
\text { positivos es mayor. }\end{array}$ & $\begin{array}{l}\text { http://www.semana.com/politica/multimedia/el- } \\
\text { gobierno-no-ha-reconocido-numero-falsos- } \\
\text { positivos-mayor/142346-3 }\end{array}$ & \begin{tabular}{|l|}
$24 / 2 / 2009$ \\
\end{tabular} \\
\hline
\end{tabular}




\begin{tabular}{|c|c|c|}
\hline $\begin{array}{l}\text { Una Industria de falsos } \\
\text { positivos }\end{array}$ & $\begin{array}{l}\text { http://www.semana.com/on-line/articulo/una- } \\
\text { industria-falsos-positivos/96044-3 }\end{array}$ & $9 / 10 / 2008$ \\
\hline El muro de los falsos positivos. & $\begin{array}{l}\text { http://www.semana.com/conflicto/multimedia/el- } \\
\text { muro-falsos-positivos/142086-3 }\end{array}$ & $6 / 3 / 2009$ \\
\hline $\begin{array}{l}\text { Relator de la ONU escuchó a } \\
\text { víctimas de falsos positivos. }\end{array}$ & $\begin{array}{l}\text { http://www.semana.com/cultura/galeria/relator- } \\
\text { onu-escucho-victimas-falsos-positivos/137506-3 }\end{array}$ & $8 / 6 / 2009$ \\
\hline $\begin{array}{l}\text { A la ONU llevaran denuncia de } \\
\text { amenazas a madres a falsos } \\
\text { positivos. }\end{array}$ & $\begin{array}{l}\text { http://www.semana.com/nacion/conflicto- } \\
\text { armado/articulo/onu-llevaran-denuncia-amenazas- } \\
\text { madres-falsos-positivos-soacha/109342-3 }\end{array}$ & $31 / 10 / 2009$ \\
\hline $\begin{array}{l}\text { Entregué a más de } 30 \text { jóvenes } \\
\text { para falsos positivos. }\end{array}$ & $\begin{array}{l}\text { http://www.semana.com/nacion/articulo/entregue- } \\
\text { mas-30-jovenes-para-falsos-positivos/101266-3 }\end{array}$ & $21 / 3 / 2009$ \\
\hline $\begin{array}{l}\text { Hubo Nuevos casos de falsos } \\
\text { positivos }\end{array}$ & $\begin{array}{l}\text { http://www.semana.com/nacion/conflicto- } \\
\text { armado/articulo/hubo-nuevos-casos-falsos- } \\
\text { positivos-2008-cinep/102276-3 }\end{array}$ & $21 / 4 / 2009$ \\
\hline $\begin{array}{l}\text { Lo que encontró la } \\
\text { investigación de falsos } \\
\text { positivos }\end{array}$ & $\begin{array}{l}\text { http://www.semana.com/nacion/conflicto- } \\
\text { armado/articulo/lo-encontro-investigacion-falsos- } \\
\text { positivos/96801-3 }\end{array}$ & $29 / 10 / 2008$ \\
\hline $\begin{array}{l}\text { Uribe dice que denuncias por } \\
\text { falsos positivos tienen sesgos } \\
\text { ideológicos. }\end{array}$ & $\begin{array}{l}\text { http://www.semana.com/nacion/seguridad/articul } \\
\text { o/uribe-dice-denuncias-falsos-positivos-tienen- } \\
\text { sesgos-ideologicos/102886-3 }\end{array}$ & $8 / 5 / 2009$ \\
\hline Memoria de la ausencia & $\begin{array}{l}\text { http://www.semana.com/multimedia/galeria/mem } \\
\text { oria-ausencia/138004-3 }\end{array}$ & $29 / 8 / 2009$ \\
\hline $\begin{array}{l}\text { Nos daban cinco días de } \\
\text { descanso por cada muerto }\end{array}$ & $\begin{array}{l}\text { http://www.semana.com/nacion/articulo/nos- } \\
\text { daban-cinco-dias-descanso-cada-muerto/90680-3 }\end{array}$ & $26 / 01 / 2008$ \\
\hline $\begin{array}{l}\text { Mi hermano fue un falso } \\
\text { positivo }\end{array}$ & $\begin{array}{l}\text { http://www.semana.com/nacion/articulo/mi- } \\
\text { hermano-falso-positivo/96639-3 }\end{array}$ & $25 / 10 / 2008 \%$ \\
\hline El legado de los atajos & $\begin{array}{l}\text { http://www.semana.com/opinion/articulo/el- } \\
\text { legado-atajos/97328-3 }\end{array}$ & $15 / 11 / 2008$ \\
\hline $\begin{array}{l}\text { Colombia un país de } \\
\text { secuestrados a un país de } \\
\text { desaparecidos }\end{array}$ & $\begin{array}{l}\text { ww.semana.com/nacion/seguridad/articulo/colom } \\
\text { bia-de-pais-secuestrados-pais-desaparecidos/1 }\end{array}$ & $6 / 3 / 2009$ \\
\hline Cinep a Santos & $\begin{array}{l}\text { http://www.semana.com/nacion/conflicto- } \\
\text { armado/articulo/cinep-santos-falsos-positivos-no- } \\
\text { han-dejado-problema/114812-3 }\end{array}$ & $25 / 3 / 2010$ \\
\hline
\end{tabular}




\begin{tabular}{|c|c|c|}
\hline $\begin{array}{l}\text { Los falsos positivos no han } \\
\text { dejado de ser un problema. }\end{array}$ & & \\
\hline $\begin{array}{l}\text { Falsos positivos. Es un } \\
\text { eufemismo técnico para } \\
\text { describir un asesinato } \\
\text { premeditado y a sangre fría de } \\
\text { Civiles inocentes. }\end{array}$ & $\begin{array}{l}\text { ww.semana.com/Buscador?query=falsos } \% 20 \text { posit } \\
\text { ivos\&post=semana\&limit=10\&offset=0\&from=2 } \\
\text { 006\%2F01\%2F01\& }\end{array}$ & $31 / 5 / 2010$ \\
\hline $\begin{array}{l}\text { Falsos positivos y Chuzadas del } \\
\text { Das en el informe DD HH en } \\
\text { Estados Unidos. }\end{array}$ & $\begin{array}{l}\text { ww.semana.com/Buscador?query=falsos } \% 20 \text { posit } \\
\text { ivos\&post=semana\&limit=10\&offset=0\&from }=2 \\
006 \% 2 \mathrm{~F} 01 \% 2 \mathrm{~F} 01 \&\end{array}$ & $11 / 3 / 2010$ \\
\hline $\begin{array}{l}\text { Comité de la ONU denuncia } \\
\text { falta de progresos en la } \\
\text { desmilitarización de Colombia }\end{array}$ & $\begin{array}{l}\text { http://www.semana.com/nacion/articulo/comite- } \\
\text { onu-denuncia-falta-progresos-desmilitarizacion- } \\
\text { colombia/119884-3 }\end{array}$ & $11 / 3 / 2010$ \\
\hline $\begin{array}{l}\text { Así se planeó un falso positivo. } \\
\text { escuche los }\end{array}$ & $\begin{array}{l}\text { http://www.semana.com/nacion/articulo/asi- } \\
\text { planeo-falso-positivo-escuche-audios- } \\
\text { aqui/119417-3 }\end{array}$ & $17 / 7 / 2010$ \\
\hline $\begin{array}{l}\text { Inteligencia Militar, la marca : } \\
\text { Fredy Padilla León, }\end{array}$ & $\begin{array}{l}\text { http://www.semana.com/nacion/articulo/inteligen } \\
\text { cia-militar-marca-freddy-padilla-leon/119806- }\end{array}$ & $27 / 7 / 2010$ \\
\hline $\begin{array}{l}\text { Ministro del Interior y de } \\
\text { Justicia. Fabio Valencia : Falsos } \\
\text { positivos }\end{array}$ & $\begin{array}{l}\text { http://www.semana.com/conflicto/multimedia/mi } \\
\text { n-interior-justicia-fabio-valencia-falsos- } \\
\text { positivos/141618-3 }\end{array}$ & $31 / 10 / 2008$ \\
\hline $\begin{array}{l}\text { Fiscal Mario Iguaran .Falsos } \\
\text { positivos }\end{array}$ & $\begin{array}{l}\text { ww.semana.com/Buscador?query=falsos } \% 20 \text { posit } \\
\text { ivos\&post=semana\&limit=10\&offset=10\&from= } \\
\text { 2006\%2F01\%2F01\&to=2010\%2F12\%2F31\& }\end{array}$ & $31 / 10 / 2008$ \\
\hline $\begin{array}{l}\text { Juan Manuel Hernández. } \\
\text { Representanta la cámara. } \\
\text { Falsos positivos. }\end{array}$ & $\begin{array}{l}\text { http://www.semana.com/Buscador?query=falsos } \\
\% 20 \text { positivos\&post=semana\&limit=10\&offset=1 } \\
\text { 0\&from=2006\%2F01\%2F01\&to=201 }\end{array}$ & $31 / 10 / 2008$ \\
\hline $\begin{array}{l}\text { Familiares de desaparecidos de } \\
\text { Soacha reclamaron nuevamente } \\
\text { justicia. }\end{array}$ & $\begin{array}{l}\text { http://www.semana.com/nacion/articulo/familiare } \\
\text { s-desaparecidos-soacha-reclamaron-nuevamente- } \\
\text { justicia/102296-3 }\end{array}$ & $22 / 4 / 2009$ \\
\hline $\begin{array}{l}\text { Ejecuciones más que pocas } \\
\text { Manzanas podridas. }\end{array}$ & $\begin{array}{l}\text { http://www.semana.com/nacion/conflicto- } \\
\text { armado/articulo/ejecuciones-mas-pocas- } \\
\text { manzanas-podridas-relator-onu/104257-3 }\end{array}$ & $18(06 / 2009$ \\
\hline
\end{tabular}




\begin{tabular}{|c|c|c|}
\hline $\begin{array}{l}\text { Indignación por inoperancia de } \\
\text { la justicia. }\end{array}$ & $\begin{array}{l}\text { http://www.semana.com/nacion/articulo/indignaci } \\
\text { on-inoperancia-justicia/111723-3 }\end{array}$ & $08 / 01 / 2010$ \\
\hline $\begin{array}{l}\text { Johnny quería ser militar y } \\
\text { terminó de falso positivo. }\end{array}$ & $\begin{array}{l}\text { http://www.semana.com/nacion/conflicto- } \\
\text { armado/articulo/jonny-queria-militar-termino- } \\
\text { falso-positivo/113467-3 }\end{array}$ & $22 / 2 / 2010$ \\
\hline $\begin{array}{l}\text { Colombia sigue en deuda con } \\
\text { los DD HH }\end{array}$ & $\begin{array}{l}\text { http://www.semana.com/nacion/articulo/colombia } \\
\text {-sigue-deuda-derechos-humanos- } \\
\text { http://www.semana.com/nacion/articulo/capturad } \\
\text { os-doce-militares-colombianos-acusados- } \\
\text { ejecuciones-extrajudiciales/120164-3hrw/112170- } \\
\underline{3}\end{array}$ & $21 / 01 / 2010$ \\
\hline El muerto quedo vivo. & $\begin{array}{l}\text { http://www.semana.com/opinion/articulo/el- } \\
\text { muerto-quedo-vivo/112008-3 }\end{array}$ & $16 / 1 / 2010$ \\
\hline $\begin{array}{l}\text { Desaparecidos en Bogotá, } \\
\text { muertos en combate en Boyacá. }\end{array}$ & $\begin{array}{l}\text { ww.semana.com/nacion/conflicto- } \\
\text { armado/articulo/desaparecidos-bogota-muertos- } \\
\text { combate-boyaca/99137-3 }\end{array}$ & $16 / 1 / 2009$ \\
\hline ¿Será mucho pedirle al 2009? & $\begin{array}{l}\text { ww.semana.com/opinion/articulo/sera-mucho- } \\
\text { pedirle-2009/98687-3 }\end{array}$ & $3 / 27200$ \\
\hline $\begin{array}{l}\text { Las imágenes que no queremos } \\
\text { ver }\end{array}$ & $\begin{array}{l}\underline{\text { http://www.semana.com/nacion/articulo/las- }} \\
\text { imagenes-no-queremos-volver-ver/98011-3 }\end{array}$ & $6 / 12 / 2008$ \\
\hline Los procuradores de bolsillo. & $\begin{array}{l}\text { ww.semana.com/opinion/articulo/procuradores- } \\
\text { bolsillo/101941-3 }\end{array}$ & $11 / 4 / 2009$ \\
\hline $\begin{array}{l}\text { Crítica situación de Derechos } \\
\text { Humanos en colombio registra } \\
\text { Naciones Unidas en el informe } \\
\text { anual. }\end{array}$ & $\begin{array}{l}\underline{\text { http://www.semana.com/nacion/problemas- }} \\
\text { sociales/articulo/critica-situacion-derechos- } \\
\underline{\text { humanos-colombia-registra-nacion }}\end{array}$ & $5 / 3 / 2009$ \\
\hline Detrás de cámaras & $\begin{array}{l}\text { http://www.semana.com/gente/articulo/detras- } \\
\text { camaras/104098-3 }\end{array}$ & $13 / 6 / 2013$ \\
\hline
\end{tabular}

